\title{
Between sounds and words. Neurophysiological studies on speech processing in adults, normally reading children, and children with developmental dyslexia
}

Citation for published version (APA):

Bonte, M. L. (2005). Between sounds and words. Neurophysiological studies on speech processing in adults, normally reading children, and children with developmental dyslexia. [Doctoral Thesis, Maastricht University]. Datawyse / Universitaire Pers Maastricht. https://doi.org/10.26481/dis.20051005mb

Document status and date:

Published: 01/01/2005

DOI:

$10.26481 /$ dis.20051005mb

Document Version:

Publisher's PDF, also known as Version of record

Please check the document version of this publication:

- A submitted manuscript is the version of the article upon submission and before peer-review. There can be important differences between the submitted version and the official published version of record. People interested in the research are advised to contact the author for the final version of the publication, or visit the DOI to the publisher's website.

- The final author version and the galley proof are versions of the publication after peer review.

- The final published version features the final layout of the paper including the volume, issue and page numbers.

Link to publication

\footnotetext{
General rights rights.

- You may freely distribute the URL identifying the publication in the public portal. please follow below link for the End User Agreement:

www.umlib.nl/taverne-license

Take down policy

If you believe that this document breaches copyright please contact us at:

repository@maastrichtuniversity.nl

providing details and we will investigate your claim.
}

Copyright and moral rights for the publications made accessible in the public portal are retained by the authors and/or other copyright owners and it is a condition of accessing publications that users recognise and abide by the legal requirements associated with these

- Users may download and print one copy of any publication from the public portal for the purpose of private study or research.

- You may not further distribute the material or use it for any profit-making activity or commercial gain

If the publication is distributed under the terms of Article 25fa of the Dutch Copyright Act, indicated by the "Taverne" license above,

Download date: 26 Apr. 2023 


\section{Between sounds and words}

Neurophysiological studies on speech processing in adults, normally reading children, and children with developmental dyslexia 
ISBN 9052784728

Printed by Datawyse / Universitaire Pers Maastricht Copyright 2005 by Milene Bonte. All rights reserved. 


\section{Between sounds and words}

Neurophysiological studies on speech processing in adults, normally reading children, and children with developmental dyslexia

\section{PROEFSCHRIFT}

ter verkrijging van de graad van doctor

aan de Universiteit Maastricht, op gezag van de Rector Magnificus,

Prof.mr. G.P.M.F. Mols

volgens het besluit van het College van Decanen,

in het openbaar te verdedigen

op woensdag 5 oktober 2005 om 14.00 uur

door

Milene Linde Bonte

geboren op 9 maart 1976 te Warnsveld

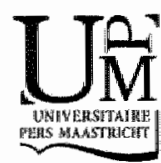


Promotor:

Prof.dr. R.W. Goebel

Copromotor:

dr. L. Blomert

\section{Beoordelingscommissie:}

Prof.dr. J. van Heerden (voorzitter)

Prof.dr. V. Csépe (Hungarian Acadlemy of Sciences, Budapest, Hungary)

dr. B.M. Jansma

dr. L. Jonkman

Prof. G. Schulte-Körne (Philipps-University, Marburg, Germany) 


\section{Contents}

1 Introduction 1

2. Developmental changes in ERP correlates of spoken word recognition during early school years: A phonological priming study

3 Developmental Dyslexia: ERP correlates of anomalous phonological processing during spoken word recognition

4 Auditory cortical tuning to statistical regularities in phonology

5 Deviant neural processing of phonological regularities in dyslexic children

6 Time course of top-down and bottom-up influences on syllable processing in the auditory cortex

Suminary

Samenvatting

Acknowledgements

Curriculum Vitae 


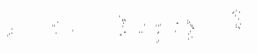

$\vdots$

$$
\therefore-\therefore \quad \therefore
$$
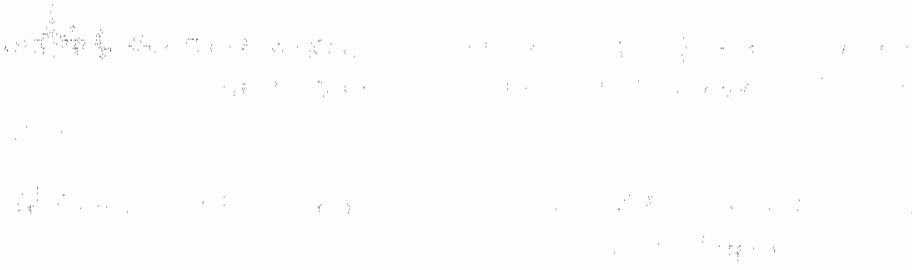


\section{Chapter 1}

\section{Introduction}

Speech is a highly complex sound with crucial relevance in our daily life. It contains a large variety of acoustic features like quasi-periodic and noise-based segments, steady state periods, spectral transitions, brief periods of silence and noise bursts (Figure 1). Speech reaches the ear as a continuous stream of overlapping sounds without clear boundaries for linguistic units like words, syllables or phonemes. Despite such complexity, we continuously extract meaning from speech in a seemingly effortless way, undisturbed by radical changes in the acoustic characteristics of the signal that occur when e.g. listening to a male or female voice, to speakers with different accents, or when listening to speech through a mobile phone in a noisy street. Such robust and efficient mapping from acoustic signals to meaning-based neural representations requires a set of highly specialized neural operations which are finely tuned to the language environment of the perceiver.

This thesis focuses on the time course of speech processing in the brain with an emphasis on prelexical analysis. We use the term 'prelexical' to refer to acoustic, phonetic and phonological levels of speech processing prior to the recognition of word forms and their meanings, to which we refer as 'lexico-semantic' processing. Prelexical analysis thus involves the mapping of acoustic speech sounds to discrete phonological categories (e.g. phonemes), used for the representation of words. This mapping may be mediated by language-specific processing of phonetic features. The studies in this thesis utilize the high temporal resolution of electroencephalography (EEG; chapters 2 to 5) and magneto-encephalography (MEG; chapter 6) to discover neurophysiological correlates of prelexical (and lexicosemantic) speech processing in adults, normally reading children and children with developmental dyslexia.

\section{Prelexical processing of speech}

What do we know about the prellexical processing of speech? In psycholinguistic models of spoken word recognition, the nature and existence of a prelexical level of processing, intermediate between acoustic features and lexical representations, remains a crucial and yet unresolved issue (Jusczyk and Luce, 2002; McQueen and Cutler, 2001). Some authors have argued against the existence of any sort of prelexical level and instead propose a direct mapping between acoustic features and long-term lexical representations (Marslen-Wilson and Warren, 1994). A large body of behavioural evidence, however, has indicated the psychological reality of intermediate prelexical representations like phonemes, phoneme clusters and syllables (Jusczyk and Luce, 2002; McQueen and Cutler, 2001).

Functional brain imaging studies support the idea of experience-dependent prelexical processing of speech in the brain. In recent hemodynamic brain imaging studies, distinct brain areas, and in particular the (left) posterior superior temporal 
cortex, have been suggested to form the neural basis for e.g. "constructing soundbased representations of speech" (Hickock and Poeppel, 2000), "the analysis of phonetic features" (Jäncke et al., 2002) and "processes tuned to the phonology of the native language" (Jacquemot et al.., 2003). Furthermore, based on event-related potential (ERP) activity reflecting the processing of native vs. non-native phoneme contrasts, Dehaene-Lambertz et al. (2000) suggested that the speech signal is directly parsed into the phonological format of the native language which may thereby facilitate lexical access.

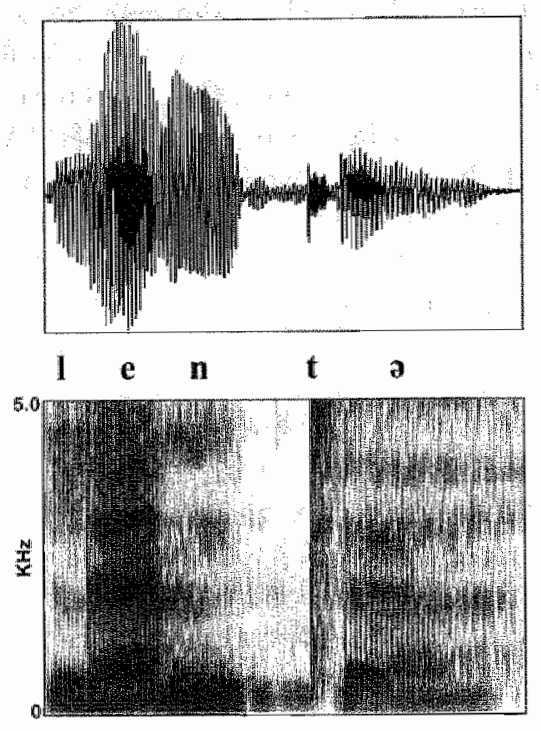

Figure 1. Acoustic waveform (top) and spectrogram (bottom) of the Dutch word "lente" (spring)

The EEG/MEG investigations in this thesis provide empirical evidence for the existence of several levels of prelexical processing and/or representation in the brain. In particular, they stiggest that the neural processing of speech is influenced by subtle acoustic-phonetic cues (chapter 6), phonetic-phonological information of word onsets (chapters 2 and 3 ) and phonological regularities in the sequential arrangements of phonemes (chapters 4 and 5). Moreover this thesis contributes to a better understanding of normal developmental changes in prelexical processing (chapters 2,3 and 5) and prelexical processing anomalies in children with developmental dyslexia (chapters 3 and 5). 


\section{Developmental changes in prelexical processing}

The neural system subserving prelexical speech processing develops during early childhood. How do infants learn to parse the auditory world and how do they discover the critical units of language? Infants are born with basic, universal, capacities for speech perception, including categorical perception (Jusczyk, 1997; Jusczyk and Luce, 2002; Kuhl, 2000). During subsequent development in the first year of life, the processing of speech radically changes to a language-specific mapping that strongly favours speech sounds that are prototypical in the native language over those that are not present in the natural language input. A large amount of evidence for the development of language-specific phoneme representations comes from studies using behavioural paradigms (Jusczyk and Luce 2002; Kuhl, 2000). Furthermore, recent neurophysiological and hemodynamic brain imaging studies suggest that (left) posterior perisylvian areas may form the neural basis for these developmental changes (Dehaene-Lambertz and Gliga, 2004).

During early development, the neural system underlying speech perception may exploit statistical regularities in the speech input to facilitate the acquisition, recognition and representation of spoken language. Between 6-12 months of age, infants have been found to respond to statistical regularities in speech at several levels of representation like allophonic cues', phonemes, and phonotactic probabilities $^{2}$ (Jusczyk, 1999). Infants may use statistical relationships between neighbouring speech sounds to infer which sounds can be combined to form words, and to segment these words in fluent speech (Saffran et al., 1996). Numerous behavioural studies have shown that phonotactic regularities continue to influence the processing of speech across the life-span (Auer and Luce, 2003). Furthermore, the ERP findings reported in chapters 4 and 5 suggest that auditory cortical responses to speech are modulated by phonotactic regularities of phoneme clusters, with comparable effects in adults and children.

Although the early development of speech perception during infancy has been studied quite extensively, less is known about continued developmental changes during early school years. Brain maturation of the temporal lobe, including the network of brain areas involved in prelexical speech processing, e.g. the superior temporal gyri (Hickok and Poeppel, 2004; Scott and Wise, 2004) has been shown to continue until early adulthood (Gogtay et al., 2004). During such a protracted period of maturation, the linguistic and cognitive environment may continue to substantially influence the underlying neural circuitry (Johnson, 2001). In this way, major cognitive achievements like the acquisition of reading may further change the neural processing of speech. On a behavioural level both vocabulary growth (Metsala and Walley, 1998) and the acquisition of reading (Goswami et al., 2003; Liberman, 1973; Morais et al., 1986) have been shown to refine the phonological representation of speech, in particular at the level of phonemes. Chapter 2 extends these findings and provides neurophysiological correlates of such developmental changes in phonological processing.

\footnotetext{
Allophones are variants of the same phoneme which occur during the production of speech ${ }^{2}$ Phonotactic probability refers to the distributional frequency of phoneme combinations in the syllables and words of a given language
} 


\section{Prelexical processing in developmental dyslexia}

Developmental dyslexia is a specific language-based disorder of constitutional origin characterized by difficulties in reading and/or spelling which are unexpected in relation to age and other cognitive abilities (Reid Lyon, 1995). It affects a relatively large percentage of the population with prevalence estimates ranging from 3-10\% (Pennington, 1990). A recent nationwide study of an elementary school population in The Netherlands estimated a prevalence of reading and/or spelling problems of $8,8 \%$, of which $3.6-4 \%$ were dyslexic (Blomert, 2003). The phenotype of dyslexia may vary across different languages, and may be related to differences in the transparency of grapheme-phoneme correspondences in these languages. For example, in a recent study, Italian dyslexics were found to perform better on reading tasks than English and French dyslexics (Paulesu et al., 2001). Nevertheless, during implicit and explicit reading, all dyslexics showed similarly reduced activity in the left temporal cortex, indicating a common neurobiological basis for dyslexia in alphabetic languages. These results agree with converging evidence from other hemodynamic brain imaging studies on dyslexia, which suggest a specific dysfunction of left temporo-parietal areas crucial for language functions (for reviews see Demonet et al., 2004; McCandliss and Noble, 2003; Temple, 2002).

The last 25 years of research (from Vellutino, 1979 to Snowling, 2000 and Vellutino et al., 2004) have firmly established the idea that phonological processing difficulties play a central role in developmental dyslexia (see also chapters 3 and 5). However, the debate on the underlying causes(s) is still continuing. One puzzling aspect of dyslexia is the variety of symptoms that are associated with it. Apart from difficulties in reading and phonological processing, also sensory difficulties in the auditory and visual domains and problems with automatisation, balance and motor control may occur (Ramus et al., 2003). Furthermore, reading and spelling problems also occur in other neuro-developmental disorders, such as specific language impairment (SLI) and attention deficit hyperactivity disorder (ADHD) (Snowling, 2000 ). Different theories disagree on the role that is attributed to this variety of associated symptoms.

The phonological theory assumes that dyslexia originates from a very specific pattern of linguistic deficits associated with phonological processing, which sometimes co-occurs with a more general sensorimotor syndrome (Snowling, 2000; Ramus, 2003). This phonological deficil is thought to impair the acquisition of grapheme-phoneme correspondences which subsequently causes difficulties in learning to read. Other theories assume that the phonological deficit is secondary to a more general primary impairment, such as a basic auditory dysfunction in the processing of short, acoustic transients (Tallal, 1980), a visual dysfunction in the magnocellular system (Lovegrove et al., 1980), a cerebellar/motor dysfunction (Nicolson et al, 2001), or slow attentional shifting (Hari and Renvall, 2001). Furthermore, the magnocellular theory tries to unify these different sensorimotor theories and assumes a generalized weakness in magnocellular functions (Stein and Walsh, 1997).

The ERP studies of chapters 3 and 5 investigate the hypothesis that the neurobiological impairment underlying developmental dyslexia affects the development of prelexical (phonetic-phonological) processing of speech. The 
interaction between phonological processing and reading acquisition is strongly bidirectional. On the one hand, the acquisition of reading has been found to influence the formation of fine-grained phonological representations (see above). On the other hand, numerous studies have shown that the failure to develop accurate phonological skills and representations during early childhood may lead to reading problems such as experienced in developmental dyslexia (Snowling, 2000). Our ERP findings in dyslexic children indicate anomalies in the phoneticphonological processing of speech that may not be reducible to difficulties at a basic acoustic level (chapters 3 and 5). Furthermore our data show normal lexicosemantic processing of words (chapter 3), indicating that these phonological difficulties may specifically occur at a prelexical level of analysis.

\section{EEG/MEG correlates of speech processing}

The recording of EEG and MEG are non-invasive techniques that provide excellent measures to investigate on-line information processing in the brain with millisecond precision (for recent reviews on EEG and MEG see Fabiani et al, 2000; Hari et al,, 2000; Kutas and Dale, 1997). EEG and MEG reflect complementary information arising from synchronous activation of neuronal populations in the brain. The neural currents resulting from this activation generate an external electric potential and magnetic field distribution that can be measured with EEG and MEG respectively. MEG mostly provides information about synchronous activation of tangentially oriented populations of pyramidal cells located superficially within cortical sulci. EEG is sensitive to both superficial and deep sources at various orientations relative to the scalp (tangential and radial). MEG has the advantage of being largely unaffected by tissues outside the brain (e.g. skull and scalp). Because MEG signals are thus less distorted and receive a contribution from a more limited set of brain areas than the corresponding EEG patterns, modelling of the underlying neural sources is more straightforward. Both EEG and MEG can be used to examine event-related and ongoing brain activity. The studies in the present thesis focus on event-related EEG and MEG activity, which is elicited by discrete sensory stimuli and can be extracted from the background activity by means of time-locked averaging.

Event-related responses have been an important tool in characterizing the time course of neural systems involved in different aspects of language processing including those related to the processing of acoustic-phonetic (Eggermont and Ponton, 2002), and phonological and semantic information (Kutas and Schmitt, 2003). Although the processing of speech may involve a parallel and interactive activation of different levels of analysis, distinct event-related responses, or time windows, have been primarily associated with acoustic-phonetic, phonological or lexico-semantic processing.

Acoustic-phonetic features of speech modulate activity in non-primary auditory cortex from $50-100 \mathrm{~ms}$ onwards, as reflected in a robust response that emerges $100 \mathrm{~ms}$ after sound onset and is usually referred to as the $\mathrm{N} 1 / \mathrm{N} 1 \mathrm{~m}$ (Eggermont and Ponton, 2002; Kuriki and Murase, 1989; Obleser et al., 2003; Parviainen et al., 2004; Poeppel et al., 1996). Furthermore the N1 response may reflect the prelexical processing of word onsets during on-line speech perception (Sanders and Neville, 2003a; Sanders and Neville, 2003b; chapters 2 and 3). 
Language specific phonetic-phonological analysis has been estimated to start at about 100-200 ms. In this time window, an EEG/MEG response associated with mnemonic functions of the auditory association cortex, i.e., the mismatch negativity (MMN), indicates access to phonological categories (Phillips et al,, 2000; Vihla et al. 2000) and distinct processing of native vs. non-native phonetic contrasts (Natätänen et al., 1997, Winkler et al, 1999). The MMN findings of chapter 4 suggest that the phonotactic probability of phoneme clusters modulates the neural processing of speech in this same time window.

Further phonological and lexico-semantic processing of words and word-like speech stimuli has been related to EEG/MEG activity from $200 \mathrm{~ms}$ onwards. Since the original report of Kutas and Hillyard (1980), a large amount of research has focused on a sustained activity starting at about $200 \mathrm{~ms}$ and peaking around $400 \mathrm{~ms}$, the $\mathrm{N} 400 / \mathrm{N} 400 \mathrm{~m}$ response. MEG studies have indicated that this sustained response most likely originates from neural activation in the posterior superior temporal cortex (Helenius et al., 2002; Kujala et al., 2004; Marinkovic et al., 2003; chapter 6) and may involve additional sources in (left) temporal and frontal areas (Marinkovic et al., 2003). The $N 400$ has been primarily associated with lexico-semantic processing of words (Kutas and Federmeier, 2000), but recent EEG/MEG studies suggest that it probably reflects multiple processes, ranging from phonological analysis to lexical access and semantic processing (for discussions see chapters 2,3 and 6). The strength of $\mathrm{N} 400$ peak activation is believed to reflect the amount of neural processing required for the recognition and/or integration of a word in a given context. Thus, facilitating factors like semantic or phonological priming tend to reduce its peak amplitude (chapters 2 and 3; Dumay et al., 2001; Helenius et al., 2002; Perrin et al., 2003; Rugg, 1984). In contrast, prelexical phonological processing of speech and lexical access processes seem to modulate activity in the preceding time window around the N400 onset, i.e. between $200-350 \mathrm{~ms}$ (chapter 6; Hagoort and Brown, 2000; Helenius et al., 2002; Van den Brink et al., 2001; Van Petten et al., 1999).

\section{Developmental changes in event-related responses}

Due to developmental changes in perceptual and cognitive processes as well as the maturation of neuro-anatomical structures and neurophysiological processes, auditory EEG/MEG responses show substantial morphological and functional differences in children vs. adults (Ponton and Eggermont, 2001). In fact, most $\mathrm{EEG} / \mathrm{MEG}$ responses do not reach their adult form until late adolescence. A precise neuro-developmental characterisation of the interplay between underlying developmental processes, the generation of EEG/MEG activity, and their functional significance regarding the development of auditory language skills is still in its infancy. Evidence from EEG/MEG studies has led to a fairly consistent descriptive characterisation of developmental changes in obligatory event-related responses ${ }^{3}$ elicited during passive listening to clicks, tones, meaningless consonant-vowel syllables and bisyllabic non-words (Ceponiene et al., 2002; Csépe, 1995; Kraus et al., 1993; Paetau et al., 1995; Ponton et al., 2000; Shafer et al., 2000; Sharma et al., 1997; Takeshita et al., 2002; chapter 5). This research has indicated substantial

${ }^{3}$ Those event-related responses which are elicited by any sound onset 
A

passive listening to a bisyllable non-word
B

active recogintion of bisyllabic words
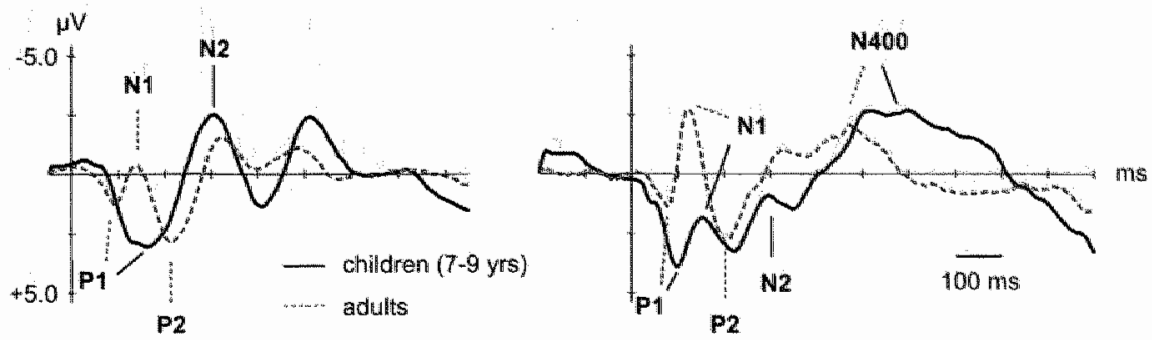

Figgure 2. Grand average waveforms at the frontocentral electrode $\mathrm{FCz}$ in adults and children. ERP activity was measured during passive listening to bisyllabic non-words (A) or in response to words during the performance of an auditory lexical decision task (B).

developmental changes in the morphology of obligatory auditory responses. In adults, any sound elicits a sequence of P1 $(\sim 75 \mathrm{~ms}), \mathrm{N} 1(\sim 100 \mathrm{~ms})$ and $\mathrm{P} 2(\sim 150$ $\mathrm{ms})$ peaks. However, in children up to about 10 years of age, auditory event-related responses are dominated by a P1-N2 complex (see Figure 2A). The P1 recorded in children typically occurs with a latency of about $100 \mathrm{~ms}$ and has been consistently related to the adult P1 (Sharma et al., 1997). The subsequent N2 response, also called N250, has a more variable latency around $200-300 \mathrm{~ms}$ and has been suggested to reflect auditory cortical processing until efficient, adult, cortical networks are established (Ceponiene et al., 2002; Takeshita et al., 2002). Probably due to both a relatively long $N 1$ recovery cycle and its overlap with stronger P1 and N2 peaks, the N1 is typically not visible in children when inter stimulus intervals (ISIs) are shorter than $1 \mathrm{~s}$ and passive listening conditions are used (Bruneau et al., 1997; Ceponiene et al, 2002; Karhu et al., 1997). In sum, developmental changes in obligatory EEG/MEG responses do not only include a general age-related decrease of latency, but also additional and more complex structural and functional changes. Caution is thus required when using the much more extensive adult EEG/MEG literature as a reference for interpreting neurophysiological activity in children (see also chapters 2, 3 and 5).

EEG/MEG studies on auditory speech perception in children (and adults see above) have often employed a passive oddball paradigm to study an automatic neurophysiological change detection response, the MMN (mismatch negativity). The MMN is elicited by any discriminable change (i.e. infrequent deviant stimuli) in a repetitive aspect of auditory stimulation (i.e. frequent standard stimuli). Experimental evidence has shown that size and latency characteristics of the MMN may provide a valuable measure of experience-dependent changes in auditory cortical responses to speech (Naätänen, 2001; chapters 4 and 5). Because its recording does not require any attention or task performance, the MMN is particularly suited for the study of automatic speech processing in young children 
and children with language difficulties (Kujala and Näätänen, 2001; chapter 5). Furthermore, the MMN displays functional similarities in infants, children and adults (Csépe, 1995; Dehaene-Lambertz and Gliga, 2004; chapters 4 and 5).

Only a few developmental studies have investigated ERP activity in children elicited by meaningful speech stimuli (words) during the performance of an active experimental task (auditory lexical decision: chapters 2 and 3; rhyme judgments: Coch et al., 2002). Comparable to the obligatory auditory ERPs elicited during passive listening to meaningless auditory (speech) stimuli, spoken words were found to elicit $\mathrm{P} 1$ and $\mathrm{N} 2$ responses in $7-9$ year old children (Figure $2 \mathrm{~A}$ vs. 2B). Furthermore, like in adults, words elicited a sustained N400 response. Attentively processed. words additionally elicited an N1 response at a latency of $\sim 150 \mathrm{~ms}$ in children as young as 7-8 year old and with ISIs shorter than 1 second. These N1 findings contrast with studies on passive listening and may relate to an increased attention level during performance of an active task (Näätänen and Picton, 1987) and the linguistic relevance of word stimuli (Sanders and Neville, 2003a,b).

An important and challenging issue to be addressed in future studies is how these complex developmental changes in functional and structural characteristics of EEG/MEG responses relate to underlying changes in functional and structural characteristics of the network of brain areas involved in speech perception. New advancements in methods of cognitive neuroimaging are particularly promising and enable the parallel investigation of detailed changes in cortical neuro-anatomy (magnetic resonance imaging, MRI), and neurophysiological (EEG/MEG) and hemodynamic (functional MRI) correlates of auditory cortical processing. Such a combined approach has great potential for improving our knowledge on individual differences in auditory learning and plasticity and for providing a basis for a better understanding of developmental disorders such as developmental dyslexia. 


\section{References}

Auer, $J_{\text {, }}$ E.T., and $\mathbb{L}$ uce, P. A. (2003). Probabilistic Phonotactics in Spoken Word Recognition In University at Buffalo Working Papers on Language and Perception, C. T. McLennan, P. A. Luce, G. Mauner, and J. Charles-Luce, eds., pp. 164-202.

Blomert, L. (2003). Dyslexie: stand van zaken (Dyslexia: State of Affairs in the Netherlands). Report for the Dutch Ministry of Health. In Dyslexie naar een vergoedingsregeling, R. Reij, ed. (Amstelveen, Dutch Health Care Insurance Board), pp. 1-119, publication number 03/144.

Brumeau, N., Roux, S., Guerin, $P_{*}$, Barthelemy, $C$, and Lelord, G. (1997). Temporal prominence of auditory evoked potentials (N1 wave) in 4-8-year-old children. Psychophysiology 34, 32-38.

Ceponiene, R., Rinne, T., and Natatåneta, R. (2002). Maturation of cortical sound processing as indexed by event-related potentials. Clinical Neurophysiology $113,870-882$.

Coch, D., Grossi, G., Coffey Corina, S., Holcomb, P. J., and Neville, H. J. (2002). A developmental investigation of ERP auditory rhyming effects. Developmental Science 5,467 . 489.

Csépe, V. (1995). On the origin and development of the mismatch negativity. Ear and Hearing 16 , $91-104$.

Dehaene-Lambertz, G., Dupoux, E, and Gout, A. (2000). Electrophysiological correlates of phonological processing: a cross-linguistic study. Journal of Cognitive Neuroscience 12, 635-647.

Dehaene-Lambertz, G., and Gliga, T. (2004). Common neural basis for phoneme processing in infants and adults. Journal of Cognitive Neuroscience 16, 1375-1.387.

Demonet, J. F., Taylor, M. J., and Chaix, Y. (2004). Developmental dyslexia. Lancet 363, 14511460.

Dumay, N., Benraiss, A., Barriol, B., Colin, C., Radeau, M., and Besson, M. (2001). Behavioral and electrophysiological study of phonological priming between bisyllabic spoken words. Journal of Cognitive Neuroscience 13,121-143.

Eggermont, J. J., and Ponton, C. W. (2002). The neurophysiology of auditory perception: from single units to evoked potentials. Audiology and Neurootology 7, 71-99.

Fabiami, M., Gratton, G., and Coles, M. G. H. (2000). Event-Related Brain Potentials Methods, Theory, and Applications. In Handbook of Psychophysiology, J. T. Cacioppo, L. G. Tassinary, and G. G. Bernison, eds. (New York, Cambridge University Press), pp. 53-77.

Gogtay, N., Giedd, J. N., Lusk, L., Hayashi, K. M., Greenstein, D., Vaituzis, A. C., Nugent, T. F., 3 rd, Herman, D. H., Clasen, L. S., Toga, A. W., ef al. (2004). Dynamic mapping of human cortical development during childhood through early adulthood. Proceedings of the National Academy of Sciences USA 101, 8174-8179.

Goswami, U., Ziegler, J. C., Dalton, L., and Schneider, W. (2003). Nonword reading across orthographies: How flexible is the choice of reading units? Applied Psycholinguistics 24, $235 \mathrm{~m}$ 247

Hagoort, P., and Brown, C. M. (2000). ERP effects of listening to speech: Semantic ERP effects. Neuropsychologlia $38,1518-1530$.

Hari, R., Levanen, S., and Raij, T. (2000). Timing of human cortical functions during cogntion: role of MEG. Trends in Cognitive Sciences 4, 455-462.

Hari, R, and Renvall, H. (2001). Impaired processing of rapid stimulus sequences in dyslexia. Trends in Cognitive Sciences 5, 525-532. 
Helenus, $P$., Salmalin, $R$, Service, E., Connolly, I. F, Leinonen, S., and Lyytinen, H. (2002). Cortical activation during spoken-word segmentation in nonreading-impaired and dyslexic adults. Jourial of Newroschence $22,2936-2944$.

Hickok, G, and Poeppel, D. (2000). Towards a functional neuroarnatomy of speech perception. Trends in Cognitive Sciences 4, 131-138.

Hickok, $G$, and Poeppel, D (2004). Dorsal and ventral streams a lamework for understanding aspects of the functional anatomy of language. Cognition 92,67-99.

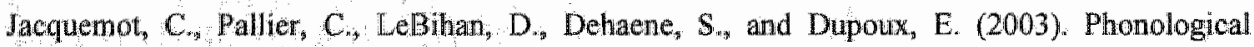
grammar shapes the auditory cortex: a functional magnetic resonance imaging study. Journal of Neurosicience $23,9541,-9546$.

Jancke, L. Wustenberg, $T$., Scheich, H, and Heinze, H. J. (2002). Phonetic perception and the temporal cortex. Neuroimage 15,733-746.

Johnson, M. H. (2001). Functional brain development in humans. Nature Reviews Neuroscience $2,475-483$.

Jusczyk, P. W. (1997). The discovery of spoken language (Cambridge, MA, US, The MIT Press).

Jusczyk, P. W. (1999). How infants begin to extract words from speech. Trends in Cognitive Sciences $3,323-328$.

Jusczyk, P. W., and Luce, P. A. (2002). Speech perception and spoken word recognition: past and present. Far and Hearing $23,2-40$.

Karhu, J., Herrgard, E., Paakkonen, A., Luoma, L., Airaksinen, E., and Partanen, J. (1997). Dual cerebral processing of elementary auditory input in children. Neuroreport $8,1327-1.330$.

Kraus, N, McGee, T., Carrell, T., Sharma, A., Micco, A., and Nicol, T. (1993). Speech-evoked cortical potentials in children. Journal of the American Academy of Audiology 4, 238-248.

Kuhl, P. K. (2000). A new view of language acquisition. Proceedings of the National Academy of Sciences USA $97,11850-11857$.

Kujala, A., Alho, K., Service, E., Ilmoniemi, R. J., and Connolly, J. F. (2004). Activation in the anterior left auditory cortex associated with phonological analysis of speech input: localization of the phonological mismatch negativity response with $\mathrm{MEG}$. Cognitive Brain Research 21, 106 113.

Kujala, T., and Nabtanen, R. (2001). The mismatch negativity in evaluating central auditory dysfunction in dy slexia. Neuroscience Biobehavioral Reviews 25, 535-543.

Kuriki, $\mathrm{S}_{\text {, }}$ and Murase, M. (1989). Neuromagnetic study of the auditory responses in right and left hemispheres of the human brain evoked by pure tones and speech sounds. Experimental Brain Research 77, 127-134.

Kutas, M., and Dale, A. M. (1997). Eletrical and magnetic readings of mental functions. In Cognitive Neuroscience, M. D. Rugg, ed. (Sussex, UK, Psychology Press).

Kutas, M., and Federmeier, K. D. (2000). Electrophysiology reveals semantic memory use in language comprehension. Trends in Cognitive Sciences 4, 463-470.

Kutas, M., and Hillyard, S. A. (1980). Reading senseless sentences: brain potentials reflect semantic incongruity. Science 207, 203-205. 
Kutas, M, and Schmit, B. M. (2003). Language in Mierovolts, In Mind, Brain, and Language: Multidisciplinary Perspectives, M. T. Banich, and M. A. Mack, eds. (Mahwah, NJ, US, Erlbaum Assoc. Inc, Lawrence), pp. 171-209.

Liberman, I Y. (1973). Segmentation of the spoken word and reading acquisition Bulletin of the Orton Society $23,65-77$.

Lovegrove, W. J., Bowling, A., Badcock, D., and Blackwood, M. (1980). Specific reading disability: differences in contrast sensitivity as a function of spatial frequency. Seience 210,439 . 440.

Marinkovic, K., Dhond, R. P., Dale, A. M., Glessner, M., Cart, V., and Halgren, E. (2003). Spatiotemporal dynamics of modality-specific and supramodal word processing. Neuron 38,487 . 497.

Marslen-Wilson, W., and Warren, P. (1994). Levels of perceptual representation and process in lexical access: words, phonemes, and features. Psychological Review 101, 653 675.

McCandliss, B. D., and Noble, K. G. (2003). The development of reading impairment: a cognitive neurosience model. Mental Retardation and Developmental Disabilities Research Reviews 9 , 196-204.

McQueen, J. M., and Cutler, A. (2001). Spoken. word aceess processes: An introduction. Language and Cognitive Processes 16, 469-490.

Metsala, J. L., and Walley, A. C. (1998). Spoken vocabulary growth and the segmental restructuring of lexical representations: Precursors to phonemic awareness and early reading ability. In (1998). Word recognition in beginning literacy., J. L. Metsala, ed. (Mahwah, NJ, US, Lawrence Erlbaum Associates, Publishers), pp. 89-120.

Morais, J., Bertelson, P., Cary, L., and Alegria, J. (1986). Literacy training and speech segmentation. Cognition 24, 45-64.

Näatänen, R. (2001). The perception of speech sounds by the human brain as reflected by the mismatch negativity (MMN) and its magnetic equivalent (MMNm). Psychophysiology 38, 1-21.

Näătänen, R., Lehtokoski, A., Lemnes, M., Cheour, M., Huotilainen, M., Iivonen, A., Vainio, M.. Alku, P., Ilmoniemi, R. J., Luuk, A., et al. (1997). Language-specific phoneme representations revealed by electric and magnetic brain responses. Nature $385,432-434$.

Näatänen, R., and Picton, T. (1987). The NI wave of the human electric and magnetic response to sound: a review and an analysis of the component structure. Psychophysiology $24,375-425$.

National Research Council (1998). Report on preventing reading difficulties in young children (Washington DC, Nationall Academy Press).

Nicolson, R. I., Fawcett, A. J. and Dean, P. (2001). Developmental dyslexia: the cerebellar deficit hypothesis. Trends in Neurosciences 24,508-511.

Obleser, I., Lahiri, A., and Eulitz, C. (2003). Auditory-evoked magnetic fieeld codes place of articulation in timing and topography around 100 milliseconds post syllable onset. Neuroimage $20,1839-1847$.

Paetau, R., Ahonen, A., Salonen, O., and Sams, M. (1995). Auditory evoked magnetic fixlds to tones and pseudowords in healthy children and adults. Journal of Clinical Neurophysiology 12, $177-185$.

Parviainen, T., Helenius, P., and Salmelin, R. (2005). Cortical differentiation of speech and nonspeech sounds at 100 ms: implications for dyslexia. Cerebral Cortex 15, $1054-1063$. 


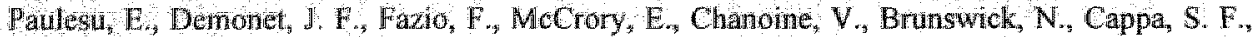
Cossu, $\mathrm{C}_{\text {, }}$ Habib, M, Frith, C D, and Frith, U. (2001). Dyslexia: cultural diversity and biological unity. Sclence $29 \%, 2165-2167$.

Peninington, B. F. (1990). The genetics of dyslexia. Jounal of Child Psychology and Psychiatry $31,193-201$.

Perrin, F, and Garcia-Larrea, L. (2003). Modulation of the N400 potential during auditory phonological/semantic interaction. Cognitive Brain Research 17,36-47.

Phillips, C, Pellathy, T, Marantz, A., Yellin, E., Wexler, K., Poeppel, D., MeGimis, M., and Roberts, T. (2000). Auditory cortex accesses phonological categories: an MEG mismatch study. Journal of Cognitive Neuroscience 12, 1038-1055.

Poeppel, D., Yellin, E, Phillips, C., Roberts, T. P., Rowley, H. A., Wexler, K., and Marantz, A. (1996). Task-induced asymmetry of the auditory evoked M100 neuromagnetic field elicited by speech sounds. Cognitive Brain Research 4, 231-242.

Ponton, $_{\text {C. W. }}$, and Eggermont, J. J. (2001). Of kittens and kids: altered cortical maturation following profound deafness and cochlear implant use. Audiology and Neurootology 6,363-380.

Ponton, C. W., Eggermont, J. J., Kwong, B., and Don, M. (2000). Maturation of human central auditory system activity: evidence from multi-channel evoked potentials. Clinical Neurophysiology $111,220-236$.

Ramus, F. (2003). Developmental dyslexia: specific phonological deficit or general sensorimotor dysfunction? Current Opinion in Neurobiology 13, 212-218.

Ramus, f., Rosen, S., Dakin, S. C., Day, B. L., Castellote, J. M., White, S., and Frith, U. (2003). Theories of developmental dyslexia: insights from a multiple case study of dyslexic adults. Brain $126,841-865$.

Reid Lyon, G. (1995). Toward a definition of dyslexia. Annals of Dyslexia 45, 3-27.

Rugg, M. D. (1984). Event-related potentials and the phonological processing of words and nonwords. Neuropsychologia 22, 435-443.

Saffran, J. R., Aslin, R. N., and Newport, E. L. (1996). Statistical learning by 8-month-old infants. Scrence $2 \pi 4,1926-1928$.

Sanders, L. D., and Neville, H. J. (2003a). An ERP' study of continuous speech processing. I. Segmentation, semantics, and syntax in native speakers. Cognitive Brain Research 15, 228-240.

Sanders, L. D., and Neville, H. J. (2003b). An ERP study of continuous speech processing. II. Segmentation, semantics, and syntax in non-native speakers. Cognitive Brain Research 15, 214 227.

Scott, S. K., and Wise, R. J. (2004). The functional neuroanatomy of prelexical processing in

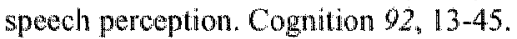

Shafer, V. L., Morr, M. L., Krenzer, J. A., and Kurtzberg, D. (2000). Maturation of mismatch negativity in school-age children. Ear and Hearing 21,242-251.

Sharma, A., Kraus, N., McGee, T. J., and Nicol, T. G. (1997). Developmental changes in PI and NI central auditory responses elicited by consonant-vowel syllables. Electroencephalography and Clinical Neurophysiology 104, 540-545.

Snowling, M. J. (2000). Dyslexia, 2nd edn (Oxford UK, Blackwell Publishers). 
Stem, J, and Walsh, V. (1997). To see but not to read; the magnocellitur theory of dvslexia. Trends in Neurosciences 20, 147-152.

Takeshita, K., Nagamine, T., Thuy, D. H., Satow, T., Matsuhash, M. Yamamoto, J, Takayama, M., Fujiwara, N., and Shibasaki, H. (2002). Maturational change of parallel auditory processing lin school-aged children revealed by simultaneous recording of magnetic and electric cortical responses. Clinical Neurophysiology 113, 1470-1484.

Tallal, P. (1980). Auditory temporal perception, phonics, and reading disabilities in children. Brain and Language 9, 182-198.

Temple, E. (2002). Brain mechanisms in normal and dyslexic readers. Current Opinion un Nevirobiology 12, 178-183.

Van den Brink, D., Brown, C. M., and Hagoort, P. (2001). Electrophysiological evidence for earty contextual influences during spoken-word recognition: N200 versus N400 effects. Journal of Cognitive Neuroscience 13, 967-985.

Van Petten, C. K., Coulson, S., Rubin, S., Plante, E., and Parks, M, (1999). Time course of word identification and semantic integration in spoken language. Journal of Experimental Psychology Learning Memory and Cognition 25, 394-417.

Vellutino, F. R. (1979). Dyslexia: Research and Theory (Cambridge, MA, MIT Press).

Vellutino, F. R., Fletcher, J. M., Snowling, M. J., and Scanlon, D. M. (2004). Specific reading disability (dyslexia): what have we learned in the past four decades? Journal of Child Psychology and Psychiatry 45, 2-40.

Vihla, M., Lounasmaa, O. V., and Salmellin, R. (2000), Cortical processing of change detection: dissociation between natural vowels and two-frequency complex tones. Proceedings of the National Academy of Sciences USA 97, 10590-10594.

Winkler, I., Lehtokoski, A., Alku, P., Vainio, M., Czigler, I., Csépe, V., Aaltonen, O., Raimo, I., Alho, K., Lang, H., et al (1999). Pre-attentive detection of vowel contrasts utilizes botli phonetic and auditory memory representations. Cognitive Brain Research 7, 357-369. 


\title{
Chapter 2
}

\section{Developmental changes in ERP correlates of spoken word recognition during early school years: A phonological priming study ${ }^{4}$}

\begin{abstract}
We investigated event-related potential (ERP) correllates of developmental changes in spoken word recognition during early school years. We focused on implicit processing of word onsets as this may change considerably due to vocabulary growth and reading acquisition. Subjects were pre-schoolers (5/6 yr), beginning readers (7/8 yr) and adults. Two experiments examined phonological onset priming effects on ERP measures in an auditory lexical decision task. Primes were words (Experiment 1) or non-words (Experiment 2). ERPs elicited by words showed clear developmental changes in ERP latency and morphology, especially with regard to early negativities like the N1. Prominent priming effects were an enhanced N400 amplitude due to alliterating word primes in beginning readers, and typical phonological N400 reductions due to alliterating non-word primes in all groups. Priming further led to opposite early effects with word primes (N1/ $\mathrm{N}_{200}$ reduction) vs. non-word primes (P1/N1 enhancement) in all groups. These changes in ERP morphology and priming effects suggest that the lexical system undergoes substantial restructuring at the level of phonological processing and representation. In particular, our results indicate distinct processing of word onsets in beginning readers, confirming that vocabulary growth and the acquisition of reading may critically contribute to the formation of a fully segmental lexical system.
\end{abstract}

\footnotetext{
4his chapter is based on Bonte, $M_{\text {. }}$ and Blomert, L. (2004). Developmental changes in ERP correlates of spoken word recognition during early school years: A phonological priming study, Clinical Neurophysiology, $115,409-423$.
} 


\section{Introduction}

The recognition of spoken words requires mapping of a continuous stream of speech sounds onto meaning-based neural representations. As the auditory speech signal does not consist of discrete units like words, syllables or phonemes, specialized neural operations are needed to derive meaning from this acoustic information.

The neural system subserving these operations develops during early childhood. The acquisition of phonetic contrasts and structural regularities of the native language occurring during infancy forms the basis for word segmentation in fluent speech and has been studied quite extensivelly (for a review see Jusczyk, 1999). In contrast, less is known about developmental changes in the access and representation of lexical information, i.e., in the transformation of words into meaning. In adults, these aspects of lexical processing may rely on the analysis of subtle phonetic details and capitalize on word-initial information (Marslen-Wilson and Warren, 1994; McQueen and Cutler, 2001). In children, words may be recognized in a more holistic manner, both with respect to the detail of phonetic/phonological representations and to the importance of position-specific information (Jusczyk, 1993; Metsala and Walley, 1998). Initially, the acquisition of novel words may be aided by the exploitation of salient features throughout words (e.g., Walley, 1988). Then, during vocabulary growth, the implementation of more fine-grained, segmental representations is necessary to enable the distinction of an increasing number of words with overlapping acoustic properties (Jusczyk, 1993; Metsala and Walley, 1998). Such a restructuring of lexical representation may be organized around salient and robust word initial information, and eventually leads to the fast and efficient adult word recognition system (Jusczyk, 1993). This process may have a protracted developmental course and probably extends over early school years. In particular, the formation of fully specified phonological representations may critically depend on the acquisition of reading (Liberman, 1973; Morais et al., 1986).

Here we investigate the neural correlates of these developmental changes in lexical restructuring. We measured event-related potentials (ERPs) during an auditory lexical decision task in combination with phonological onset priming in pre-schoolers ( $5 / 6$ years), beginning readers (7/8 years) and adults. Primes were words (Experiment 1) and non-words (Experiment 2). This enabled us to compare ERP correlates of onset priming due to word processing, which requires both prelexical and lexical processing, and non-word processing, which mainly requires prelexical processing. The influence of phonological priming on word onsets was expected to change dependent on the subject's level of lexical restructuring. Our groups were thus selected to represent three different levels of lexical organization, ranging from a relatively unsegmented, holistic lexical organization (pre-schoolers) to an automatised and completely segmented lexical system (adults), with the beginning readers representing an intermediate level of lexical organization, with ongoing major developments in segmental restructuring (e.g., Goswami et al., 2003).

Dependent on the level at which the primes exert their influence, we may expect effects of phonological priming on different ERP components which have been related to phonetic/phonological processing in adults. One of these ERP 
effects is a modulation of a late negative potential (e.g., Praamstra et al, 1994; Rugg, 1984), comparable to the semantic $\mathrm{N} 400$ effect originally reported by $\mathrm{Kutas}$ and Hillyard (1980). The semantic N400 is elicited by visual and auditory words presented in sentences, lists or pairs. Its amplitude appears to reflect the extent to which a word is semantically primed, i.e., a word which is semantically expected elicits a reduced N400 (for a review see Kutas and Van Petten, 1994). Similarly, phonological priming, i.e., alliteration or rhyme, has been found to reduce the amplitude of the N400 waveform (e.g., Grossi et al., 2001; Praamstra et al ${ }_{\llcorner;}$1994; Radeau et al., 1998), sometimes called N450 (Rugg, 1984). These phonological $\mathrm{N} 400$ effects occur earlier for word onset (alliteration) than thyme priming, which suggests that they may be a useful index of the temporal dynamics of spoken word processing (Praamstra et al., 1994). Both semantic and phonological N400 effects depend on the level of attention directed to the stimuli and might belong to a broader category of 'discordance negativities' (Perrin and Garcia-Larrea, 2003). However, phonological N400 effects are less robust than their semantic counterpart and are mainly reported in experiments using active phonological tasks (Perrin and Garcia-Larrea, 2003).

In studies using a variation of the semantic N400-paradigm in which not only semantic, but also phonological expectancy is systematically varied, unexpected word onsets have been shown to modulate a separate negativity at a latency of 200 to $300 \mathrm{~ms}$, preceding the N400 (e.g., Connolly and Phillips, 1994; Hagoort and Brown, 2000; Van den Brink et al., 2001). Connolly and Phillips (1994), for example, reported a negative potential (phonological mismatch negativity, PMN) around $270 \mathrm{~ms}$, elicited whenever sentence final words had a phonologically unexpected onset (e.g., 'Don caught the ball with his glove'), with a double effect, i.e., PMN and a semantic $\mathrm{N} 400$, in case of a double violation, i.e., phonological and semantic (e.g., 'The dog chased the cat up the queen'). Negativities like PMN have been interpreted to reflect the phonological processing of word onsets and/or the initial activation of lexical candidates. Other studies using the same paradigm, failed to find a separate negativity preceding the $\mathrm{N} 400$, but found a relation between processing of word onsets and onset latency of the semantic N400 effect (e.g., Helenius et al., 2002; Van Petten et al., 1999).

Psycholinguistic experiments in adults suggest that word-initial speech input may activate multiple word candidates already on the basis of the first $100-150 \mathrm{~ms}$ of a word, or one to two phonetic segments (Marslen-Wilson, 1987). Furthermore, ERP and magneto-encephalographic (MEG) studies deploying the mismatch negativity (MMN) as a measure of the automatic comparison of phonemic contrasts, suggest that at $150-200 \mathrm{~ms}$ after speech onset, native vs. non-native phonetic contrasts are already processed differently (Näätänen et al., 1997; Winkler et al., 1999) and phonological categories may have been accessed (Phillips et al., 2000; Vihla et al., 2000). The neural sources underlying the MMN effect may partly overlap with those of the auditory N1 (Näătänen and Picton, 1987). Whereas the MMN is assumed to reflect an automatic change detection response elicited by any discriminable change in a repeated sound, the auditory N1 reflects an ubiquitous response to any sound onset in healthy adults (Näätänen and Picton, 1987). The NI has been associated with processing in non-primary auditory cortex and may selectively respond to the phonetic structure of speech sounds (Ackermann et al., 
1999, Eggermont and Ponton, 2002; Eulitz et al., 1995; Kuriki and Murase, 1989; Tiitinen et al., 1999). Furthermore, recent studies suggested that neural processes underlying the N1 may contribute significantly to the processing of word onsets during the perception of continuous speech (Sanders and Neville, 2003a,b; Sanders et al., 2002). Thus, in our experiments; the N1 may be a good candidate to look for effects of early acoustic/phonetic processing of word onsets during the recognition of spoken words.

During development, the time window(s) influenced by task manipulations involving word onset processing may also change. Little is known about the ERP elicited by spoken words in young children and about its comparability to the adult ERP. Thus, ERP studies on spoken word recognition in children are essential to understand the morphology of the ERP signal and how it may reflect the development of underlying lexical organization and retrieval (Jusczyk, 1993; Metsala and Walley, 1998). To our knowledge there are no previous reports of such developmental ERP data. However, ERP/MEG studies on processing of clicks, tones and consonant-vowel stimuli provide important information regarding developmental changes in general, and with respect to speech specific auditory processing. These studies revealed that the morphology of ERPs and corresponding magnetic fields changes substantially until the late teens (e.g., Bruneau et al., 1997; Ceponiene et al., 1998; Ceponiene et al., 2002; Csépe, 1995; Kraus et al., 1993; Paetau et al., 1995; Pang and Taylor, 2000; Ponton et al., 2000; Shafer et al., 2000; Sharma et al., 1997; Takeshita et al., 2002). Whereas the auditory ERP in adults is consistentlly characterized by a P1-N1-P2 complex, results are less clear in children. The auditory ERP which is most robustly observed in children is a biphasic positive-negative complex (e.g., Ceponiene et al., 2002; Takeshita et al., 2002). The early positivity typically occurs with a latency of about $100 \mathrm{~ms}$ and has been consistently related to the adult PI (e.g., Sharma et al., 1997). The subsequent negativity has a more variable latency which centres around $200-250 \mathrm{~ms}$, and has often been called N2 or N250 (Ceponiene et al., 2002; Takeshita et al., 2002). Several reports have suggested that this $\mathrm{N} 2$ observed in children does not correspond to the component referred to as the N1 in adults (Csépe, 1995; Shafer et al., 2000; Takeshita et al., 2002). The childhood N2 possibly relates to the adult N2 and its prominent amplitude in childhood may reflect auditory sensory processing until the effieient adult cortical networks are established (Takeshita et al., 2002). Overall, the component structure of the auditory ERP in children, and especially the presence of an N1, may depend on stimulus content, e.g., tone frequency (Csépe, 1995) and inter stimulus intervals (ISIs) (Bruneau et al., 1997; Ceponiene et al, 1998; Ceponiene et al., 2002; Paetau et al., 1995). Determination of the maturational course of the $\mathrm{NI}$ and its recording possibilities, are further complicated by the fact that this component consists of several subcomponents, each with its own dependence on stimulus parameters, state of the subject and developmental course (see Bruneau and Gomot, 1998; Bruneau et al., 1997; Pang and Taylor, 2000; Ponton et al., 2000). Whereas these studies provide useful information on the complex pattern of developmental changes in ERPs in response to meaningless auditory (speech) stimuli, it is less clear what changes to expect in ERPs elicited to words during an auditory lexical decision task as used in the present study. 
In summary, based on the review of ERP studies in adults, we expect that several components may be influenced by phonological onset priming. First, priming effects related to acoustic/phonetic processing of word onsets may modulate the N1. Second, priming effects on subsequent phonologieal processing: may modulate a PMN-like negativity. And third, in case priming has an effect on a phonological/lexical level, we expect priming effects in the N400 window. Based on cognitive models of lexical development (Jusczyk, 1993; Metsala and Walley, 1998) and previous developmental ERP studies, we expect changes in the level of segmental restructuring to be reflected in the size and nature of phonological priming effects. Furthermore, we expect additional group differences, independent of priming, in ERP latency and morphology, especially with regard to the early negativities.

\section{Methods}

\section{Subjects}

35 subjects (16 pre-schoolers, 10 beginning readers and 9 adults) participated in Experiment 1 and 26 subjects ( 9 pre-schoolers, 10 beginning readers and 7 adults) in Experiment 2. In Experiment 1, data of 27 subjects were included in the analysis, including 11 pre-schoolers ( $5 \mathrm{f}$, mean age: $6.2 \pm 0.41$ years ), 8 beginning readers ( 6 f; mean age: $7.9 \pm 0.41$ ) and 8 adults ( $6 \mathrm{f}$; mean age: $24.5 \pm 3.3$ ). In Experiment 2, data of 23 subjects were included in the analysis, including 8 pre-schoolers ( $4 \mathrm{f}$; mean age: $6.1 \pm 0.43), 8$ beginning readers ( $6 \mathrm{f}$; mean age: $7.9 \pm 0.38$ ) and 7 adults ( $5 \mathrm{f}$; mean age: $24.7 \pm 3.5$ ). In total, data of 6 pre-schoolers, 4 beginning readers, and 1 adult were discarded, due to excessive movement artefacts, and/or an incidental technical problem. Of each age group, 7 subjects participated in both experiments.

\begin{tabular}{|c|c|c|}
\hline & Pre-schoolers $(n=12)$ & Beginning readers $(n=9)$ \\
\hline $\begin{array}{l}\text { Age } \\
\text { (years) }\end{array}$ & $6.2 \quad(0.4)$ & $7.9 \quad(0.4)$ \\
\hline $\begin{array}{l}\text { passive vocabulary } \\
\text { (C-scores, norm beginning readers) }\end{array}$ & $3.4(1.4)$ & $6.3 \quad(1.8)$ \\
\hline $\begin{array}{l}\text { passive vocabulary } \\
\text { (C-scores, norm preschoolers) }\end{array}$ & $7.5 \quad(1.6)$ & - \\
\hline $\begin{array}{l}\text { word completion } \\
\text { (C-scores max. norm } 7 \text { yrs) }\end{array}$ & $5.6 \quad(1.3)$ & $4.6(1.2)$ \\
\hline $\begin{array}{l}\text { phoneme deletion } \\
\text { (\% correct, total } 28 \text { items) }\end{array}$ & $9.5 \% \quad(16 \%)$ & $95 \%(4 \%)$ \\
\hline $\begin{array}{l}\text { word reading } \\
\text { (C-scores) }\end{array}$ & no reading. & $6.1(1.1)$ \\
\hline $\begin{array}{l}\text { nonword reading } \\
\text { (C-scores) }\end{array}$ & no reading & $6.3(1.2)$ \\
\hline
\end{tabular}

Table 1. Mean (SD) performance on language tests for pre-schoolers and beginning readers. 
Adults were paid for participation and children were given a present. Informed consent was obtained from all the adult subjects and parents of children, according to the approval by the Ethical Committee of the Faculty of Psychology at the University of Maastricht. All subjects were right-handed native Dutch speakers with normal hearing. Handedness was assessed with Annett's Handedness Questionnaire (Arnett, 1979). All adult subjects and parents of children reported the absence of any history of hearing loss. Children were given standardized language tests (see Table 1); including a passive vocabulary test (Bleichrodt, 1984), a word completion test (Van Bon, 1982), a phoneme deletion test (unpublished test, Regional Institute of Dyslexia, Maastricht), and two reading tests, word reading (Brus and Voeten, 1999) and non-word reading (Van den Bos et al., 1999). The phoneme deletion test asks children to delete the first phoneme of a spoken word and pronounce the remaining word. Pre-schoolers were only selected for participation in case they were not yet able to read or write. All pre-schoolers scored within normal limits on the vocabulary and word completion tests, but scored very low or were not able at all to perform the phoneme deletion test. The latter result agrees with the finding that in all languages studied so far, children typically perform close to floor in tasks measuring phoneme awareness prior to learning to read (Liberman, 1973; Morais et al, 1986). All beginning readers included in the analysis scored within the normal range on the performed language tests.

\section{Materials}

Stimuli were mono-morphemic bisyllabic Dutch words and non-words, all with a consonant onset. Non-words were created from words by changing one or two phonemes according to Dutch phonotactic rules. Words were selected using estimates of age of acquisition (AOA) rather than adult frequency ratings. The choice of this selection criterion was indicated by a recent study in which $A O A$ was shown to be a more sensitive measure of lexical familiarity - than either word frequency or neighbourhood density - for making developmental comparisons of spoken word recognition in children (Garlock et al., 2001). Our AOA criterion was 6 years or earlier. Estimates of $A O A$ were based on two published ratings: (1) vocabulary estimates of 6 year-olds (Schaerlaekens et al., 1999), (2) AOA of Dutch words (Ghyselinck et al., 2000), and a subsequent student/parent familiarity rating of the selected words.

The stimuli were spoken by a female native Dutch speaker and recorded on a DAT recorder at a sampling rate of $44.01 \mathrm{kHz}$. Word onsets and offsets were determined using a speech waveform editor. The digitized stimuli were D/A converted with an 8 bit resolution, band-pass filtered $(30 \mathrm{~Hz}-10.6 \mathrm{kHz})$ and resampled at $22.05 \mathrm{kHz}$. The mean acoustical duration of word primes was $596 \mathrm{~ms}$ (range: 413-819), non-word primes 619 ms (range: 409-796), alliterating word targets 576 ms (range: $387-789$ ), unrelated word targets $603 \mathrm{~ms}$ (range: 464-760) alliterating non-word targets $626 \mathrm{~ms}$ (range: 433-864), and unrelated non-word targets 592 ms (range: $353-786$ ). Statistical comparison of prime or target lengths only showed significant differences between unrelated and related non-word targets $(p<.025)$ 


\begin{tabular}{lll}
\hline Primes & Targets & \\
\hline (A) Experiment 1 & word & word \\
word & zuster (sister) & modder (mud) \\
morgen (norning) & non-word & non-word \\
word & zeppel & hapel \\
hamer (hammer) & word & word \\
(B) Experiment 2 & zuster (sister) & modder (mud) \\
nonword & non-word & non-word \\
morben & zeppel & hapel \\
non-word & & \\
hazer & &
\end{tabular}

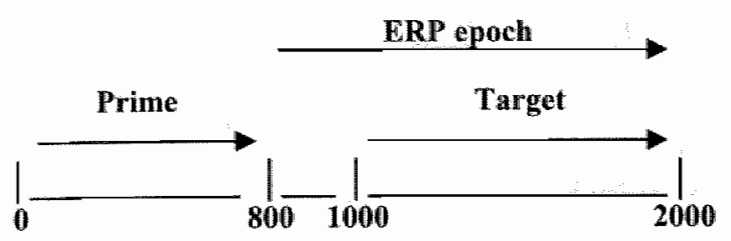

time from prime onset (ins)

Figure 1. Design and example stimuli of Experiment 1 (A) and Experiment 2 (B). Prime-target pairs were either phonologically unrelated (unrellated) or shared the initial two phonemes. (alliterating).

\section{Design}

In both experiments, we used an auditory lexical decision task in combination with phonological onset priming. In Experiment 1 primes were words, in Experiment 2 primes were non-words. Prime-target pairs were either phonologically unrelated (unrelated), or shared the initial two phonemes (alliterating) (see Figure 1). In both experiments, the same set of targets was used: 116 words and 116 non-words. Within each experiment, primes were presented twice, in separate blocks, once in combination with an unrelated and once with an alliterating word or non-word target. In this way targets were never repeated within the same experiment. Prime and target were never semantically related and had the same syllable stress pattern.

\section{Procedure}

Subjects were tested individually in a sound-attenuating and electrically shielded room. They were seated in a comfortable chair in front of a computer monitor. Before the experiment started, subjects performed a separate 5 minutes block of practice trials with stimuli that did not occur in the experiment. Stimuli were presented binaurally through loudspeakers at $65 \mathrm{~dB}$ SPL. Each trial started with a fixation cross which stayed on the screen until the end of the trial. Subjects were instructed not to move their eyes and sit quietly especially when the fixation cross was present. At a variable interval (400 to $1000 \mathrm{~ms}$ ) after appearance of the fixation cross the prime was presented. Prime-target stimulus onset asynchrony 
(SOA) was 1 second. Maximum response time was set at $3000 \mathrm{~ms}$, the inter trial interval was $2000 \mathrm{~ms}$. Subjects were told to ignore the primes, attend carefully to the targets and press the right button in case of real words and the left button in case of non-words. Both speed and accuracy were encouraged. Cartoons of a blue thumb up (near right button) and a red thumb down (near left button) were used to prevent confusion of response hands. Children were given a short break every 20 trials. Both experiments consisted of 12 blocks, after the first 6 blocks there was a longer break. Between subjects, we varied the order in which Experiment 1 and 2 were performed. Within subjects, there was a break of at least two weeks (and maximally 3 months) between the two experiments.

\section{EEG Recording and Data Analysis}

EEG data were recorded from 29 electrodes (Extended international 10-20 system): $\mathrm{FP} 1 / 2, \mathrm{~F} 7 / 8, \mathrm{~F} 3 / 4, \mathrm{Fz}, \mathrm{FT} 8 / 7, \mathrm{FC} 3 / 4, \mathrm{FCz}, \mathrm{T} 3 / 4, \mathrm{C} 3 / 4, \mathrm{Cz}, \mathrm{TP} 7 / 8, \mathrm{CP} 3 / 4, \mathrm{~T} 5 / 6$, $\mathrm{P} 3 / 4, \mathrm{Pz}_{\mathrm{z}} \mathrm{O} / 2,2, \mathrm{Oz}$. Blinks and vertical eye movements were monitored with electrodes placed at the sub- and supra-orbital ridge of the left eye. Lateral eye movements were monitored by a bipolar montage using two electrodes placed on the right and left externall canthus. All electrode impedance levels (EEG and EOG) were kept below $5 \mathrm{k} \Omega$. Electrophysiological signals were amplified with a bandpass filter of $0.01-50 \mathrm{~Hz}$ and digitized at a rate of $250 \mathrm{~Hz}$. EEG signals were recorded with a left mastoid reference, and were offline re-referenced to the average of the right and left mastoid. Epochs of $1200 \mathrm{~ms},-200$ to $1000 \mathrm{~ms}$ relative to target onset, were created from the continuous EEG data. Only trials with correct responses were analyzed. Data were baseline corrected to a $100 \mathrm{~ms}$ pre-stimulus interval, $1-30 \mathrm{~Hz}$ bandpass filtered, and trials containing conspicuous artefacts were rejected (the averages of all subjects, with the exception of one pre-reader, met our rejection criterion of $30 \%$, corresponding to the inclusion of at least 40 trials per condition). In Experiment 1, the mean number of the accepted epochs in the grand averages for alliterating and unrelated word and non-word targets were $45,44,47$ and 48 in pre-schoolers, 52, 51, 51 and 52 in normal readers and 55, 56, 56 and 57 in adults. In Experiment 2, the mean number of the accepted epochs were 48, 47, 50 , and 49 in pre-schoolers, 52, 51,52 and 51 in normal readers and 56, 56, 57 and 57 in adults. Vertical eye-movements (i.e., blink artefacts) were corrected (Semlitsch et al., 1986).

Statistical analysis of behavioural and ERP data were performed using SPSS and Neuroscan software (Neuroscan Labs, El Paso, Texas). Mean reaction times (RT) and error percentages were tested separately for word and non-word targets using an analysis of variance for repeated measures with Overlap (alliterating vs. unrelated) as within, and Group as between subjects factor. Post-hoc t-tests (least significance difference, LSD) were performed only when main effects reached significance or two factors interacted significantly.

Experimental ERP effects were assessed separately for each subject group using mean amplitude values in the time windows corresponding to prominent ERP components in the group grand averages. For ERPs prior to the N400, time windows were selected separately for each subject group by computing individual peak scores and taking the minimum and maximum latency values of these peak scores. In pre-schoolers, the first prominent negative peak was labelled $\mathrm{N}_{200}$, 
according to its mean latency (for a similar approach see Shafer et al, 2000). In beginning readers the two early negativities were labelled N1 and N2. Three consecutive $100 \mathrm{~ms}$ windows were selected to assess N400 effects (for a similar approach see Perrin and Garcia-Larrea, 2003). The resulting tine windows were as follows, pre-schoolers: $\mathrm{Pl}: 90-120 \mathrm{~ms}, \mathrm{~N}_{200}: 170-225 \mathrm{~ms}$, beginning readers: $\mathrm{Pl}$ : 90-110 ms, N1: $120-170 \mathrm{~ms}, \mathrm{~N} 2: 250-350 \mathrm{~ms}$. The three consecutive N400 windows for all children were N400a: $450-550 \mathrm{~ms}$, N400b: $550-650 \mathrm{~ms}$, N400c: 650-750 ms. For adults latencies were earlier: P1: $40-70 \mathrm{~ms}, \mathrm{N1}: 105-140 \mathrm{mss}$, N400a: $300-400 \mathrm{~ms}$, N400b: $400-500 \mathrm{~ms}$, N400c: $500-600 \mathrm{~ms}$.

For further analysis, we selected electrodes in which the ERP components are most frequently reported to occur, as we did not investigate underlying sources or topographical differences between groups. This selection was further corroborated by visual inspection of our data (see Figures $2-6$ ). Thus, as the early components are typically reported for vertex, or fronto-central sites (e.g., Kraus et al., 1993; Sharma et al., 1997; Takeshita et al., 2002), P1, N1, $\mathrm{N}_{200}$, and N2 effects were tested on Fz, $\mathrm{FCz}$ and $\mathrm{Cz}$. As previous literature indicated a more posterior and lateralized predominance for the phonological N400 effect (Rugg, 1984), Fz, Cz, Pz, T3 and T4 were included when testing priming effects in the $\mathrm{N} 400$ time windows. For each subject group, separate anallyses of variance for repeated measures were carried out on mean amplitudes for word and non-word targets with Overlap (unrelated vs. alliterating) and Electrode as within subject variables. Because of large group differences in component morphology and latencies we did not perform an analyses with Group as between subjects factor. We only report results reaching significance at $p<0.05$ after Geisser-Greenhouse correction.

\section{Results}

\section{Experiment 1: word primes}

In the first experiment, subjects performed a lexical decision task, responding to word/non-word targets which were preceded by word primes. The word primes were either unrelated or shared the initial two phonemes (i.e., alliterated) with the targets (see Figure 1A). In this experiment, onset priming effects may result from pre-lexical and/or lexical processing, as word primes involve both levels of processing.

\section{Behavioral Measures}

Error Rates. All subjects performed the task accurately with error rates below or around $10 \%$ (see Table 2), indicating that even the youngest participants were able to accurately perform our experimental task. For word targets, there was a significant Group difference $(F(2,24)=8.6 ; p<.005)$ and a significant Overlap $\mathrm{x}$ Group $(F(2,24)=3.9 ; p<.05)$ interaction. As for the overall Group effect, post hoc ttests indicated that pre-schoolers made more errors than beginning readers $(p<, 005)$ and adults $(p<.005)$, but beginning readers did not differ from adults $(p=0.87)$. The Overlap x Group interaction was due to nonsignificant trends towards more errors in case of alliterating word targets for pre-s hoolers and more errors in case of 
unrelated word targets for both beginning readers and adults. The same analyses for non-word targets did not yield any significant effect.

Reaction Times. RT analysis (see Table 2 ) yielded significant main effects of Group for word $(F(2,24)=10.8 ; p<0.001)$ and non-word targets $(F(2,24)=9.9$; $p<0.005$ ). Post hoc t-tests showed that RTs of pre-schoolers and beginning readers did not differ significantly for word $(p=0.21)$, or non-word targets $(p=0.56)$, but both groups were significantly slower than adults for word $(p<0.001$ and $p=0.005)$ and non-word targets $(p<0.001$ and $p=0.005)$. There were no significant effects of Overlap.

Table 2. Mean (SE) of RTs in milliseconds and error percentages, for pre-schoolers, beginning readers and adults in Experiment 1.

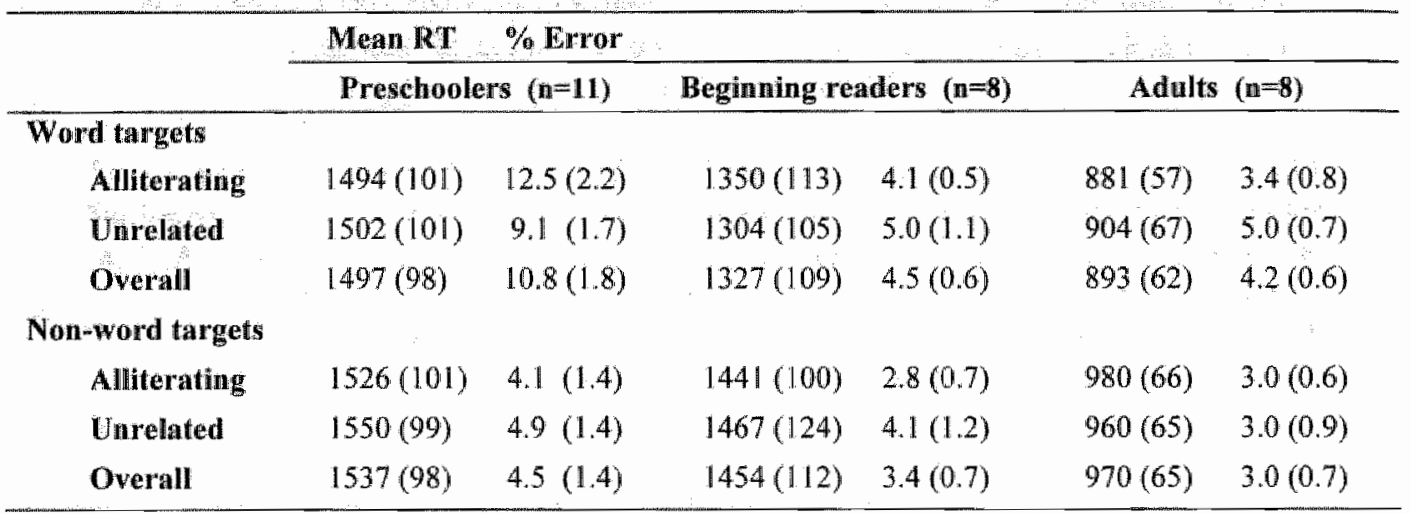

\section{Developmental differences in ERP morphology, amplitude and latency}

ERP waveforms elicited by word targets are given in Figure 2. ERP morphology showed clear age differences between groups (see also Figure 6). Word targets elicited a typical PI-N1-P2-N400 pattern in adults, with a biphasic N400 over fronto-central electrodes. Beginning readers showed a comparable ERP morphology, but also an additional negativity at a latency around $300 \mathrm{~ms}$ present at fronto-central electrodes, which we will refer to as N2. Pre-schoolers showed a biphasic positive-negative complex, which we will refer to as $P 1-\mathrm{N}_{200}$, and a subsequent N400. In addition to these morphological differences, visual inspection of the data revealed longer latencies for corresponding ERP components in children vs. adults, i.e., P1, and N400, and in beginning readers vs. adults, i.e. N1. Furthermore, P1 amplitude was larger in children than in adults. 


\section{Word Targets}
A) pre-sichoolers
B) begimning readers
C) adurts
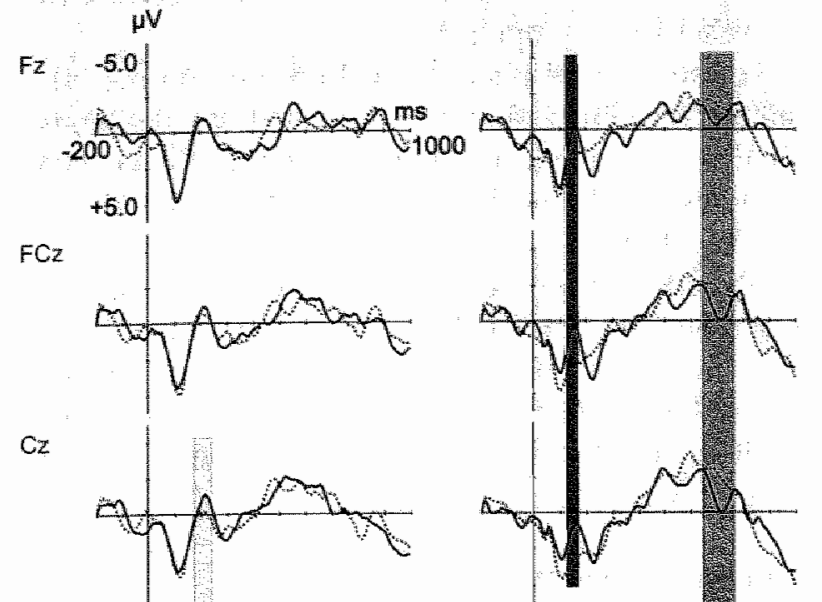

$\mathrm{Pz}$

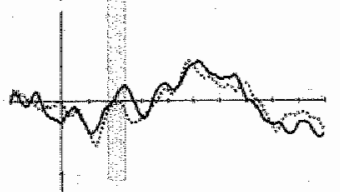

T3

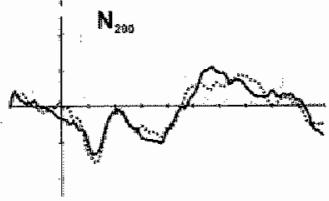

T4
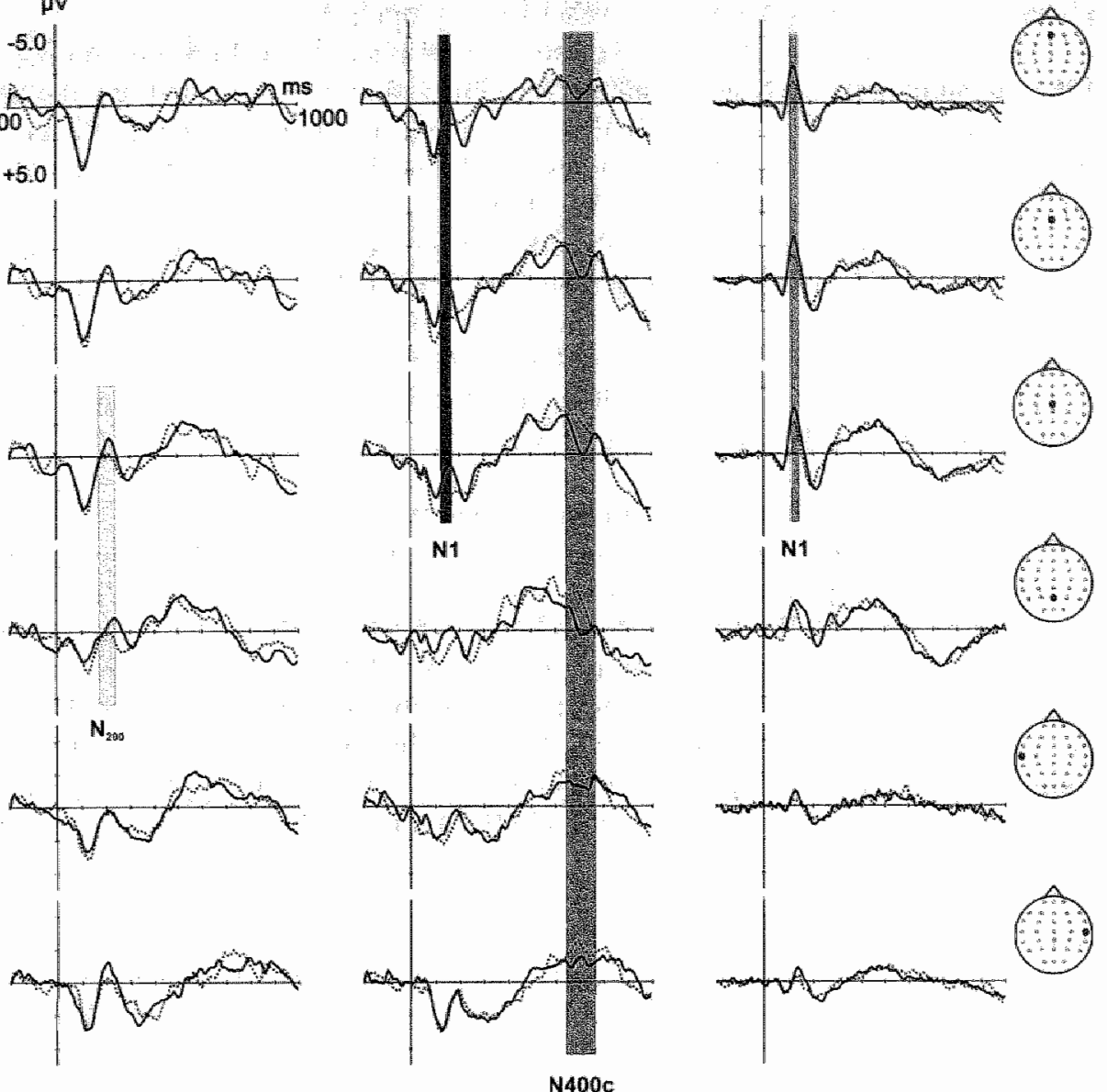

Unrelated

Aliterating

p-values $<0.05<0.01<0.005$

Figure 2. Grand Average ERP waveforms for word targets in Experiment 1 (word primes), for (A) pre-schoolers, (B) beginning readers, and (C) adults, for midline $\left(\mathrm{Fz}_{2}, \mathrm{FCz}_{y} \mathrm{Cz}, \mathrm{Pz}\right)$, lett (T3), and right (T4) hemisphere electrodes. 


\section{Phonological Priming effects: Word targets}

Adults (Figure 2C) showed a phonological priming effect on the N1, i.e., alliterating word targets elicited a reduced N1 response as compared to unrelated word targets $(F(1,7)=11.0 ; p<0.025)$. Adults did not show significant effects of phonological priming on any of the other ERP components.

Beginning readers (Figure 2B) also showed phonological priming on the N1. Like in adults, the $\mathbb{N} 1$ was smaller for alliterating vs. unrelated word targets $(F(1,7)=18.5 ; p<0.005)$. Additionally, beginning readers showed a rather late priming effect in the $\mathrm{N} 400 \mathrm{c}$ window, with an increased $\mathrm{N} 400$ amplitude to alliterating word targets $(F(1,7)=13.3 ; p<0.01)$.

Pre-schoolers (Figure $2 \mathrm{~A}$ ) showed a reduced $\mathrm{N}_{200}$ to alliterating as compared to unrelated word targets. This $\mathrm{N}_{200}$ reduction did not show a significant effect over the three central electrodes $(F(1,10)=1.6$; n.s. $)$, but it was significant $(p<0.05)$ when tested at electrodes $\mathrm{Cz}$, and $\mathrm{Pz}$ where the effect was also most clearly visible (see Figure 2A). Pre-schoolers did not show significant effects of phonological priming in any of the three $\mathrm{N} 400$ windows.

\section{Phonological Priming effects: Non-word targets}

ERP responses to non-word targets are given in Figure 3. In all subject groups, ERP morphology in response to non-word targets was comparable to that elicited by word targets. Overall the ERP signal to non-word targets showed a relatively large variability. The phonological priming effect in the $N 400 \mathrm{c}$ window as shown to word targets by beginning readers, was not present with non-word targets, neither were the $\mathrm{N} 1 / \mathrm{N}_{200}$ effects as shown to word targets by all subject groups. The only significant phonological priming effect on ERPs to non-word targets, was an enhanced $\mathrm{N} 2$ response due to alliteration in beginning readers $(F(1,7)=7.4 ; p<0.05)$.

\section{Experiment 2: non-word primes}

In the second experiment, subjects performed the same lexical decision task as in Experiment 1, but primes were alliterating or unrelated non-words instead of words (see Figure 1B). In this experiment, onset priming effects were expected to result from pre-lexical processing as non-word primes do not have a lexical representation. Thus, if the late enhanced $\mathrm{N} 400 \mathrm{c}$ for beginning readers and the $\mathrm{N} 1 / \mathrm{N}_{200}$ reductions to alliterating word targets in Experiment $\mathrm{I}$, in fact reflect developmental differences in lexical organization, they should not be replicated in Experiment 2. If these ERP priming effects reflect phonological processing independent of the lexical status of the primes, the ERP results of Experiment 2 are expected to replicate those of Experiment 1. 


\section{Non-word Targets}
A) pre-schoolers
B) beginning readers
C) adults
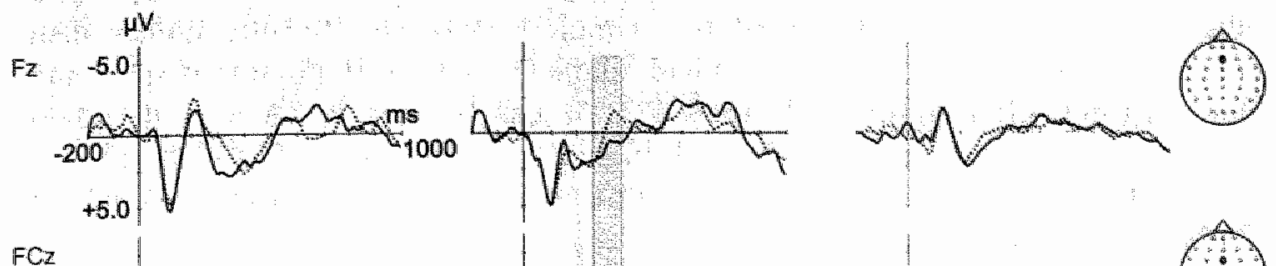

$\mathrm{Cz}$
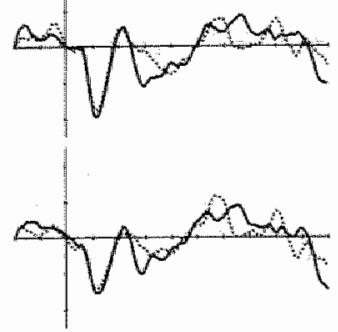

$\mathrm{Pz}$

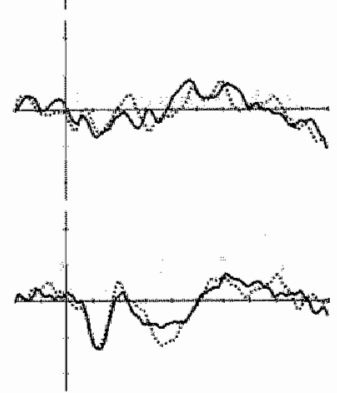

T4
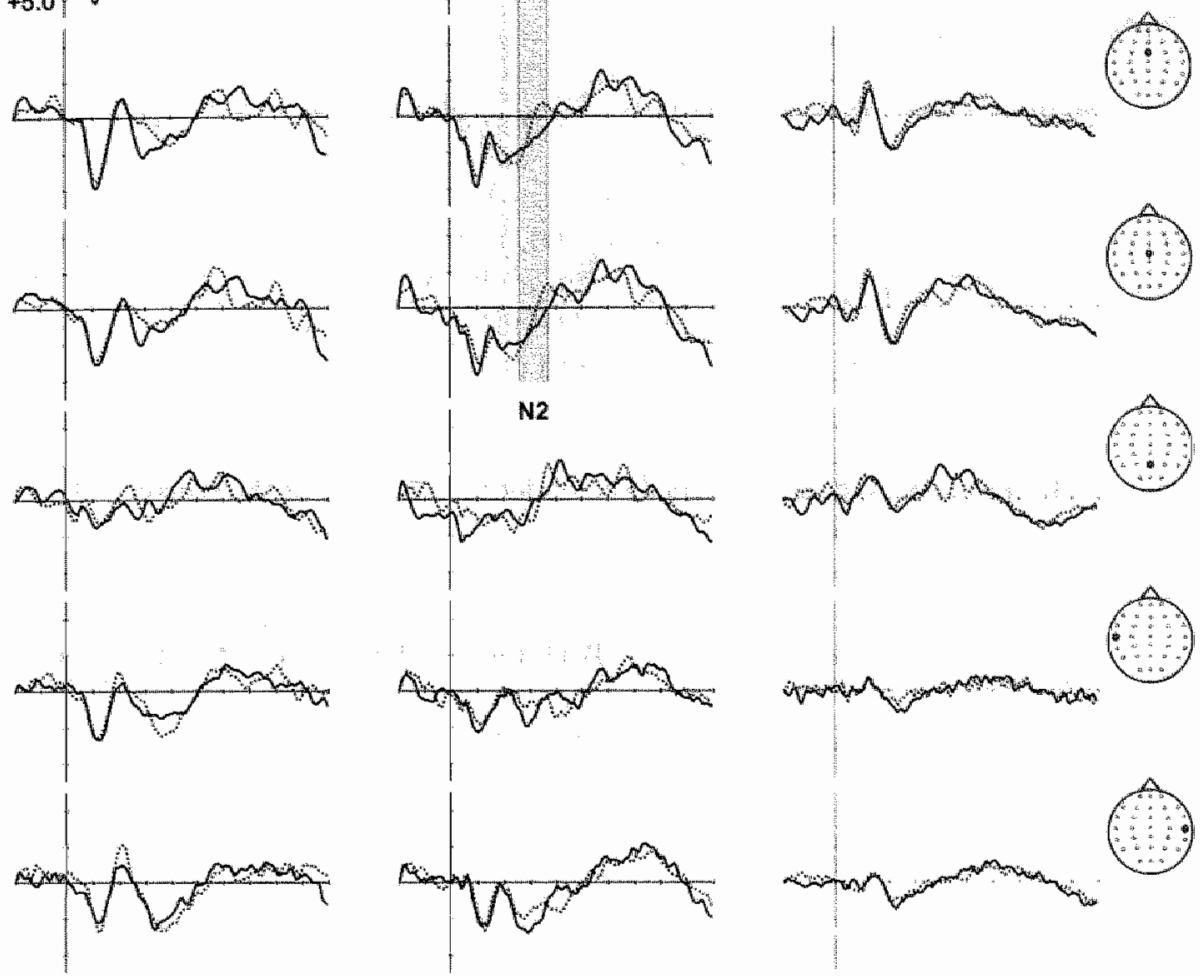

Figure 3. Grand Average ERP waveforms for non-word targets in Experiment 1 (word primes), for (A) pre-schoolers, (B) beginning readers, and (C) adults, for midline ( $F Z, F C z, C z, P Z)$, left (T3), and right (T4) hemisphere electrodes. 


\section{Behavioral Measures}

Error Rates. All subjects performed the task accurately with error rates below or around $10 \%$ (see Table 3). Word targets showed significant main effects of Overllap $(F(1,20)=5.0 ; p<0.05)$, and Group $(F(2,20)=6.1 ; p<0.01)$. Post hoc t-tests indicated that error percentages of pre-schoolers were significantly higher than those of beginning readers $(p<0.025)$ and adults $(p<0,005)$. Beginning readers and adults did not differ significantly $(p=0.45)$. As can be seen in Table 3 , the main effect of Overlap was due to an overall, higher error percentage for alliterating as compared to unrelated word targets. The same anallyses for non-word targets did not yield any significant effect.

Reaction Times. RT analysis (see Table 3) yielded significant main effects of Group for word $(F(2,20)=10.6 ; p<0.005)$ and non-word targets $(F(2,20)=10.5$; $p<0.005)$. Post hoc t-tests showed that RTs of pre-schoolers and beginning readers did not differ significantly for word $(p=0.67)$, or non-word targets $(p=0.35)$, but both groups were significantly slower than adults for word $(p<0.001$ and $p<0.005)$ and non-word targets $(p<0.001$ and $p<0.005)$. Separate within group analyses did not show any significant RT effects for word or non-word targets.

Table 3. Mean (SE) of RTs in milliseconds and error percentages, for pre-schoolers, beginning readers and adults in Experiment 2.

\begin{tabular}{|c|c|c|c|c|c|c|}
\hline \multirow{2}{*}{ Word targets } & \multicolumn{6}{|c|}{ Mean RT \% Error } \\
\hline & \multicolumn{2}{|c|}{ Preschoolers $(n=8)$} & \multicolumn{2}{|c|}{ Beginning readers $(n=8)$} & \multicolumn{2}{|c|}{ Adults $(n=7)$} \\
\hline Alliterating & $146 \rrbracket(116)$ & $10.1(1.5)$ & $1373(133)$ & $4.1(1.1)$ & $817(22)$ & $3.4(0.5)$ \\
\hline Unrelated & $1401(83)$ & $6.5(1.2)$ & $1366(137)$ & $4.3(1.5)$ & $815(18)$ & $2.5(1.4)$ \\
\hline Overall & $1431(99)$ & $8.3(1.1)$ & $1370(135)$ & $4.2(1.3)$ & $8 \| 6(19)$ & $3.0(0.9)$ \\
\hline \multicolumn{7}{|l|}{ Non-word targets } \\
\hline Alliterating & $1618(120)$ & $5.2(1.1)$ & $1447(132)$ & $3.2(1.1)$ & $901(24)$ & $1.7(0.5)$ \\
\hline Unrelated & $1603(137)$ & $3.9(2.3)$ & $1471(150)$ & $3.0(0.9)$ & $873(26)$ & $1.4(0.6)$ \\
\hline Overall & $161 .(127)$ & $4.5(1.6)$ & $1459(141)$ & $3.1(0.9)$ & $887(24)$ & $1.6(0.4)$ \\
\hline
\end{tabular}




\section{Word Targets}
A) pre-schoolers
B) beginning readers
c) adults

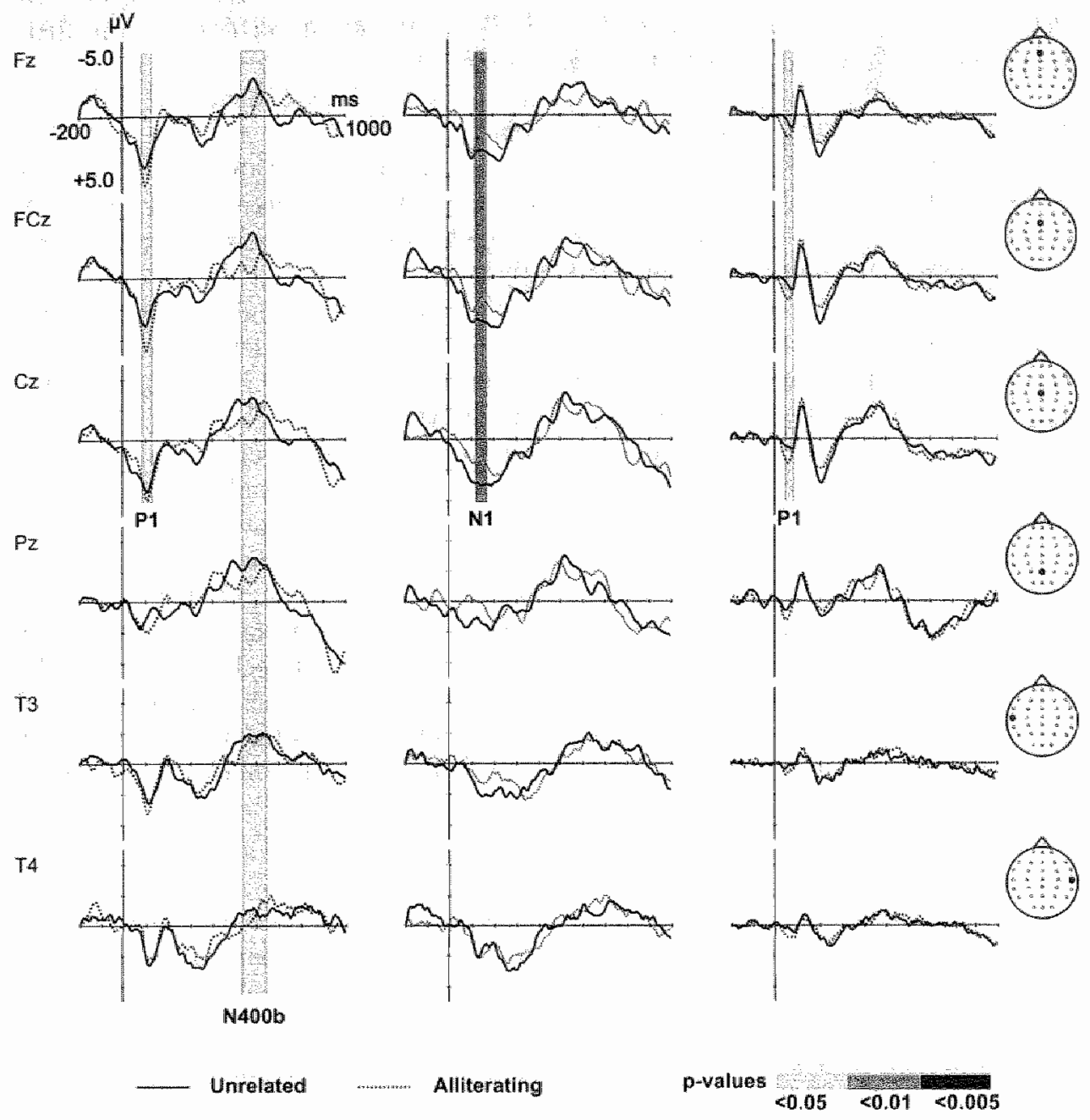

Figure 4. Grand Average ERP waveforms for word targets in Experiment 2 (non-word primes), for (A) pre-schoolers, (B) beginning readers, and (C) adults, for midline ( $\mathrm{Fz}, \mathrm{FCz}, \mathrm{Cz}, \mathrm{Pz}$ ), left (T3), and right (T4) hemisphere electrodes. 


\section{Developmental differences in ERP morphology, amplitude and latency}

ERP waveforms elicited by word targets are given in Figure 4. Word targets elicited the same ERP components and showed the same group differences in ERP morphology and latency as reported in Experiment 1.

\section{Phonological Priming effects: Word targets}

As for ERP effects of word onset priming, visuall inspection of the data (Figure 4) indicated that neither the enhanced $\mathrm{N} 400 \mathrm{c}$ elicited by alliterating word targets in beginning readers, nor the early $\mathrm{N} 1 / \mathrm{N}_{200}$ reductions to word targets as shown by all groups in Experiment 1, were replicated in Experiment 2.

In adults (Figure 4C), a comparison of the two overlap conditions indicated a very early $\mathrm{Pl}$ amplitude difference. The priming effect, a larger $\mathrm{Pl}$ to alliterating as compared to unrelated word targets, was significant $(F(1,6)=9.2 ; p<0.025)$. Later ERP components did not show any significant effects.

In beginning readers (Figure $4 \mathrm{~B}$ ), alliterating word targets elicited a larger $\mathrm{NI}$ than unrelated word targets $(F(1,7)=12.9 ; p<0.01)$. Beginning readers did not show onset priming effects on the P1. Although the N400b window indicated some amplitude reduction to alliterating word targets, this effect did not reach significance.

Pre-schoolers (Figure 4A), showed a larger P1 to alliterating as compared to unrelated word targets $(F(1,7)=9.2 ; p<0.025)$. Whereas in pre-schoolers this early priming effect occurred as a P1 difference, its latency range was similar to that of the NI priming found for beginning readers. Pre-schoolers also showed an effect of Overlap in the N400b window $(F(1,7)=8.3 ; p<0.025)$ : alliterating word targets elicited a reduced negativity.

\section{Phonological Priming effects: Non-word targets}

ERP responses to non-word targets are given in Figure 5. Like in Experiment 1, ERP morphology in response to non-word targets was comparable to the ERP elicited by word targets, but showed considerably more variability. Phonological priming did not lead to any significant effects in pre-schoolers. Beginning readers showed both an enhanced $\mathrm{N} 1(F(1,7)=5.9 ; p<0.05)$ and an enhanced $\mathrm{N} 2$ amplitude $(F(1,7)=7.1 ; p<0.05)$ to alliterating as compared to unrelated non-word targets. In the N400b window, both beginning readers and adults showed a significantly reduced amplitude to alliterating non-word targets $(F(1,7)=8.9 ; p<0.025$, and $F(1,6)=14.5 ; p<0.01)$. 


\section{Non-word Targets}
A) pre-schoolers
B) beginning readers
C) adults
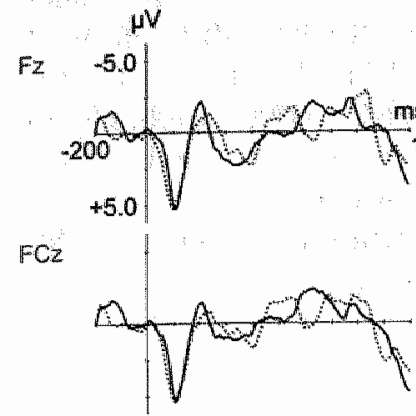

$\mathrm{CZ}$

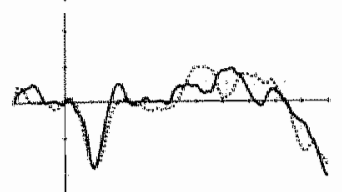

$\mathrm{Pz}$

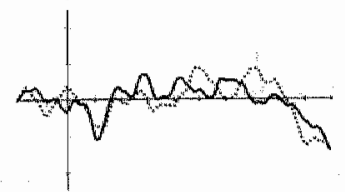

$T 3$

T4
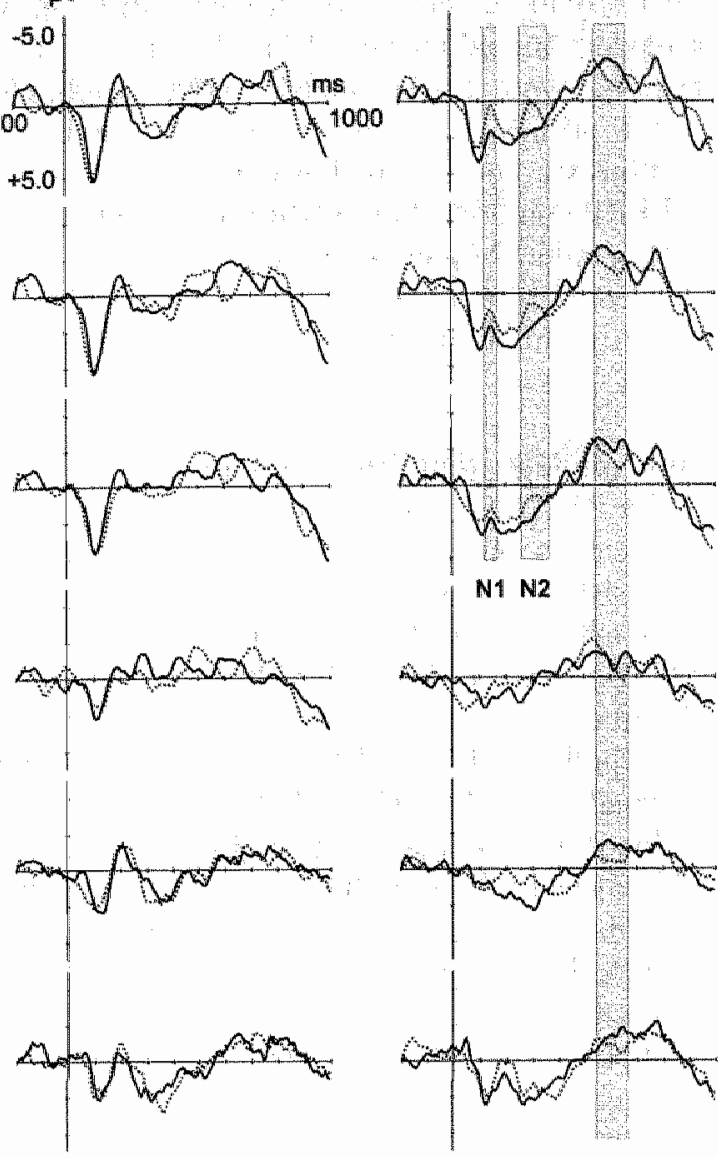

N400b
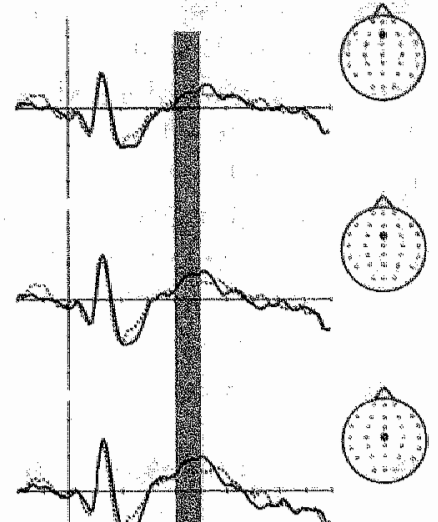

- Unrelated

Alliterating

p-Wallues $<0.05<0.01<0.005$

Figure 5. Grand Average ERP waveforms for non-word targets in Experiment 2 (non-word primes), for (A) pre-schoolers, (B) beginning readers, and $(\mathrm{C})$ adults, for midline $\left(\mathrm{Fz}, \mathrm{FCZ}_{\mathrm{z}} \mathrm{Cz}, \mathrm{Pz}\right.$ ), left (T3), and right (T4) hemisphere electrodes. 


\section{Discussion}

We studied the development of spoken word recognition in early school years as reflected by phonological onset priming effects on ERP responses to words and non-words in an auditory lexical decision task. Our ERP recordings presented agedependent patterns of responses that provide evidence for structural differences of ERPs in pre-schoolers, beginning readers and adults (see 4.1). The most prominent effects of phonological onset priming were an enhanced $\mathrm{N} 400 \mathrm{c}$ amplitude to alliterating word targets with word primes in beginning readers, and typical phonological $\mathbf{N} 400$ reductions with non-word primes in all groups.

Onset priming also influenced ERP components in earlier time windows, with opposite effects for word (i.e., $\mathrm{N} 1 / \mathrm{N}_{200}$ reduction) and non-word primes (i.e., P1/N1 enhancement) in all groups. These electrophysiological modulations and their age(in)dependency seem to be related to maturational levels of the subject's lexical system (see 4.2 and 4.3 ).

\section{Developmental changes in ERP morphology, amplitude and latency}

Word and non-word targets elicited a P1-N1-P2-N400 pattern in adults, a P1-N1$\mathrm{P} 2-\mathrm{N} 2-\mathrm{N} 400$ pattern in beginning readers and a $\mathrm{Pl}-\mathrm{N}_{200}-\mathrm{N} 400$ pattern in preschoolers. These patterns are consistent with previous developmental ERP investigations, in which clicks, tones, and consonant-vowel stimuli were used (e.g., Ceponiene et al., 2002; Csépe, 1995; Kraus et al., 1993; Paetau et al., 1995; Ponton et al., 2000; Shafer et al., 2000; Sharma et al., 1997; Takeshita et al., 2002). Our data bring additional support to the hypothesis that the PI, as measured in children, represents a delayed equivalent of the adult P1. The relatively large P1 amplitude in children is also consistent with earlier studies (e.g., Kraus et al., 1993; Sharma et al., 1997). The observed group differences in the morphology of early negativities (see Figure 6) suggest that maturational ERP changes include not only a general decrease in latency (as it is conventionally assumed), but also additional and more complex structural changes. On a more general level, our findings show that caution is required when the adult ERP literature is used as a reference for interpreting ERP components in children.

As for ERPs in beginning readers, morphology, latency, as well as phonological priming effects suggest that their first negativity reflects a delayed equivalent of the adult $\mathrm{N} 1$. The presence of an $\mathrm{N1}$ in $7 / 8$ year old children with a relatively short SOA of 1 second, may seem unexpected considering previous studies (e.g., Bruneau et al., 1997; Ceponiene et al., 1998; Ceponiene et al., 2002). However, in contrast to these previous studies in which subjects passively listened to meaningless auditory (speech) stimuli, our subjects had to actively perform lexical decisions on word and non-word stimuli. As N1 amplitude has been found to increase with attention level (Näätänen and Picton, 1987) and linguistic relevance (Sanders and Neville, 2003a,b), the requirements of our experimental task may have increased the likelihood of recording the $\mathrm{N} 1$ in children. It is interesting to note that these same factors did not lead to an obvious $\mathrm{N1}$ in the $5 / 6$ year olds (for a comparable finding in a comparison of 4 vs. 9 year olds see Ceponiene et al., 2002). 

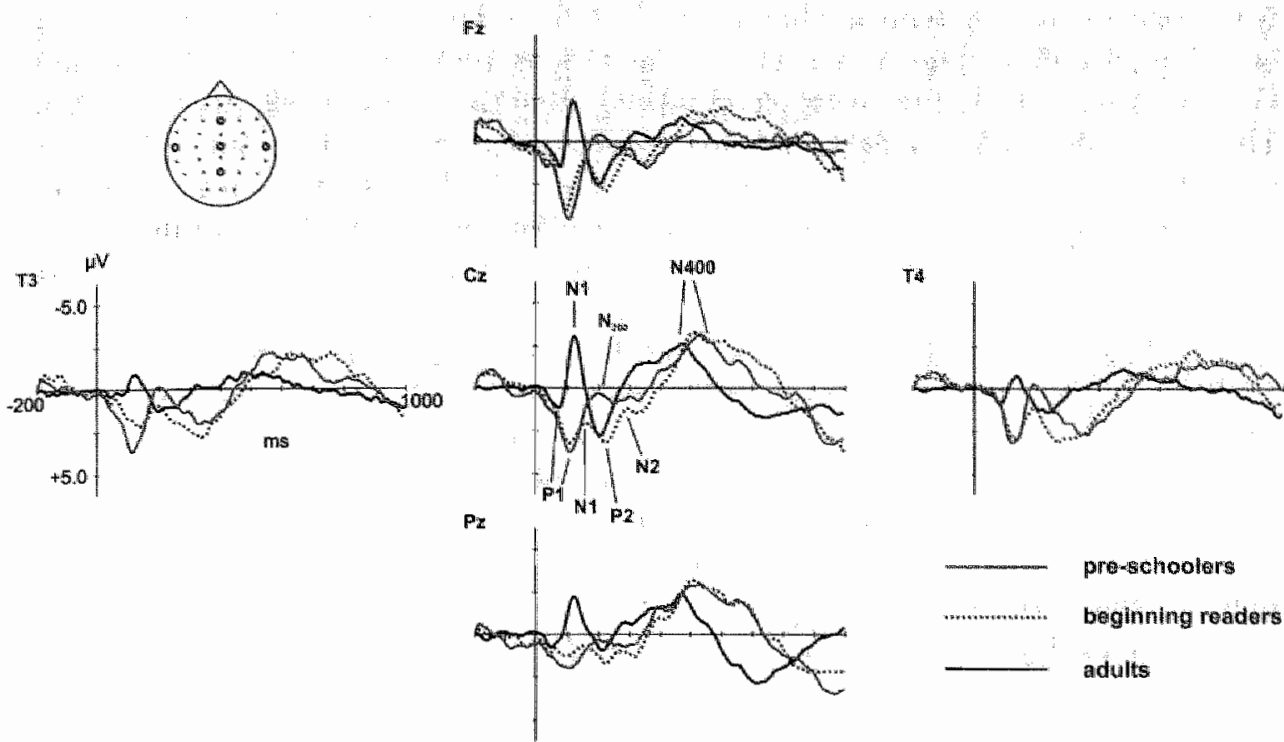

Figure 6. Grand average ERP waveforms of word targets (collapsed over Experiment 1. and 2) for all three subject groups.

The biphasic N1-N2 pattern in beginning readers may represent an intermediate developmental stage between the early negativities measured in preschoolers and adults. The $\mathrm{N}_{200}$ as measured in pre-schoolers revealed some functional similarity with the N1 recorded in both older subject groups (e.g., amplitude reduction to alliterating word targets in Experiment 1). But its long latency and broad peak would suggest that it rather relates to the most consistently reported negativity in children, the N2/N250 (Ceponiene et al., 2002; Takeshita et all, 2002). As the $\mathrm{N}_{200}$ seems to share some characteristics with the $\mathrm{NI}$ and the childhood $\mathrm{N} 2$, one may hypothesize that age group differences in the shape of these early negativities reflect a continuous development of partly overlapping neural sources involved in acoustic/phonetic processing of speech.

\section{ERP correlates of lexical restructuring: $\mathbf{N} 400$ effects}

One of the main goals of the present study was to investigate whether developmental changes in lexical access and organization produce measurable ERP manifestations. Importantly, our findings confirmed that the maturational level of the lexical processing system of the different groups is relevant for explaining the observed patterns of ERP effects. In particular, we suggest that the effects shown by beginning readers, and especially their late $\mathrm{N} 400 \mathrm{c}$ enhancement to alliterating word targets in Experiment 1, may be related to the peculiarity of the maturational stage of the lexical system in this age group (Jusczyk, 1993; Metsala and Walley, 1998), i.e., it is undergoing substantial segmental restructuring.

It is worth remarking that this group-specific $\mathrm{N} 400 \mathrm{c}$ effect was only present when word targets were preceded by alliterating word primes. Moreover, this effect 
was opposite to the typical phonological N400 effect, observed when subjects attend to the phonological aspects of the task (Grossi et al., 2001; Perrin and Garcia-Larrea, 2003; Praamstra et al., 1994; Radeau et al., 1998; Rugg, 1984). These considerations suggest that this $\mathrm{N} 400 \mathrm{c}$ enhancement does not reflect the typical processing of phonological discordance. Rather, they indicate that, in beginning readers, alliterating word primes increase rather than decrease the neural processing required for word target recognition. Furthermore, they suggest that this effect may occur at a lexical level.

In beginning readers; as a result of both vocabulary growth (Metsala and Walley, 1998) and acquisition of reading (Goswami et al, 2003; Liberman, 1973; Morais et al., 1986), the lexical system is undergoing substantial segmental restructuring. This restructuring possibly involves remarkable changes in the contribution of word onset information to lexical processing. It is thus possible that in beginning readers, compared to adults, lexical operations are slower and suboptimal and that, at the prime-target SOA used in the present study, lexical processing of the word target can be influenced by residual processing of the word prime.

In adults, behavioural evidences suggest that, in conditions which hamper word recognition (e.g., word identification in noise), alliterating word primes inhibit RTs to word targets (Zwitserlood, 1994). Based on a cohort-model, these effects are usually explained in terms of an increased processing effort related to lexical competition during lexical access and selection (Marslen-Wilson, 1987). A similar situation may be present in our experiment for beginning readers, which would predict their effortful lexical processing of alliterating word targets and consequently, the functionally related $\mathrm{N} 400 \mathrm{c}$ enhancement.

This interpretation also predicts longer RTs to alliterating word prime - word target pairs in beginning readers. In a previous behavioural study with the same experimental design, and partly the same subjects, we found such an inhibition of RTs to be significant in the same age group (Blomert and Bonte, 2002). Similarly, in the present study, a trend toward the same effect was present but it did not reach significance (see Table 2). The smaller size of the sample and the overall increase in RTs of children performing the task in the ERP recording setting may have compromised the detection of the expected effect. Furthermore, it should be considered that behavioural phonological priming effects in lexical decision tasks are intrinsically small, as they tend to be obscured by additional post-lexical strategic processes associated with decision making (Chumbley and Balota, 1984). Our ERP results show that the $\mathrm{N} 400$, which reflects primarily word-based processing (Kounios and Holcomb, 1992), might be a sensitive marker for these phonological priming effects.

Under the same experimental conditions alliteration did not elicit a similar N400 enhancement in adults and pre-schoolers. In adults, this is presumably due to a fast and automatised lexical processing of word primes. In pre-schoolers, on the other hand, a more holistic lexical system may process word onset information differently (Walley, 1988).

In Experiment 2, effects of non-word primes were expected to result from prelexical phonological levels of processing. In this experiment, alliterating non-word primes led to a reduced negativity that seems to gradually disappear with age, i.e., it 
is strong in pre-schoolers, weak in beginning readers, and absent in adults (see Figure 4). This developmental change suggests that with age, late phonological/lexical aspects of spoken word recognition become less prone to prelexical effects of onset priming as elicited by alliterating non-word primes. In the case of non-word targets, beginning readers and adults showed a typical phonological N400 effect (i.e., N400 reduction due to alliteration). This confirms previous findings indicating that the phonological N400 effect tends to be better detectable when it is not occluded by concomitant and effortful semantic processing of words (Perrin and Garcia-Larrea, 2003). The lack of a similar effeet in preschoolers is likely due to this group's large variability of the ERP signal in the N400 time-window, probably reflecting the fact that these children used a variety of different strategies to process non-words.

\section{Phonological priming in early time windows}

In all subject groups, alliteration also modulated word target ERPs prior to the $\mathrm{N} 400$, i.e., the $\mathrm{P} 1$ and/or $\mathrm{N} 1 / \mathrm{N}_{200}$, indicating that phonological priming started to exert its effect already at the level of acoustic/phonetic processing. These priming effects support recent ERP findings which indicated that neural generators underlying the N1 may be specifically involved in the processing of word onsets (Sanders and Neville, 2003a,b). Furthermore, the opposite priming effects in Experiment 1 and 2, may suggest that the acoustic/phonetic processing of word onsets was differentially affected by word vs. non-word primes. These opposite priming effects dependent on the lexical status of the primes, might imply that already at a very early stage, processing of speech sounds does not only rely on acoustic complexity but also depends on language experience or expectancy (Liebenthal et al., 2003). However, because similar effects were not present when targets were non-words, these results should be interpreted with caution. Further experiments, using e.g., identical target stimuli in a cross-linguistic comparison between native and non-native listeners are required to verify and confirm our current interpretation.

Group differences in early priming effects may reflect further developmental changes in word onset processing. Again, several findings indicate relatively strong onset priming effects for beginning readers as compared to both other age groups. For example, unlike both other groups, beginning readers showed an N1 enhancement to alliterating word as well as non-word targets in Experiment 2, and a similarly enhanced $\mathrm{N} 2$ to alliterating non-word targets in both experiments. These N1/N2 enhancements may reflect comparable increases in neural response due to alliteration when primes and/or targets consisted of non-word stimuli.

The N1 reduction to alliterating word targets in Experiment 1, as shown by both beginning readers and adults, may indicate similar early processing of word initial information. The weak and delayed $\mathrm{N}_{200}$ reduction in pre-schoolers, suggests relatively slow and possibly different processing of word onsets. These findings may further corroborate the idea that in pre-schoolers, word-initial information does not yet have the same status in the process of word recognition, as suggested for adults and older children (e.g., Walley, 1988). 


\section{Conclusion}

Our data show that ERPs elicited by spoken words undergo substantial changes during early school years, even in a period as short as 2 years. Developmental changes in ERP morphology and latency may reflect an increase in speed and efficiency of neural processes necessary for word recognition.

The distinct pattern of priming effects on ERPs in our age groups support the view that the system subserving the recognition of spoken words undergoes a substantial restructuring of processing and representation of phonological information. Most importantly, our ERP' results indicate distinct processing of word onsets in beginning readers, suggesting that vocabulary growth and the acquisition of reading critically contribute to the formation of a fully segmental lexical system that capitalizes on word-initial phonological information.

In conclusion, our study indicates that phonological priming in combination with ERP measurements provides a useful framework for investigating developmental changes in language comprehension. In future studies, the sensitivity of distinct ERP components to the manipulation of phonological information in this context may also help in investigating phonological processing anomalies in developmental language disorders such as developmental dyslexia.

\section{Acknowledgements:}

We are grateful to Basisschool de Kring en St. Aloysius for their support in acquiring subjects. We thank Elia Formisano, Lisa Jonkman, Bernadette Jansma for useful comments on the manuscript. 


\section{References}

Ackernarn, H., Lutzenberger. W., and Hetrich, I. (1999). Hemispheric lateralization of the neural encoding of temporal speech features: A whole-head magnetoencephalography study. Cognitive Brain Research 7, 511-518.

Annett, M. (1979). Family handedness in three generations predicted by the right shift theory. Annals of human genetics $42,479-491$.

Bleichrodt, N., Drenth, P.J.D., Zaal, J.N., and Resing, W.C.M. (1984) Revisie Amsterdamse Kinder Intelligentie Test. Instructie, normen, psychometrische gegevens. (Lisse, Swets \& Zeitlinger).

Blomert, L., and Bonte, M. L. (2002). Brain correlates of pre-lexical and lexical phonological processing in dyslexia. Paper presented at: 9 th annual meeting of the Cognitive Neuroscience Society (San Francisco, USA).

Bruneau, N., and Gomot, M. (1998). Auditory evoked potentials (N1 wave) as indices of cortical development. In Neuroimaging in child neuropsychiatric disorders, B. Garreau, ed. (Berlin, Springer), pp. 113-124.

Bruneau, N., Roux, S., Guerin, P., Barthelemy, C., and Lelord, G. (1997). Temporal prominence of auditory evoked potentials (N1 wave) in 4-8-year-old children. Psychophysiology 34, 32-38.

Brus, B. T., and Voeten, M. J. M. (1999). Een-Minuut-Test (Lisse, Swets, and Zeitlinger).

Ceponiene, R., Cheour, M., and Näätänen, R. (1998). Interstimulus interval and auditory eventrelated potentials in children: evidence for multiple generators. Electroencephalography and Clinical Neurophysiology $108,345-354$.

Ceponiene, R., Rinne, T., and Näătänen, R. (2002). Maturation of cortical sound processing as indexed by event-related potentials. Clinical Neuroplyysiology 113,870-882.

Chumbley, J. I., and Balota, D. A. (1984). A word's meaning affects the decision in lexical decision. Memory and Cognition 12, 590-606.

Connolly, J. F., and Phillips, N. A. (1994). Event-related potential components reflect phonological and semantic processing of the terminal word of spoken sentences. Journal of Cognitive Neuroscience $6,256-266$.

Csépe, V. (1995). On the origin and development of the mismatch negativity. Ear and Hearing 16 , 91-104.

Eggermont, J. J., and Ponton, C. W. (2002). The neurophysiology of auditory perception: from single units to evoked potentials. Audiology and Neurootology 7, 711-99.

Eulitz, C., Diesch, E., Pantev, C., Hampson, S., and Elbert, T. (1995). Magnetic and electric brain activity evoked by the processing of tone and vowel stimuli. Journal of Neuroscience 15, 27482755 .

Garlock, V. M., Walley, A. C., and Metsala, J. L. (2001). Age-of-acquisition, word frequency, and neighborhood density effects on spoken word recognition by children and adults. Journal of Memory and Language 45, 468-492.

Ghyselinck, M., de Moor, W., and Brysbaert, M. (2000). Age-of-Acquisition Ratings for 2816 Dutch Four- and Five-letter Nouns. Psychologica-Belgica 40, 77-98. 
Goswami, U., Ziegler, J. C., Dalton, L., and Schneider, W. (2003). Nonword reading across orthographies: How flexible is the choice of reading units? Applied Psycholinguistics 24, 235247.

Crossi, $G_{,}$, Coch, D., Coffey Corina, S., Holcomb, D. I and Neville, H. I. (2001). Phonological processing in visual thyming: a developmental emp study. Joumal of Cognitive Neuroscience 13 , $610-625$.

Hagoort, P., and Brown, C. M. (2000). ERP effects of listening to speech Semantic ERP effects. Neuropsychologia $38,1518-1530$.

Helenius, P., Salmelin, R., Service, $\mathbb{E}_{\text {, }}$ Connolly, J. F., Leinonen, $\mathrm{S}$, and Lyytinen, H. (2002). Cortical activation during spoken-word segmentation in nonreading-impatred and dyslexic adults. Joumal of Neuroscience $22,2936-2944$.

Juscayk, P. W. (1993). From general to language-specific capacities: The WRAPSA model of how speech perception develops. Journal of Phonetics 21, 3-28.

Jusczyk, P. W. (1999). How infants begin to extract words from speech. Trends in Cognitive Scilences $3,323-328$.

Kounios, J., and Holcomb, P. J. (1992). Structure and process in semantic memory: Evidence from event-related brain potentials and reaction times, Journall of Experimental Psychology: General $12 l_{9}, 459-479$.

Kraus, N., McGee, T., Carrell, T., Sharma, A., Micco, A., and Nicol, T. (1993). Speech-evoked cortical potentials in children. Journal of the American Academy of Audiology 4, 238-248.

Kuriki, S., and Murase, M. (1989). Neuromagnetic study of the auditory responses in right and left hemispheres of the human brain evoked by pure tones and speech sounds. Experimental Brain Research 77, 127-134.

Kutas, M., and Hillyard, S. A. (1980). Reading senseless sentences: brain potentials reflect semantic incongruity. Science 207, 203-205.

Kutas, M., and Van Petten, C. K. (1994). Psycholinguistics electrified: event-related brain potential investigations. In Handbook of Psycholinguistics, M. A. Gernsbacher, ed. (San Diego, Academic Press), pp. 83 - 143.

Liberman, 1. Y. (1973). Segmentation of the spoken word and reading acquisition. Bulletin of the Onton Society $23,65-77$.

Liebentlual, E., Binder, J. R., Piorkowski, R. L., and Remez, R. E. (2003). Short-term reorganization of auditory analysis induced by phonetic experience. Journal of Cognitive Neurosience $15,549-558$

Marslen-Wilson, W. D. (1987). Functional parallellism in spoken word-recognition. Cognition 25 , $71-102$

Marslen-Wilson, W., and Warren, P. (1994). Levels of perceptual representation and process in lexical access: words, phonemes, and features. Psychological Review 101,653-675.

McQueen, J, M., and Cutler, A. (2001). Spoken word access processes: An introduction. Language and Cognitive Processes $16,469-490$.

Metsala, I. L., and Walley, A. C. (1998). Spoken vocabulary growth and the segmental restructuring of lexical representations: Precursors to phonemic awareness and early reading ability. In (1998). Word recognition in beginning literacy., J. L. Metsala, ed. (Mahwah, NJ, US, Lawrence Erlbaum Associates, Publishers), pp. 89-120. 
Morais, J. Bertellson, P. Cary, L, and Alegria, J. (1986). Literacy traning and speech segmentation. Cognition $24,45-64$

Natatänen, $R_{\text {, }}$ Lehtokoski, A., Lennes, M., Cheour, M., Huotilainen, M., livonen, . $_{\text {, Vaino, }}$ M., Alku, P., Ilmoniemi, R. J., Lunk, A, et al. (1997). Language-specific phoneme representations revealed by electric and magnetic brain responses. Nature $385,432-434$.

Naatanen, $\mathrm{R}$, and Picton, T. (1987). The N1 wave of the human electric and magnetic response to sound: a review and an analysis of the component structure: Psychophysiology 24, 375-425.

Paetau, R., Ahonen, A., Salonen, O., and Sarns, M. (1995). Auditory evoked magnetic fields to tones and pseudowords in healthy children and adults. Journal of Clinical Neurophysiology 12 , $177-185$.

Pang, E. W., and Taylor, M. J. (2000). Tracking the development of the NL from age 3 to adulthood: an examination of speech and non-speech stimuli. Clinical Neurophysiology 111,388 397.

Perrin, F., and Garcia-Larrea, L. (2003). Modulation of the $N 400$ potential during auditory phonological/semantic interaction. Cognitive Brain Research $17,36-47$.

Phillips, C., Pellathy, T., Marantz, A., Yellin, E., Wexler, K., Poeppel, D., McGinnis, M., and Roberts; T. (2000). Auditory cortex accesses phonological categories: an MEG mismatch study; Journal of Cognitive Neuroscience 12, 1038-1055.

Ponton, C. W., Eggermont, J. J., Kwong, B., and Don, M. (2000). Maturation of human central auditory system activity: evidence from multi-channel evoked potentials. Clinical Neurophysiology $111,220-236$.

Praamstra, P., Meyer, A. S., and Levelt, W. J. M. (1994). Neurophysiological manifestations of phonological processing: Latency variations of a negative ERP component timelocked to phonological mismatch. Journal of Cognitive Neuroscience 6, 204-219.

Radeau, M., Besson, M., Fonteneau, E., and Castro, S. L. (1998). Semantic, repetition and rime priming between spoken words: behavioural and electrophysiological evidence. Biological Psychology 48, 183-204.

Rugg, M. D. (1984). Event-related potentials and the phonological processing of words and nonwords. Neuropsychologia $22,435-443$.

Sanders, L. D., and Neville, H. J. (2003a). An ERP study of continuous speech processing. I. Segmentation, semantics, and syntax in native speakers. Cognitive Brain Research 15, 228-240.

Sanders, L. D., and Neville, H. J. (2003b). An ERP study of continuous speech processing. II. Segmentation, semantics, and syntax in non-native speakers. Cognitive Brain Research 15,214 227 .

Sanders, L. D., Newport, E. L., and Neville, H. J. (2002). Segmenting nonsense: an event-related potential index of perceived onsets in contimuous speech. Nature Neuroscience 5,700-703.

Schaerlaekens, A., Kohnstamm, D., and Lejaegere, M. (1999). Streeflijst woordenschat voor zesjarigen, 3th revised edition edn (Lisse, Swets, and Zeitlinger).

Semlitsch, H. V., Anderer, P., Schuster, P., and Presslich, O. (1986). A solution for reliable and valid reduction of ocular artefacts, applied to the P300 ERP. Psychophysiology 23, 695-703.

Shafer, V. L., Mort, M. L., Kreuzer, J. A., and Kurtzberg, D. (2000). Maturation of mismatch negativity in school-age children. Ear and Hearing $21,242-251$. 
Sharma, A, Kraus, W. McGee, T. J, and Nieol, T. G. (1997). Dewelopmental changes in PI and N1 central auditory responses elicited by consonant-vowel syllables. Electroencephalography and Clinical Neurophysiology $104,540-545$.

Takeshita, K., Nagamine, T. Thuy, D. H., Satow, T, Matsuhashi, M., Yamamoto, J., Takayama, M. Fujiwara, N, and Shibasak, H. (2002). Maturational change of parallel auditory processing in school-aged children revealed by simultaneous recording of magnetic and electric cortical responses. Clinical Neurophysiology $113,1470-1484$.

Títinen, $H_{.}$, Sivonen, $P_{*}$ Allku, P., Virtanen, $\mathbb{J}$, and Nääänen, R. (1999), Electromagnetic recordings reveal atency differences in speech and tone processing in humans. Cognitive Brain Research $8,355-363$ :

Van Bon, W. H. J. (1982). Taaltest woor kinderen (Lisse, Swets, and Zeitlinger).

Van den Bos, K. P. lutje Spelberg; H. C, Scheepsma, A. J. M., and de Vries, J. R. (1999). De Kapel (Lisse, Swets, and Zeitlinger).

Van den Brink, D., Brown, C. M., and Hagoort, P. (2001). Electrophysiological evidence for early contextual influences during spoken-word recognition: $N 200$ versus $\mathbb{N} 400$ effects. Journal of Cognitive Neurosience $13,967-985$.

Van Petten, C. K., Coulson, S., Rubin, S., Plante, E, and Parks, M. (1999). Time course of word identification and semantic integration in spoken language. Journal of Experimental Psychology Learning Memory and Cognition 25, 394-417.

Vihla, M., Lounasmaa, O. V., and Salmelin, R. (2000). Cortical processing of change detection: dissociation between natural vowels and two-fiequency complex tones. Proceedings of the National Academy of Sciences U S A 97, 10590-10594.

Walley, A. C. (1988). Spoken word recogmition by young children and adults. Cognitive Development 3, 137-165.

Winkler, I., Lelntokoski, A., Alku, P., Vainio, M., Czigler, I., Csépe, V., Aaltonen, O., Raimo, I.,, Alho, K., Lang, H., et al. (1999). Pre-attentive detection of vowel contrasts utilizes both phonetic and auditory memory representations. Cognitive Brain Research 7, 357-369.

Zwitserlood, P. (1994). Access to phonological-form representations in language comprehension and production. In Perspectives on sentence processing, C. Clifton, L. Frazier, and K. Rainer, eds. (Mahwah, NJ, US, Lawrence Erlbaum Associates). 


\title{
Chapter 3
}

\section{Developmental Dyslexia: ERP correlates of anomalous phonological processing during spoken word recognition ${ }^{5}$}

\begin{abstract}
Ample evidence suggests that developmental dyslexia results from a phonological deficit that may not be reducible to a low-level auditory deficit. Yet, on-line phonological processing (in)capacities in dyslexics remain virtually unexplored, as studies have typically focused on either meta-phonological awareness tasks or, at the other extreme, basic perceptual tasks. The present study investigates eventrelated potential (ERP) correlates of implicit phonological processing during the recognition of spoken words in dyslexic and normally reading children (7-10 years). We examined general ERP morphology and alliteration priming effects on ERP measures in an auditory lexical decision task. Primes were words (Experiment 1) and non words (Experiment 2). Alliteration priming effects suggested a distinct pattern of normal wersus anomalous aspects of spoken word processing in dyslexic children. Whereas dyslexics showed deviant priming effects in earlier time windows encompassing the $\mathrm{N} 1$ and $\mathrm{N} 2$, later N400 priming effects were comparable to those of normal readers. The same pattern of results was also present in group comparisons of general ERP morphology. These findings suggest that dyslexics have selective processing anomalies at an earlier phonetic/phonological level, while processing at a later phonological/lexical level proceeds normally. In particular, our results indicate an anomalous contribution of phonological (word onset) information to the processing of spoken words, which may be related to time course aspects of phonetic/phonological processing.
\end{abstract}

\footnotetext{
"This chapter is based on Bonte, M. L., and Blomert, L. (2004). Developmental dyslexia: ERP' correlates of anomalous phonological processing during spoken word recognition. Cognitive Brain Research 21, 360-376.
} 


\section{Introduction}

The acquisition of reading is a complex cultural achievement that builds on primary spoken language skills (Perfetti and Sandak, 2000). In particular, the development of efficient processing and awareness of the sound structure of language, its phonological make-up, has been found to constitute a critical prerequisite for the acquisition of fluent reading (National Research Council, 1998). Moreover, numerous studies indicate that the failure to adequately develop these phonological skills may underlie difficulties in reading and/or spelling such as experienced in developmental dyslexia (Snowling, 2000).

Developmental dyslexia is a specific language-based disorder of constitutional origin characterized by difficulties in reading and/or spelling which are unexpected in relation to age and other cognitive abilities (Reid Lyon, 1995). It affects a relatively large percentage of the population with prevalence estimates ranging from 3-10\% (Pennington, 1990). A recent nationwide study of an elementary school population in The Netherlands estimated a prevalence of reading and/or spelling problems of $8.8 \%$, of which $3.6-4 \%$ were dyslexic (Blomert, 2003). Empirical evidence suggests that developmental dyslexia is associated with a phonological deficit (National Research Council, 1998). Dyslexics perform below average on a large variety of experimental tasks which require phonological skills, like rhyme judgment, phoneme deletion or verbal short term memory tasks (Snowling, 2000). Moreover, during performance of such tasks, dyslexics show abnormal patterns of brain activation, with a typical disruption in left temporoparietal regions as revealed by neuro-imaging studies, and various time course differences as shown by event-related potential (ERP) and magnetoencephalographic (MEG) studies (for reviews see Habib, 2000; Temple, 2002).

Yet, on-line phonological processing (in)capacities in dyslexics remain virtually unexplored, as studies have typically focused on either indirect metaphonological awareness tasks like rhyme judgments or, at the other extreme, perceptual tasks involving the discrimination and categorization of speech sounds. Behavioral studies using the latter type of perceptual tasks reported poor categorical perception of phonemes at the onset of CV syllables in dyslexics (e.g., $/ \mathrm{ba} / / \mathrm{da} /$, Mody et al., 1997; Tallal, 1980). Furthermore, ERP studies have indicated poor sensory change detection (as measured with the mismatch negativity (MMN)) to CV syllables in dyslexic adults (Schulte-Körne et al., 2001) and children (SchulteKörne et al., 1998). The observed categorical perception deficit has been suggested to result from poorly specified phonological representations (Mody et al., 1997; Snowling, 2000), or alternatively, an underlying auditory deficit related to the processing of short, acoustic transients (Reed, 1989; Stein and Walsh, 1997; Tallal, 1980). Recent evidence suggests that low-level auditory perception deficits are only present in a subset of dyslexics (Kronbichler et al., 2002; Ramus et al., 2003), and that if present, they may not typically reflect an impairment in the perception of rapidly presented acoustic information (Mody et al., 1997; Nittrouer et al., 1999; Ramus, 2003; Serniclaes et al., 2001). Moreover, as studies that reported categorical perception problems in dyslexics have typically used synthetic speech stimulli (Mody et al., 1997; Reed, 1989; Schulte-Körne et al., 2001), further studies are needed to examine whether these problems affect natural speech perception. Especially because in a recent study dyslexic children only showed categorical 
perception deficits for synthetic but not for natural speech stimuli (Blomert and Mitterer, 2004). Furthermore, a series of experiments on different levels of context effects in speech perception indicated that the quality of acoustic and phonetic representations used in the perception of natural speech may be similar in dyslexic and normally reading children (Blomert and Mitterer, in press). These findings suggest that even if difficulties in early acoustic and phonetic processing are present, they may not hamper on-line speech perception in dyslexics. Thus, it becomes interesting to investigate the quality and use of pre-lexical phonetic/phonological representations necessary for lexical access (McQueen and Cutler, 2001). Accordingly, the present study compares ERP correlates of implicit phonological processing of word onsets during the recognition of spoken words in dyslexic and normally reading children. In this way, we further investigate the hypothesis that the neurobiological impairment underlying developmental dyslexia affects the development of the phonological component of spoken language.

The recording of ERPs is one of the few techniques that is both usable with children and adequate for the investigation of on-line information processing in the brain on a millisecond basis (Fabiani et al., 200). In normally reading adults, ERPs have been an important tool in characterizing the time course of neural systems involved in different aspects of language processing including those related to the processing of phonological, semantic and syntactic information (Kutas and Schmitt, 2003). An ERP component typically elicited during the processing of written or spoken words is the $\mathrm{N} 400$, a sustained negativity peaking around $400 \mathrm{~ms}$ (Kutas and Schmitt, 2003). The amplitude of the N400 appears to reflect the extent to which a word is semantically primed, i.e., a word that is semantically expected elicits a reduced N400. Similarly, phonological priming, i.e., alliteration (shared word onsets) or rhyme, has been found to reduce the amplitude of an N400 waveform (Dumay et al., 2001; Perrin and Garcia-Larrea, 2003; Radeau et al., 1998; Rugg, 1984). In the auditory modality, such phonological N400 effects start earlier for alliteration than for rhyming, suggesting that the effect may follow the temporal dynamics of spoken word processing (Praamstra et al., 1994). Whereas semantic N400 effects persist during word processing tasks that discourage semantic processing, phonological N400 effects are less robust and mainly occur in experiments that encourage explicit phonological processing (Perrin and GarciaLarrea, 2003).

ERP studies in adults further suggest that during auditory sentence processing, phonological expectations may modulate a negativity at a latency of 200 to $300 \mathrm{~ms}$ preceding the N400 (e.g., Connolly and Phillips, 1994; Hagoort and Brown, 2000; Van den Brink et al., 2001). Similar to the phonological N400 effect, this negativity, labelled e.g., phonological mismatch negativity (PMN), shows an increased amplitude when words/non-words do not match a phonological expectation. Negativities like the PMN have been interpreted to reflect phonological processing of word onsets and/or the initial activation of lexical candidates. More specifically, Newman et al. (2003) suggested that the PMN may reflect a pre-lexical stage of spoken word recognition involving the translation of acoustic input into pre-lexical phonological representations necessary for lexical access. To our knowledge, there are no previous reports of PMN effects in children. 
Developmental ERP studies with normal readers have reported adult-like phonological $\mathrm{N} 400$ effects for auditory and visual rhyming in adolescents (McPherson et al, 1998), and even in children as young as 7 years (Coch et al, 2002, Grossi et al., 2001). In contrast, dyslexic adolescents have been reported to show a deviant phonological $\mathrm{N} 400$ effect for rhyming words in visual studies (e.g., Ackerman et al., 1994), and to show abnormal phonological N400 effects with auditory rhyming (McPherson et al., 1998) and auditory alliteration (McPherson and Ackerman, 1999). These deviant phonological $\mathrm{N} 400$ effects in dyslexics may reflect ERP correlates of their difficulties with phonological awareness tasks. However, the complex task requirements of these explicit phonological awareness tasks may alter the way in which phonological information is usually processed. It may even be questioned if the usual phonological awareness task taps phonological processing aspects of the ongoing word recognition process. That is, the defining element of a phonological awareness task (phoneme monitoring, deletion or insertion) may be performed after, rather than prior to, the point at which a word is recognized (e.g., Thierry et al., 1998). Furthermore, these tasks require a set of processes over and above the word recognition processes; for example, high attention and memory loads (Ramus, 2001). As a consequence, it is hard to disentangle which of these processes is instrumental in the typically reported poor performance and which processes contribute to the reported deviant N400 effects in dyslexies.

The present study addresses the question whether dyslexic children show differences in phonological priming effeets on ERP measures when phonological monitoring or awareness is not an explicit task requirement. We investigate alliteration priming effects on ERPs elicited by words and non-words in a lexical decision task. In a previous study this paradigm proved to be a valuable method for the investigation of normal developmental changes in implicit phonological processing during the recognition of spoken words (Bonte and Blomert, 2004). In that study we examined adults and children of different age groups (pre-schoolers: $5 / 6$ years and beginning readers: $7 / 8$ years) in two experiments, with word primes (experiment 1) and non-word primes (experiment 2). We were interested in these age groups because during early school years the lexical system may show substantial restructuring of phonological processing and representation, especially at the level of word onsets (Bonte and Blomert, 2004; Metsala and Walley, 1998). In addition to a general decrease of ERP latency with age, our data showed substantial developmental changes in the negativities elicited in the latency range of the adult N1-P2 complex. The corresponding negativities, which we labelled as $\mathrm{N}_{200}$ (pre-schoolers) and N1-N2 (beginning readers) most likely do not simply reflect delayed equivalents of the same components in adults and show complex structural and functional changes with age (Bonte and Blomert, 2004; Bruneau and Gomot, 1998; Ceponiene et al., 2002; Karhu et al., 1997). Prominent phonological priming effects were an enhanced $\mathrm{N} 400$ amplitude due to alliterating word primes in beginning readers, and reduced $\mathrm{N} 400$ amplitudes due to alliterating non-word primes in all age groups. The $\mathrm{N} 400$ amplitude reductions are similar to the phonological N400 effects reported in the literature (Coch et al., 2002; Praamstra et al., 1994) and may analogously indicate less effortful neural processing in case of alliteration with non-word primes. In contrast, the $\mathrm{N} 400$ amplitude enhancement as 
uniquely shown by beginning readers, may reflect more effortul neural processing in case of alliterating word pairs, possibly reflecting a neural correlate of the common finding in psycholinguistic research that words sharing onsets compete for activation during spoken word recognition (see Bonte and Blomert, 2004). Under the same experimental conditions alliteration did not elicit an $N 400$ enhancement in adults and pre-schoolers. In adults, this was presumably due to fast and automatised lexical processing of word primes. In pre-schoolers, on the other hand, spoken word recognition may not yet capitalize on word onset information (see Bonte and Blomert, 2004; Metsala and Walley, 1998). Priming further led to opposite early effects with word primes $\left(\mathrm{N} 1 / \mathrm{N}_{200}\right.$ reduction) vs. non-word primes (P1/N1 enhancement) in all groups (see Coch et al., 2002 for phonological priming effects at a similar latency). These opposite priming effects shown in all age groups, may suggest that the processing of word onsets was differentially affected by word vs. non-word primes. Overall, the distinct pattern of priming effects obtained in the three age groups supports the view that during early school years the spoken word recognition system undergoes substantial restructuring at the level of phonological processing and representation as a result of both vocabulary growth and the acquisition of reading (Bonte and Blomert, 2004; see also Jusczyk, 1993; Metsala and Walley, 1998). Most importantly, our study revealed particularly strong alliteration priming effects in beginning readers, as compared to both other age groups. This indicates distinct processing of word-initial phonological information in children around 8 years old. Here we use the same experimental design to investigate ERP correlates of implicit phonological processing in dyslexic children in the same age range and compare them to the results previously obtained with normally reading children.

The presence or absence of normal alliteration priming effects in dyslexïc children is expected to differentiate underlying difficulties at distinct levels of processing. First, deviant early, $\mathrm{N} 1 / \mathrm{N} 2$, priming effects may indicate processing anomalies at a phonetic/phonological level. Second, deviant N400 priming effects may indicate processing abnormalities at a later phonological/lexical level. Dependent on the experimental task used, dyslexics have been reported to show abnormalities in both the auditory NI (Heim et al., 2003; Helenius et al., 2002a) and the auditory N400 time-window (Lovrich et al., 1996; Lovrich et al., 1997; McPherson and Ackerman, 1999; McPherson et al., 1998). Finally, deviant ERP latency and morphology in response to words may indicate anomalies in the speed and efficiency of spoken word recognition in dyslexic children. 


\section{Methods}

\section{Subjects}

29 subjects (15 dyslexics, 14 normal readers) participated in Experiment 1 and 27 subjects (14 dyslexics, 13 normal readers) in Experiment 2. In Experiment 1, data of 24 subjects were included in the analysis, i,e. 12 dyslexics $(6 \mathrm{f}$; mean age: $8.8 \pm$ 0.70 ) and 12 normal readers ( 9 f, mean age: $8.0 \pm 0.64$ ). In Experiment 2, data of 23 subjects were ineluded in the analysis, i.e. 12 dyslexics ( $6 \mathrm{f}$, mean age: $8.8 \pm 0.65$ ) and 11 normal readers $(8 \mathrm{f}$, mean age: $8.0 \pm 0.53)$. In totall, data of 5 dyslexics and 4 normal readers were discarded, due to excessive movement artefacts or an incidental technical problem. 8 normal readers and 10 dyslexics participated in both experiments.

All children were given a present for participation. Informed consent was obtained from the parents of the children. Approval for the study was granted by the Ethical Committee of the Faculty of Psychology at the University of Maastricht. Dyslexic children were recruited from the Regional Institute of Dyslexia (RID), which is one of the major specialized dyslexia institutes in The Netherlands. Prior to the present study, they were diagnosed as dyslexic after an extensive cognitive psycho-diagnostic procedure by the RID. This testing procedure included an intelligence test (WISC-R, Dutch version: WISC-R projectgroup, 1986), the results of which were used in the present study. Normal readers were recruited from local schools, and were judged by their school teachers to be average or above average in academic achievement.

Subject characteristics and results of behavioural tests are given in Table 1. All subjects were native Dutch speakers. With the exception of one of the dyslexics, all subjects were right-handed, as assessed with Annett's Handedness Questionnaire (Annett, 1979). All parents of children reported the absence of any history of hearing loss. Dyslexic children were on average 8 montlis older than normal readers. All subjects had normal or above normal IQ scores, as measured with the Raven Coloured Progressive Matrices (Raven et al., 1998) in normal readers, and the WISC-R (WISC-R projectgroup, 1986) in dyslexics. Both dyslexics and normal readers performed standardized language tests, including two reading tests, the Eenminuut-leestest (one-minute-reading test (Brus and Voeten, 1999) and a non-word reading test (Van den Bos et al., 1999), a passive vocabulary test (Bleichrodt, 1984), and additionally, an unpublished phoneme-deletion task (devised by the RID). The phoneme deletion test asks children to delete the first phoneme of a spoken word and pronounce the remaining word. On each of the language tests, dyslexics performed significantly worse than normal readers, who scored at an ageappropriate level. Performance on the reading tests showed that the reading level of the dyslexic group lagged one and a half to two years behind. Moreover, dyslexics performed worse than normal readers even when age-appropriate norms were disregarded and absolute performance was compared. Performance on the phoneme deletion test showed that all dyslexics suffered from phonological problems. It is important to note that although the groups differed on the passive vocabulary test, it is unlikely that it biased our results, as the words used in the present experiments were all simple words with an age of acquisition of 6 years or earlier (see below). 
Table 1. Descriptive data for normal readers and dyslexics

\begin{tabular}{|c|c|c|c|}
\hline & Normal readers $(\mathrm{n}=15)$ & Dyslexics $(n=14)$ & Differences \\
\hline Age (years; months) & $8 ; 2(7 ; 5-9 ; 4)$ & $8 ; 10(7 ; 9-10 ; 0)$ & $t=-3.0 p=0.005$ \\
\hline $\mathrm{IQ}(\min -\max )$ & $95-125$ & $99-123$ & $\mathrm{t}=1.7 p=\mathrm{ns}$ \\
\hline Word reading & $6.7(1.2)$ & $2.5(1.7)$ & $t=7.9 p<0.001$ \\
\hline Word reading ${ }^{\text {b }}$ & $55(8)$ & $38(12)$ & $=4.5 p<0.001$ \\
\hline Non-word reading" & $6.7(1.2)$ & $3.2(1.3)$ & $t=7.7 p<0.001$ \\
\hline Non-word reading & $47(9)$ & $30(12)$ & $t=4.2 p<0.001$ \\
\hline Passive Vocabulary & $6.8(2.0)$ & $2.8(2.7)$ & $t=4.6 p<0.001$ \\
\hline Passive Nocabulary ${ }^{b}$ & $43(5)$ & $37(9)$ & $t=2.1 p<0.05$ \\
\hline Phoneme deletion $^{{ }^{c}}$ & $95 \%(5 \%)$ & $83 \%(13 \%)$ & $t=3.1 p<0.005$ \\
\hline
\end{tabular}

IQ scores (range) and performance on language tests (mean (SD)).

Age-appropriate norms (standardized scale; mean $=5, \mathrm{SD}=2$ )

th Absolute values (number of correct items)

"Percentage correct, $\max =28$ items

\section{Stimuli}

Stimuli were mono-morphemic bisyllabic Dutch words and non-words, all with a consonant onset. Non-words were created from words by changing one or two phonemes according to Dutch phonotactic rules. Words were selected using estimates of age of acquisition (AOA) rather than adult frequency ratings. The choice of this selection criterion was indicated by a recent study in which AOA was shown to be a more sensitive measure of lexical familiarity - than either word frequency or neighbourhood density - for making developmental comparisons of spoken word recognition in children (Garlock et al., 2001). Our AOA criterion was 6 years or earlier. Estimates of AOA were based on two published ratings: (1) vocabulary estimates of 6 year-olds (Schaerlaekens et al., 1999), (2) AOA of Dutch words (Ghyselinck et al., 2000), and a subsequent student/parent familiarity rating of the selected words.

The stimuli were spoken by a female native Dutch speaker and recorded on a DAT recorder at a sampling rate of $44.01 \mathrm{kHz}$. Word onsets and offsets were determined using a speech waveform editor. The digitized stimuli were $\mathrm{D} / \mathrm{A}$ converted with an 8 bit resolution, band-pass filtered $(30 \mathrm{~Hz}-10.6 \mathrm{kHz})$ and resampled at $22.05 \mathrm{kHz}$. The mean acoustical duration of word primes was $596 \mathrm{~ms}$ (range: 413-819), non-word primes $619 \mathrm{~ms}$ (range: 409-796), alliterating word targets $576 \mathrm{~ms}$ (range: 387-789), unrelated word targets $603 \mathrm{~ms}$ (range: 464-760) alliterating non-word targets $626 \mathrm{~ms}$ (range: 433-864), and unrelated non-word targets $592 \mathrm{~ms}$ (range: $353-786$ ). Statistical comparison of prime or target lengths only showed significant differences between unrelated and related non-word targets $(p<0.025)$. 


\begin{tabular}{|c|c|c|}
\hline Primes & Targets & \\
\hline \multicolumn{3}{|l|}{ (A) Experiment 1} \\
\hline Woird & word & word \\
\hline morgen (morning) & Zuster (sister) & modder (mud) \\
\hline word & non-word & non-word \\
\hline haner (hommer) & zeppel & hapel \\
\hline (B) Experiment 2 & & \\
\hline nonword & word & word \\
\hline worben & zuster (sister) & modder (mud) \\
\hline non-word & non-word & non-word \\
\hline Hazer & zeppel & hapel \\
\hline
\end{tabular}

Figure 1. Design and example stimuli of Experiment 1 (A) and Experiment 2 (B). Prime-target pairs were either phonologically unrelated (unrelated) or shared the initial two phonemes (alliterating).

\section{Design}

In both experiments, we used an auditory lexical decision task in combination with alliteration priming. In Experiment 1 primes were words, in Experiment 2 primes were non-words. Prime-target pairs were either phonologically unrelated (unrelated), or shared the initial two phonemes (alliterating) (see Figure 1). In both experiments, the same set of targets was used: 116 words and 116 non-words. Within each experiment, primes were presented twice, in separate blocks, once in combination with an unrelated and once with an alliterating word or non-word target. In this way targets were never repeated within the same experiment. Prime and target were never semantically related and had the same pattern of syllable stress.

\section{Procedure}

Subjects were tested individually in a sound-attenuating and electrically shielded room. They were seated in a comfortable chair in front of a computer monitor. Before the experiment started, subjects performed a separate 5 minutes block of practice trials with stimuli that did not occur in the experiment. Stimuli were presented binaurally through loudspeakers at $65 \mathrm{~dB}$ SPL. Subjects were instructed not to move their eyes and sit quietly especially when a fixation cross was present. Each trial started with a fixation cross which remained on the screen until the end of the trial. At a variable interval ( 400 to $1000 \mathrm{~ms}$ ) after appearance of the fixation cross the prime was presented. Prime-target stimulus onset asynchrony (SOA) was 1 second. Maximum response time was set at $3000 \mathrm{~ms}$. Upon the response of the subject, a new trial started after an inter trial interval of $2000 \mathrm{~ms}$. Subjects were told to ignore the primes, attend carefully to the targets and press the right button in case of real words and the left button in case of non-words. Both speed and accuracy were encouraged. Cartoons of a blue thumb up (near right button) and a red thumb 
down (near left button) were used to prevent confusion of response hands. Children were given a short break every 20 trials. Both experiments consisted of 12 blocks, after the first 6 blocks there was a longer break. Between subjects, we varied the order in which Experiment 1 and 2 were performed. Within subjects, there was a break of at least a week (and maximally 3 months) between the two experiments.

\section{EEG Recording and Data Analysis}

Mean reaction times (RT) and error percentages were tested separately for word and non-word targets using an analysis of variance for repeated measures with Overlap (alliterating vs. unrelated) as within, and Group as between subjects factor. Group differences were further assessed with two-tailed independent samples t-tests.

EEG data were recorded from 29 electrodes (Extended international 10:20 system, Nuwer et al., 1998): FP1/2, F7/8, F3/4, Fz, FT8/7, FC3/4, FCz, T3/4, C3/4, $\mathrm{Cz}, \mathrm{TP} 7 / 8, \mathrm{CP} 3 / 4, \mathrm{~T} 5 / 6, \mathrm{P} 3 / 4, \mathrm{Pz}, \mathrm{O} 1 / 2, \mathrm{Oz}$. Blinks and vertical eye movements were monitored with electrodes placed at the sub- and supra-orbital ridge of the left eye. Lateral eye movements were monitored by a bipolar montage using two electrodes placed on the right and left external canthus. The effects of blink artefacts were corrected (Semlitsch et al., 1986). All electrode impedance levels (EEG and EOG) were kept below $5 \mathrm{k} \Omega$. Electrophysiological signals were amplified with a band-pass filter of $0.01-50 \mathrm{~Hz}$ and digitized at a rate of $250 \mathrm{~Hz}$. EEG signals were recorded with a left mastoid reference, and were offline rereferenced to the average of the right and left mastoid. Epochs of $1200 \mathrm{~ms},-200$ to $1000 \mathrm{~ms}$ relative to target onset, were created from the continuous EEG data. Only trials with correct responses were analyzed. Data were baseline corrected to a 100 ms pre-stimulus interval, $1-30 \mathrm{~Hz}$ bandpass filtered, and trials containing data exceeding a maximum voltage criterion of $\pm 100 \mu \mathrm{V}$ were rejected (automatic artefact rejection procedure, Neuroscan software (Neuroscan Labs, El Paso TX)). The averages of all subjects, with the exception of the averages to non-word targets in one of the dyslexics, met our rejection criterion of $30 \%$, corresponding to the inclusion of at least 40 trials per condition. In Experiment 1, the mean (range) number of the accepted epochs in the grand averages for alliterating and unrelated word and non-word targets were $52(45-57), 52(49-55), 51(46-57)$ and $52(47-58)$ in normal readers and $52(43-56), 51$ (44-57), 50 (40-56) and 49 (39-54) in dyslexics. In Experiment 2, the mean (range) number of the accepted epochs were $52(42-57), 51(43-56), 51(40-57)$ and $51(41-58)$ in normal readers and $51(43-58)$, $51(42-56), 51(45-56)$ and $48(39-53)$ in dyslexics.

Experimental ERP effects were assessed by calculating mean amplitude values in time windows corresponding to prominent components in the ERP grand averages. The two negativities preceding the $\mathrm{N} 400$ were labelled $\mathrm{N} 1$ and $\mathrm{N} 2$. It should be noted that our ERP labels are meant as notifications, and refer to e.g., a first (N1) and a second (N2) negativity, without assuming exact equivalence with adult components with the same names. We used different time windows to assess $\mathrm{N} 1$ effects at central versus lateral electrodes, as the peaks measured at these sites differed in latency and duration (see Results). Two consecutive $200 \mathrm{~ms}$ windows were selected to assess early versus late phonological N400 effects. We used a single $\mathrm{N} 2$ window because this led to the same results as the use of two N2 windows. The resulting time windows were as follows: P1: $80-120 \mathrm{~ms}$, central NI: 
$120-170 \mathrm{~ms}$, lateral $\mathrm{N} 1: 140-240, \mathrm{~N} 2: 250-350 \mathrm{~ms}$ and $\mathrm{N} 400 \mathrm{a}: 400-600 \mathrm{~ms}, \mathrm{~N} 400 \mathrm{~b}$ : $600-800 \mathrm{~ms}$. Analyses of variance for repeated measures were carried out on mean amplitudes for word and non-word targets with Overlap (unrelated vs. alliterating) and Electrode as within subject factors and Group as between subjects factor. For further analyses we selected electrodes in which the ERP components are most frequently reported to occur, as we did not investigate underlying sources or topographical differences between groups. This selection was further justified by visual inspection of our data (see Figures 2-6). Thus, as these ERP components are typically reported for vertex and fronto-central sites (Sharma et al., 1997; Takeshita et al, 2002), P1, N1, and $\mathrm{N} 2$ effects were tested on $\mathrm{Fz}, \mathrm{FCz}$ and $\mathrm{Cz}$. Because the N1 also has a clear temporal component (Bruneau et al., 1997; Karhu et al., 1997), we additionally tested N1 effects at T3 and T4. Because previous literature indicated a more posterior and lateral predominance for the phonological N400 effect (Coch et al., 2002; Praamstra et al., 1994), Fz, Cz, $\mathrm{P} z, \mathrm{~T} 3$ and T4 were included when testing priming effects in the N400 time windows. The Greenhouse-Geisser correction was applied to repeated measures variables with more than two levels and is reported as corrected $p\left(p_{c o r}\right)$.

Dyslexic children have been reported to show anomalies in overall amplitude and latency measures of ERP/MEG components (Helenius et al., 2002a; Helenius et al., 2002b). To assess such differences, we performed additional planned comparisons (independent samples two-tailed t-tests) on ERP peak latencies and mean ERP amplitudes of average responses to word targets (collapsed over both Experiments).

\section{Results}

\section{General pattern of ERPs elicited by word targets}

We investigated the general morphology of ERPs during word recognition by averaging responses to word targets from Experiment 1 and 2 (see Figure 2). In both dyslexics and normal readers; word targets elicited a P1-N1-P2-N2-N400 pattern at central electrodes and a P1-N1-N400 pattern at lateral electrodes. None of these ERPs showed significant group differences in latency. However, ERP amplitudes and peak morphology showed significant group differences in the N1 and N2 windows. First, in the time window encompassing the lateral N1 (110-310 ms), mean ERP amplitude was significantly smaller for dyslexics as compared to normal readers at electrodes $\mathrm{T} 3(t(1,16)=3.3 ; p<0.005)$ and $\mathrm{T} 4(t(1,16)=4.5$ $p<0.001$ ). Second, at central electrodes dyslexics showed a relatively broad N2 peak with an increased amplitude, leading to a significant group difference in mean N2 amplitude at $\mathrm{Cz}(t(1,16)=3.1 ; p<0.01)$. There were no other significant differences between dyslexics and normal readers. 

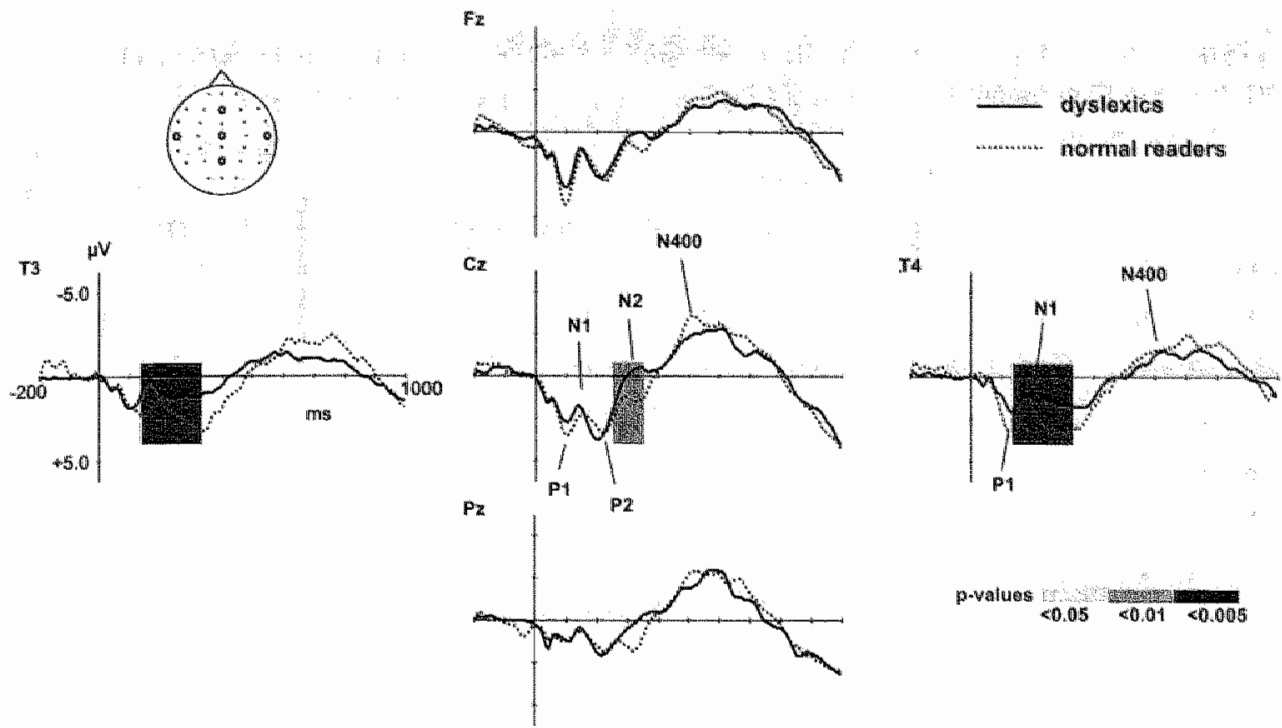

L- dyslextios normal raders

Figure 2. Grand average ERP waveforms of word targets (collapsed over Experiment 1 and 2) for midline ( ${ }^{2} \mathrm{z}, \mathrm{Cz}, \mathrm{Pz}$ ), left (T3), and right (T4) temporal electrodes for normal readers and dyslexics.

\section{Experiment 1: word primes}

In the first experiment, we investigated whether ERP data of dyslexic children indicate anomalies in the processing of phonetic/phonological representations during spoken word recognition (McQueen and Cutler, 2001). Children performed a lexical decision task to word/non-word targets which were preceded by unrelated or alliterating word primes (Figure 1A). Alliteration priming effects were expected to result from pre-lexical and/or lexical phonological processing as word primes involve both levels of processing.

\section{Behavioral Measures}

Behavioral results and $t$-statistics for group comparisons are given in Table 2.

Reaction Times. Mean RT for alliterating word targets was $1386 \mathrm{~ms}$, and for unrelated word targets $1351 \mathrm{~ms}$. This overall slower RT to alliterating as compared to unrelated word targets led to a main effect of Overlap $(F(1,22)=5.1 ; p<0.05)$. There were no group differences for RTs.

Error Raies. Both normal readers and dyslexics performed the task accurately with mean error rates of $9 \%$ or lower. Error rates for word targets did not show significant effects of Overlap or differences between groups. Error rates for nonword targets also did not show effects of Overlap, but dyslexics had a significantly higher error rate than normal readers as indicated by a main effect of Group $(F(1,22)=17.2 ; p<0.001)$. 
Table 2. Mean (SEM) of RT in milliseconds and error percentages for normal readers and dyslexics in Experiment I.

\begin{tabular}{|c|c|c|c|c|c|c|}
\hline & Mean RT & $\%$ Error & & & & \\
\hline & \multicolumn{2}{|c|}{ Normal readers $(n=12)$} & \multicolumn{2}{|c|}{ Dyslexics $(n=12)$} & $t(d f=22)$ & 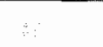 \\
\hline \multicolumn{7}{|l|}{ Ward targets } \\
\hline Alliterating & $1314(79)$ & $4.2(0.4)$ & $1459(88)$ & $5.7(1.1)$ & 1.2 & 1.3 \\
\hline Unrelated & $1274(70)$ & $3.9(0.9)$ & $1428(89)$ & $5.2(0.7)$ & 1.4 & 1.1 \\
\hline Overall & $1294(74)$ & $4.0(0.5)$ & $1443(88)$ & $5.5(0.8)$ & 1.3 & 1.5 \\
\hline \multicolumn{7}{|l|}{ Non-word targets } \\
\hline Alliterating & $1398(72)$ & $3.0(0.7)$ & $1593(70)$ & $9.2(1.3)$ & 19 & $4.2 * * *$ \\
\hline Unrelated & $1407(86)$ & $3.6(0.9)$ & $1560(62)$ & $7.9(1.2)$ & 1.4 & $2.8 *$ \\
\hline Overall & $1403(78)$ & $3.3(0.6)$ & $1576(64)$ & $8.5(1.1)$ & 1.7 & $4.1 \%$ \\
\hline
\end{tabular}

\section{Phonological priming effects: word targets}

ERP responses to alliterating and unrelated word targets are given in Figure 3. A comparison of unrelated vs. alliterating word targets led to a significant main effect of Overlap $(F(1,22)=4.9 ; p<0.05)$ and a significant Overlap* Group interaction $(F(1,22)=5.8 ; p=0.025)$ for the central N1. Whereas dyslexics did not show any significant effect of phonological priming $(F(1,11)=0.015$; n.s.), normal readers showed a significant priming effect, i.e. alliterating word targets elicited a reduced N1 response as compared to unrelated word targets $(F(1,11)=12.3 ; p=0.005)$. There were no significant priming effects in the $\mathrm{N} 1$ window at lateral electrode sites, nor in the $\mathrm{N} 2$ window at central electrodes.

As for the N400 time windows, both dyslexics and normal readers showed an enhanced N400 amplitude in response to alliterating as compared to unrelated word targets, leading to a significant main effect of Overlap in the $\mathrm{N} 400 \mathrm{~b}$ window $(F(1,22)=8.3 ; p<0.01)$ and no significant Overlap*Group interaction. 


\section{Word Targets}

A) normal readers

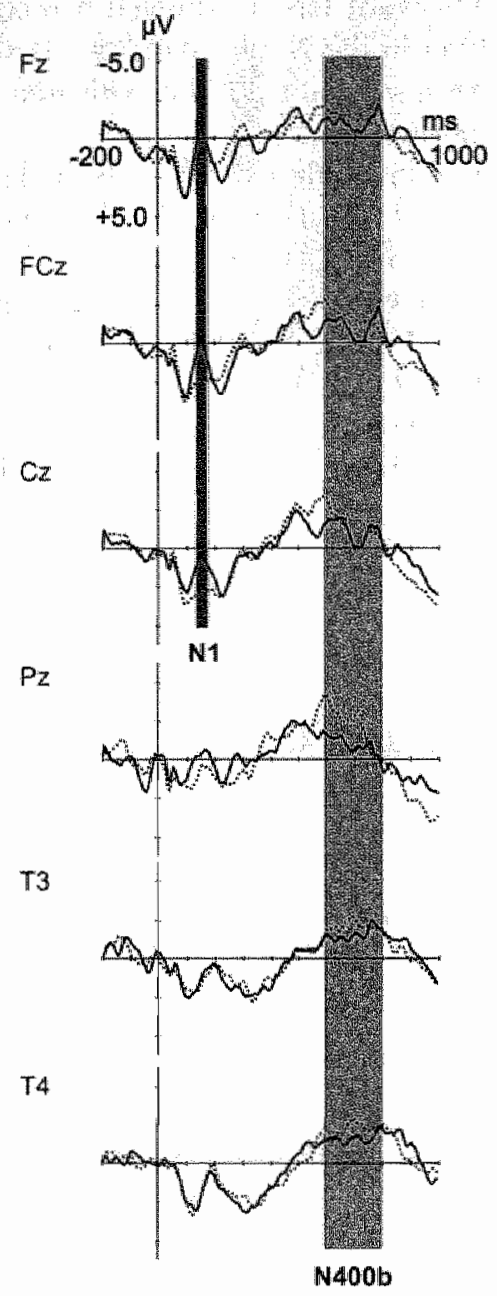

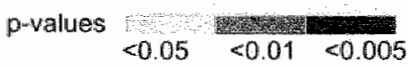

B) dyslexics
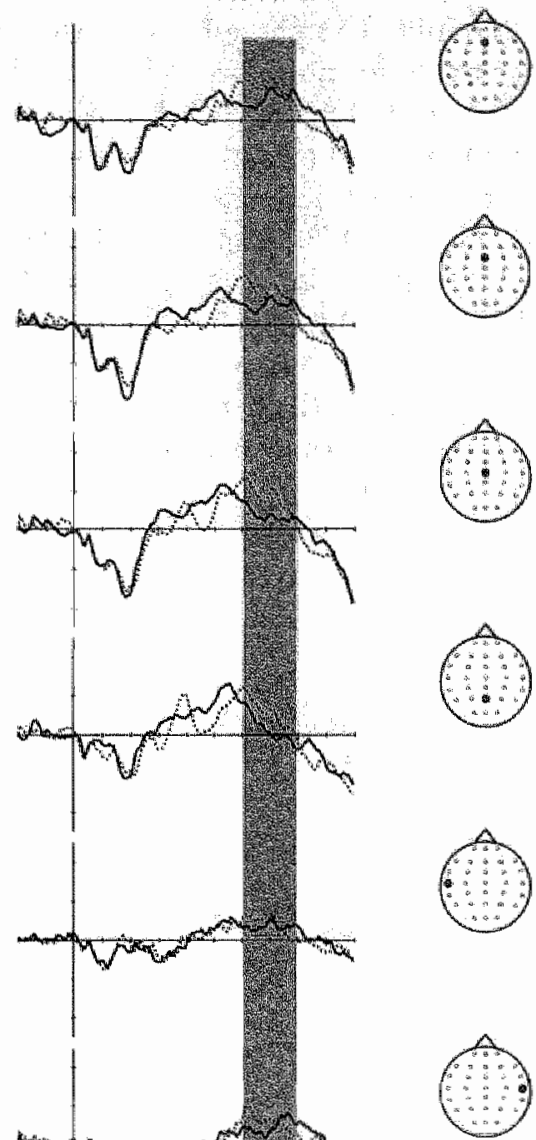

Figure 3. Grand Average ERP waveforms elicited by word targets in Experiment 1 (word primes), in (A) normal readers and (B) dyslexics at midline ( $\mathrm{Fz}, \mathrm{FCz}, \mathrm{Cz}, \mathrm{Pz}$ ), left (T3), and right (T4) temporal electrodes. 


\section{Phonological priming effects: non-word targets}

ERP responses to non-word targets are given in Figure 4 . In both subject groups, ERP morphology in response to non-word targets was comparable to that elicited by word targets. Overall the ERP signal to non-word targets showed a relatively large variability. The phonological priming effect in the $\mathrm{N} 400 \mathrm{~b}$ window, as shown to word targets by normal readers and dyslexics, was not present with non-word targets, neither was the $\mathrm{N} 1$ effect as shown by normal readers.

With non-word targets, alliteration led to comparable effects in dyslexics and normal readers as indicated by main effects of Overlap in the N2 window $(F(1,22)=11.9 ; p<0.005)$ and the N400a window $(F(1,22)=6.2 ; p<0.025)$. In both groups, alliterating non-word targets elicited an enhanced N2 amplitude and a reduced $\mathrm{N} 400$ amplitude as compared to unrelated non-word targets. A significant Overlap* Group interaction in the $\mathrm{N} 400 \mathrm{~b}$ window $(F(1,22)=4.2, p=0.05)$, suggested a different priming effect in normal readers and dyslexics. Within groups, Overlap led to a trend in normal readers $(F(1,11)=4.6 ; p=0.06)$ and no effect in dyslexics $(F(1,1)=1.7$; n.s. $)$. 


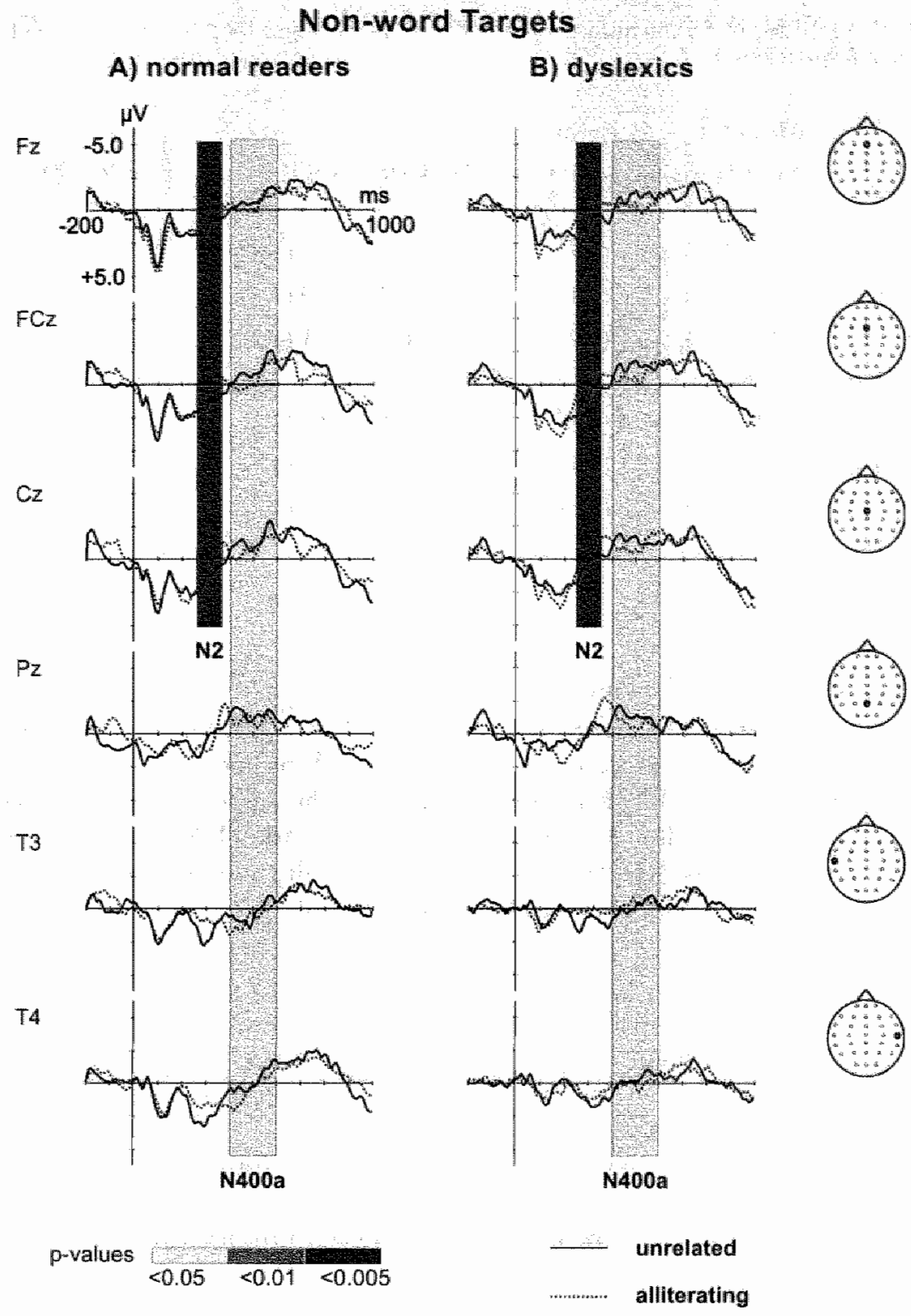

Figure 4. Grand Average ERP waveforms elicited by non-word targets in Experiment 1 (word primes), in (A) normal readers and (B) dyslexics at midline ( $F z, F C z, C z, P z)$, left (T3), and right (T4) temporal electrodes. 
Table 3. Mean (SEM) of RTs in milliseconds and error percentages for normal readers and dystexics in Experiment 2

\begin{tabular}{|c|c|c|c|c|c|c|}
\hline & Mean RT & \multicolumn{5}{|l|}{ \% Errour } \\
\hline & \multicolumn{2}{|c|}{ Normal readers $(n-11)$} & \multicolumn{2}{|c|}{ Dyslexics $(\mathrm{n}=12)$} & \multicolumn{2}{|c|}{$n(d f=2 l)$} \\
\hline Wordtargets & & 8 & & & $\because$ & \\
\hline Alliterting & $1306(103)$ & $39(0,8)$ & $1411(69)$ & $7.3(1.5)$ & 0.9 & 2.0 \\
\hline Uarelated & $1287(107)$ & $3.8(11)$ & $1415(61)$ & $6.9(1.5)$ & 1.1 & 1.7 \\
\hline Overall & $1296(105)$ & $3.8(0.9)$ & $1413(64)$ & $7.1(1.3)$ & 1.0 & 20 \\
\hline Non-woirdtargets & 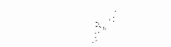 & & & & & \\
\hline Allitenating & $1408(96)$ & $3.3(0.8)$ & $1641(69)$ & $9.9(2.1)$ & 2.0 & $3.0^{* *}$ \\
\hline Un related & $1423(110)$ & $3.1(0.7)$ & $1581(78)$ & $6.2(1.7)$ & 1.2 & 1.6 \\
\hline Overall & $1415(103)$ & $3.2(0.6)$ & $1611(72)$ & $8.0(1,8)$ & 1.6 & $2.5^{*}$ \\
\hline
\end{tabular}

$* p<0.05, * * 0<0.01$

\section{Experiment 2: non-word primes}

In the second experiment, we investigated whether dyslexic children show anomalies in alliteration priming effects resulting from pre-lexical phonological processing. In this experiment, children performed the same lexical decision task, but primes were alliterating or unrelated non-words instead of words (see Figure lB). Alliteration priming effects were expected to result from pre-lexical processing as non-word primes do not have a lexical representation.

\section{Behavioral Measures}

Behavioral results and $t$-statistics for group comparisons are given in Table 3 .

Reaction Times. Mean RT for alliterating word targets was $1361 \mathrm{~ms}$ and for unrelated word targets 1354 ms. There were no significant effects of Overlap or differences between groups for RTs.

Error rates. Both normal readers and dyslexics performed the task accurately with mean error rates of $10 \%$ or lower. Error rates for word targets did not show significant effects of Overlap or differences between groups. Error rates for nonword targets showed significant main effects of Overlap $(F(1,21)=6.1 ; p<0.025)$ and Group $(F(1,21)=6.0 ; p<0.025)$ and an Overlap*Group interaction $(F(1,21)=5.2$; $p<0.05$ ). Whereas normal readers did not show significant effects of Overlap, dyslexics made significantly more errors for alliterating as compared to unrelated non-word targets $(F(1,11)=8.0 ; p<0.025)$. Dyslexics further showed a significantly higher error rate than normal readers for alliterating $(t(1,21)=3.0 ; p<0.01)$, but not for unrelated $(t(1,21)=1.6 ;$ n.s. $)$ non-word targets. 

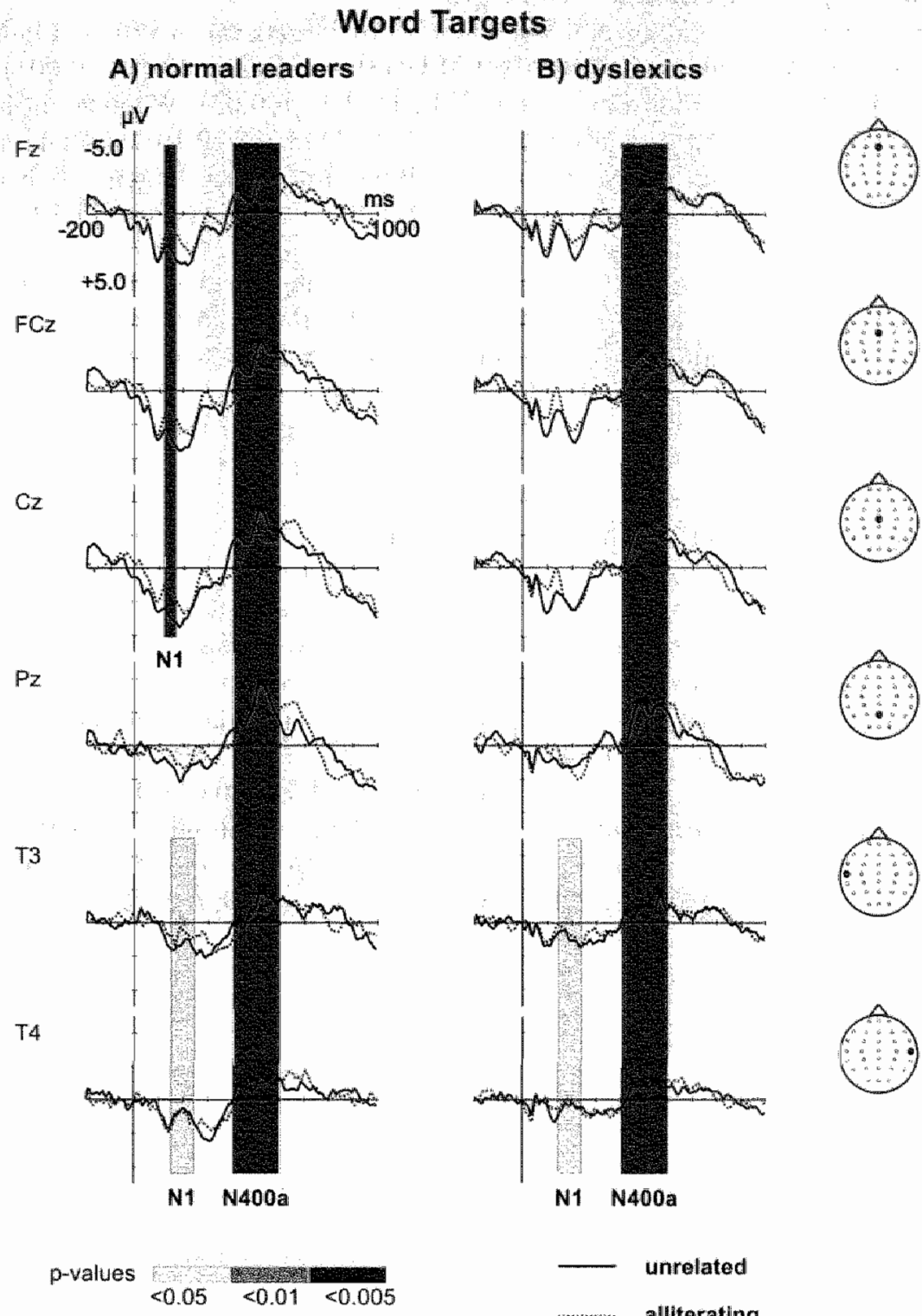
B) dyslexics
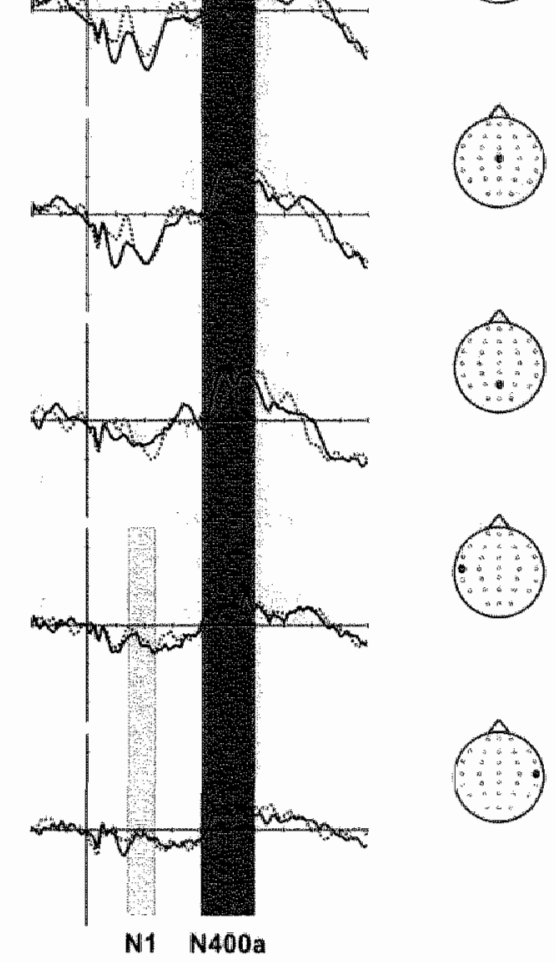

Figure 5. Grand Average ERP waveforms elicited by word targets in Experiment 2 (non-word primes), in (A) normal readers and $(B)$ dyslexics at midline ( $F z, F C z, C x$, $P z)$, left $(T 3)$, and right (T4) temporal electrodes. 


\section{Phonological priming effeets: word targets}

ERP responses to alliterating and unrelated word targets are given in Figure 5. Phonological priming led to a main effect of Overlap $(F(1,21)=19.5 ; p<0.001)$, and a significant Overlap*Group interaction $(F(1,21)=4.3 ; p=0.05)$. Whereas dyslexics only showed a trend towards a priming effect $(F(1,11)=3.1 ; p=0.10)$, normal readers showed a significant priming effect, i.e. alliterating word targets elicited an enhanced N1 response as compared to unrelated word targets $(F(1,10)=18.5$; $p<0.005$ ).

At lateral sites, there was a main effect of Overlap for the NI $(F(1,21)=7.6$; $p<0.025)$ and no significant interaction effects, indicating a small enhancement of the N1 amplitude for alliterating as compared to unrelated word targets in both normal readers and dyslexics. In later time windows, there was a significant reduction in the $\mathrm{N} 400 \mathrm{a}$ amplitude elicited by alliterating as compared to unrelated word targets as indicated by a main effect of Overlap $(F(1,21)=10.0 ; p=0.005)$.

\section{Phonological priming effects: non-word targets}

ERP responses to non-word targets are given in Figure 6. Like in experiment 1, ERP' morphology in response to non-word targets was comparable to that elicited by word targets, but showed more variability. There were no significant piriming effects in the N』 window at central electrode sites. However, in both groups, alliteration led to an enhanced $\mathrm{N} 1$ response at lateral electrodes, and an enhanced $\mathrm{N} 2$ response at central electrodes, as shown by main effects of Overlap, respectively, $(F(1,21)=22.7 ; p<0.001)$ and $(F(1,21)=8.5 ; p<0.01)$. Finally, in both groups, alliteration significantly reduced the N400 amplitude in both N400 windows, as indicated by main effects of Overlap for the N400a window $(F(1,21)=12.8 ; p<0.005)$ and the $\mathrm{N} 400 \mathrm{~b}$ window $(F(1,21)=5.9 ; p<0.025)$. 


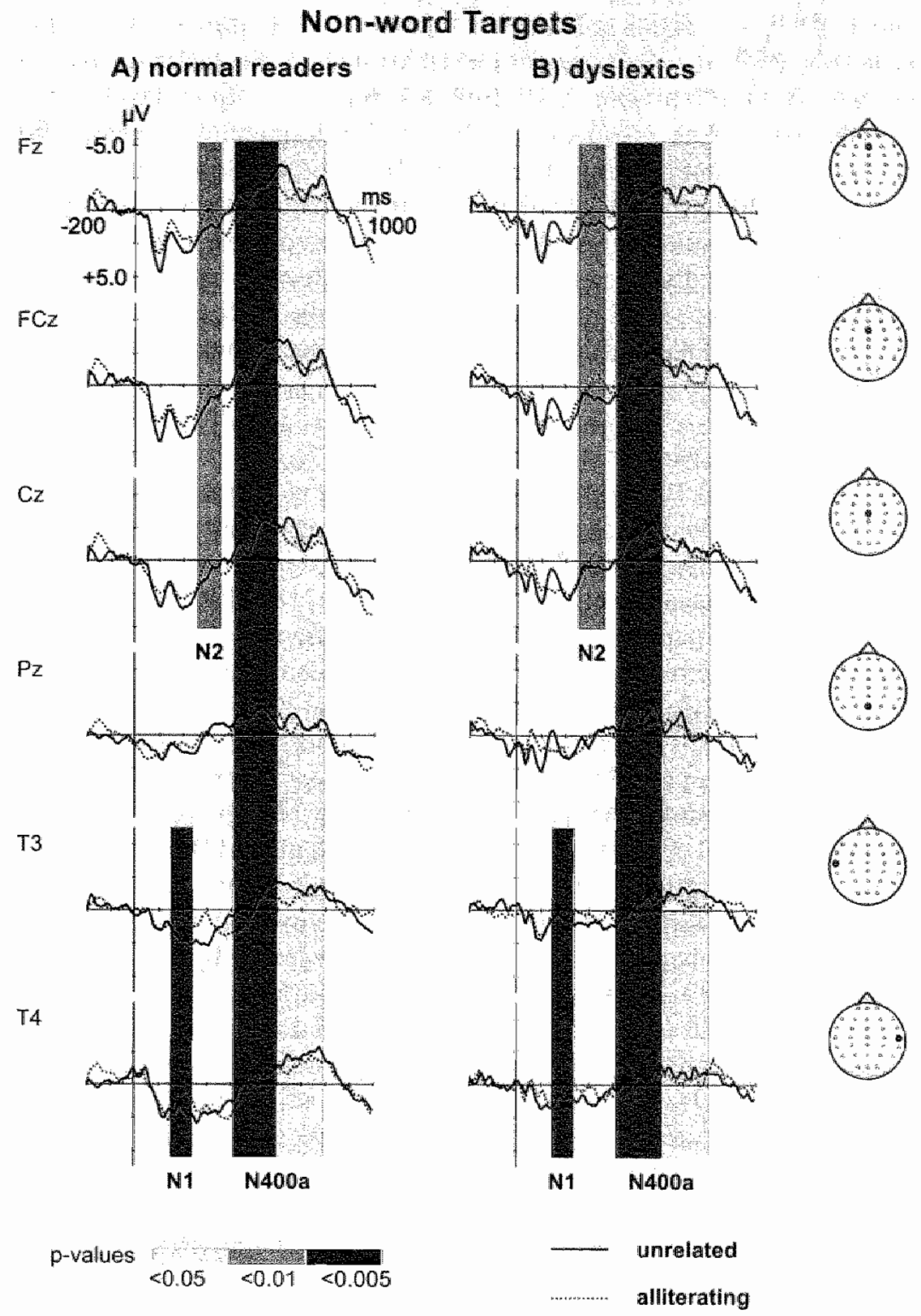

Figure 6. Grand Average ERP waveforms elicited by non-word targets in Experiment 2 (nonword primes), in (A) normal readers and (B) dyslexics at midline ( $F z, F C z, C z, P z)$, left (T3), and right (T4) temporal electrodes. 


\section{Discussion}

We studied ERP correlates of implicit phonological processing (alliteration priming) during spoken word recognition (lexical decision task) in dyslexic and normally reading children. Our ERP findings suggest distinct levels of normal versus anomalous spoken word processing in developmental dyslexia. Whereas dyslexics showed deviant priming effects in earlier time windows encompassing the $\mathrm{N} 1$ and $\mathrm{N} 2$, later $\mathrm{N} 400$ priming effects were comparable to those of normal readers. The same pattern of results was also shown by group comparisons of general ERP morphology. These findings suggest that, in the absence of phonological task requirements, dyslexics exhibit selective processing anomalies at an earlier phonetic/phonological level, while processing at a later phonological/lexical level proceeds normally.

\section{ERPs elicited by word targets}

As little is known about ERPs elicited during spoken word recognition in dyslexic and normally reading children, we first discuss the general pattern of ERPs to word targets in the present experiments. In both groups, word targets elicited a P1-N1-P2N2-N400 pattern at central electrodes and a P1-N1-N400 pattern at lateral electrodes. These ERP patterns are consistent with previous ERP data recorded in children in the same age range with clicks, tones and consonant-vowel stimuli (e.g., Ceponiene et al., 2002; Csépe, 1995; Ponton et al., 2000; Sharma et al., 1997; Takeshita et all, 2002). Furthermore, our data support the hypothesis that ERP components recorded in children may not simply reflect delayed equivalents of the same components in adults, and that especially the N1 and N2 show complex structural and functional changes with age (see also Bonte and Blomert, 2004).

The N1 probably reflects a pre-cursor of the adult N1 waveform. Most likely due to both a relatively long N1 recovery cycle and its overlap with stronger PI and $\mathrm{N} 2$ peaks, the $\mathrm{N} 1$ is typically not visible in children when ISIs are shorter than $1 \mathrm{~s}$ (e.g., Bruneau et al, 1997; Ceponiene et al., 2002; Karhu et al., 1997). Moreover, when presenting tones in trains of four with an ISI of $1 \mathrm{~s}$, Karhu et al. (1997), did not only find a large decrease in N1 amplitude but also an increase in N2 amplitude upon tone repetition in 9-year-old children, but not in adults. In contrast to previous developmental ERP studies in which children typically passively listened to repetitive meaningless auditory (speech) stimuli, our children performed active lexical decisions on word and non-word targets. As the N1 amplitude has been found to increase with attention level (Näătănen and Picton, 1987) and linguistic relevance (Sanders and Neville, 2003a; Sanders and Neville, 2003b), the requirements of our experimental task, together with the use of non-repetitive meaningful stimuli, presumably increased the likelihood of recording the N1 in our children groups. Similar to previous studies that used longer ISIs and measured the NI to tones in children, the N1 to word targets was characterized by a prominent negativity at temporal sites and a small amplitude negativity at fronto-central sites, whereas this pattern is typically reversed in adults (e.g., Bruneau et al., 1997). Like in adults (Eggermont and Ponton, 2002; Näätänen and Picton, 1987), the N1 wave in children has been reported to reflect the activity of several subcomponents each with its own dependence on stimulus parameters, state of the subject and developmental course (Bruneau et al., 1997; Pang and Taylor, 2000; Ponton et al., 
2000). Similarly, in the present study, both ERP priming effects and group differences in $\mathrm{N} 1$ responses (see below) suggest that the N1 responses measured at fronto-central and lateral sites do not reflect identical aspects of speech processing.

The $\mathrm{N} 2$ measured in our experiments may reflect a typical childhood $\mathrm{N} 2$, sometimes called $\mathrm{N} 250$, which is the most prominent negativity of the auditory obligatory ERPs in children up to about 10 years of age (e.g., Bruneau and Gomot, 1998; Ceponiene et al., 2002; Csépe, 1995; Takeshita et al., 2002). This childhood N2 possibly relates to the adult obligatory "basic" N2 (Näätänen and Picton, 1986) and its prominent amplitude in childhood may reflect audutory sensory processing until the efficient aduit cortical networks are established (Ceponiene et al., 2002; Takeshita et al., 2002). The childhood N2 is predominantly recorded at frontocentral sites, which would agree with our findings, and its neural sources have been suggested to include the supratemporal auditory cortex (Bruneau and Gomot, 1998). However, the ERP literature on spoken word recognition in adults offers and alternative explanation for our N2 waveform, that is, in terms of the PMN (Connolly and Phillips, 1994; Hagoort and Brown, 2000; Newman et al., 2003; Van den Brink et al., 2001). Because the PMN has been reported in studies involving phonological priming, we will further address this alternative interpretation below, in our discussion of phonological priming effects.

\section{Anomalous speech processing in dyslexia: N1 and N2 findings}

Our results indicate that the auditory $\mathrm{N} 1$ and $\mathrm{N} 2$ as measured in children may not only mark substantial changes in normal development, but may also be particularly relevant in delineating subtle anomalies in speech processing underlying developmental disorders like dyslexia. In particular, we suggest that the group differences in N1 and N2 morphology indicate a different recruitment of neural sources during speech processing in dyslexic children. Moreover, we suggest that the group differences in $\mathrm{N} 1$ and $\mathrm{N} 2$ alliteration priming effects imply that these anomalies may relate to phonetic/phonological processing of spoken words.

In the time window encompassing the lateral N1, dyslexics showed significantly smaller ERP amplitudes at temporal electrodes than normal readers. This deviant lateral N1 response may have originated from several functional and/or anatomical anomalies in neural sources involved in speech processing. In adults, the N1 represents an obligatory auditory ERP response to any sound onset, with major neural sources in non-primary auditory cortex, e.g., the planum temporale (Eggermont and Ponton, 2002). Planum temporale activity presumably reflects more complex auditory computations than that of the primary auditory cortex (Griffiths and Warren, 2002). Recent studies suggest, for example, that the planum temporale subserves the processing of phonetic contrasts (Jäncke et al., 2002), phonotactic regularity of the native language (Jacquemot et al., 2003) and the processing of grapheme-phoneme associations (Van Atteveldt et al., 2004). Similarly, the NI may selectively respond to the phonetic structure of speech sounds (Eulitz et al., 1995; Obleser et al., 2003; Tiitinen et al., 1999) and to word onsets during the perception of continuous speech (Bonte and Blomert, 2004;

\footnotetext{
6 This obligatory $\mathrm{N} 2$ differs from other negative components in the same latency range related to attentional processes (the $\mathrm{N} 2 \mathrm{~b}$ ) or sound-change detection (the MMN))
} 
Sanders and Neville, 2003a; Sanders and Neville, 2003b). Furthermore, dyslexia has been associated with a deviant planum temporale morphology (see Habib, 2000). Thus, the deviant $N 1$ response as observed in dyslexics in the present study, may indicate a deviant source location (Heim et al., 2003) and/or a deviant strength in neural activation (Helenius et al., 2002a; Helenius et al., 2002b) of N1 sources involved in similar aspects of speech processing. Although previous behavioural (Blomert and Mitterer, 2004; Blomert et al., in press) and ERP/MEG (Helenius et al, 2002a; Schulte-Körne et al,, 1998; Schulte-Körne et al., 2001) findings imply that these deviancies may be specific to the processing of speech, our data do not exclude the possibility of more general deviancies in auditory processing, e.g., the discrimination of complex temporal information (Kujala et al,, 2000; Nagarajan et $\left.\mathrm{al}_{.}, 1999\right)$.

The effects of alliteration priming on ERPs observed in the present study suggest that some of the group differences between dyslexic and normally reading children may be specifically related to the processing of word onsets. Significant effects of alliteration were found in the N1 window, indicating that phonological priming started to exert its effect already at the level of acoustic or phonetic processing of speech sounds (see Coch et al., 2002) for phonological priming effects at a similar latency). In normal readers, opposite priming effects were observed with word targets in Experiment 1 (word primes), i.e. an N1 reduction with alliteration, and Experiment 2 (non-word primes), i.e., an N1 enhancement with alliteration, suggesting that the processing of word onsets was affected by the lexical status of the primes. These opposite alliteration effects may have resulted from differences in e.g., the time course of word vs. non-word prime processing and/or more general context or expectancy effects with word vs. non-word primes (see also Bonte and Blomert, 2004). In dyslexics, the absence of these alliteration effects at the central N1 with both word and non-word primes, indicates an anomalous contribution of phonetic/phonological (word onset) information to the recognition of spoken words. Because in our previous study both pre-schoolers and adults showed the same pattern of opposite early priming effect as normally reading children, this deviance in dyslexics probably did not result from differences in reading level or a maturational delay.

In the subsequent time window encompassing the N2, dyslexics showed overall larger ERP amplitudes than normal readers. In both experiments, dyslexics and normal readers showed the same N2 amplitude enhancement to alliterating nonword targets. As indicated before, the N2 recorded in the present study may reflect a typical childhood $\mathrm{N} 2$, or alternatively a PMN response. Although both alternatives would lead to a similar conclusion in terms of a pre-lexical processing deviancy in dyslexics, the exact interpretation of our N2 findings would be different. So, if the $\mathrm{N} 2$ would in fact represent the obligatory auditory $\mathrm{N} 2$ component that is typically very robust in children (Bruneau and Gomot, 1998; Ceponiene et al., 2002; Csépe, 1995; Takeshita et al., 2002), our findings may reflect differences in speech processing that may not be observable when studying adult dyslexics. Previous evidence for the potential importance of the $\mathrm{N} 2$ response as a marker for the development of auditory processing and language acquisition, comes from a study which showed deviant $\mathrm{N} 2$ responses in children with language impairment (Tonnquist-Uhlen, 1996). Although the precise nature of the processes underlying 
the childhood N2 has still to be elucidated, several possibilities have been suggested in the literature. Karhu et al., (1997) found an N2 amplitude increase upon sound repetition in 9-year old children, but not in adults, and suggested that this amplitude increase may reflect an automatic build-up of neuronal representations in developing networks. Furthermore, the N2 has been related to the processing of sensory stimulus attributes such as acoustical complexity (Ceponiene et al., 2001). The increased $\mathrm{N} 2$ response to word targets as shown by dyslexics in the present study may thus reflect subtle anomalies in similarly basic aspects of pre-lexical speech processing. The $\mathrm{N} 2$ alliteration priming effects observed with non-word targets in both groups in both experiments, indicate that neural sources underlying the N2 may also be involved in speech specific processes.

Alternatively, these alliteration priming effect may support the hypothesis that the N2 reflects a PMN response (Connolly and Phillips, 1994; Newman et al., 2003; Van den Brink et al., 2001). The PMN may be present whenever an experimental task requires phonological processing, and it shows enhanced activity whenever sound-based speech representations do not match a phonological expectation that is build in verbal working memory (D'Arcy et al., 2004). Thus, the observed N2 enhancement, rather than the typically reported reduction, elicited by alliterating non-word targets, would imply that alliterating non-word targets initially deviated more from the expected speech input than unrelated non-word targets. This may be due to task-related factors; for example, the auditory lexical decision task may primarily build an expectation for lexicality (i.e. word targets require an affirmative response), rather than for specific word onsets, which is the case in studies that reported PMN effects (Connolly and Phillips, 1994; D'Arcy et al., 2004; Newman et al., 2003; Van den Brink et al., 2001). Along the same line, an PMN interpretation would suggest that the generally enhanced $\mathrm{N} 2$ response to word targets in dyslexics as compared to normal readers reflects a relatively increased effort in accessing phonological representations in working memory (D'Arcy et al., 2004). Or, in other words, dyslexics may experience increased processing effort during the translation of acoustic input into pre-lexical phonological representations necessary for lexical access (Newman et al., 2003). It is important to note that the two proposed interpretations of the $\mathrm{N} 2$ may not be mutually exclusive, that is, in principle the N2 response may reflect a typical childhood N2, with superimposed PMN effects. Overall, both our $\mathrm{N1}$ and $\mathrm{N} 2$ results suggest an anomalous contribution of phonological (word onset) information to the processing of spoken words in dyslexic children, which may be related to time course aspects of pre-lexical phonetic/phonological processing.

\section{Comparable $\mathrm{N} 400$ priming effects in normal readers and dyslexics}

A main goal of the present study was to investigate ERP measures of phonological processing in dyslexic children without imposing the requirements of an explicit phonological task. Previous ERP studies mainly used phonological awareness tasks, and reported deviant phonological N400 effects in dyslexics (McPherson and Ackerman, 1999; McPherson et al., 1998). Our results indicate that without such a phonological task, dyslexics may show normal phonological priming effects in the N400 window. In both dyslexics and normal readers, alliteration led to a late N400 amplitude enhancement to word targets preceded by word primes (Experiment 1), 
and to $\mathrm{N} 400$ amplitude redurtions in all other conditions. The N400 amplitude reductions due to alliteration are similar to the phonological $N 400$ effects reported in the literature (Coch et all, 2002; Praanstra et al., 1994). Furthermore, our results support the hypothesis that the phonological $N 400$ effect tends to be better detectable without concomitant and effortful semantic processing of words (Perrin and Garcia-Larrea, 2003). That is, the $\mathrm{N} 400$ amplitude reduction was largest when both primes and targets were non-words and it was clearly smaller when either primes or targets were non-words.

The opposite effect of alliteration when both primes and targets were words, i.e. an $\mathrm{N} 400$ amplitude enhancement, as shown by both groups, may reflect specific priming effects at a lexico-phonological level of processing. In both children groups alliteration also led to significantly longer RTs in this condition. Words sharing onsets are assumed to compete for activation during spoken word recognition (McQueen and Cutler, 2001). In the present study, this lexical competition process may have resulted in an increased processing effort in case of alliterating wordword pairs in both normally reading and dyslexic children, and may explain both the increased RT and the enhanced N400 amplitude. In our previous study neither pre-schoolers nor adults showed this RT inhibition effect or N400 amplitude enlnancement (Bonte and Blomert, 2004). The presence of these priming effects may thus reflect age-specific characteristics of lexical processing which are similar for dyslexics and normal readers.

\section{Conclusions}

The present ERP results indicate an anomaly in phonetic/phonological processing of spoken words in dyslexic children along with normal word processing at a phonological/lexical level. The most prominent deviance in ERP priming effects in dyslexics was the absence of an $\mathrm{N} 1$ amplitude reduction to alliterating word-word pairs. This NI priming effect is present in pre-schoolers, normal readers and adults (Bonte and Blomert, 2004), suggesting a qualitative, age-independent anomaly in phonetic/phonological processing of word onsets in dyslexics. Conversely, the N400 enhancement as shown with alliterating word-word pairs in both subject groups, has not been found in the other age groups (Bonte and Blomert, 2004) and may thus reflect age-specific characteristics of lexical processing which are similar in dyslexics and nomal readers. Furthermore, the finding of normal alliteration priming effects in the $\mathrm{N} 400$ window in dyslexics contrasts with previous studies that used explicit phonological awareness tasks. Thus suggesting that deviancies in phonological N400 effects critically depend upon the requirements of an explicit phonological task. Group comparisons of ERP morphology corroborated the pattern of abnormal processing in earlier time windows encompassing the $\mathrm{N} 1$ and $\mathrm{N} 2$, together with normal processing in the later N400 windows. It is important to note that our ERP data do not exclude the possibility of more general differences in complex auditory processing.

In conclusion, the present study explored on-line phonological processing (in)capacities in dyslexic children during spoken word recognition. ERP measures of implicit phonological processing allowed us to distinguish distinct levels of normal versus anomalous processing. In particular, the observed pattern of deviant 
early versus normal late priming effects in dyslexic children indicates a specific anomaly in the time course of phonetic/phonological processing of spoken words.

\section{Acknowledgements:}

The authors are grateful to the Regionaal Instituut voor Dyslexie (RID), the Basisschool de Kring en St. Aloysius for their support in acquiring subjects. The RID also provided us with the diagnostic data of the dyslexics. In addition, we are grateful to Nadia Zellagui and Hanne Poelmans for assistance in data acquisition, and Elia Formisano for useful comments on the manuscript. 


\section{References}

Ackeman, P. T., Dykman, R. A, and Oglesby, D. M. (1994). Visual event-related potentials of dyslexic children to rfyming and nonrhyming stimuli. Joumal of Clinical and Experimentall Neutopsychology $16,138-154$.

Annet, M. (1979). Family handedness in three genterations predicted by the right shift theory. Annals of human genetics $42,479-49$.

Blachman, B. A. (2000). Phonological awareness. In Handbook of reading research, Vol. III, M. L. Kamil, ed. (Mahwah, NJ, US, Lawrence Grlbaum Associates, Publishers), pp. 483-502.

Bleichrodi, N., Drenth, P.J.D., Zaal, I.N., and Resing, W.C.M. (1984). Revisie Amsterdamse Kinder Intelligentie Test. Instructie, notmen, psychometrische gegevens. (Lisse, Swets \& Zeitlinger).

Blomert, L. (2003). Dyslexie: stand van zaken (Dyslexia: State of Affairs in the Netherlands). Report for the Dutch Ministry of Health. In Dyslexie naar een vergoedingsregeling, $R$. Reij, ed. (Amstelveen, Dutch Health Care Insurance Board), pp. 1-119, publication number 03/144.

Blomert, L., and Mitterer, H. (2004). The fragile nature of the speech-perception deficit in dyslexia: natural ws synthetic speech. Brain and Language 89, 21-26.

Blomert, L., Mitterer, H., and Paffen, C. (2004). In Search of the Auditory, Phonetic, and/or Phonological Problems in Dyslexia: Context Effects in Speech Perception. Joumal of Speech, Language, and Hearing Research 47, 1030-1047.

Bonte, M., and Blomert, L. (2004). Developmental changes in ERP correlates of spoken word recognition during early school years: A phonological priming study. Clinical Neurophysiology $115,409-423$.

Bruneau, N., and Gomot, M. (1998). Auditory evoked potentials (N1 wave) as indices of cortical development. In Neuroimaging in child neuropsychiatric disorders, B. Garreau, ed. (Berlin, Springer), pp. 113-1.24.

Bruneau, N., Roux, S., Guerin, P., Barthelemy, C, and Lelord, G. (1997). Temporal prominence of auditory evoked potentials (N1 wave) in 4-8-year-old children. Psychophysiology 34, 32-38.

Brus, B. T., and Voeten, M. J. M. (1999). Een-Minuut-Test (Lisse, Swets, and Zeitlinger).

Ceponiene, R., Rinne, T., and Natatänen, R. (2002). Maturation of cortical sound processing as indexed by event related potentials, Clinical Neurophysiology 113,870-882.

Ceponiene, R., Shestakova, A., Balan, P, Alku, P., Yiaguchi, K., and Näätanen, R. (2001). Children's auditory event-related potentials index sound complexity and "speechness". International Journal of Neuroscience 109, 245-260.

Coch, D., Grossi, G., Coffey Corina, S, Holcomb, P. J., and Neville, H. J. (2002). A. developmental investigation of ERP auditory rhyming effects. Developmental Science 5, 467489.

Connolly, J. F., and Phillips, N. A. (1994). Event-related potential components reflect phonological and semantic processing of the terminal word of spoken sentences. Journal of Cognitive Neuroscience 6, 256-266.

Csépe, V. (1995). On the origin and development of the mismatch negativity. Ear and Hearing 16 , 91-104. 
DArey, R. C, Connolly, J. F., Service, E, Hawo, C. S, and Houlihan, M. E. (2004). Separatng phonological and semantic processing in auditory sentence processing: A highresolution teventrelated brain potential sndy. Human Brain Mapping 22, 40,51 .

Dumay, N., Benraiss, A., Barriol, B., Colin, C., Radeau, M., and Besson, M. (2001). Behavioral and electrophysiological study of phonological priming between bisyllabie spoken words. Joumal of Cognitive Neuroscience $13,121-143$.

Eggemont, J. J., and Ponton, C. W. (2002). The neurophysiology of andilory perception: fron single units to evoked potentials. Audiology and Neurootology $7,71-99$.

Eulitz, C., Diesch, E., Pantew, C., Hampson, S, and Elbert, T. (1995). Magnetic and alectric brain activity evoked by the processing of tone and vowel stimuli. Journal of Neuroscience 15,2748 2755 .

Fabiani, M., Gratton, G., and Coles, M. G. H. (2000). Event-Related Brain Potentials. Methods, Theory, and Applications. In Handbook of Psychophysiology, J. T. Cacioppo, L. G. Tassinary, and G. G. Berntson, eds. (New York, Cambridge University Press), pp. 53-77.

Garlock, V. M., Walley, A. C., and Metsala, J. L. (2001). Age-of-acquisition, word frequenoy, and neighborhood density effects on spoken word recognition by children and adults. Journal of Memory and Language 45, 468-492.

Ghyselinck, M., de Moor, W., and Brysbaert, M. (2000). Age-of-Acquisition Ratings for 2816 Dutch Four- and Five-letter Nouns. Psychologica-Belgica 40, 77-98.

Griffiths, T. D., and Warren, J. D. (2002). The planum temporale as a computational hub. Trends in Neurosciences 25, 348-353.

Grossi, G, Coch, D., Coffey Corina, S., Holcomb, P. J., and Neville, H. J. (2001). Phonological processing in visual rhyming: a developmental erp study. Joumal of Cognitive Neuroseience 13 , 610-625.

Habib, M. (2000). The neurological basis of developmental dyslexia: an overview and working hypothesis. Brain 123, 2373-2399.

Hagoort, P., and Brown, C. M. (2000). ERP effects of listening to speech: Semantic ERP effects. Neuropsychologia $38,1518-1530$.

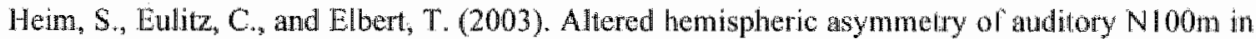
adults with developmental dyslexia. Neuroreport 14, 501-504.

Helenius, P., Salmelin, R., Richardson, U., Leinonen, S, and Lyytinen, H. (2002a). Abnomal auditory cortical activation in dyslexia $100 \mathrm{msec}$ after speech onset. Joumal of Cognitive Neuroscience 14,603-617.

Helenius, P., Salmelin, R. Service, E, Connolly, J. F, Leinonen, S., and Lyytinen, H. (2002b). Cortical activation during spoken-word segmentation in nonreading-impaired and dyslexic adults. Journal of Neuroscience 22, 2936-2944.

Jacquemot, C., Pallier, C., LeBihan, D., Dehaene, S., and Dupoux, E. (2003). Phonological grammar shapes the auditory cortex: a functional magnetic resonance imaging study. Journal of Neuroscience 23, $9541-9546$.

Jäncke, L., Wustenberg, T., Scheich, H., and Heinze, H. J. (2002). Phonetic perception and the temporal cortex. Neuroimage 15, 733-746.

Jusczyk, P. W. (1993). From general to language-specific capacities: The WRAPSA model of how speech perception develops. Journal of Phonetics 21, 3-28. 
Karhu, J, Hergard, E, Paakkonen, A., Luoma, L., Airaksinen, E, and Partanen, J. (1997). Dual cerebral processing of elcmentary auditory imput in children. Neuroreport $8,1327-1330$.

Kronbichler, M., Huizler, F., and Wimmer, H. (2002). Dyslexia: verbal impaiments in the absence of magnocellular impaiments. Neuroreport $13,617-620$.

Kujala, T., Myllyvita, K., Tervaniemi, M, Aho, K, Kallio, J, and Năätänen, R. (2000) Basic auditory dysfunction in dyslexia as demonstrated by brain activity measurements. Psychophysiology 37, 262-266.

Kutas, M.j. and Schmitt, B. M. (2003). Language in Microvolts. In Mind, Brain, and Language: Multidisciplinary Perspectives; M. T. Banich, and M. A. Mack, eds. (Mahwah, NI, US, Erlbaum Assoc. Ine., Lawrence), pp. 171-209.

Lovrich, D., Cheng, J. C., and Velting, D. M. (1996). Late cognitive brain potentials, phonological and semantic classification of spoken words, and reading ability in children. Journal of Clinical Neuropsychology $18 ; 161-177$.

Lovrich, D., Cheng, J. C., Velting, D. M., and Kazmerski, V. (1997). Auditory ERPs during thyme and semantic processing: Effects of reading ability in college students. Journal of Clinical and Experimental Neuropsychology 19, 313-330.

McPherson, W. B., and Ackerman, P. T. (1999). A study of reading disability using event-related brain potentials elicited during auditory alliteration judgments. Developmental Neuropsychology $15,359-378$.

MoPherson, W. B., Ackerman, P. T., Holcomb, P. J., and Dykman, R. A. (1998) Exent-related brain potentials elicited during phonological processing differentiate subgroups of reading disabled adolescents, Brain and Language 62, 163-185.

McQueen, J. M., and Cutler, A. (2001). Spoken word access processes: An introduction. Language and Cognitive Processes $16,469-490$.

Metsala, J. Ln, and Walley, A. C. (1998). Spoken vocabulary growth and the segmental restructuring of lexical representations: Precursors to phonemic awareness and early reading ability. In (1998). Word recognition in beginning literacy, J. L. Metsala, ed. (Mahwah, NJ, US, Lawrence Erlbaum Associates, Publishers), pp. 89-120.

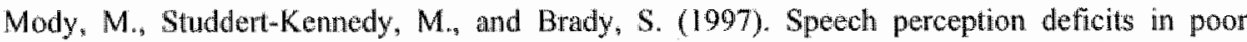
readers: auditory processing or phonological coding? Journal of Experimental Child Psychology $64,199-231$

Nastanen, $R_{n}$, and Picton, $T$. $(1987)$. The $N 1$ wave of the human electric and magnetic response to sound: a review and an analysis of the component structure. Psychophysiology 24, 375-425.

Naiatanen, R., and Picton, T. W. (1986). N2 and automatic versus controlled processes. Wectroencephalogr Clinical Neurophysiology Supplement $38,169-186$.

National Research Council (1998). Report on preventing reading difficulties in young children (Washington DC. National Academy Press).

Newman, R. L., Connolly, I. F., Service, E, and Mclvor, K. (2003). Intluence of phonological expectations during a phoneme deletion task: ewidence from event-related brain potentials. Psychophysiology 40, 640-647.

Nittrouer, S. (1999). Do temporal processing deficits cause phonological processing problems? Journal of Speech Language and Hearing Research 42, 925-942. 
Nuwer, M. R, Coni, G, Enrerson, R, Fuglsang-frederiksen, A., Guerit, I. M, Hinrichs, H, Ikeda, A, Luccas, F, I, and Rappelsburger, P. (1998, IFCN standards for digital treconding of clinical EEG. Intemational Federation of Climical Neuroplnystology. Electroencephalography and Clinical Neurophysiology $106,259-261$.

Obleser, J., Lahiri, A., and Eulitz, C. (2003). Auditory-ewoked magnetic field codes place of articulation in timing and topography around 100 milliseconds post syllable onset. Neuroimage $20,1839-1847$.

Pang, E. W., and Taylor, M. J. (2000). Tracking the development of the N1 from age 3 to adulthood: an examination of speech and non-speech stimuli. Clinical Neurophysiology $111,388-$ 397.

Pennington, B. F. (1990). The genetics of dyslexia. Journal of Child Psychology and Psychiatry $31,193-201$.

Perfetti, C. A., and Sandak, R. (2000). Reading optimally builds on spoken language: Implications for deaf readers. Joumal of Deaf Studies and Deaf Education 5, 32 -50.

Perrin, F., and Garcia-Larrea, L. (2003). Modulation of the N400 potential during auditory phonological/semantic interaction. Cognitive Brain Research 17, 36-47.

Ponton, C. W., Eggermont, J. J., Kwong, B., and Don, M. (2000). Maturation of human central auditory system activity: evidence from multi-channel evoked potentials. Clinical Neurophysiology $111,220-236$.

Praamstra, P., Meyer, A. S., and Levelt, W. J. M. (1994). Neurophysiologicall manifestations of phonological processing: Latency variations of a negative ERP component timelocked to phonological mismatch. Journal of Cognitive Neuroscience 6, 204-219.

Radeau, M., Besson, M., Fonteneau, E., and Castro, S. L. (1998). Semantic, repetition and rime priming between spoken words: behavioural and electrophysiological evidence. Biological Psychology 48, 183-204.

Ramus, F. (2001). Outstanding questions about phonological processing in dyslexia. Dyslexia 7 , $197-216$.

Ramus, F. (2003). Developmental dyslexia: specific phonological deficit or general sensorimotor dysfunction? Current Opinion in Neurobiology $13,212-218$.

Ramus, F., Rosen, S., Dakin, S. C., Day, B. L., Castellote, J. M., White, S., and Frith, U. (2003), Theories of developmental dyslexia: insights from a multiple case study of dyslexic adults. Brain $126,841-865$.

Rawen, J, Raven, J. C., and Court, J. H. (1998). Coloured Progressive Matrices, 1998 edn (Oxford, Oxford Psychologists Press Ltd).

Reed, M. A. (1989). Speech perception and the discrimination of brief auditory cues in reading disabled children. Journal of Experimental Child Psychology 48, 270-292.

Reid Lyon, G. (1995). Toward a definition of dyslexia. Annals of Dyslexia 45, 3-27.

Rugg, M. D. (1984). Event-related potentials and the phonological processing of words and nonwords. Neuropsychologia 22, 435-443.

Sanders, L. D., and Neville, H. J. (2003a). An ERP study of continuous speech processing. I. Segmentation, semantics, and syntax in native speakers. Cognitive Brain Research 15, 228-240. 
Sanders, L. D., and Neville, H. J. (2003b). An ERP study of continuous speech processing II. Segmentation, semantics, and syntax in non-native speakers. Cognitive Bram Research 15, 214 227.

Schaerlaekens, A, Kohnstamm, D., and Lejaegere, M. (1999). Streeflyst woordenschat voor zesjarigen, 3th revised edition edn (Lisse, Swets, and Zeitlinger).

Schulte-Köne, G, Deimel, W, Bartling, $J_{s,}$ and Remschmid, $\mathrm{H}$ (1998). Auditory processing and dyslexia: evidence for a specific speech processing deficit. Neuroreport 9, 337-340.

Schulte-Korne; $G$, Deimel, $W$., Bartling, $J$, and Remschmidi, H. (2001). Speech perception deficit in dystexic aduts as measured by mismatch negativity (MMN). Intemational Journal of Psychophysiology $40,77-87$.

Semlitsch, H. V., Anderer, P., Schuster, P., and Presslich, O. (1986). A solution for reliable and valid reduction of ocular artefacts, applied to the P300 ERP. Psychophysiology 23, 695-703.

Serniclaes, W., Sprenger-Charolles, L., Carre, R., and Demonet, J. F. (2001). Perceptual discrimination of speech sounds in developmental dyslexia. Journal of Speech Language and Hearing Research 44, 384-399.

Sharma, A., Kraus, N., McGee, T. J., and Nicol, T. G. (1997). Developmental changes in PI and N1 central auditory responses elicited by consonant-vowel syllables. Electroencephalography and Clinical Neurophysiology $104,540-545$.

Snowling, M. J. (2000). Dyslexia, 2nd edn (Oxford UK, Blackwell Publishers).

Stein, J., and Walsh, V. (1997). To see but not to read; the magnocellular theory of dyslexia. Trends in Neurosciences 20, 147-152.

Takeshita, K., Nagamine, T., Thuy, D. H., Satow, T., Matsuhashi, M., Yamamoto, J., Takayama, M., Fujiwara, N., and Shibasaki, H. (2002). Maturational change of parallel auditory processing in school-aged children revealed by simultaneous recording of magnetic and electric cortical responses. Clinical Neurophysiology $113,1470-1484$.

Tallal, $\mathrm{P}$. (1980). Auditory temporal perception, phonics, and reading disabilities in children. Brain and Language $9,182-198$.

Temple, E. (2002). Brain mechanisms in normal and dyslexic readers. Current Opinion in Neurobiology $12,178-183$.

Thierry, $G$, Doyon, B., and Demonet, J. F. (1998), ERP mapping in phonological and lexical semantic monitoring tasks: A study complementing previous PET results. Neuroimage $8,39 \|$ 408 .

Tiitinen, H., Sivonen, P., Alku, P., Virtanen, J., and Naatänen, R. (1999). Electromagnetic recordings reveal latency differences in speech and tone processing in humans. Cognitive Brain Research 8, 355-363.

Tonnquist-Lhlen, I. (1996). Topography of auditory evoked long-llatency potentials in children with severe language impaiment: the $\mathrm{P} 2$ and $\mathrm{N} 2$ components. Ear and Hearing 17, 314-326.

Van Atteveldt, N., Formisano, E., Goebel, R., and Blomert, L. (2004). Integration of letters and speech sounds in the human brain. Neuron 43, 271-282.

Van den Bos, K. P., lutje Spelberg, H. C., Scheepsma, A. J. M., and de Vries, J. R. (1999). De Klepel (Lisse, Swets, and Zeitlinger). 
Van den Brink, D, Brown, C. M, and Hagoort, P. (2001). Electrophysiological evidence for tarly contextual influences during spoken-word recognition: N200 versus N400 effects. Jounnal of Cognitive Neuroscience 13,967-985.

WISC-R projectgroep:, Haasen v, P. P., De Brwyn, E. E. J., Pijl, Y, J, Poortinga, Y. H, Spelberg, H. C., Van der Steene, G., Coetsier, P., Spoelders-Claes, R, and Stinissen, $\mathcal{J}$ (1986). WISC-R, Nederlandstalige uitgave (Lisse, Swets \& Zeitlinger). 


\title{
Chapter 4
}

\section{Auditory cortical tuning to statistical regularities in phonology ${ }^{7}$}

\begin{abstract}
Ample behavioural evidence suggests that distributional properties of the language environment influence the processing of speech. Yet, how these characteristics are reflected in neural processes remains largely unknown. The present ERP study investigates neurophysiological correlates of phonotactic probability: the distributional frequency of phoneme combinations. We employed an ERP measure indicative of experience-dependent auditory memory traces, the mismatch negativity (MMN). We presented pairs of nonwords that differed by the degree of phonotactic probability in a modified passive oddball design that minimizes the contribution of acoustic processes. In Experiment 1 the non-word with high phonotactic probability (notsel) elicited a significantly enhanced. MMN as compared to the non-word with low phonotactic probability (norkel). In Experiment 2 this finding was replicated with a non-word pair with a smaller acoustic difference (notsel-notfel). This MMN enhancement was not observed in a third acoustic control experiment with stimuli having comparable phonotactic probability (so-fo). Our data suggest that auditory cortical responses to phoneme clusters are modulated by statistical regularities of phoneme combinations. This study indicates that the language environment is relevant in shaping the neural processing of speech. Furthermore, it provides a potentially useful design for investigating implicit phonological processing in children with anomalous language functions like dyslexia.
\end{abstract}

${ }^{7}$ This chapter is based on Bonte, M.L., Mitterer, H., Zellagui, N., Poelmans H. and Blomert L. Auditory cortical tuning to statistical regularities in phonology. Submitted. 


\section{Introduction}

Auditory environments play a crucial rolle in defining the functional organization of the auditory cortex. Recent studies using invasive electrophysiological recordings have demonstrated that statistical regularities in the basic acoustic properties of environmental sounds shape the neural circuitry in the primary auditory cortex of animals (Nelken, 2004; Zhang et al, 2001). Whether and to what extent neural processing in non-primary auditory cortical areas, for example those involved in phonetic-phonological processing of speech (Jacquemot et al, 2003; Jäncke et al., 2002), are similarly tuned to statistical regularities in abstract properties of complex sounds is unknown. In humans, speech constitutes the most relevant complex sound which is routinely dealt with. Thus, it can be hypothesized that the neural system underlying speech perception exploits the distributional properties of speech input to facilitate the acquisition, recognition and representation of spoken language.

The present study investigates event-related potential (ERP) correlates of auditory cortical tuning to distributional frequencies of speech sounds, i.e. phonemes, in the language environment. These distributional frequencies are typically referred to as phonotactic probabilities, where phonotactic refers to the sequential arrangement of phonemes in the syllables and words of a given language (Trask, 1996). In behavioural studies, phonotactic probability has been shown to strongly influence language processing across the lifespan. The sensitivity to phonotactic probability emerges during the first year of life, most likely between the age of 6 to 9 months (Jusczyk, 1999). Infants may use statistical relationships between neighbouring speech sounds to infer which sounds can be combined to form words, and how to segment these words from fluent speech (Saffran et al., 1996). During subsequent language development in children, high phonotactic probability leads to a faster acquisition of words (Storkel, 2001), a better recall of non-words (Gathercole et al., 1999) and a higher accuracy of non-word repetition (Coady and Aslin, 2004). In adults, phonotactic probability affects a large number of language processes, ranging from the speed and ease of spoken word recognition (Vitevitch and Luce, 1999) to listeners' metalinguistic judgments of word-likeness (Bailey and Hahn, 2001). Although these and other behavioural effects are relatively well documented (for a review see Auer and Luce, 2003), neural correlates of phonotactic probability remain largely unexplored.

An ERP measure that is particularly suited for the investigation of experiencedependent neurophysiological changes is the so-called mismatch negativity (MMN). The MMN is elicited by an infrequently occurring discriminable change (i.e. deviant stimuli) in a repetitive aspect of auditory stimulation (i.e. standard stimuli). The MMN represents an automatic change detection response indicative of experience-dependent auditory memory traces (Näätänen, 2001; Näätänen et al., 2001; Picton et al, 2000). The properties of these memory traces may be reflected by the size, latency and topographical distribution of the MMN. Interestingly, the MMN appears to be sensitive to language-specific phoneme representations (Mitterer and Blomert, 2003; Näätänen, 2001; Näätänen et al., 1997; Phillips et al., 2000; Winkler et al., 1999) and lexical representations of words (Jacobsen et al., 2004a; Pulvermüller et al., 2001). In particular, both in adults (Dehaene-Lambertz, 1997; Näatänen et al., 1997) and in infants (Cheour et al., 1998; Dehaene-Lambertz and Baillet, 1998), phonemes that are prototypical in the native language elicit 
larger MMN responses as compared to phonemes that do not-oceur in that langtage but are still discriminable. Moreover, the processing of phoneme contrasts has been shown to elicit an MMN when the phoneme contrast occurs in the native language of the listener but not in case of a non-native contrast that can not be discriminated (Dehaene-Lambertz et al., 2000).

Table 1. Log-values of the frequency counts of phonenes and phoneme sequences in our nonword stimuli. Frequency counts were weighted for word trequency and based on the Celex corpus with 42 million Dutch words. [...] indicates the phoneme(s) for which counts are given, $c=$ consonant, v=vowel. For example, the $3^{\mathrm{td}}$ column: cv [celvc, gives frequency counts for $/ \mathrm{ts} / \mathrm{t}$, $\mathrm{t}$ and $/ \mathrm{tk} /$ respectively. The frequency counts of the single phonemes $/ \mathrm{s}$, / $/ \mathrm{l}$ and $/ \mathrm{kJ}$ in the $2^{\text {nd }}$ column only include syllable-initial occurrences. " " indicates a frequency of 0 .

\begin{tabular}{ccccccc}
\hline cvecve & cve[c]ve & cv[cc]ve & c[vec] ve & cvlecv]c & c[vecv]c & [cvecvel \\
\hline notsel & 6.50 & 5.83 & 4.32 & 4.59 & 3.99 & . \\
notfel & 5.69 & 4.72 & 3.02 & 3.82 & 2.91 & - \\
notkel & 6.45 & 4.51 & 2.53 & 0.95 & - & - \\
\hline cv & {$[\mathrm{c}] \mathrm{v}$} & [cv] & & & & \\
\hline so & 6.50 & 4.60 & & & & \\
fo & 5.69 & 4.72 & & & & \\
\hline
\end{tabular}

Here we employ the MMN to investigate whether the phonotactic probability of phoneme clusters influences the processing of meaningless speech. In two passive auditory oddball experiments we presented non-words with medial consonant clusters that either had a high (HPP) or a low (LPP) phonotactic probability (see Figure 1; Table 1). To minimize the effects of acoustic differences between stimuli, we used a reversed oddball design that has been shown to be suitable for studying mismatch detection at a relatively abstract level of representation (Eulitz and Lahiri, 2004). In Experiment I, stimuli were the HPP non-word notsel and the LPP non-word notkel. In Experiment 2 we used non-words which differ in phonotactic probability but are acoustically more similar (see Figure 1 and Methods), i.e. the HPP non-word notsel and the LPP non-word notfel. To further control for purely acoustic effects in Experiments 1 and 2 we conducted a third experiment (Experiment 3) in which we analyzed mismatch effects for $/ \mathrm{s} /$ versus $/ f /$ changes (as in Experiment 2) but in a neutral context. This was achieved by presenting the consonant-vowel syllables so and fo, which have a comparable phonotactic probability. MMN difference waves were derived from the ERP activity elicited by the same non-word presented as standard and deviant in separate experimental blocks. This enabled us to estimate MMN correlates of our non-words independent of variation in general ERP morphology resulting from physical stimulus characteristics. Such variation in ERP morphology is not necessarily related to change detection and may result from the partial overlap of the MMN with other ERP components, e.g. the N1, which may show different amplitude 
and/or latency characteristics for different consonants (Gage et al., 1998; Obleser et al., 2003).

Enhanced MMNs in response to prototypical phonemes have been suggested to reflect language-specific phoneme traces in the auditory cortex (Näătånen, 2001). Accordingly, if distributional frequencies at the level of phoneme clusters would influence auditory cortical processing of speech sounds, we would expect enhanced MMN responses for the HPP as compared to LPP non-words in Experiments 1 and 2. Importantly, a similar enhancement is not expected for stimuli with comparable phonotactic probability (Experiment 3).
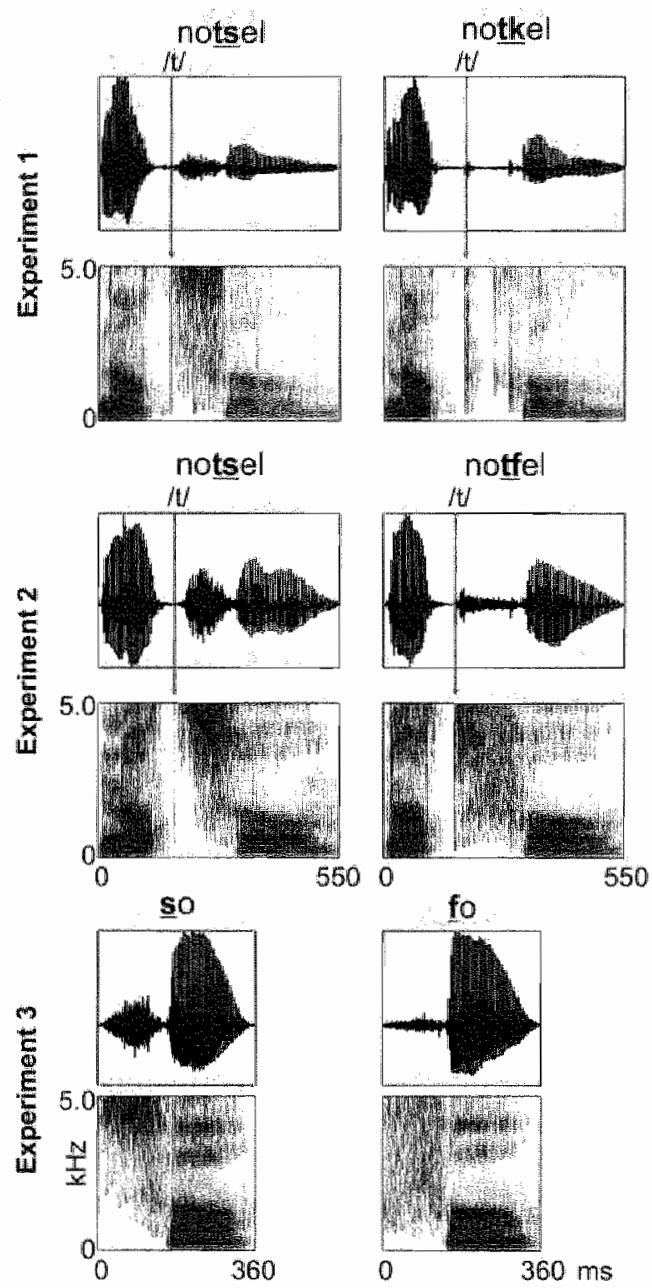

Figure 1. Waveforms (upper rows) and spectrograms (lower rows) of one exemplar stimulus for each of the nom-word stimuli used in Experiment I: notsel [notsal] and notkel [notkol], Experiment 2: notsel [notsol] and notfel [notfol], and Experiment 3: so [so] and fo [fo]. In Experiments 1 and 2, auditory stimulus deviation occurred around $160 \mathrm{~ms}$ at the onset of the stimulus medial consonant clusters $/ \mathrm{ts} /, / \mathrm{tk} / \mathrm{tff}$, and in Experiment 3 at stimulus onset. 


\section{Methods}

\section{Subjects}

Thirteen undergraduate students (10 female; 2 left handed) participated in Experiment 1, 14 students (13 female; 2 left handed) in Experiment 2, and 14 students (12 female; I left handed) in Experiment 3. None of the subjects participated in more than one of the experiments. Subjects gave their informed consent and received course credits or payment for participation. Approval for the study was granted by the Ethical Committee of the Faculty of Psychology at the University of Maastricht. All subjects were native speakers of Dutch.

\section{Stimuli and Task}

In Experiments 1 and 2, stimuli were pairs of bisyllabic non-words, one with high and the other with low phonotactic probability (HPP and LPP). The non-words were phonotactically legal in Dutch and the stress was on the first syllable, the default stress in Dutch. Table 1 gives the phonotactic probabilities of our stimuli as determined by counts of phoneme sequences weighted for word frequency in the Dutch word form database (CELEX corpus, Baayen et al., 1995). In Experiments I and 2 the same HPP non-word was used, i.e. notsel [notsal]. The LPP non-words were notkel [notkal] in Experiment 1 and notfel [notfal] in Experiment 2. As can be seen in Table 1, the probability of the individual phonemes, that is $/ \mathrm{s} /, / \mathrm{f} /$ and $/ \mathrm{k} /$ is similar for $/ \mathrm{s} /$ and $/ \mathrm{k} /$ but much lower for $/ \mathbb{f} /$. However, the consonant cluster $/ \mathrm{ts} /$ has a higher phonotactic probability than $/ \mathrm{t} f /$ and $/ \mathrm{tk} /(/ \mathrm{ts} />/ \mathrm{tf} />/ \mathrm{k} /)$. The relative difference in phonotactic probability between these stimuli is further increased by the vowels $/ \mathrm{o} /$ and $/ \mathrm{e} /$ that precede and follow the consonant clusters. As illustrated by the waveforms and spectrograms in Figure 1, the acoustic difference between the non-words was smaller in Experiment 2 than in Experiment 1, i.e. whereas /s/ and $/ \mathrm{f} /$ are both fricatives with a difference in place of articulation (alveolair vs. labial), $/ \mathrm{k} /$ is a plosive with a velar place of articulation. No Dutch word starts with the phoneme sequence $/$ nots/, /notk/ or /notf/, or contains the phoneme sequences /notsel/, /notkel/ or /notfel/, thus making top-down lexical effects unlikely.

In Experiment 3, stimuli were the consonant-wowel syllables so [so] and fo [fo] which, like notsel and notfel in Experiment 2, involve a syllable-initial /s/ versus / f/ contrast, but with a comparable phonotactic probability (see Figure 1 and Table 1).

Stimuli were spoken by two female native Dutch speakers and recorded at a sampling rate of $44.01 \mathrm{kHz}$ on a DAT recorder. We used a different female speaker for the stimuli in Experiment 1, and the same female speaker for Experiments 2 and 3. The digitized stimuli were $\mathrm{D} / \mathrm{A}$ converted with a 16 bit resolution, bandpass filtered $(100 \mathrm{~Hz}$ to $10.5 \mathrm{KHz})$, resampled at $22.05 \mathrm{KHz}$, and edited with Praat software (Boersma and Weenink, 2002). Editing included matching for loudness, by equating the maximal amplitude to $95 \%$ of the dynamic range, which resulted in equal rms amplitudes for the stimuli in each of the Experiments. In Experiment 1 and 2, stimulus length was equated to $550 \mathrm{~ms}$ (original range: $480-600 \mathrm{~ms}$ ), and in Experiment 3 to $360 \mathrm{~ms}$ (original range: $345-371)$ using PSOLA ( $140 \mathrm{~Hz}-280 \mathrm{~Hz}$ as extrema of the F0 contour). We carefully checked our stimuli for possible alterations in $\mathrm{F} 0$ after length equation and did not find any detectable changes. To minimize the likelihood that the MMN would be determined by only one or a few 
particular acoustic features (Eulitz and Lahiri, 2004; Jacobsen et al., 2004b), we used four utterances of each non-word stimulus. Figure 2 illustrates that within each experiment, each set of non-word utterances showed comparable variation in pitch and intensity. In Experiments 1 and 2, auditory stimulus deviation occurred around the onset of the medial consonant clusters $/ \mathrm{ts} /, / \mathrm{tk} /, \mathrm{tf} /$, about $160 \mathrm{~ms}$ after stimulus onset The onset of stimulus deviation is approximate because we used multiple utterances of natural speech stimuli. The preceding vowel /o/ did not show systematic differences between our non-word stimuli. In Experiment 3, auditory stimulus deviation occurred at stimulus onset.

During the experiments, subjects watched a silent movie while the stimuli were presented binaurally through loudspeakers at $65 \mathrm{~dB}$ SPL. Stimuli were presented with an inter-stimulus interval of $650 \mathrm{~ms}$. All three experiments consisted of four experimental blocks with 600 stimuli each. In two of these blocks, the HPP non-word (or neutral / $/ \mathrm{so} /$ in Experiment 3) served as standard (84\%) and the LPP non-word (or neutral /fo/ in Experiment 3) as deviant (16\%), in the other two blocks standards and deviants were reversed, i.e. the LPP non-word (or neutral /fo/) was the standard and the HPP non-word (or neutral /so/) the deviant. The order of experimental blocks was counterbalanced between subjects. In total, 1008 standards and 192 deviants were presented for each non-word.

\section{EEG recording and analysis}

EEG data were recorded $(0.01-50 \mathrm{~Hz}$, sampling rate $250 \mathrm{~Hz})$ in a soundattenuating and electrically shielded room from 30 electrode positions (Extended International 10-20 system, Nuwer et al., 1998) relative to a nose reference. Eyemovements and blinks were measured with bipolar VEOG/HEOG channels. All electrode impedance levels (EEG and EOG) were kept below $5 \mathrm{k} \Omega$. The raw EEG data were corrected for vertical eye-movements (i.e. blink artefacts; Semlitsch et al., 1986). EEG data were epoched from -50 to $850 \mathrm{~ms}$ relative to stimulus onset, baseline corrected ( $50 \mathrm{~ms}$ pre-stimulus interval), and $1-30 \mathrm{~Hz}$ bandpass filtered. Epochs containing data exceeding a maximum voltage criterion of $75 \mu \mathrm{V}$ were rejected. Standards immediately following deviants were not included in the anallysis.

Statistical analyses were performed on electrodes covering the frontocentral $(\mathrm{Fz}, \mathrm{Cz}, \mathrm{FC} 3, \mathrm{FC} 4)$ and centroparietal region $(\mathrm{Pz}, \mathrm{CP} 3$ and $\mathrm{CP} 4)$. Amplitude and latency measures were calculated from the ERP signal rereferenced to the average signal of the left and right mastoids, which provides an integrated measure of the total neural activity underlying the auditory MMN (Eulitz and Lahiri, 2004; Schrogger, 1998). This integrated measure of MMN activity led to identical experimental results as obtained with the plain ERP signal, but to an improved detection of MMN responses (at frontocentral electrodes) on an individual subject level.

For each experiment, we first analyzed the strength and timing of ERP activity elicited by standard and deviant stimuli using repeated-measures ANOVA with stimulus type (standard vs. deviant), phonotactic probability (HPP vs. LPP; Expts. 1,2) / syllable (so vs. fo; Expt. 3), and electrode sites as within subjects factors. Timing of ERP responses in the MMN window was measured by determining individual peak latencies between 250-360 ms after stimulus onset (about 90-200 
ms after auditory stimulus deviation) in Experiments 1 and 2, and between 90-250 $\mathrm{ms}$ after stimulus onset (=auditory stimulus deviation) in Experiment 3. Amplitude measures included both individual peak amplitudes and mean amplitude taken from the $50 \mathrm{~ms}$ window around the individual peak latency.

Mismatch effects were further examined with deviant-standard difference waveforms that were calculated for separately for each non-word (across blocks) by subtracting the ERP signal elicited its standards from that of its deviants e.g. notsel as deviant minus notsel as standard. MMN peak latency, peak amplitude and mean amplitude ( $50 \mathrm{~ms}$ window around the peak) were again determined individually for each subject. MMN parameters were tested with a repeated-measures ANOVA with phonotactic probability (HPP vs. LPP; Expts. 1,2)/ syllable (so vs. fo; Expt. 3) and electrode sites as within subjects factors, and with post-hoc t-tests. We only report results reaching significance at $p<0.05$ after Geisser-Greenhouse correction.

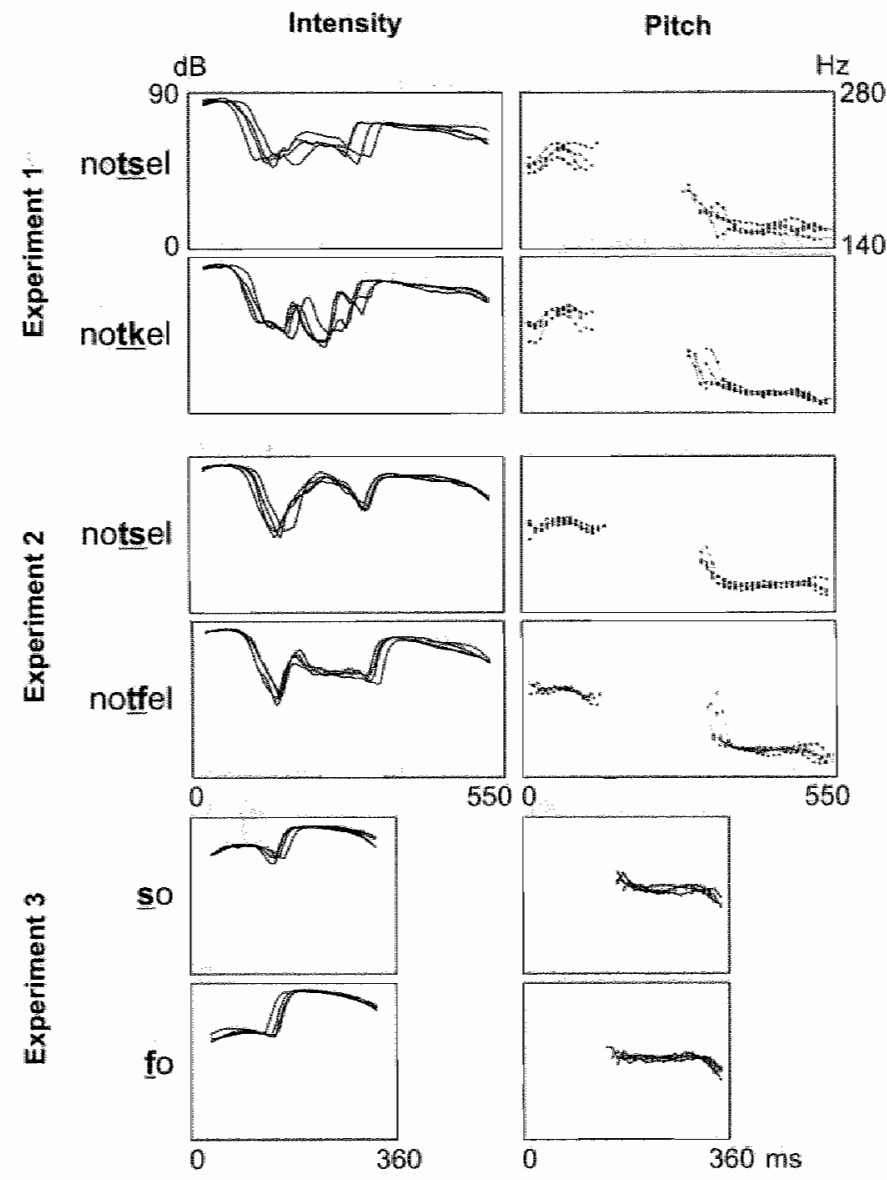

Figure 2. Pitch and intensity contours of the non-word stimuli used in Experiment 1: notsel and notkel, Experiment 2: notsel and notfel, and Experiment 3: so and fo. We used 4 utterances of each non-word. Within each experiment, each set of non-word utterances showed comparable variation in pitch and intensity. 


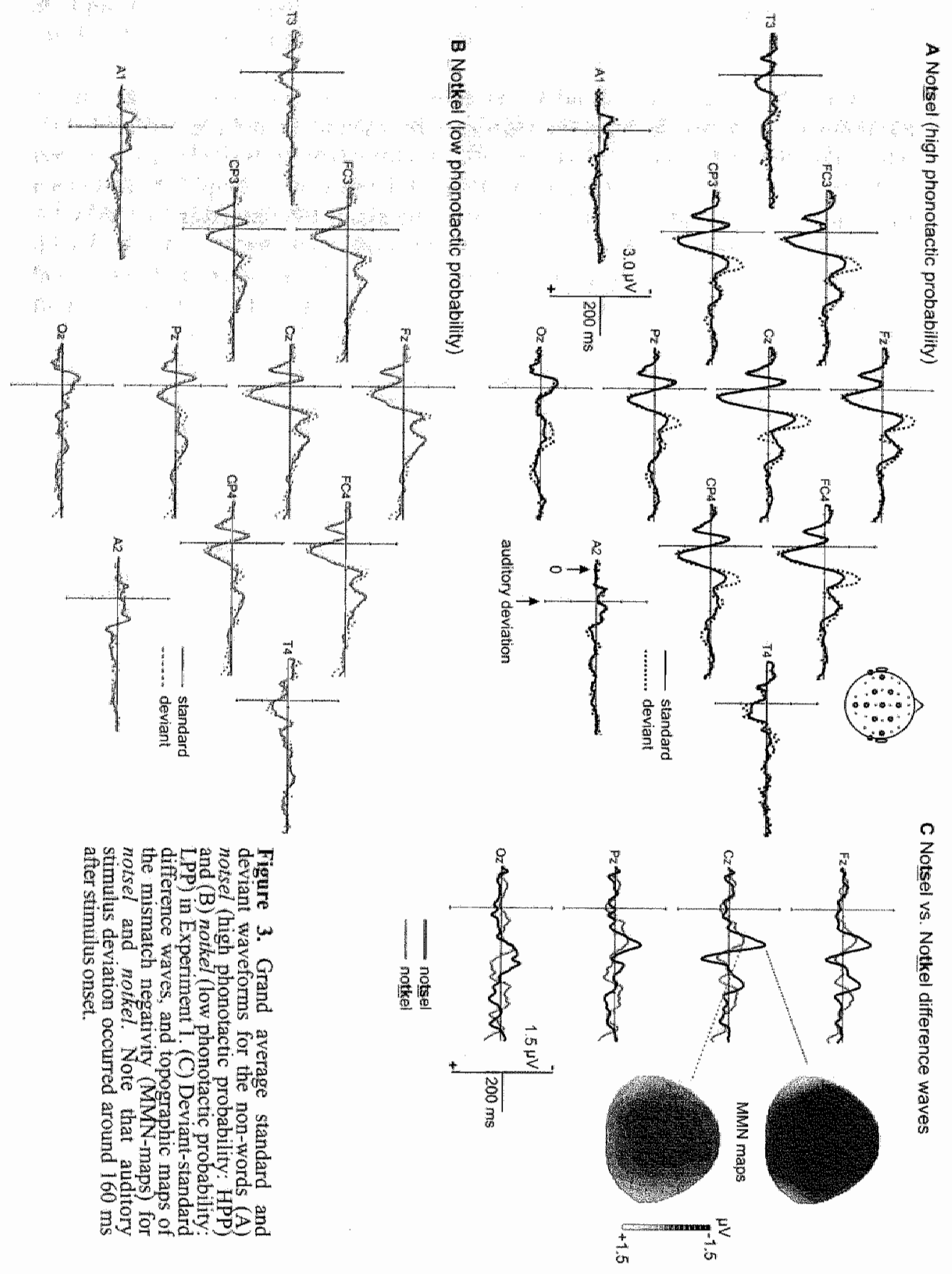




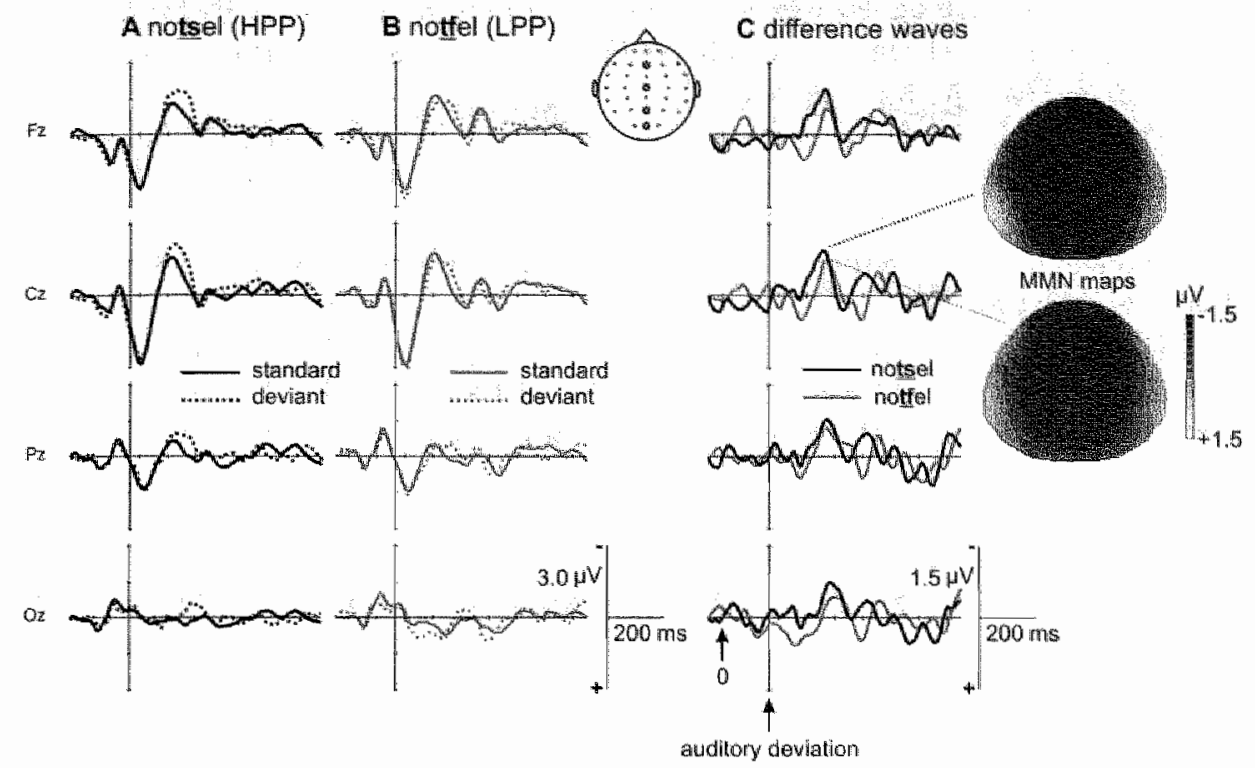

Figure 4. Grand average standard and deviant waveforms for the non-words (A) notsel (high phonotactic probability: HPP) and (B) notfel (low phonotactic probability: LPP) in Experiment 2. (C) Deviant-standard difference waves, and topographic maps of the mismatch negativity (MMN-maps) for notsel and notfel. Note that auditory stimulus deviation occurred around $160 \mathrm{~ms}$ after stimulus onset.

\section{Results}

\section{Experiments 1 and 2: effects of phonotactic probability}

Figures 3 and 4 show the grand average ERPs $(A, B)$ and difference waveforms (deviant-standard stimuli) (C) for non-words with a high vs. low phonotactic probability in Experiments $\mathbb{L}$ (Figure 3 ) and 2 (Figure 4). All non-word contrasts elicited an MMN between 100-200 ms after the onset ${ }^{8}$ of auditory stimulus deviation (Figures $3 \mathrm{C}$ and $4 \mathrm{C}$ - difference waves), with a topographical distribution that is typically reported (Figure 3C and 4C-MMN maps; Picton et al,, 2000; Schröger, 1998). Crucially, in both experiments, the strength of the MMN responses followed the relative phonotactic probability of our non-word stimuli.

Amplitude and latency characteristics of ERP activity in the MMN timewindow were first analyzed using a 2 (stimulus type) by 2 (phonotactic probability) by 7 (electrode sites) repeated-measures ANOVA. In Experiment 1, there were general morphological differences in ERP responses to the different non-words. Indeed, notsel elicited significantly stronger ERP responses than notkel as indicated by main effects of phonotactic probability for peak amplitude $(F(1,12)=38.1$; $p=0.000$ ) and mean amplitude in the $50 \mathrm{~ms}$ window around the individual peaks $(F(1,12)=42.8 ; p=0.00)$. Conversely, in Experiment 2 ERP activity for the non-

\footnotetext{
"this onset is approximate because we used multiple tokens of natural stimuli
} 
words notsel and noffel did not show any significant difference in response strength. The timing of ERP responses was very similar for both notsel and notkel (Expt. 1), and notsel and notfel (Expt. 2), as indicated by the absence of significant effects of phonotactic probability for peak latency.

The main goal of the present study was to investigate whether ERP mismatch responses would be sensitive to manipulation of phonotactic probability. Thus, we further analyzed the responses reflecting stimulus mismatch. As expected, deviant stimuli elicited a significantly stronger negative ERP response than standard stimuli in both experiments (main effects of stimulus type for peak amplitude in Expt. 1: $F(1,12)=24.1 ; p=0.000$ and Expt. $2: F(1,13)=14.9 ; p<0.005)$; and for mean amplitude in Expt. 1: $F(1,12)=15.9 ; p<0.005$ and Expt. $2: F(1,13)=5.8 ; p<0.05$ ). Crucially, this mismatch effect showed a significant interaction with phonotactic probability in both experiments (stimulus type-by-phonotactic probability interaction for peak amplitude in Expt. 1: $F(1,12)=9.6 ; p<0.01$, Expt. 2: $F(1,13)=$ $4.6 ; p=0.05$; and for mean amplitude in Expt. 1: $\mathrm{F}(1,12)=9.4 ; p=0.01$, Expt. 2: $F(1,13)=6.3 ; p<0.05)$. As illustrated in Figures 3 and 4 , this interaction resulted from stronger mismatch responses to the HPP non-word notsel as compared to both the LPP non-word notkel (Expt. 1) and the LPP non-word notfel (Expt. 2). Peak latency did not show any differences in Experiment 1, but showed a general delay for deviants as compared to standards in Experiment 2 (main effect of stimulus type $F(1,13)=14.0 ; p<0.005)$

To further test the mismatch effects, we examined within non-word differences, by subtracting the activity elicited by standards and deviants across blocks; e.g. notsel deviant minus notsel standard. Based on the observation that in all conditions, the MMN was prominent at frontocentral sites (Figures 3 and 4), we tested MMN effects using a 2 (phonotactic probability) by 4 (frontocentral electrode sites) repeated-measures ANOVA. The analysis led to main effects of phonotactic probability for MMN peak amplitude (Expt. 1: $(F(1,12)=8.9 ; p<0.025$, Expt. 2: $F(1,13)=10.2 ; p<0.01$ ), and mean MMN amplitude (Expt. 1: $(F(1,12)=8.2$; $p<0.025$ and Expt. 2: $F(1,13)=5.3 ; p<0.05)$. MMN peak latency did not show any significant effect of phonotactic probability.

Figure 5 illustrates MMN amplitude and latency measures at frontal, central and parietal midline ellectrodes. In Experiment 1, notsel (HPP) elicited a significantly stronger $\mathrm{MMN}$ than notkel (JPP) at $\mathrm{Fz}(p<0.01)$, at $\mathrm{Cz}(p<0.05)$, but not at $\mathrm{Pz}(p=0.16)$, and in Experiment 2 , notsel (HPP) elicited a significantly stronger $\mathrm{MMN}$ than notfel (LPP) at $\mathrm{Fz}(p<0.05)$, almost at $\mathrm{Cz}(p<0.06)$, but not at $\mathrm{Pz}$ (0.97). As for the timing of the MMN responses at these midline electrodes, peak latencies occurred around $325 \mathrm{~ms}$ in Experiment 1 and $338 \mathrm{~ms}$ in Experiment 2. Relative to auditory stimulus deviation $(\sim 160 \mathrm{~ms}$ after stimulus onset), these latencies correspond to $\sim 165$ and $\sim 178 \mathrm{~ms}$ respectively. With the exception of a significantly longer latency for notsel (HPP) vs. notkel (LPP) at electrode $\mathrm{Cz}$ $(p<0.05)$, MMN latencies did not show clear differences between non-words with a high vs. low phonotactic probability. 


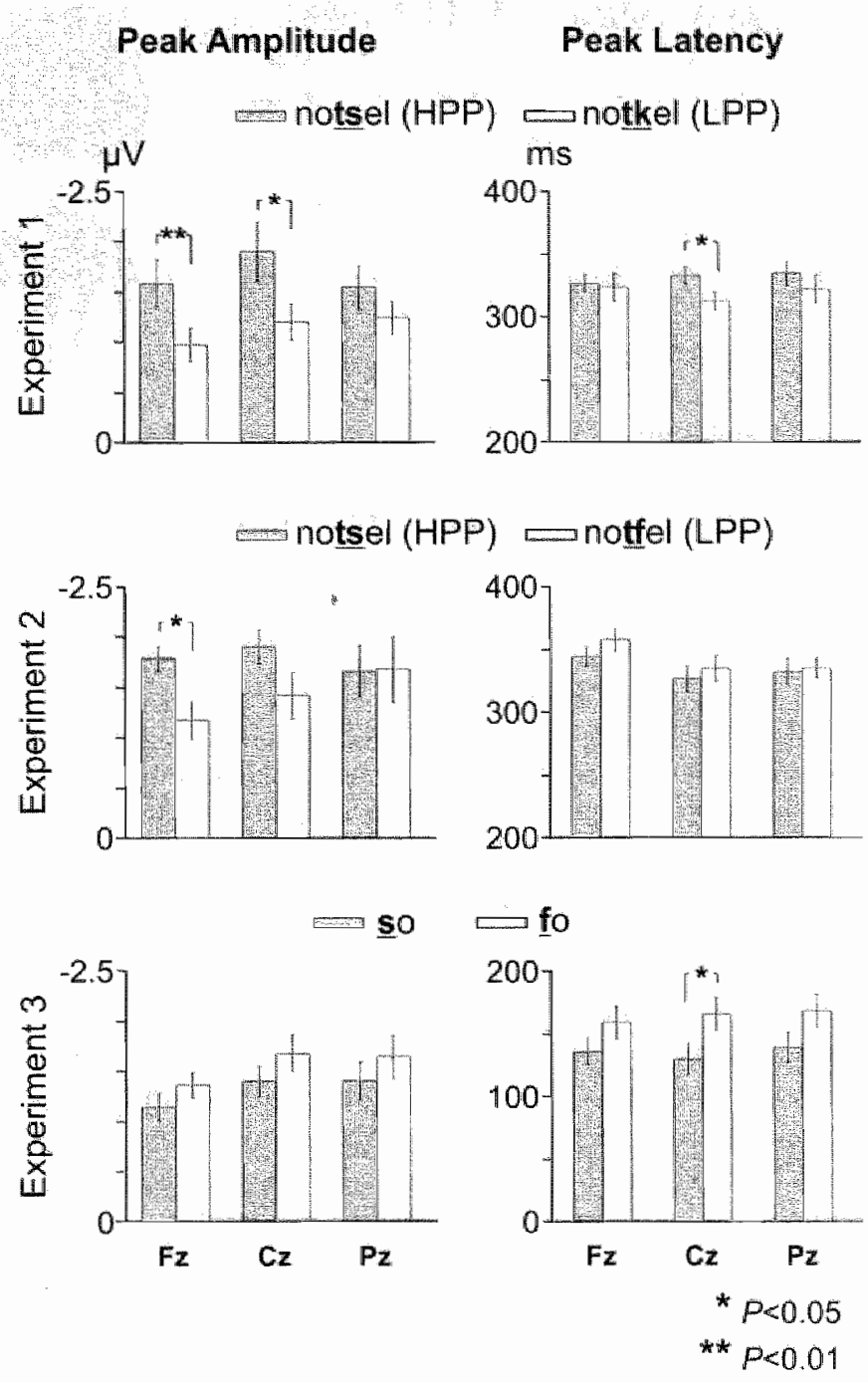

Figure 5. Mean (SEM) peak latencies and peak amplitudes of mismatch responses elicited by non-words in Experiment 1,2 and 3. Asterisks indicate significant differences between conditions (post hoc $t$ comparisons). Note that latency values are given relative to stimulus onset. Auditory stimulus deviation occurred at $\sim 160 \mathrm{~ms}$ after stimulus onset in Experiments 1 and 2 and at stimulus onset in Experiment 3 . 


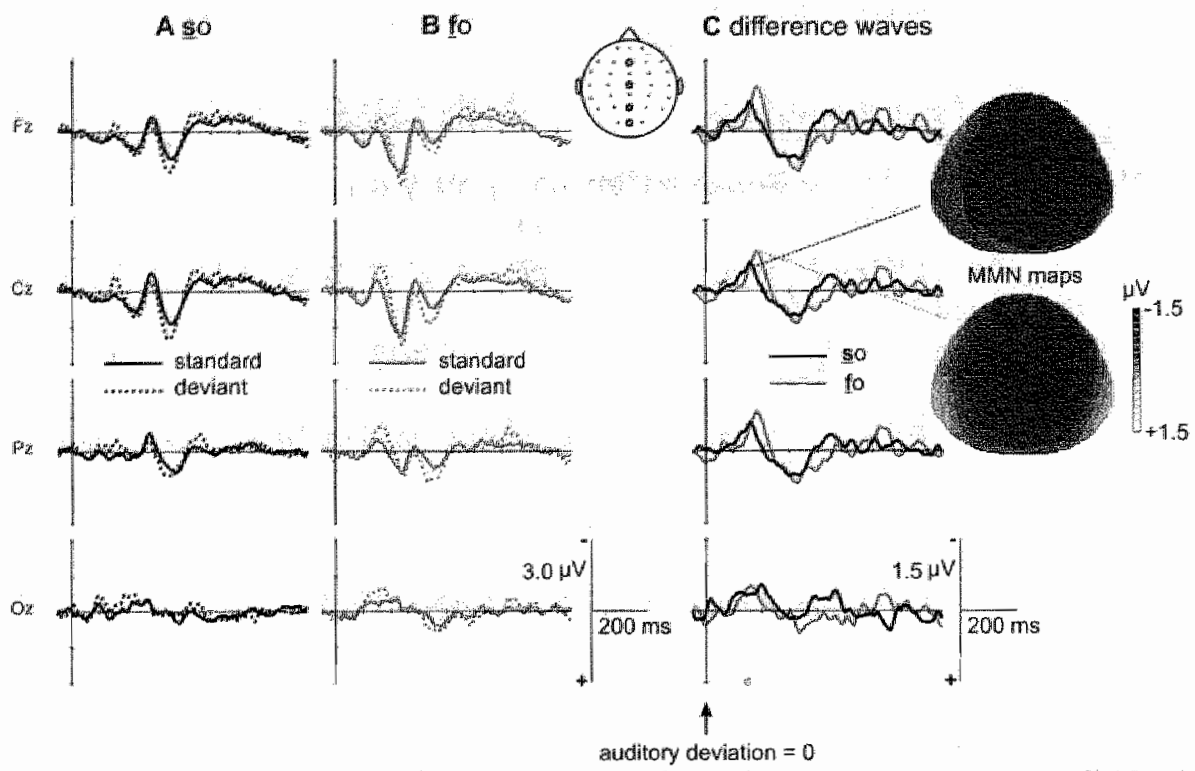

Figure 6. Grand average standard and deviant waveforms for the consonant-vowel syllables (A) so and $(\mathrm{B})$ fo in Experiment 3. Like notsel and notfel in Experiment 2, these syllables involve a /s/ versus /f/ contrast, but they do not differ in phonotactic probability. (C) Deviant-standard difference waves, and topographic maps of the mismatch negativity (MMN-maps) for so and fo. Auditory stimulus deviation occurred at stimulus onset.

\section{Experiment $3: / \mathrm{s} / \mathrm{vs}$. /f/ in a neutral context}

To further investigate the nature of our findings in Experiments 1 and 2, we performed a third experiment in which we compared mismatch effects for a $/ s /-|f\rangle$ change (as in Experiment 2) with stimuli of comparable phonotactic probability: so and fo. An interpretation of the enhanced MMN response for the HPP non-word norsel versus the LPP non-word notfel observed in Experiment 2 (and notsel vs. notkel in Experiment 1) in terms of phonotactic probability, would predict such enhancement for $/ s /$ to be disrupted by its presentation in the neutral context of Experiment 3 (i.e. no difference in phonotactic probability). Vice-versa, an interpretation of the modulation of MMN responses observed in Experiments $\mathbb{l}$ and 2 in terms of acoustic differences between the stimuli would predict a similar MMN modulation in Experiment 3. The analysis of the ERP activity elicited by standards vs. deviants of so (Fig. 6A,6C) and fo (Fig. 6B, 6C) indicates that there is no significant difference between mismatch responses for $/ s\rangle$ and $|f\rangle$ when phonotactic probability is controlled for, thus lending support to the first interpretation.

As in Experiment $\mathbb{1}$ and 2, both so and fo elicited a significant MMN between 100-200 ms after stimulus onset (which corresponded to stimulus mismatch), with a typical topographical distribution (Fig. 6C, compare to MMN maps in Figs. 3C and 4C). A 2 (stimulus type) by 2 (syllable) by 7 (electrode sites) repeated-measures ANOVA of amplitude and latency of ERP activity in the MMN window showed that there were no significant differences in response strength or timing of ERP 
responses to so vs. fo stimuli. Importantly, however, deviant stimuli elicited significantly stronger negative ERP responses than standard stimuli; similarly for so and $f o$. This is indicated by significant main effects of stimulus type for peak amplitude $(F(1,13)=46.1, p=0.000)$ and mean amplitude $(F(1,13)=39.7 ; p=0.000)$ and the absence of significant stimulus tope-by-syllable interactions for peak amplitude $(F(1,13)=0.77$; n.s. $)$ and mean amplitude $(F(1,13)=0.75$; n.s. $)$. Peak latency did not show any significant difference between standard and deviant responses.

As in Experiments $\mathbb{1}$ and 2, mismatch effects were further tested by calculating a difference wave for each syllable (e.g. so deviant minus so standard). Amplitude and latency characteristics were tested with a 2 (syllable) by 4 (frontocentral electrode sites) repeated-measures ANOVA. In concordance with the previous analysis, amplitude measures did not show significant main effects of syllable. However, unlike standard and deviant ERPs, the peak latency of the difference waves showed a significant effect of syllable $(F(1,13)=5.1 ; p<0.05)$. As can be seen in Figure 6C, this is due to a longer MMN peak latency for fo as compared to so. Figure 5 (lower panel) shows that at midline electrodes, the MMN peak occurred around $135 \mathrm{~ms}$ for so stimuli and around for $165 \mathrm{~ms}$ for fo stimuli. At the level of single midline electrodes, the latency difference was significant at $\mathrm{Cz}$ $(p<0.05)$, but not at $\mathrm{Fz}(p=0.18)$ or $\mathrm{Pz}(p=0.12)$. Peak amplitude measures shown in the left panel of Figure 5 again illustrate that the results of Experiment 3 did not replicate a response enhancement for a $/ \mathrm{s} / \mathrm{vs}$. $/ f /$ contrast in a neutral context.

\section{Discussion}

The present ERP study used a reversed oddball paradigm to investigate how the phonotactic probability of phoneme clusters influences the processing of meaningless speech. Our results revealed an enhanced MMN response to non-words with a high vs. low phonotactic probability in two separate experiments. Furthermore, a similar MMN enhancement was not found in a third acoustic control experiment in which we presented a single phoneme contrast in the context of a stimulus pair that did not differ in phonotactic probability. The present findings may thus reflect auditory cortical tuning to distributional frequencies of phoneme clusters in the language environment.

Acoustic change detection and phoneme-specific processes have been shown to contribute in parallel to the MMN elicited by speech stimuli (Näătänen, 2001). 1 n this study the $M M N$ was used as a neurophysiological index of a relatively highlevel phonological process (as opposed to a mere acoustic process). This type of investigation necessarily requires using spectrally complex stimuli, which not only differ in the high-level variable of interest but also in several other low-level acoustic features. These low-level features may influence amplitude and latency characteristics of the MMN (Näätänen, 2001; Picton et al., 2000). Our design and analysis ensured that the contribution of such acoustic processes was minimized (see Eulitz and Lahiri, 2004, for a similar example). First, MMN difference waves were derived from the ERP activity elicited by the same non-word presented as standard and deviant in separate experimental blocks. This provided a measure of MMN responses to HPP vs. LPP non-words unconfounded by variation in general 
ERP morphology that may result from physical stimulus characteristics per se. Second, we used four utterances of each non-word stimulus so that both standard and deviant stimuli were acoustically variable (see Figure 2). Such acoustic variability is typical in natural speech and reduces the likelihood that the MMN is determined by only one or a few particular acoustic features (Jacobsen et al., 2004b). Third, across experimental blocks, the acoustic difference between standard and deviant stimuli was identical, with the only difference being the directionality of change, e.g. standard $\rightarrow$ deviant was either notsel $\rightarrow$ notkel (notsel $\rightarrow$ notfel) or notkel $\rightarrow$ notsel (notfel $\rightarrow$ notsel). It may be argued that our results actually reflect such a directionality effect, e.g. a (t)k $\rightarrow(t) s$ change would elicit a different response than a $(t) s \rightarrow(t) k$ change. This interpretation appears unlikely however. Non-word stimuli were acoustically more similar in Experiment 2 (notsel and notfel) than in Experiment 1 (notsel and notkel; see Figure 1 and Methods). Thus, if directionality of consonant change would have caused the enhanced MMN for notsel in the context of notkel (Experiment 1), notsel would have been expected to elicit a smaller MMN in the context of notfel (Experiment 2). In contrast, notsel elicited a very similar MMN in both experiments. Moreover, an MMN enhancement for a $/ \mathrm{s} /$ versus / $f$ / contrast was not shown in the context of the phonotactically comparable stimuli so and fo in Experiment 3. This finding further suggests that the MMN results of Experiments 1 and 2 reflect differences in neurophysiological responses to particular phoneme combinations rather than acoustic processes at the level of single phonemes. Given the amount of nonlinearities in the auditory system and the acoustic complexity of natural speech stimuli, however, a partial contribution of 'acoustic directionality' to the observed effects cannot be excluded completely.

Visual inspection of the MMN effects in each of the three experiments also renders unlikely an interpretation of our findings in terms of individual phoneme frequencies (Figs. 3-6). Whereas the frequencies of the phonemes $/ \mathrm{s} /$ and $/ \mathrm{k} /$ are relatively similar, /f/ has a much lower frequency (see Table 1). Thus, if the strength of MMN effects would depend on differences in the distributional frequencies of $/ \mathrm{s} / / \mathrm{k} /$, and $/ \mathrm{f} /$ alone, we would expect a relatively similar MMN for notsel, so, and notkel, but a much smaller MMN for notfel and fo, which is clearly not the case. In sum, the present MMN results suggest enhanced neural responses to phoneme clusters that frequently occur in the speech input.

Why would a non-word with a high phonotactic probability lead to an enhanced MMN response? One possible explanation follows from Hebbian associative learning principles, that is, frequently co-occurring events lead to the formation of neural memory representations (Cruikshank and Weinberger, 1996; Polk and Farah, 1998; Pülvermuller, 2001). Previous electrophysiological studies revealed neural changes in animal primary auditory cortex dependent on the distributional frequencies of simple acoustic features (Nelken, 2004; Zhang et al., 2001). The present $M M N$ findings suggest that the frequent exposure to certain phoneme sequences during development, i.e. those with a high phonotactic probability, may lead to enhanced auditory cortical responses and, possibly, to the formation of auditory cortical memory traces. Alternatively, our results may reflect a combination of experience-dependent phonological and basic acoustic influences related to universal principles of phonotactics. It is important to note that these two factors are not independent. Phoneme combinations that are perceptually more 
distinctive and/or easier to articulate tend to occur more frequently across languages (Hume and Johnson, 2001) and may thus have a higher phonotactic probability. In order to disentangle the contribution of language-specific and universal processes, it would be interesting to compare the processing of a single set of stimuli in a crosslinguistic study with speakers of languages with different distributional properties for the relevant sounds. However, a cross-linguistic comparison of phonotactic probabilities (as opposed to phonotactic violations) would be extremely difficult, because, for example, the same phoneme typically has a different phonetic implementation in different languages (e.g. Cho and Ladefoged, 1999). Furthermore, in case comparable phoneme sequences do occur in different languages, their phonotactic probabilities tend to be similar. This is also why behavioural studies on phonotactic probability typically do not try to distinguish language-specific from universal phonotactics (e.g. Pitt and McQueen, 1998). In general, enhanced auditory cortical responses to speech stimuli with a high phonotactic probability may relate to the extensively reported behavioural finding that these stimuli are easier to acquire, recognize and memorize (see Auer and Luce, 2003).

Only a few visual studies previously investigated neural correlates of phonotactic probability (Pylkkänen et al., 2002; Stockall et al., 2004). These studies used magneto-encephalography (MEG) to measure brain activity during performance of visual lexical decision tasks and found modulations of event-related responses between 200-400 ms after stimulus onset. In both studies, an MEG response around $350 \mathrm{~ms}$ showed an earlier latency for words and non-words with a high as compared to low phonotactic probability, indicating facilitated neural processing. Yet, it is not clear whether similar results would occur during spoken language processing because our MMN data show phonotactic probability effects between 160-200 ms.

Our ERP results suggest auditory cortical correlates of phonotactic probability, but do not provide a precise anatomical localization. Previous studies have shown that the location of the neural MMN sources depends on the nature of the auditory stimuli involved, with prominent generators located in the superior temporal cortex and in particular the planum temporale (Giard et al., 1990; Liebenthal et al., 2003; Molholm et al., 2005). A recent functional magnetic resonance imaging (fMRI) study indicated that the neural processing of language-specific phonotactic constraints involves the left superior temporall and the left anterior supramarginal gyri (Jacquemot et al., 2003). Although the present MMN findings indirectly suggest that similar auditory cortical areas may provide a neural substrate for the processing of phonotactic probabilities, further studies using different imaging techniques like fMRI will be needed to provide a more precise characterization of the underlying network of brain areas. 


\section{Conclusion}

We used a reversed oddball paradign to investigate neurophysiological correlates of phonotactic probability. We found significantly enhanced MMN responses to non-words with a high vs. low phonotactic probability suggesting auditory cortical tuning to statistical regularities of phoneme combinations in the language input. Furthermore, this finding was not replicated when we presented a single phoneme contrast in the neutral context of phonotactically comparable stimuli. These findings indicate the relevance of the language environment in shaping the neural system underlying speech perception.

\section{Acknowledgements:}

The authors are grateful to Elia Formisano and Nienke van Atteveldt for useful comments on the manuscript. 


\section{References}

Awer, J., E.T., and Luce, P. A. (2003). Probabilistic Phonotactics in Spoken Word Recogrition: In University at Buffalo Working Papers on Language and Perception, C. T. McLennan, P. A. Luce; G. Mauner, and J. Charles-Luce, eds., pp. 164-202.

Bayyen, R. H., Piepenbrock, R., and Gulikers, L. (1995). The CELEX Lexical Database (Release 2) [CD-ROM] (Philadelphia, PA, Linguistic Data Consortium, University of Pennsylvanta [Distributor]).

Bailey, T. M., and Halun, U. (200L). Determinants of Wordlikeness: Phonotactics or Lexical Neighborhoods? Journal of Memory and Language 44, 568-591.

Boersma, P., and Weenink, D. (2002). Praat 4.0: a system for doing phonetics with the computer [Computer software] (Amsterdan, The Netherlands, Universiteit van Amsterdam).

Cheour, M., Ceponiene, R., Lehtokoski, A., Luuk, A., Allik, J., Alho, K., and Natatanen, R. (1998). Development of language-specific phoneme representations in the infant brain. Nature Neuroscience $1,35 \downarrow-353$.

Cho, T, and Ladefoged, P. (1999). Variations and universals in VOT: evidence from 18 languages. Journal of Phonetics 27, 207-229.

Coady, J. A., and Aslin, R. N. (2004). Young children's sensitivity to probabilistic phonotactics in the developing lexicon. Journal of Experimental Child Psychology 89, 183-213.

Cruikshank, S. J., and Weinberger, N. M. (1996). Evidence for the Hebbian hypothesis in experience-dependent physiological plasticity of neocortex: a critical review. Brain Research Reviews 22, 191-228.

Dehaene-Lambertz, G. (1997). Electrophysiological correlates of categorical phoneme perception un adults. Neuroreport 8,919-924.

Dehaene-Lambertz, G., and Baillet, S. (1998). A phonological representation in the infant brain. Neuroreport 9, 1885-1888.

Dehaene-Lambertz, G., Dupoux, E., and Gout, A. (2000). Electrophysiological correlates of phonological processing: a cross-linguistic study, Joumal of Cognitive Neuroscience 12,635-647.

Eulitz, C, and Lahiri, A. (2004). Neurobiological evidence for abstract phonological representations in the mental lexicon during speech recognition. Joumal of Cognitive Neuroscience $16,577-583$.

Gage, N., Poeppel, D., Roberts, T. P., and Hickok, G. (1998). Auditory evoked Ml00 reflects onset acoustics of speech sounds. Brain Research 814, 236-239.

Gathercole, S. E., Frankish, C. R., Pickering, S. J., and Peaker, S. (1999). Phonotactic influences on short-term memory. Journal of Experimental Psychology Learning Memory and Cognition 25 , $84-95$.

Giard, M. H., Perrin, F., Pernier, J., and Bouchet, P. (1990). Brain generators implicated in the processing of auditory stimulus deviance: a topographic event-related potential study. Psychophysiology 27, 627-640.

Hume, E., and Johnson, K. (2001). A model of the interplay of speech perception and phonology. In The role of Speech Perception in Phonology, E. Hume, and $K$.Johnson, eds. (New York, N.J., Academic Press), pp. 3-26. 
Jacobsen, T., Horvath, J., Schroger, Ex, Latmer, S., Widmann, A., and Winkler, I. (2004a). Preattentive auditory processing of lexicality. Brain and Language 88, 54-67.

Jacobsen, T., Sichoger, E, and Alter, K. (2004b). Pre-attentive perception of wowel phonemes from variable speech stimuli. PSychophysiollogy $41,654-659$.

Jacquemot, C., Pallier, C., LeBihan, D, Dehaene, $S_{,}$and Dupoux, E. (2003). Phonological grammar shapes the auditory cortex a functonal magnetic resonance imaging study. Jounal of Neuroscience $23,9541-9546$.

Jancke, L., Wustenberg, T., Scheich, H., and Heinze, H. J. (2002). Phonetic perception and the temporal cortex. Neuromage $15,733-746$.

Jusczyk, P. W. (1999). How infants begin to extract words from speech. Trends in Cognitive Solences $3,323-328$.

Liebenthal, E., Ellingson, M. L., Spanaki, M. V., Prieto, T. E., Ropella, K. M., and Binder, J. R. (2003). Simultanteous ERP and IMRI of the auditory cortex in a passive oddball paradigm. Neuroimage $19,1395-1404$.

Mitterer, H., and Blomert, L. (2003). Coping with phonological assimilation in speech perception: evidence for early compensation. Perception and Psychophysics 65, 956-969.

Molholm, S., Martinez, A., Ritter, W., Javitt, D. C., and Foxe, J. I. (2005). The Neural Circuitry of Pre-attentive Auditory Change-detection: An fMRI Study of Pitch and Duration Mismatch Negativity generators. Cerebral Cortex $15,545-551$.

Naatanen, R. (2001). The perception of speech sounds by the human brain as reflected by the mismatch negativity (MMN) and its magnetic equivalent (MMNm). Psychophysiology 38, 1-21.

Näatanen, R. Lehtokoski, A., Lennes, M., Cheour, M., Huotilainen, M., livonen, A., Vainio, M. Alku, P., IImoniemi, R. J. Luuk, $A_{. j}$ ef al (1997). Language-specific phoneme representations revealed by electric and magnetic Brain Researchponses. Nature 385, 432-434.

Năatänen, R., Tervaniemi, M., Sussman, E., Paavilainen, P., and Winkler, L. (2001). "Primitive intelligence" in the auditory cortex. Trends in Neurosciences 24, 283-288.

Nelken, I. (2004). Processing of complex stimuli and natural scenes in the auditory cortex. Current Opinion in Neurobiology 14, 474-480.

Nuwer, M. R., Comi, G., Emerson, R., Fuglsang-Frederiksen, A., Guerit, J. M., Hinrichs, H., Ikeda, A., Luccas, F. J, and Rappelsburger, P. (1998). IFCN standards for digital recording of clinical EEG. Intenational Federation of Clinical Neurophysiology. Electroencephalography and Clinical Neurophysiology 106, 259-261.

Obleser, 1., Lahiri, A., and Eulitz, C. (2003). Auditory-ewoked magnetic field codes place of articulation in timing and topography around 100 milliseconds post syllable onset. Neuroimage $20,1839-1847$

Philuips, C., Pellathy. T., Marantz, A., Yellin, E., Wexler, K., Poeppel, D., McGinnis, M., and Robeuts, T. (2000). Auditory cortex accesses phonological categories: an MEG mismatch study. Journal of Cognitive Neuroscience 12, 1038-1055.

Picton, T. W., Alain, C., Otten, L., Ritter, W., and Achim, A. (2000). Mismatch negativity; different water in the same river. Audiology and Neurootology 5, 1111-139.

Pitt, M. A., and McQueen, J. M. (1998). Is compensation for coarticulation mediated by the lexicon? Journal of Memory and Language $39,347-370$. 
Polk, T. A. and Farah, M. J. (1998). The neural development and onganiration of letter recognition: evidence from functional neuroimaging, computational modeling, and behavioral studies. Proceedings of the National Academy of Sciences U S A 95, 847-852.

Pulvermuller, F., Kujala, T., Shtyrov, Y., Simola, I. Thinen, H. Alku, P., Alho, K. Martinkauppi, S., Ilmoniemi, R. J., and Näatinem, R. (2001). Memory traces for words as revealed by the mismatch negativity. Neuroimage $14,607-616$.

Pylkkänen, L., Stringfellow, A., and Marantz, A. (2002). Neuromagnetic ewdence for the timing of lexical activation: an MEG component sensitive to phonotactic probability but not to neighborhood density. Brain and Language 81, 666-678.

Saffran, J. R., Aslin, R. N., and Newport, E. L. (1996). Statistical learning by 8-month-old infants. Science $274,1.926-1928$.

Schröger, E. (1998). Measurement and interpretation of the mismatch negativity. Behavior Research Methods, Instruments and Computers 30, 13:1-145.

Semlitsch, H. V., Anderer, P., Schuster, P., and Presslich, O. (1986). A solution for reliable and valid reduction of ocular artifacts, applied to the P300 ERP. Psychophysiology 23,695-703.

Stockall, L., Stringfellow, A, and Marantz, A. (2004). The precise time course of lexical activation: MEG measurements of the effects of frequency, probability, and density in lexical decision. Brain and Language $90,88-94$.

Storkel, H. L. (2001). Learning new words: phonotactic probability in language development. Journal of Speech Language and Hearing Research 44, $1321-1337$.

Trask, R. L. (1996). A dictionary of phonetics and phonology (London, Routledge).

Vitevitch, M. S., and Luce, P. A. (1999). Probabilistic phonotactics and neighborhood activation in spoken word recognition. Journal of Memory and Language 40, 374-408.

Winkler, I., Lehtokoski, A., Alku, P., Vainio, M., Czigler, I., Csepe, V., Aaltonen, O., Raimo, I., Alho, K., Lang, H., et al. (1999). Pre-attentive detection of vowel contrasts utilizes both phonetic and auditory memory representations. Cognitive Brain Research 7, 357-369.

Zhang, L. I., Bao, S., and Merzenich, M. M. (2001). Persistent and specific influences of early acoustic environments on prinary auditory cortex. Nature Neuroscience 4, 1123-1130. 


\title{
Chapter 5
}

\section{Deviant neural processing of phonological regularities in dyslexic children'}

\begin{abstract}
Developmental dyslexia is strongly associated with a phonological deficit. Yet, on-line phonological processing (injcapacities in dyslexia remain relatiwely unexplored. Here we use a neurophysiological response sensitive to experience-dependent auditory memory traces, i.e. the misnatch negativity (MMN), to investigate implicit phonological processing of natural speech in dyslexic and normally reading children. In a modified passive oddball design that minimizes the contribution of acoustic processes, we presented non-words that differed by the degree of phonotactic probability, i.e. the distributional frequency of phoneme combinations in a given language. Our results showed comparable acoustic-phonetic processing of stimulus differences in both children groups. Furthermore, in normal readers the strength of auditory cortical responses followed the distributional frequencies of phoneme clusters, i.e. the non-word with high phonotactic probability (notsel) elicited a significantly larger MMN than the non-word with low phonotactic probability (notkel). In contrast, dyslexic children did not show this sensitivity to phonotactic probability. Children's neurophysiological sensitivity to phonotactic probability correlated with behavioural measures of their phonological skills. These findings indicate that the phonological problems often reported in dyslexia may already start at the implicit phonetic-phonological processing of speech.
\end{abstract}

\footnotetext{
${ }^{9}$ This chapter is based on Bonte, M.L., Poelmans H. and Blomert L. Deviant implicit phonological processing of speech in dyslexic children as indicated by event-related potentials. Submitted.
} 


\section{Introduction}

The efficient processing and representation of speech sounds, i.e. phonological skills, constitutes a common bottleneck to fluent reading (National Research Council, 1998). In particular, numerous studies indicate that the failure to adequately develop these phonological skills may underlie reading problems such as experienced in developmental dyslexia (Snowling, 2000). Developmental dyslexia is a specific reading disorder that is characterized by difficulties in reading and/or spelling that are unexpected in relation to age and other cognitive abilities (Reid Lyon, 1995). It affects a relatively large percentage of the population with prevalence estimates ranging from 3-10\% (Pennington, 1990). A recent nationwide study of an elementary school population in The Netherlands estimated a prevalence of reading and/or spelling problems of $8.8 \%$, of which $40 \%$ were dyslexic (Blomert, 2003). Poor phonological skills form a core deficit in dyslexia, although they may sometimes be accompanied by additional sensory deficits in the auditory, visual and/or motor domains (Nicolson et al., 2001; Ramus et al., 2003; Stein and Walsh, 1997).

Phonological difficulties are apparent from dyslexics' poor behavioural performance on phonological tasks involving e.g. phonological awareness (e.g. phoneme deletion, rhyme judgments) or verbal memory (Howes et al., 1999; O'Neill and Douglas, 1991; Tijms, 2004). Furthermore, during performance of such tasks dyslexics show abnormal patterns of brain activation, with a typical dysfunction in left temporo-parietal regions as revealed by hemodynamic brain imaging studies, and neural time course differences as shown by studies using electroencephalography (EEG) or magnetoencephalography (MEG) (for reviews see McCandliss and Noble, 2003; Temple, 2002]). These deviant brain responses in dyslexics reflect their difficulties with explicit phonological tasks. However, explicit phonological tasks entail processing demands over and above language processes, for example, high attention and memory loads. Moreover, task-related cognitive requirements may alter the way in which phonological information is usually processed under normal perceptual conditions (Bonte and Blomert, 2004, chapter 3; Hickok and Poeppel, 2004). As a consequence, explicit phonological tasks may not be sensitive to subtle underlying anomalies in the phonological processing of speech.

Event-related potential (ERP) measures of implicit phonological processing are particularly suited to explore on-line phonological processing (in)capacities in dyslexic children. A recent investigation of phonological priming effects on ERP responses to spoken words and non-words revealed selective processing anomalies in dyslexics at a prelexical phonetic-phonological level, along with normal processing at a phonological-lexical level (Bonte and Blomert, 2004, chapter 3). The present study utilizes ERP correlates of implicit processing of phonological regularities in speech to further investigate these phonetic-phonological anomalies. We focus on a phonological regularity that influences the earliest stages of spoken language acquisition (Jusczyk, 1999; Saffran et al., 1996) and contimues to influence speech processing across the life-span (Auer and Luce, 2003), i.e., phonotactic probability. Phonotactic probability corresponds to the distributional frequency of phonemes and phoneme sequences in the syllables and words of a given language (Trask, 1996). During normal development, the neural system 
underlying speech perception may become finely tuned to these distributional properties of the language input which thereby facilitate the acquisition, recognition and representation of spoken language (Auer and Luce, 2003).

In the present study, we employed an automatic ERP response associated with mnemonic functions of the auditory association cortex, i.e. the mismatch negativity (MMN) (Näätänen, 2001; Näätänen et al., 2001; Picton et al., 2000). The MMN response is automatically elicited by any discriminable change (i.e. infrequent deviant stimuli) in a repetitive aspect of auditory stimulation (i.e. frequent standard stimuli). The size, latency and topographical distribution of this automatic change detection response may reflect the properties of auditory and/or phonemic memory traces activated by the standard and deviant stimuli (Näătänen et al., 2001; Winkler et al., 1999). Enhanced MMN responses to phonemes that are prototypical in the perceiver's native language have been suggested to reflect the existence of permanent phoneme traces in the auditory cortex of adults (Dehaene-Lambertz, 1997; Näätänen, 1997; Näätänen et al.., 2001) and infants (Cheour et al., 1998; Dhaene-Lambertz and Baillet, 1998). Similarly, we found stronger MMN responses to non-words with a high phonotactic probability than non-words with a low phonotactic probability (Chapter 4), suggesting auditory cortical sensitivity to statistical regularities of phoneme combinations.

Here we used a passive oddball paradigm that was specifically constructed to minimize the contribution of acoustic processes and to study mismatch detection at a relatively abstract, phonological, level of representation (Eulitz and Lahiri, 2004; Chapter 4). Non-words with a high (notsel) or a low (notkel) phonotactic probability were both presented as standards and deviants in a reversed oddball design. This non-word pair was selected because it involves a clear phonetic contrast (/s/ fricative vs. $/ \mathrm{k} /$ stop consonant) for which no auditory discrimination problems have been reported in dyslexics (Adlard and Hazan, 1998; Mody et al., 1997). MMN difference waves were derived from the ERP activity elicited by the same non-word presented as standard and deviant in separate experimental blocks. This enabled us to estimate auditory cortical (MMN) correlates of variation in phonotactic probability independent of differences in ERP morphology due to acoustic-phonetic stimulus differences per se. Importantly, our experimental design allowed us to study both these more general differences in ERP morphology due to auditory stimulation and specific phonological MMN effects.

The clear phonetic contrast between our stimuli was expected to similarly influence general ERP morphology in normal readers and dyslexics. Furthermore, we expected a similar sensitivity to phonotactic probability in normally reading children as previously found in adults, i.e. enhanced MMN responses to non-words with a high vs. low phonotactic probability (Chapter 4). The presence or absence of comparable MMN effects in dyslexic children may indicate whether their phonological processing difficulties already occur during the neural processing of phonological regularities in speech. 
Table 1. Deseriptive data for nomal readers and dyslexics.

Dyslexic children were on average 1.3 year older than normall readers. All subjects had normal or above normal 19 scores. On the reading tests, dyslexics performed significantly worse than normal readers, who scored at an age-appropriate level. Dyslexics and normal readers did not differ in vocabulary skills. Performance on the phoneme deletion test showed that all dyslexics suffered from phonological problems.

\begin{tabular}{|c|c|c|c|c|}
\hline & Normal readers $(n=14)$ & Dyslexics $(\mathrm{n}=12)$ & \multicolumn{2}{|c|}{ Differences } \\
\hline Age (years) & $8.2(7.1-9.5)$ & $9.5(8.1-11.3)$ & $t=-3.6$ & $P<0.005$ \\
\hline 10 & $109(90-130)$ & $106(90-126)$ & $t=0.7$ & n.s. \\
\hline Word reading & $6.1(1.8)$ & $2.6(2.1)$ & $t=4.6$ & $p<0.001$ \\
\hline Non-word reading & $5.9(1.5)$ & $3.0(1.7)$ & $t=4.7$ & $P<0.001$ \\
\hline Vocabulary & $5.8(1.1)$ & $6.3(1.7)$ & $t=-1.0$ & n.s. \\
\hline Phoneme deletion & $88 \%(8 \%)$ & $78 \%(15 \%)$ & $t=2.1$ & $p<0.05$ \\
\hline
\end{tabular}

10 scores (mean(range)) and performance on language tests (mean (SD)).

Age-zppropriate norms (standardized scale; mean $=5, \mathrm{SD}=2$ )

Percentage correct, nax-28 items

\section{Materials and Methods}

\section{Subjects}

30 subjects ( 15 dyslexics, 15 normal readers) participated in the present study. Data of 26 subjects were included in the analysis, including 12 dyslexics ( $5 \mathrm{f}$; mean age: $9.5 \pm 1.1$ years) and 14 normal readers ( $9 \mathrm{f}$; mean age: $8.2 \pm 0.7$ years). Data of 3 dyslexics and 1 normal reader were discarded due to excessive movement artefacts.

All children were given a present for participation. Informed consent was obtained from the parents of the children. Approval for the study was granted by the Ethical Committee of the Faculty of Psychology at the University of Maastricht. Dyslexic children were recruited from the Regional Institute of Dyslexia (RID), which is one of the major specialized dyslexia institutes in The Netherlands. Prior to the present study, they were diagnosed as dyslexic after an extensive cognitive psycho-diagnostic procedure by the RID. This testing procedure also included an intelligence test (WISC-R, Dutch version, WISC-R project group, 1986), the results of which were used in the present study. Normal readers were recruited from local schools, and were judged by their school teachers to be average or above average in academic achievement.

All subjects were native Dutch speakers. As assessed with Annett's Handedness Questionnaire (Annett, 1979), 3 dyslexics were left-handed and all other subjects right-handed. All parents of children reported the absence of any history of hearing loss. Subject characteristics and results of behavioural tests are given in Table 1. IQ was measured with the Raven Colored Progressive Matrices (Raven et al., 1998) in normal readers, and the WISC-R (WISC-R projectgroup, 1986) in dyslexics. Both dyslexics and normal readers performed standardized language tests, including two reading tests, the Een-minuut-leestest (one-minutereading test. Brus et al., 1999) and a non-word reading test (Van de Bos et al., 
1999), an active vocabulary test (subtest of WISC-R. WISC-R project group, 1986), and additionally, an unpublished phoneme-deletion task (devised by the RID). The phoneme deletion test asks children to delete the first phoneme of an auditorily presented word and to pronounce the remaining word.

Table 2. Frequency counts of phonemes and phoneme combinations in our non-word stimuli (log-transformed). Frequency counts were weighted for word frequency and based on the Celex corpus with 42 million Dutch words [4]. [..] indicates the phoneme(s) for which counts are given, $c=$ consonant, $v=$ vowel. For example, the $3^{\text {rd }}$ column: $c v[c c] v c$, gives trequency counts for / $t \mathrm{~s} /$ and $/$ th $/$ respectively. The frequency counts of the single phonemes / $/$ / and $/ \mathrm{k} /$ in the $2^{\text {nt }}$ column only include syllable-initial occurrences. " " indicates a frequency of 0.

\begin{tabular}{ccccccc}
\hline crecve & cve[c]ve & cv[ec]ve & c[vec] ve & cv[ecv] & c\|vecv]c & [crecve] \\
\hline notsel & 6.50 & 5.83 & 4.32 & 4.59 & 3.99 & - \\
notkel & 6.45 & 4.51 & 2.53 & 0.95 & - & - \\
\hline
\end{tabular}

\section{Stimuli and Task}

Stimuli were two bisyllabic non-words, one with high phonotactic probability (HPP: notsel [notsal]), and the other with low phonotactic probability (LPP: notkel [notkal]). Table 2 gives the phonotactic probabilities of our stimuli as determined by counts of phoneme sequences weighted for word frequency in a Dutch word form database (CELEX corpus, Baayen et al., 1995). As can be seen in Table 2 , the probabilities of the individual phonemes, that is $/ \mathrm{s} /$ and $/ \mathrm{k} /$ alone, are similar. However, the consonant cluster/ts/ has a higher phonotactic probability than $/ \mathrm{tk} /$. The relative difference in phonotactic probability between the stimuli is further increased by the vowels $/ \mathrm{o} /$ and /e/ that precede and follow the consonant clusters. Importantly, no Dutch word starts with the phoneme sequence /nots/ or /notk/, thus making top-down lexical effects unlikely. Both non-words have a strong-weak metrical stress pattern.

Stimuli were spoken by a female native Dutch speaker and recorded at a sampling rate of $44.01 \mathrm{kHz}$ on a DAT recorder. The digitized stimuli were D/A converted with a 16 bit resolution, bandpass filtered $(100 \mathrm{~Hz}$ to $10.5 \mathrm{KHz}$ ), resampled at $22.05 \mathrm{KHz}$, and edited with Praat software (Boersma and Weenink, 2002). Editing included matching for loudness, i.e. equating the maximal amplitude to $95 \%$ of the dynamic range, and equating stimulus length to $550 \mathrm{~ms}$ (original range: $480-600 \mathrm{~ms})$ using PSOLA $(140 \mathrm{~Hz}-280 \mathrm{~Hz}$ as extrema of the F0 contour). We used 4 utterances of each non-word stimulus. Figure 1 illustrates that both sets of non-word utterances showed comparable variation in pitch and intensity. Auditory stimulus deviation occurred around $160 \mathrm{~ms}$ at the onset of the stimulus medial consonant clusters / $/ \mathrm{s} /$ and $/ \mathrm{tk}$.

During the experiment, children watched a silent movie while the stimuli were presented binaurally through loudspeakers at $65 \mathrm{~dB}$ SPL. Stimuli were presented with an inter-stimulus interval of $650 \mathrm{~ms}$. There were 4 experimental blocks with 600 stimuli each. In 2 of these blocks, the HPP non-word served as standard ( $84 \%)$ and the LPP non-word as deviant $(16 \%)$, in the other 2 blocks standards and 
deviants were reversed, i.e. the LPP non-word was the standard and the HPP nonword the deviant. The order of experimental blocks was counterbalanced between subjects. In total, 1008 standards and 192 deviants were presented for each nonword.
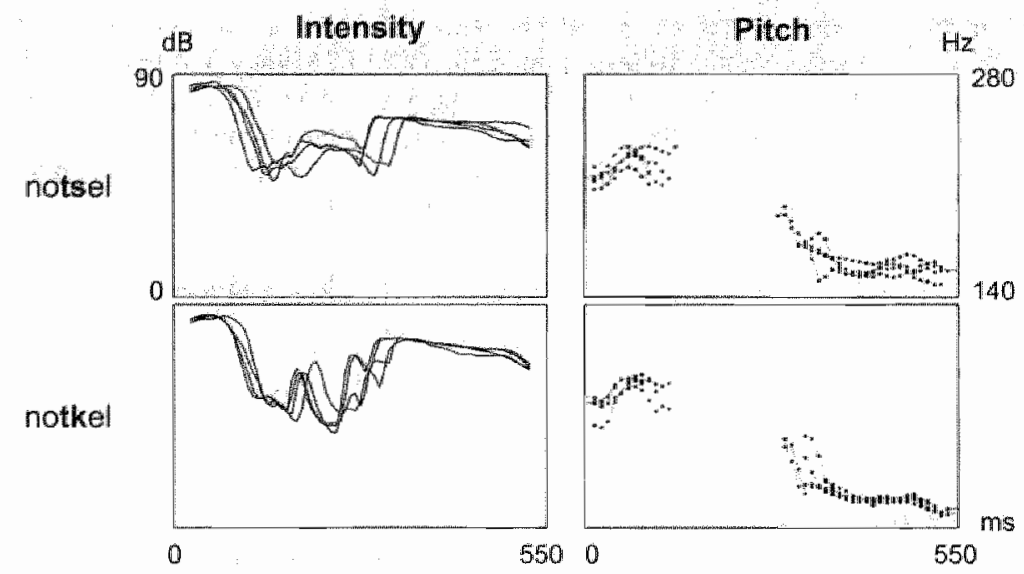

Figure 1. Stimuli: Pitch and intensity contours of the non-word stimuli used in the Experiment: notsel [notsal] and notkel [notkol], which have a high ws. low phonotactic probability. We used 4 utterances of each non-word.

\section{EEG recording and analysis}

EEG data were recorded in a sound-attenuating and electrically shielded room $(0.01$ $-50 \mathrm{~Hz}$, sampling rate $250 \mathrm{~Hz}$ ) from 30 electrode positions (Extended International 10-20 system, Nuwer et al., 1998) relative to a nose reference. Eye-movements and blinks were measured with bipolar VEOG/HEOG channels. All electrode impedance levels (EEG and EOG) were kept below $5 \mathrm{k} \Omega$. The raw EEG data were corrected for blink artefacts (Semlitsch et al., 1986). EEG data were epoched from 50 to $850 \mathrm{~ms}$ relative to stimulus onset, baseline corrected $(50 \mathrm{~ms}$ pre-stimulus interval), and $1-30 \mathrm{~Hz}$ bandpass filtered. Epochs containing data exceeding a maximum voltage criterion of $100 \mu \mathrm{V}$ were rejected. Standards immediately following deviants were not included in the analysis. The mean (SD) number of accepted epochs in normal readers and dyslexics were respectively, $163(16)$ and 169 (10) for HPP deviants, 158 (21) and 167 (9) for LPP deviants, 673 (72) and 701 (50) for HPP standards and 684 (69) and 713 (44) for LPP standards.

Statistical analyses were performed on the central electrode $\mathrm{Cz}$, where $\mathrm{MMN}$ responses were clearly detectable. We first analyzed the strength and timing of ERP activity elicited by the standard and deviant non-word stimuli using repeatedmeasures ANOVA with stimulus type (standard vs. deviant) and phonotactic probability (HPP vs. LPP) as within subjects factors and group (normal readers vs. dyslexics) as between subjects factor. Timing of ERP responses was measured by determining individual peak latencies in the $250-350$ window ("N2") and 450-550 
window ("N4"). Amplitude measures included both individual peak amplitudes and mean amplitude taken from the $50 \mathrm{~ms}$ window around the nean peak latency.

Mismatch effects were further examined on deviant-standard difference waveforms that were calculated separately for each non-word by subtracting the ERP signal elicited by its standards from that of its deviants; e.g. notsel deviant minus notsel standard. From these difference waves we calculated timing and amplitude parameters of mismatch responses that were tested using repeatedmeasures ANOVA with phonotactic probability (HPP vs. LPP) as within subjects factor and group (normal readers vs. dyslexics) as between subjects factor. MMN peak latency was determined for each individual subject in the time window between $360-61.0 \mathrm{~ms}$ after stimulus onset $(\sim 200-450$ after auditory stimulus deviation). MMN amplitude measures included both individual peak amplitude and mean amplitude taken from the $50 \mathrm{~ms}$ window around the individual MMN peak latencies. To investigate correlations between MMN measures and language skills, age and IQ, we computed Pearson's correlation coelficients.

\section{Results}

\section{ERP morphology}

Figure $2 \mathrm{~A}$ illustrates the mean time course of ERP activity elicited by the nonwords notsel (HPP) and notkel (LPP). Non-words elicited a very similar sequence of activity in normal readers and dyslexics, which was characterized by a broad positivity peaking around $160 \mathrm{~ms}$ followed by two negative responses peaking around 290 and $510 \mathrm{~ms}$ after stimulus onset. We will refer to these negativities as N2 and N4.

Figure $2 \mathrm{~B}$ shows the mean difference waves of the ERP activity evoked by the two non-words (notsel - notkel), indicating that there was stronger activation for notsel than notkel in the N2 and N4 windows. The time course and amplitudes of these stimulus related differences were very similar in normal readers and dyslexics. Figure $2 \mathrm{~A}$ shows the topographic distribution of $t$-values (notsel - norkel) for these N2 and N4 amplitude differences. In both groups, the notsel-notkel differences were characterized by a broadly distributed negativity in the $N_{2}$ window, and a more anterior negativity in the $\mathrm{N} 4$ window.

Amplitude and latency characteristics of the N2 and N4 responses were analyzed at electrode $\mathrm{Cz}$ using a 2 (stimulus type) $\times 2$ (phonotactic probability) repeated-measures ANOVA with subject group as between subjects factor. In both normal readers and dyslexics, notsel ellicited significantly stronger N2 and N4 responses than notkel as indicated by main effects of phonotactic probability for the peak amplitudes of the $\mathrm{N} 2(F(1,24)=9.0, P<0.01)$ and the $\mathrm{N} 4(F(1,24)=5.5$, $P<0.05)$. The same analysis of mean amplitude in $50 \mathrm{~ms}$ time windows around the $\mathrm{N} 2$ (265-315 ms) and N4 (485-535) peaks corroborated these findings (main effects of phonotactic probability $F(1,24)=16.8, P<0.001$ and $F(1,24)=9.5, P=0.005)$. The peak latencies of the N2 and N4 were very similar for both non-words and both subject groups and did not show any significant effects. 


\section{A) grand awerages and $t$-maps}

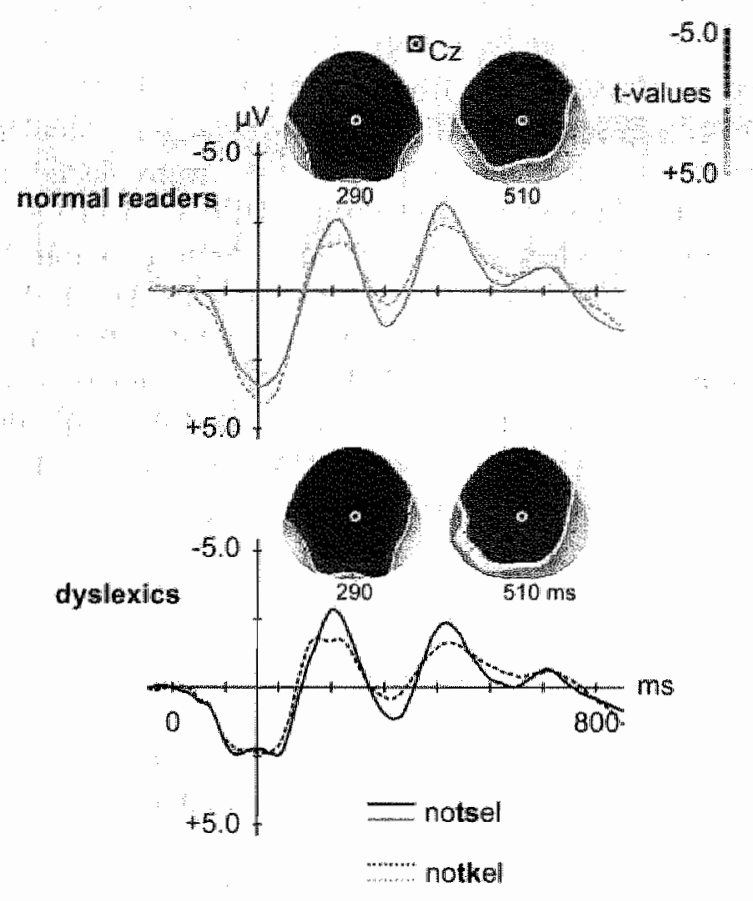

B) difference waves: notsel - notkel

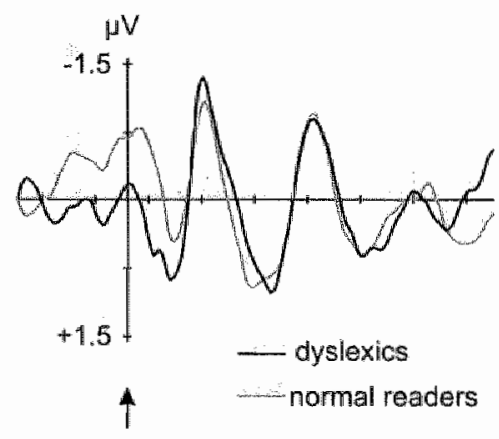

auditory deviation

Figure 2. ERP activity elicited by the non-word stimuli used in the present Experiment, notsel and rotkel, for both normal readers and dyslexics. (A) Grand average ERPs elicited by both non-word stimuli and statistical maps indicating stimulus differences ( $t$-statistics: notsel - notkel). (B) ERP difference waves (notsel - notkel) indicating enhanced ERP responses for notsel vs. notkel in both subject groups. Note that auditory stimulus deviation occurred $\sim 160$ ms after stimulus onset. 
Notsel (HPP)

A) grand averages

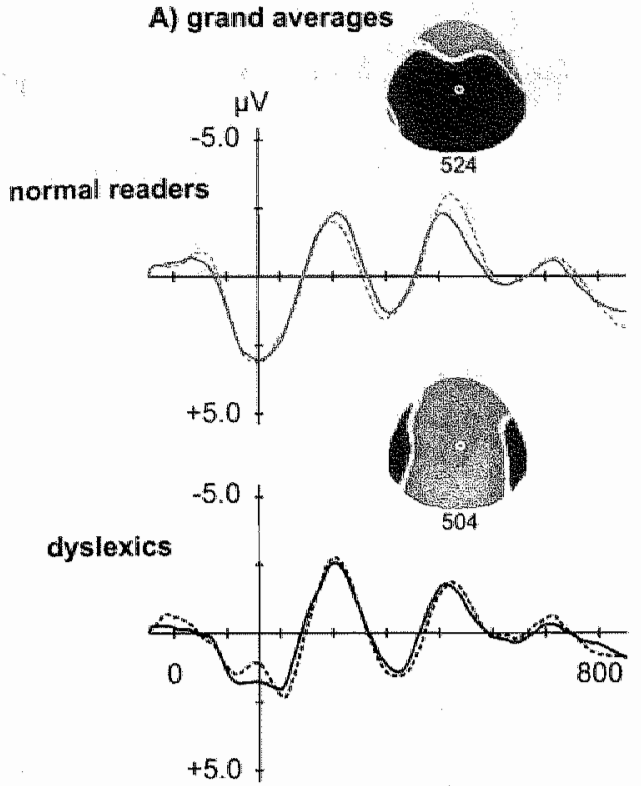

Ensien standard

\section{Notkel (LPP)}

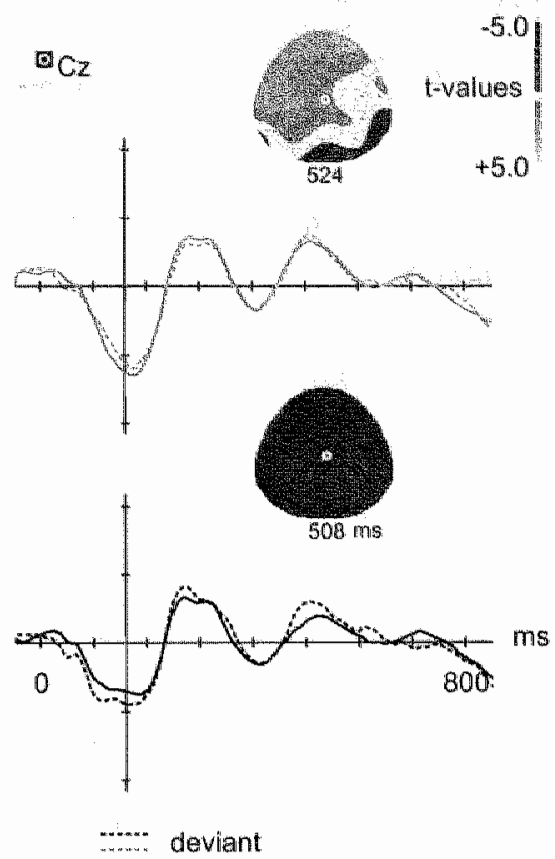

B) difference waves: deviant - standard

uV
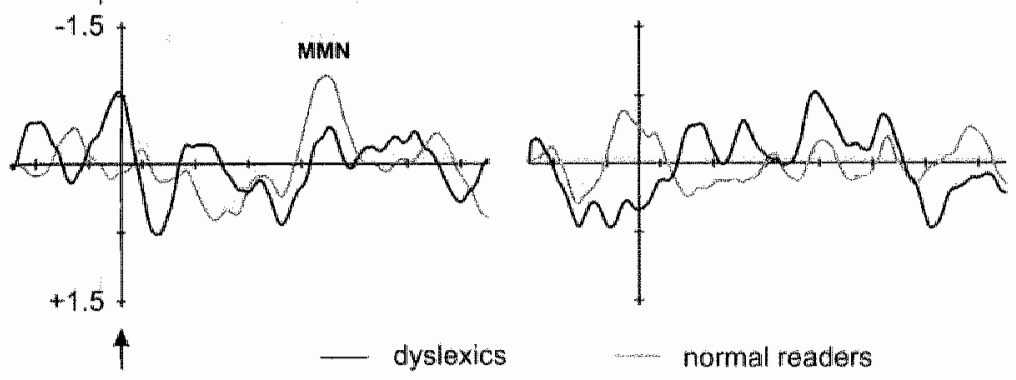

normal readers

auditory deviation

Figure 3. ERP activity elicited by standard and deviant stimuli for both normal readers and dyslexics. (A) Grand average ERPs elicited by standard and deviant stimuli and statistical maps indicating mismatch effects for HPP (t-statistics: notsel deviant - notsel standard) and LPP (t-statistic: notkel deviant - notkel standard) non-words. (B) ERP difference waveforms of normal readers and dyslexics for HPP (notsel deviant - notsel standard) and LPP (notkel deviant - notkel standard) non-words. Note that auditory stimulus deviation occurred $\sim 160 \mathrm{~ms}$ after stimulus onset. 
Table 3. Mean (SEM) latency and amplifude characteristics of MMN activity in nomal readers and dyslexics. Peak latency, peak amplitude and nean amplitude $(50 \mathrm{~ms}$ window around the peak latency) were determined individually for weh subject.

\begin{tabular}{|c|c|c|c|}
\hline & Pealk dutuncy (ms) & Peak amplitude $(\mu \mathrm{V})$ & Mean amplitude (uW) \\
\hline Normal reader & $y$ & की & \\
\hline Notsel (HPP) & $501 \pm 16$ & $-2.42 \pm 0.29$ & $-1.90 \pm 0.28$ \\
\hline Notkel (LPP) & $511 \pm 17$ & $-1.45 \pm 0.31$ & $-0.86 \pm 0.30$ \\
\hline$t(\mathrm{df}=13)$ & .0 .5 & $-2.3 *$ & $-2.3 *$ \\
\hline \multicolumn{4}{|l|}{ Dyslexics } \\
\hline Notsel (MPP) & $490 \pm 20$ & $-1.73 \pm 0.23$ & $-1.10+0.20$ \\
\hline Notkel (LPP) & $503 \pm 19$ & $-2.16 \pm 0.30$ & $-1.61 \pm 0.29$ \\
\hline$t(\mathrm{~d} f=11)$ & -0.6 & 1.0 & 1.3 \\
\hline
\end{tabular}

\section{MMN findings}

The main goal of the present study was to investigate whether ERP mismatch responses to non-words with a high (HPP) vs. low (LPP) phonotactic probability would indicate a sensitivity to phonotactic probability in normally reading and dyslexic children. To get an overall impression of ERP activity elicited by standard and deviant stimuli we first analyzed $\mathrm{N} 2$ and $\mathrm{N} 4$ amplitude and latency values at $\mathrm{Cz}$ using a 2 (stimulus type) $\times 2$ (phonotactic probability) repeated-measures ANOVA with subject group as between subjects factor. The N2 response did not show significant differences between standard and deviant stimuli. However, in both subject groups, deviant stimuli elicited stronger N4 responses than standard stimuli (main effects of stimulus type for $\mathrm{N} 4$ peak amplitude and $F(1,24)=15.1, P=0.001$ and mean $N 4$ amplitude $F(1,24)=7.7, P<0.025)$. Furthermore, in normal readers and dyslexics this mismatch effect was differentially influenced by phonotactic probability, as indicated by stimulus type-by-phonotactic probability-by-group interactions for $\mathrm{N} 4$ peak amplitude $F(1,24)=4.5, P<0.05$, and mean N4 amplitude $F(1,24)=4.3, P<0.05$. These mismatch effects were further tested by examining latency and amplitude characteristics of ERP activity derived from deviant-standard difference waves.

Figure 3 shows the grand average ERPs, difference waves and statistical maps for notsel (HPP) and notkel (LPP). Difference waves and statistical maps were derived from the ERP activity elicited by the same non-word presented as standard and deviant in separate experimental blocks. This enabled us to estimate MMN correlates of HPP vs. LPP non-words independent of variation in ERP morphology resulting from physical stimulus differences per se. The importance of this specifically adapted design is emphasized by our finding of significantly enhanced $\mathrm{N} 2$ and $\mathrm{N} 4$ responses to notsel vs. notkel (see Figure 2). Whereas these general N2 and N4 effects were very similar in both subject groups, Figure 3 shows a strikingly different influence of phonotactic probability on mismatch responses in normal readers and dyslexics. 

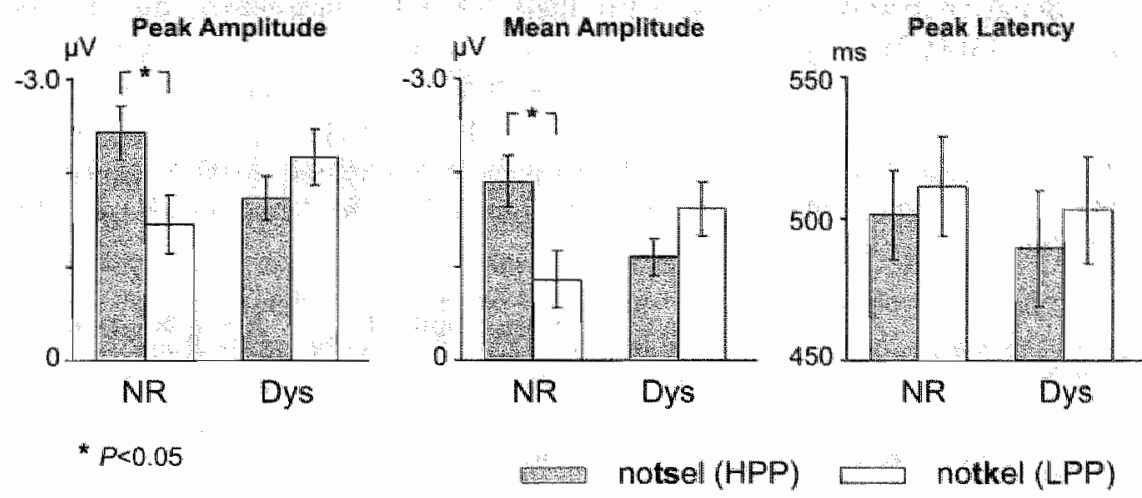

Figure 4. Mean (SEM) latency and amplitude characteristics of MMN activity in nomal readers (NR) and dyslexics (Dys). Peak latency, peak amplitude and mean amplitude $(50 \mathrm{~ms}$ window around the peak latency) were determined individually for each subject. Error bars represent standard error of the mean. Asterisks indicate significant differences between conditions (post hoc $t$ comparisons).

In normal readers, notsel (HPP) deviants elicited a clear MMN at $\sim 505 \mathrm{~ms}$ after stimulus onset ( $\sim 345$ after auditory stimulus deviation) with a posterior-central distribution and a small leftward bias (Figure 3A; see also Csépe, 1995), whereas notkel (LPP) deviants did not lead to a distinguishable MMN effect at the group level. In contrast, dyslexics did not show a stronger MMN response to the HPP than the LPP non-word (Figure 3). In fact, at the group level, notkel deviants elicited a negativity around $500 \mathrm{~ms}$ ( -340 after auditory stimulus deviation) which was broadly distributed over the scalp, whereas notsel deviants did not elicit a clear MMN response.

To test these effects of phonotactic probability, we performed repeatedmeasures ANOVAs with phonotactic probability as within and group as between subjects factor on latency and amplitude measures derived from the deviantstandard difference waves at $\mathrm{Cz}$ (Figure 4 and Table 3). Individual mismatch responses peaked on average at around $500 \mathrm{~ms}$ ( -340 after auditory stimulus deviation), with no significant latency differences between notsel and notkel or subject groups. The peak latencies showed a large variability between subjects (see Table 3). Because of this latency variability and the small magnitude, the grand average difference waveforms showed no $\mathrm{MMN}$ activity for notkel in normal readers and notsel in dyslexics (Figure 3), whereas the individually determined peak and mean amplitudes showed negative activity in all conditions (Figure 4 and Table 3).

Analysis of MMN amplitude led to significant phonotactic probability-bygroup interactions for peak amplitude $(F(1,24)=5.5, P<0.05)$ and mean amplitude $(F(1,24)=6.3, P<0.025)$. In normally reading children the HPP non-word notsel elicited a significantly stronger MMN than the LPP non-word notkel, as indicated by post-hoc t-tests of MMN peak amplitude $(t(1,13)=-2.3, P<0.05)$ and MMN mean amplitude $(t(1,13)=-2.3, P<0.05)$. However, in dyslexics, the opposite effect, a 
stronger negative response to the LPP than the HPP non-word, did not reach Mignificance (Table 3).

Table 4. Pearson"s correlations between MMN difference scores (notsel-notkel) of latency, peak amplitude and mean amplitude (50 ms window around the peak latency), and age, IQ and behawioural neasures for all subjects.

\begin{tabular}{lccc}
\hline & Latency & Peak amplitude & Mean amplitude \\
\hline Age (years) & 0.28 & 0.29 & 0.28 \\
IQ & -0.14 & 0.23 & 0.21 \\
Word reading" & 0.04 & -0.18 & -0.20 \\
Non-word reading" & 0.03 & $-0.42^{*}$ & $-0.44^{*}$ \\
Vocabulary" & 0.17 & -0.00 & -0.01 \\
Phoneme deletion' & -0.26 & $-0.36 \quad P=0.07$ & $-0.38 \quad P=0.06$ \\
\hline \multicolumn{4}{c}{ Pe 0.05} \\
$\quad$ Age-appropriate norms (standardized scale; mean $=5, \mathrm{SD}=2)$
\end{tabular}

\section{Correlations with behavioural measures}

The extent to which notsel (HPP) elicited stronger MMN activity than notkel (LPP) may reflect subjects' neurophysiological sensitivity to the phonotactic probability of phoneme sequences. To further investigate the phonological nature of this neurophysiological measure we examined whether it was correlated with subjects' phonological skills as measured with the non-word reading test (phonological decoding) and phoneme deletion test (phonological awareness). For each of the normal readers and dyslexics the sensitivity to phonotactic probability was estimated from individual difference scores (notsel-notkel) of MMN peak amplitude, mean amplitude and peak latency. We computed correlations between these individual $\mathrm{MMN}$ difference scores and age, IQ, word reading, non-word reading, vocabullary and phoneme deletion skills. As shown in Table 4, this analysis revealed significant correlations between MMN difference scores of peak amplitude and non-word reading $(r=-0.42, P<0.05)$, and mean amplitude and non-word reading ( $r=-0.44, P<0.05$ ). Additionally, both peak and mean amplitude measures tended to correlate with performance on the phoneme deletion test $(r=-0.36$, $P=0.07$ and $r=-0.38, P=0.06$ ). As indicated by these negative correlations, children with better phonological skills showed a larger MMN enhancement for notsel (HPP) as compared to notkel (LPP). There were no significant correlations between MMN difference scores and any of the other behavioural measures, age or IQ. 


\section{Discussion}

We investigated implicit phonological processing of meaningless speech in normally reading and dyslexic children by comparing ERP mismatch responses to non-words with a high (HPP) vs. low (LPP) phonotactic probability, tee. notsel and notkel. Both non-words elicited a comparable sequence of ERP responses in normal readers and dyslexics. Furthermore, both subject groups showed similarly enhanced ERP responses to notsel as compared to norkel stimuli. The analysis of ERP mismatch responses for HPP (notsel deviant - notsel standard) vs. LPP (notkel deviant - notkel standard) non-words indicated a clearly enhanced MMN response for the HPP non-word in normally reading children, analogous to our findings in adults (see chapter 4) In contrast, ERP activity of dyslexic children did not reflect this sensitivity to phonotactic probability, supporting the idea that their phonological difficulties involve the inplicit phonetic-phonological processing of speech (Bonte and Blomert, 2004). Furthermore, our neurophysiological measure of subjects' sensitivity to variations in phonotactic probability (notsel-notkel difference scores of MMN amplitude) correlated significantly with behavioural measures of phonological skills. That is, children with better phonological decoding skills (non-word reading) showed a larger MMN enhancement for notsel (HPP) as compared to notkel (LPP).

The general sequence of ERP activity elicited by non-words was similar in normal readers and dyslexics and was characterized by a broad positivity peaking around $160 \mathrm{~ms}$, followed by two negative responses peaking around 290 ("N2") and $510 \mathrm{~ms}$ ("N4") after stimulus onset. The broad positivity and the first negativity "N2" resemble the P1-N2 (sometimes called P1-N250) complex which dominates the auditory obligatory ERPS in children up to about 10 years of age (Bruneau and Gomot, 1998; Ceponiene et al., 2002; Csépe, 1995; Takeshita et al., 2002). ERP activity in the P1-N2 window shows substantial structural and functional changes with age and probably reflects auditory sensory processing until efficient adult cortical networks are established (Ceponiene et al., 2002; Takeshita et al., 2002). Activity in the "N4" window, in which also the MMN responses occurred, probably reflects continued processing of complex natural speech stimuli like the bisyllabic non-words used in the present experiment. Importantly, morphological differences in ERP activity elicited by our two non-word stimuli, i.e. stronger N2 and N4 responses for notsel than notkel, were identical in both subject groups, indicating a comparable neurophysiological processing of acoustic-phonetic stimulus differences in normal readers and dyslexics.

The present study specifically investigated the influence of phonotactic probability on MMN activity elicited by HPP vs. LPP non-words in normally reading and dyslexic children. In the following paragraphs we will discuss our MMN design and MMN findings in each of the subject groups. The MMN elicited by speech stimuli has been shown to reflect both acoustic change detection and phoneme-specific processes (Näätänen, 2001; Winkler et al., 1999). Because we aimed to study the neural correlates of a relatively high-level phonological process, we used a reversed MMN design, in which the contribution of acoustic processes is minimized (Eulitz and Lahiri, 2004; Chapter 4). First, MMN difference waves were derived from the ERP activity elicited by the same non-word presented as standard and deviant in separate experimental blocks. This provided a measure of MMN 
responses to HPP ws. LPP non-words independent of variation in ERP morphology that resulted from physical stimulus differences per se, i.e. enhanced ERP responses to notsel vs: notkel. Second, we used four utterances of each non-word stimulus so that both standard and deviant stimuli were acoustically variable (Figure 1). Such acoustic variability is typical in natural speech perception and reduces the likelihood that the MMN is determined by only one or a few particular acoustic features (Jacobsen et al, 2004). Third, across experimental blocks, the acoustic difference between standard and deviant stimuli was identical, with the only difference being the directionality of change, i.e. standard $\rightarrow$ deviant was either notsel $\rightarrow$ notkel or notkel $\rightarrow$ notsel. It is unlikely that our MMN findings can be fully explained by such a directionality effect. First, in a previous study, comparable MMN effects were found for the HPP vs. LPP non-word pair notsel-notkel and the acoustically more similar HPP vs. LPP non-word pair notsel-notfel (Chapter 4). If directionality of consonant change would have caused the enhanced MMN for notsel in the context of notkel, a smaller MMN would have been expected for notsel in the context of notfel. Moreover, an MMN enhancement was not observed in a third acoustic control experiment with stimuli having comparable phonotactic probability (so-fo). Second, it would be difficult to explain why dyslexic children would show a different acoustic directionality effect than normal readers but similar N2-N4 response enhancements to notsel vs. notkel stimuli. Given the amount of nonlinearities in the auditory system and the acoustic complexity of natural speech stimuli, however, a partial contribution of 'acoustic directionality' to the observed effects cannot be excluded completely. The phonological nature of our MMN findings was supported by the correlation between our neurophysiological measure of phonotactic probability and behavioural measures of subjects" phonological skills.

In normally reading children, notsel (HPP) elicited a clear MMN response around $340 \mathrm{~ms}$ after auditory stimulus deviation with a posterior-central distribution over the scalp, and a small leftward bias. In contrast, notkel (LPP) did not lead to a clear MMN effect. In our previous study we found a similarly enhanced MMN for a HPP non-words in adults (Chapter 4). These mismatch responses thus indicate comparable functional properties in normally reading children and adults and may suggest similar auditory cortical tuning to distributional frequencies of phoneme sequences in the speech input.

Consistent with previous developmental ERP investigations (e.g. Martin et al., 2003; Shafer et al., 2000, but see Ponton et al., 2000), the MMN effect in children was delayed as compared to that of adults, with mean peak latencies for both groups at respectively 340 and $165 \mathrm{~ms}$. A latency delay of $\sim 175 \mathrm{~ms}$ in $8-10 \mathrm{yr}$ old children is larger than the delays typically reported for simple tone stimuli (Martin et al., 2003; Shafer et al,. 2000). This increased delay probably relates to the complexity of our speech stimuli and is also consistent with previous findings indicating that $\mathrm{CV}$-syllables elicit an MMN response at about $\sim 350 \mathrm{~ms}$ in $\sim 9.5$ year old children (Csépe, 1995). The topographical distribution of the $\mathrm{MMN}$ response in normally reading children is more posterior than the fronto-central distribution typically reported for simple sound features in adults (Picton et al., 2000; Schröger, 1998). But different, e.g. more posterior, distributions have been also reported for the 
MMN in response to complex auditory (language) stimuli in adults (Gomes et al, 1997; Chapter 4) and in 8-10 year old children (Csépe, 1995).

Crucially, ERP difference waves of dyslexic children did not indicate the same sensitivity to phonotactic probability. Previously reported MMN results with dyslexic adults are variable and partly contradictory. Diminished MMN responses have been reported for e.g. speech but not tone stimuli (Schulte-Körne et al., 2001.), complex tone patterns (Kujala et al., 2000; Kujala et al., 2003) pitch changes but not duration changes of tones (Baldeweg et al., 1999) and pitch changes in the left but not the right auditory cortex (Renvall and Hari, 2003). Furthermore, dyslexic adolescents were found to have diminished MMN responses to speech but not to tone stimuli (Schulte-Körne et al., 1998). Our findings indicated anomalous phonological change detection responses in dyslexic children for a phoneme contrast that may be assumed to be normally processed at an acoustic-phonetic level (i.e. similarly enhanced N2-N4 responses to notsel vs. notkel stimuli in dyslexics and normal readers). These results support the hypothesis that developmental dyslexia involves a phonological deficit that may not be reducible to a low-level auditory/sensory deficit (Kronbichler et al., 2002; Ramus et al., 2003). In particular, they suggest that the phonological deficit involves an anomaly in implicit statistical learning and/or representation of the distributional frequencies of phoneme sequences in the language input. An interesting question for future studies would be whether this potential anomaly in implicit processing of phonological regularities specifically applies to phoneme sequences involving consonant clusters, or also to consonant-vowel clusters or single phonemes.

\section{Conclusion}

We used a reversed oddball design to investigate on-line phonological processing (in)capacities in dyslexic and normally reading children. Our findings suggest different levels of normal vs. anomalous speech processing in dyslexia. Non-words elicited a pattern of ERP activity that indicated normal acoustic processing of the phoneme contrast used in the present study (/ts/ vs. /tk/). However, ERP mismatch results indicated a strikingly different influence of phonotactic probability on the processing of these phoneme clusters. MMN responses of normal readers replicated results of adults (Chapter 4), and indicate auditory cortical tuning to statistical regularities of phoneme sequences. In contrast, MMN results of dyslexic subjects did not show the same neurophysiological sensitivity to variations in phonotactic probability. These findings indicate that the phonological problems often reported in dyslexia may already start at the implicit phonetic-phonological processing of speech.

\section{Acknowledgements:}

We are grateful to the Regionaal Instituut voor Dyslexie (RID), the Basisschool de Perroen and St. Aloysius for their support in acquiring subjects. The RID also provided us with the diagnostic data of the dyslexics. In addition we are grateful to Lisa van der Plas and Nadia Zellagui for assistance in data acquisition and Elia Formisano for useful comments on the manuscript. 


\section{References}

Adlard, A. and Hazan, $V$. (1998). Speech perception in children with specific reading difficulties (dyslexia). Quarterly Jounal of Experimental Psychology 51.4, 153-177.

Annett, $M .(1979)$. Family handedness in three generations predicted by the right shift theory. Annals of human genetics $12,479-491$.

Auer, J., E.T, and Luce, P. A. (2003). Probabilistic Phonotactics in Spoken Word Recognition. In University at Buffalo Working Papers on Language and Perception, C. T. MeLennan, P. A. Luce, G. Mauner, and ل. Charles-Luce, eds, pp, 164-202.

Bayen, R. H., Piepenbrock, R., and Gulikers, L. (1995). The CELEX Lexical Database (Release 2) [CD-ROM] (Philladelphia; PA, Linguistic Data Consortium, University of Pennsylvania [Distributor]).

Baldeweg, T., Richardson, A., Watkins, S, Foale, C., and Gruzelier, J. (1999). Impaired auditory frequency discrimnation in dyslexia detected with mismatch evoked potentials. Annals of Neurology 45, 495-503.

Blomert, L. (2002). Dyslexie: stand van zaken (Dyslexia: State of Affairs in the Netherlands). Report for the Dutch Ministry of Health. In Dyslexie naar een vergoedingsregeling, R. Reij, ed. (Amstelveen, Dutch Health Care Insurance Board), pp. publication number 03/144.

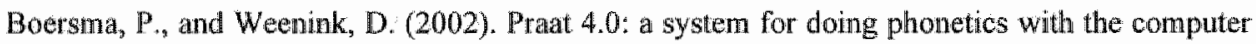
[Computer soltware] (Amsterdam, The Netherlands, Universiteit van Amsterdam).

Bonte, M. L., and Blomert, L. (2004). Developmental dyslexia: ERP correlates of anomalous phonological processing during spoken word recognition. Cognitive Brain Research $21,360-376$.

Brumeau, N., and Gomot, M. (1998). Auditory evoked potentials (N1 wave) as indices of cortical development. In Neuroimaging in child neuropsychiatric disorders, B. Garreau, ed. (Berlin, Springer), pp. 113-124.

Brus, B. T., and Voeten, M. J. M. (1999). Een-Minuut-Test (Lisse, Swets, \& Zeitlinger).

Ceponiene, R., Rinne, T., and Näatänen, R. (2002). Maturation of cortical sound processing as indexed by event-related potentials. Clinical Neurophysiology $113,870-882$.

Cheour, M., Ceponiene, R., Lehtokoski, A., Luuk, A.s Allik, J., Allho, K, and Naătänen, R. (1998). Development of language-specific phoneme representations in the infunt brain. Nature Neuroseience $1,351-353$.

Csepe, $\mathrm{V} .(1995)$. On the origin and development of the mismaich negativity. Ear and Hearing 16 , $91-104$.

Dehaene-Lambertz, G. (1997). Electrophysiological correlates of categorical phoneme perception in aduilts. Neuroreport $8,919-924$.

Dehaene-Lambertz, G., and Baillet, S. (1998). A phonological representation in the infant brain. Neuroreport $9,1885-1888$.

Eulitz, C, and Lahiri, A. (2004). Neurobiological evidence for abstract phonological representations in the mental lexicon during speech recognition. Journal of Cognitive Neuroscience $16,577-583$.

Gomes, H., Bernstein, R., Ritter, W., Vaughan, H. G., Jr., and Miller, J. (1997). Storage of feature conjunctions in transient auditory memory. Psychophysiology 34, 712-716. 
Hickok, G., and Poeppel, D. (2004) Dorsal and ventral streams: a framework for understanding aspects of the functional anatomy of language. Cognition $92,67-99$.

Howes, N. L. Bigler, E. D., Lawson, I. S., and Burlingame, G. M. (1999), Reading disability subtypes and the test of memory and leaming. Archives of Climical Neuropsychology 14,317 339.

Jacobsen, T., Schröger, E., and Alter, K. (2004). Pre-attentive perception of vowel phonemes from variable speech stimuli. Psychophysiology 41, 654-659.

Jusczyk, P. W. (1999). How infants begin to extract words from speech. Trends in Cognitive Sciences $3,323-328$.

Kronbichler, M., Hutzler, F., and Wimmer, H. (2002). Dyslexia: verbal impairments in the absence of magnocellular impairnents. Neuroreport $13,617-620$.

Kujala, T., Belitz, S., Tervaniemi, M., and Näätänen, R. (2003). Auditory sensory memory disorder in dyslexic adults as indexed by the mismatch negativity. European Journal of Neuroscience 17, 1323-1327.

Kujala, T., Myllyviita, K., Tervaniemi, M., Alho, K., Kallio, J., and Naatäanen, R. (2000). Basic auditory dysfunction in dyslexia as demonstrated by brain activity measurements. Psychophysiology 37, 262-266.

Martin, B. A., Shafer, V. L., Mor, M. L., Kreuzer, J. A., and Kurtzberg, D. (2003). Maturation of mismatch negativity: a scalp current density analysis. Ear and Hearing 24, 463-471.

McCandliss, B. D., and Noble, K. G. (2003). The development of reading impaiment: a cognitive neuroscience model. Mental Retardation and Developmental Disabilities Research Reviews 9 , $196-204$.

Mody, M., Studdert-Kennedy, M.; and Brady, S. (1997). Speech perception delicits in poor readers: auditory processing or phonological coding? Journal of Experimental Child Psychology 64, 199-231.

Näatanen, R. (2001). The perception of speech sounds by the human brain as reflected by the mismatch negativity (MMN) and its magnetic equivalent (MMNm). Psychophysiology 38, 1-21.

Näătanen, R., Lehtokoski, A., Lennes, M., Cheour, M., Huotilainen, M., livonen, A., Vainio, M., Alku, P., Ilmoniemi, R. J ., Luuk, A., et al. (1997). Language-specific phoneme representations revealed by electric and magnetic brain responses. Nature $385,432-434$.

Näătầnen, R., Tervaniemi, M., Sussman, E., Paavilainen, P., and Winkler, 1. (2001). "Primitive intelligence" in the auditory cortex. Trends in Neurosciences $24,283-288$.

National Research Council (1998). Report on preventing reading difficulties in young children (Washington DC, National Academy Press).

Nicolson, R. I., Fawcett, A. J., and Dean, P. (2001). Developmental dyslexia: the cerebellar deficit hypothesis. Trends in Neurosciences 24,508-511.

Nuwer, M. R., Comi, G., Emerson, R., Fuglsang-Frederiksen, A., Guerit, J. M., Hiturichs, H., Ikeda, A., Luccas, F. J., and Rappelsburger, P. (1998). IFCN standards for digital recording of clinical EEG. International Federation of Clinical Neurophysiology. Electroencephalography and Clinical Neurophysiology 106, 259-261.

O'Neill, M. E., and Douglas, V. I. (1991). Study strategies and story recall in attention deficit disorder and reading disability. Journal of Abnormal Child Psychol 19,671-692. 
Pennington, B. F. (1990). The genetics of dyslexia Journal of Child Psychology and Psychiatry $31_{\mathrm{s}} 193-201$.

Picton, T. W., Alain, C., Otten, L., Ritter, W., and Achim, A. (2000). Mismatch negativity: different water in the same river. Audiology and Neurootology 5, 111-139.

Ponton, C. W., Eggemiont, J. J., Don, M., Waring, M. D., Kwong, B, Cumingham, J., and Trautwein, P. (2000). Maturation of the mismatch negativity: effects of profound deafness and cochlear implant use. Audiology and Neurootology 5, 167-185.

Ramus, F., Rosen, 5., Dakin, S. C., Day, B. Li, Castellote, J. M., White, S., and Frith, U. (2003). Theories of developmental dyslexia: insights from a multiple case study of dyslexic adults: Brain $126,841-865$.

Raven, J., Raven, J. C., and Court, J. H. (1998). Coloured Progressive Matrices, 1998 edn (Oxford, Oxford Psychologists Press Ltd).

Reid Lyon, G. ( $\$ 995)$. Toward a definition of dyslexia. Amals of Dyslexia 45, 3-27.

Renvall, H, and Hari, $R$, (2003). Diminished auditory mismatch fields in dyslexic adults. Annals of Neurology $53,551-557$.

Saffran, J. R., Aslin, R. N., and Newport, E. L. (1996). Statistical learning by 8-month-old infants. Science $274,1926-1928$.

Schroger, E. (1998), Measurement and interpretation of the mismatch negativity. Behavior Research Methods, Instruments and Computers 30, 131-145.

Schulte-Korne, G., Deimel, W., Bartling, J, and Remschmidt, H. (1998). Auditory processing and dyslexia: evidence for a specific speech processing deficit. Neuroreport 9, 337-340.

Schulte-Kone, G., Deimel, W., Bartling, J., and Remschmidt, H. (2001). Speech perception deficit in dyslexic adults as measured by mismatch negativity (MMN). International Journal of Psychophysiology 40, 77-87.

Semlitsch, H. V., Anderer, P., Schuster, P., and Presslich, O. (1986). A solution for reliable and valid reduction of ocular artifacts, applied to the P300 ERP. Psychophysiology 23, 695-703.

Shafer, V. L., Mor, M. L., Kreuzer, J. A., and Kurtzberg, D. (2000). Maturation of mismatch negativity in school-age children. Ear and Hearing $21,242-251$.

Snowling, M. J. (2000). Dyslexia, 2nd edn (Oxford UK, Blackwell Publishers).

Stein, J., and Walsh, V. (1997). To see but not to read; the magnocellular theory of dyslexia. Trends in Neurosciences $20,147-152$

Takeshita, K. Nagamine, T., Thuy, D. H., Satow, T., Matsuhashi, M., Yamamoto, J., Takayama, M. Fujiwara, N., and Shibasaki, H. (2002). Maturational change of parallel auditory processing in school aged children revealed by simultaneous recording of magnetic and electric cortical responses. Clinical Neurophysiology 113, 1470-1484.

Temple, E. (2002). Brain mechanisms in normal and dyslexic readers. Current Opinion in Neurobiology $12,178-183$.

Tijms, $J$ (2004). Verbal Memory and phonological processing in dyslexia. Journal of Research in Reading $27,300-310$.

Trask, R. L. (1996). A dictionary of phonetics and phonology (London, Routledge). 
Van den Bos, K. P., lutje Spelberg, H. C., Scheepsina, A.J. M, and de Vries, I R. (1999) De Klepel (Lisse, Swets, \& Zeitlinger).

Winkler, I., Lehtokoski, A., Alku, P., Vainio, M., Czigler, I, Csepe, V., Aaltonen, O, Raino, I., Allo, K., Lang, H. ef al. (1999). Pre-attentive detection of vowel contrasts utilizes both phonetic and auditory menory representations. Cognitive Brain Research 7,357-369.

WISC-R projectgroep: Haasen V., P. P., De Bruyn, E. E. J, Pijl, Y. J., Poortinga, Y. H. Spelberg, H. C., Van der Steene, G., Coetsier, P., Spoelders-Claes, R., and Stinissen, J. (1986). WISC - R, Nederlandstalige nitgave (Lisse, Swets \& Zeitlinger). 


\title{
Chapter 6
}

\section{Time course of top-down and bottom-up influences on syllable processing in the auditory cortex ${ }^{10}$}

\begin{abstract}
In speech perception, extraction of meaning from complex streams of sounds is surprisingly fast and efficient. By tracking the neural time course of syllable processing with magnetoencephalography we show that this continuous construction of meaning-based representations is aided by both top-down (context-based) expectations and bottom-up (acousticphonetic) cues in the speech signal. Syllables elicited a sustained response at 200-600 ms ('N400m') which became most similar to that evoked by words when the expectation for meaningful speech was increased by presenting the syllables among words and sentences or using sentenceinitial syllables. This word-like cortical processing of meaningless syllables emerged at the build-up of the $\mathrm{N} 400 \mathrm{~m}$ response, $200-300 \mathrm{~ms}$ after speech onset, during the transition from perceptual to lexicalsemantic analysis. These findings show that the efficiency of meaningbased analysis of speech is subserved by a cortical system finely tuned to lexically relevant acoustic-phonetic and contextual cues.
\end{abstract}

\footnotetext{
10 This chapter is based on Bonte, M., Parviainen, T., Hytönen, K., and Salmelin, R (2005). Time course of top-down and bottom-ip influences on syllable processing in the auditory cortex.

Cerebral Cortex, in press.
} 


\section{Introduction}

The brain system underlying spoken language comprehension is exposed to a contimuously changing stream of speech sounds from which meaning must be extracted. Linguistic context and acoustic-phonetic features of the speech signal provide top-down and bottom-up cues that may be used to predict incoming information, enabling the fast and automatic recognition of up to 150 words per minute in healthy adults. The present study utilizes the high temporal resolution of magnetoencephalography (MEG) to investigate the influence of lexical-semantic context (top-down information) and acoustic-phonetic cues (bottom-up information) on the time course of the neural processing of natural speech.

MEG and electroencephalography (EEG) methods have been crucial in characterizing the time course of neural systems involved in different aspects of speech processing including those related to the processing of acoustic-phonetic (Eggermont and Ponton, 2002), phonological and semantic information (Kutas and Schmitt, 2003). MEG studies have shown that acoustic-phonetic features of speech modulate activity in non-primary auditory cortex from $50-100 \mathrm{~ms}$ onwards, as reflected in a robust response that emerges $100 \mathrm{~ms}$ after sound onset and is usually referred to as the N100/N100m (Kuriki and Murase, 1989; Poeppel et al., 1996; Obleser et al, 2004; Parviainen et al., 2005). Converging evidence from hemodynamic brain imaging studies suggests that the neural processing of acousticphonetic features specifically involves posterior superior temporal areas in the left hemisphere (Hickok and Poeppel, 2000; Scott and Johnsiude, 2003). The onset of language specific phonetic-phonological analysis has been estimated at about 100 $200 \mathrm{~ms}$. In this time window, an $\mathrm{MEG} / \mathrm{EEG}$ response associated with mnemonic functions of the auditory association cortex, i.e., the mismatch negativity (MMN), indicates access to phonological categories (Phillips et al, 2000; Vihla et al., 2000), and distinct processing of native vs. non-native phonetic contrasts (Näätänen et al., 1997; Cheour et al., 1998; Winkler et al., 1999). This is approximately the level to which cortical analysis proceeds when the stimuli are small sets of synthetic vowels or consonant-vowel (CV) syllables presented in passive paradigms or using simple perceptual tasks, as has been typically the case in these previous studies of early perceptual aspects of speech processing.

Words and word-like speech stimuli further evoke a sustained activation that starts at about $200 \mathrm{~ms}$ after stimulus onset, reaches the maximum at about $400 \mathrm{~ms}$, and lasts until 600-800 ms (Kutas and Federmeier, 2000). MEG reports based on equivalent current dipole (ECD) modelling associate this so-called $\mathrm{N} 400 / \mathrm{N} 400 \mathrm{~m}$ response (Kutas and Hillyard, 1980) with activation of the superior temporal cortex, in the immediate vicinity of the auditory cortex (Helenius et al., 2002; Kujala et al., 2004). Distributed source modelling of MEG data (Marinkovic et al,, 2003) suggests that neural activity underlying the $N 400$ response may additionally extend into (left) anterior temporal and frontal areas.

The N400 response probably reflects multiple processes, ranging from phonological analysis to lexical access and semantic processing. Facilitating factors like semantic or phonological priming tend to reduce the N400 amplitude (Van Petten et al., 1999; Dumay et al., 2001; Helenius et al., 2002; Perrin and GarciaLarrea, 2003; Bonte and Blomert, 2004). A review of previous studies suggests a rather natural division at about $350-400 \mathrm{~ms}$, around the $\mathrm{N} 400$ maximum, reflecting 
a gradual shift from predominantly phonological to predominantly semantic processing. Evidence for initial phonological analysis and lexical access in the onset window of the N400 comes from studies using a variant of the classical N400 sentence paradigm where the final word is semantically wrong (Kutas and Hillyard, 1980) but shares its initial phonemes with the expected word. This initial phonological congruency results in a delayed onset of the semantic $N 400$ effect (Van Petten et al., 1999; Helenius et al., 2002) or in a separate event-related response around 200-350 ms, preceding the N400 (Connolly and Phillips, 1994; Hagoort and Brown, 2000; Van den Brink et al, 2001). Furthermore, recent studies on the neural time course of spoken word recognition in dyslexics, who experience difficulties in phonological processing, have demonstrated specific abnormalities at 100-300 ms, prior to and during the onset of the $\mathrm{N} 400$, but not in later $\mathrm{N} 400$ windows (Helenius et al., 2002; Bonte and Blomert, 2004). These later windows probably reflect further lexical processing. For example, the latency of the N400 response maximum has been shown to depend on the time point at which the acoustic signal can only represent one particular word, i.e., the latency is delayed when this recognition point occurs later within the word (O'Rourke and Holcomb, 2002).

In the present MEG study we examined in detail the cortical processing of syllables in the time window from 200 to $350 \mathrm{~ms}$, when the utterance is processed as speech but its lexical-semantic content has not yet been established. Our stimuli of interest were natural Finnish CV syllables, potentially meaningful, but only if followed by further speech input. We assumed that increasing the expectation for a meaningful utterance would result in an increasingly word-like sustained $N 400 \mathrm{~m}$ response to these syllables. In natural speech, expectation may be built both by the linguistic context and by subtle acoustic-phonetic cues in the utterances. Here, we studied the influence of linguistic context (top-down) by varying the probability that the syllable was part of a meaningful utterance, i.e., $\mathrm{CV}$ syllables were presented in two different contexts, together with complete sentences and sentence-initial words (context) and as a separate sequence of syllables only (isolation). We studied the influence of acoustic-phonetic cues (bottom-up) by comparing $\mathrm{CV}$ syllables pronounced separately $(s y l)$ and $\mathrm{CV}$ syllables cut from the beginning of complete sentences (sylsent) (Figure 1). These two types of syllables contained different acoustic-phonetic cues that may signal the absence or presence of subsequent speech input. 

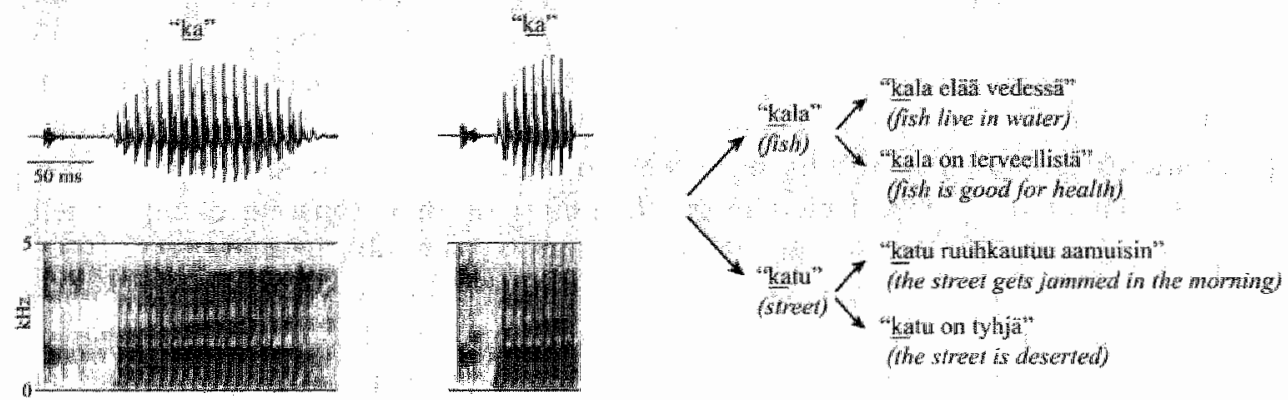

Figure 1. Stimuli used in the study.

(A) Syllables pronounced separately $(s y)$, (B) sentence-initial syllables (sy/sent), (C) words, and (D) sentences. In the complete stimulus set, two words shared the same initial syllable and two sentences the sarne initiall word. Examples of waweforms (upper rows) and spectrograms (lower rows) are given for each syllable type.

\section{Methods}

\section{Subjects}

Ten healthy Finnish-speaking members of laboratory personnel ( 5 females and 5 males; $23-29$ yrs, mean $25.5 \mathrm{yrs}$ ) took part in the study. Nine subjects were right handed, one ambidextrous. None of the subjects had a history of hearing loss or neurological abnormalities. Informed consent was obtained from all subjects, in agreement with the prior approval of the Helsinki and Uusimaa Ethics Committee.

\section{Stimuli}

Stimuli were 31 meaningless Finnish consonant-vowel (CV) syllables, e.g., "ki", 62 monomorphemic bisyllabic words (CVCV) starting with the same set of syllables, e.g." "kivi" ("stone"), and 124 sentences starting with the same set of words, e.g., "kivi putoaa maahan" ("The stone falls on the ground"). In the total stimulus set, two words shared the same initial CV syllable and two sentences shared the same initial word (see Figure 1). In this way, subjects would not expect one specific word or sentence upon hearing a syllable or word. We used two types of syllable stimuli. Words and one type of syllable stimuli (sylsent) were cut from the speech signal of the 124 sentences, resulting in two utterances of each word $(2 \times 62)$ and four utterances of each syllable $(4 \times 31)$. The second type of syllable stimuli $(s y)$ consisted of the same 31 syllables pronounced separately (again 4 utterances each).

The stimuli were spoken by a male native Finnish speaker and recorded at a sampling rate of $44.01 \mathrm{kHz}$ on a DAT recorder in an anechoic chamber (Acoustics Laboratory, Helsinki University of Technology). The digitized stimuli were D/A converted with a 16 bit resolution, bandpass filtered $(80 \mathrm{~Hz}$ to $10.5 \mathrm{kHz})$ and resampled at $22.05 \mathrm{kHz}$. We used a speech waveform editor (PRAAT 4.0: Boersma and Weenink, 2002) to determine acoustic onsets and offsets of syllables, words 
and sentences. For syllables and words cut from sentences, amplitude over the final $10 \mathrm{~ms}$ was tapered to zero to avoid acoustic transients (clicks) that would be created by a sharp cut-off. The overall sound intensity level was numerically equated across stimuli to generate equal ms values. The mean (SD) acoustical duration of syllables pronounced separately (syl) was $2 \rrbracket 2(45) \mathrm{ms}$, sentence-initial syllables (sylsent) 129 (45) $\mathrm{ms}$, words 275 (48) $\mathrm{ms}$, and sentences 1490 (171) ms. Stimulus length differed significantly between the two syllable types $(P<0.001)$, i.e., sy/sent were on average $83 \mathrm{~ms}$ shorter than syl. Furthermore, mean pitch was significantly higher for sylsent $=143(53) \mathrm{Hz}$ than for $s y l=124(13) \mathrm{Hz}(P<0.001)$.

\section{Experimental design and procedure}

Bottom-up effects on syllable processing were studied by comparing the syllables pronounced separately (syl) vs. sentence-initial syllables (sylsent). Top-down effects were investigated by comparing the processing of these syllables in two types of experimental blocks: in one block both syllable types were presented together with words and sentences (context) and in two blocks each syllable type was presented in isolation (isolation). In the three experimental blocks, stimuli were presented in a pseudo-random order, i.e., two consecutive stimuli were not allowed to form an existing word or sentence and there had to be at least five intervening stimuli between the repetition of identical syllables or words. In order to maintain a stable attention level across the experimental blocks, the subject's task was to repeat the previous stimulus (which could be any of the stimulus types) whenever they heard a beep signal ( $1 \mathrm{kHz}$ tone). The beep signal occurred in $6.5 \%$ of the trials (about once every 16 stimuli). Subject's responses were monitored on-line by the experimenter. All subjects correctly repeated the stimuli. The stimulus following a beep signal was not included in the analysis. Stimuli were presented binaurally at a comfortable listening level. The interstimulus interval (ISI) was 2 seconds for two consecutive experimental stimuli and 4 seconds after a beep signal. The total measurement time was about 40 minutes $(20 \mathrm{~min}$. context block and $2 \times 7 \mathrm{~min}$. isolation blocks). Subjects were given a short break every 5-8 minutes.

\section{MEG recording and data analysis}

MEG recordings were conducted in a magnetically shielded room using a Vectorview ${ }^{\mathrm{TM}}$ whole-head system (Neuromag Ltd., Helsinki, Finland). The device contains 102 triple sensor elements composed of two orthogonal planatr gradiometers and one magnetometer. The signals were bandpass filtered at 0.03 $200 \mathrm{~Hz}$ and digitized at $600 \mathrm{~Hz}$. The raw data was stored for off-line analysis. MEG signals were averaged on-line across trials, over an interval ranging from $200 \mathrm{~ms}$ before until $800 \mathrm{~ms}$ after stimulus onset. During the measurement, horizontal and vertical eye-movements were monitored and trials with $M E G$ or EOG signal amplitude exceeding $3000 \mathrm{fT} / \mathrm{cm}$ or $\pm 150 \mu \mathrm{V}$, respectively, were discarded. At least 100 artefact-free trials were collected for each stimulus category. The averaged MEG responses were baseline corrected to the $200 \mathrm{~ms}$ interval immediately preceding the stimulus onset and low-pass filtered at $40 \mathrm{~Hz}$.

To obtain an initial overview of the results, we calculated areal mean signals of 1) four gradiometer pairs over the left temporal lobe and 2) four gradiometer pairs over the right temporal lobe that showed the strongest response. We first 
computed vector sums by squaring the MEG signals of each gradiometer pair, summing these signals together, and then calculating the square root of this sum. The areal mean signals were computed by averaging these vector sums for each area of interest (left and right temporal lobe). The areal mean signals were computed from $400 \mathrm{~ms}$ before to $2000 \mathrm{~ms}$ after stimulus onset, individually for each subject. Finally, we calculated overall group averages. Because of the way the sensor-level areal mean signals are calculated (square root of sum of squared signals) they always have a positive value $(>0)$.

The main analysis involved an individual estimation of the time course of neural activity in distinct brain areas using Equivalent Current Dipole (ECD) analysis (Hämäläinen et al., 1993). The ECD analysis was performed up to $800 \mathrm{~ms}$ after stimulus onset. An ECD represents the mean location and strength of activation in a given brain area and the orientation of current flow therein. Dipoles were localized individually for each subject using a subset of planar gradiometers that ideally covered the distinct magnetic field patterns. After ECDs had been localized they were included into a multidipole model and, keeping their orientation fixed, their amplitudes were allowed to be adjusted to achieve maximum explanation for the measured whole-head data. All dipoles included in the model could be localized reliably with goodness-of-fit values exceeding $80-90 \%$. The final models were composed of 2-5 ECDs (mean 4). In each individual, the same set of ECDs accounted for the pattern of auditory cortical activation evoked by all stimulus categories up to and including the $\mathrm{N} 400 \mathrm{~m}$ window. The ECDs explaining the field patterns around $100 \mathrm{~ms}(\mathrm{~N} 100 \mathrm{~m})$ and $400 \mathrm{~ms}(\mathrm{~N} 400 \mathrm{~m})$ were very similar both in location (mean Euclidean distance $=8 \mathrm{~mm}$ ) and orientation (mean difference in orientation $=8$ degrees). In order to prevent spurious interactions between these two ECDs, both of these source areas were represented by a single ECD (at $\mathrm{N} 400 \mathrm{~m}$ ) in the multidipole model.

The location of the ECDs was defined in head coordinates that were set by the nasion and two reference points anterior to the ear canals: $x$-axis is directed from the left (negative) to the right (positive) preauricular point, $y$-axis towards the nasion, and z-axis towards the vertex. Prior to the MEG measurement, the locations of four Head Position Indicator (HPI) coils attached to the subject's head were measured with a three-dimensional digitizer (Polhemus, Colchester, VT, USA). Before each MEG session, the HPI coils were briefly energized to determine their location with respect to the MEG helmet.

For visualization purposes, the MR images of the individual subjects' brains were transformed into that of one representative subject (elastic transformation: Schormann et al., 1996; Woods et al., 1998). The individual ECDs were transformed accordingly to display the sources in a common coordinate system.

Strength and timing of the activation in the source areas as represented by the time course of the ECDs (source waveforms) were analyzed using repeatedmeasures ANOVA with linguistic context (context vs. isolation) and syllable type (sylsent vs. syl) as within subject factors. Hemispheric differences were tested using 


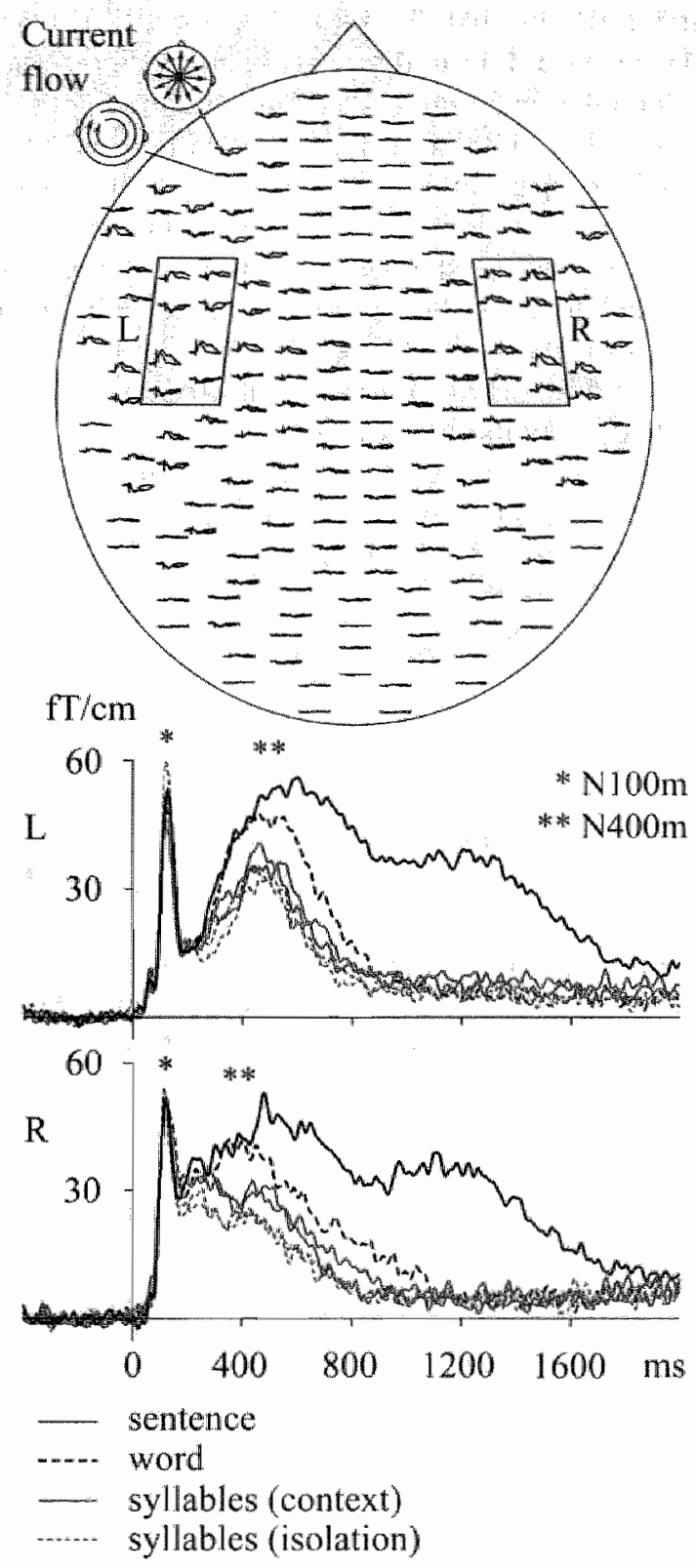

Figure 2. Grand average waveforms and areal mean signals of all 10 subjects. Areal mean signals were calculated for two sets of four MEG gradioneter pairs, indicated by parallelograms, over the left $(\mathrm{L})$ and right $(\mathrm{R})$ temporal lobes. Syllables include both syllable types (syl and sylsemt) presented in the context of word and sontences (contex) and as a separate sequence of syllables only (isolation). 
hemisphere (left vs. right) as an additional within subject factor; this comparison was justified by first verifying that the distance of the ECDs from the centre of the head (and the MEG sensors) did not differ between the hemispheres. Estimation of activation strength included maximum activation and area under the ascending and descending slope of the $\mathrm{N} 400 \mathrm{~m}$ response. Area measures were calculated individually for each subject and separately for each condition. In the left hemisphere, the ascending window was defined as the time window between the latency at which the ascending slope reached $25 \%$ of the maximum activation (mean $260 \mathrm{~ms}$ ) and the latency at the maximum. In the right hemisphere, where the $\mathrm{N} 400 \mathrm{~m}$ often started directly at the $\mathrm{N} 100 \mathrm{~m}$ response, the ascending window was defined as the time window between $200 \mathrm{~ms}$ and the latency at the maximum. In both hemispheres, the descending window was defined as the time window between the latency at the maximum and the latency at which the descending slope reached $25 \%$ of the maximum amplitude. Latency values included latency at the maximum activation, onset latency (latency at $25 \%$ of the maximum at the ascending slope), and the latencies at $50 \%$ of the maximum activation at the ascending and the descending slopes of the $\mathrm{N} 400 \mathrm{~m}$.

\section{Results}

\section{Overall effects: areal mean signals}

Figure 2 displays the overall time course of MEG signals averaged across subjects. Both at the group level and in the individual subjects activity concentrated over the left and right temporal lobes. The areal mean signals in these regions of interest are plotted in the lower panel of Figure 2. All stimuli elicited a clear and comparable $\mathrm{N} 100 \mathrm{~m}$ followed by a sustained response that reached the maximum about $450 \mathrm{~ms}$ after stimulus onset. Sentences elicited a strong sustained activity, including a second maximum at $1100-1200 \mathrm{~ms}$, which returned to the baseline at about $1750 \mathrm{~ms}$ after stimulus onset, i.e., on average $250 \mathrm{~ms}$ after sentence ending.

Visual inspection of the areal mean signals elicited by the different stimuli suggested specific response characteristics and time windows of interest for further statistical testing on the time courses of activation at the source level. First, the largest experimental effects seemed to occur between 200 and $800 \mathrm{~ms}$, in the time window of the sustained response. Second, the sustained response elicited by syllables, words and sentences seemed to show differences in both activation strength and timing. As expected, the sustained response was smallest and of shortest duration for syllables and was increased for words and sentences. Third, visual inspection suggested that the different stimulus conditions resulted in dissimilar patterns in the ascending vs. descending slopes of the sustained response. Fourth, in the right hemisphere the sustained activity often started directly at the N100m response, rendering the definition of an $N 400 \mathrm{~m}$ response less straightforward than in the left hemisphere. The areal mean signals thus suggest hemispheric differences in stimulus processing. 


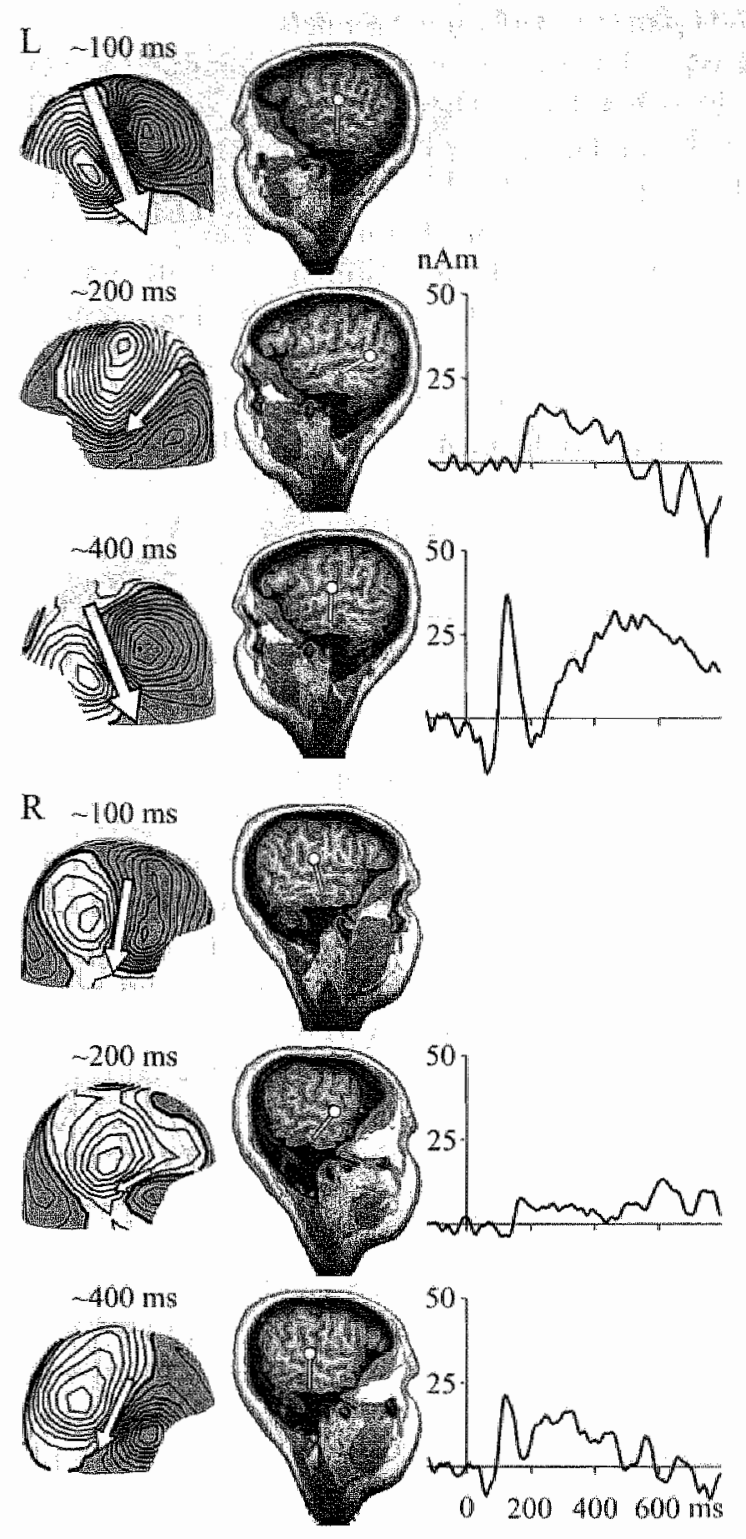

Figure 3. Typical MEG field patterns, equivalent current dipole (ECD) localization and corresponding source waveforms in response to words (single subject).

All subjects showed similar field patterns and dipole localization in the $\mathrm{N} 400 \mathrm{~m}$ window. The sources of $\mathrm{N} 100 \mathrm{~m}$ and $\mathrm{N} 400 \mathrm{~m}$ were very similar in location and orientation. The $\mathrm{N} 400 \mathrm{~m}$ source thus accounted for most of the activity in the earlier N100m window. An ECD could also be reliably determined around $200 \mathrm{~ms}$ in 7 subjects in the left hemisphere (L) and in 9 subjects in the right hemisphere $(R)$. The localization of this source showed large inter-subject variability, especially in the right hemisphere. 


\section{Overall effects: field patterns and dipole models}

Figure 3 shows a typical sequence of activation elicited by words in the left and right hemisphere, in one subject. There were clear dipolar field patterns at $\sim 100$, $\sim 200$ and $\sim 400 \mathrm{~ms}$. A similar sequence of MEG activity was obtained for syllables and sentences. The bilateral dipolar fields around $\sim 100 \mathrm{~ms}(\mathrm{~N} 100 \mathrm{~m})$ were characterized by a downward orientation of current flow perpendicular to the Sylvian fissure in both hemispheres, similarly in all subjects. ECD analysis indicated that this signal was generated by activation immediately posterior to Heschl's gyrus.

In the left hemisphere, the $N 100 \mathrm{~m}$ was followed by a field pattern at $-200 \mathrm{~ms}$ that typically reflected a strong posterior temporal source with the current flow oriented anteriorly and inferiorly, almost perpendicular to the direction of current flow in the N100m time window. Occasionally, the field pattern also suggested presence of a weaker inferior frontal component in this same time window, with an anterior-superior direction of current flow. In the right hemisphere, the field patterns showed more inter-subject variability in this time window but most often indicated an anterior temporal source. It was possible to localize an ECD around $200 \mathrm{~ms}$ in 7 subjects in the left hemisphere and in 9 subjects in the right hemisphere. A relatively large inter-subject variability in the location and orientation of these ECDs suggests that they reflected activity of a widespread network of brain areas. The corresponding source waveforms did not differentiate between stimulus conditions and are, therefore, not included in the further statistical analysis of top-down and bottom-up effects on syllable processing.

During the sustained activity peaking $\sim 400 \mathrm{~ms}$, all subjects showed clear bilateral field patterns with the current flow downward perpendicular to the Sylvian fissure (Figure 3). Figure 4 depicts the locations of the corresponding ECDs in all 10 subjects. The sources clustered around the left and right posterior superior temporal gyrus, on average $3 \mathrm{~mm}$ medially to the sources of the N100m (left $t(9)=$ $3.9, P<0.005$; right $t(9)=2.4, P<0.05$ ) but with no systematic differences along the anterior-posterior and superior-inferior axes. The orientation of current flow in the N100m and N400m time windows was essentially identical. Accordingly, the N400m sources also explained a major part of the N100m activity (see Figure 3 and Methods). The location, orientation and time course of the sources of the sustained response suggested that it corresponded to the $N 400 \mathrm{~m}$ reported in earlier MEG studies of semantic processing (e.g., Helenius et al., 2002). The $\mathrm{N} 400 \mathrm{~m}$ source waveforms for syllables, words and sentences (Figure 4) showed a pattern that was comparable to that of the areal mean signals over the left and right temporal lobes (Figure 2). 


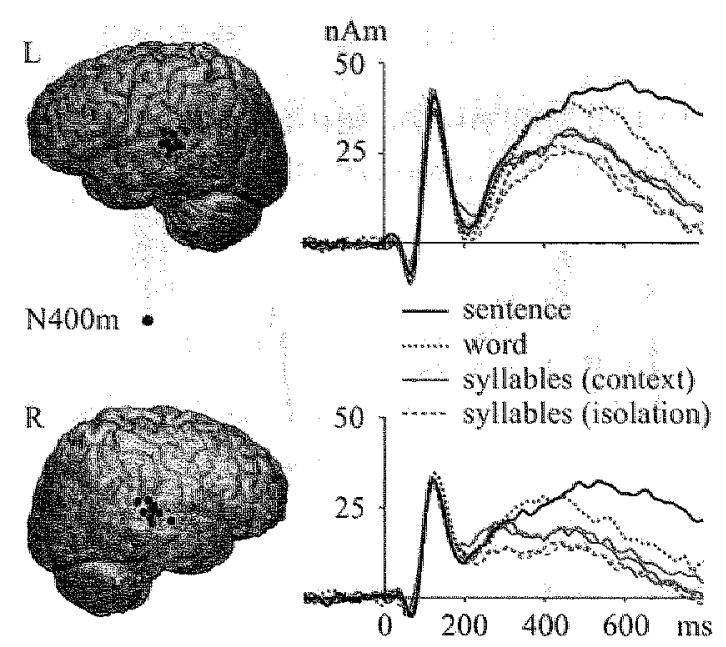

Figure 4. Locations and mean time course of the N400m sources.

Black dots indicate the individual sources for all 10 subjects in the left (L) and right ( $R$ ) posterior superior temporal areas. Syllables include both syllable types ( $s y /$ and sylsent) presented in the context of words and sentences (context) and as a separate sequence of syllables only (isolation).

\section{Top-down effects on syllable processing: context versus isolation}

Figure 5A depicts the mean time course of activation in the left and right $\mathrm{N} 100 \mathrm{~m} / \mathrm{N} 400 \mathrm{~m}$ source area when syllables cut from sentences $(s y / s e n t)$ and uttered separately $(s y l)$ were presented in the context of words and sentences (context) and when they were presented in isolation (isolation). The activation elicited by words is included for reference. Figure 5B shows the mean difference of the source waveforms (context-isolation) for each syllable type, indicating that there was stronger activation to syllables presented in context than isolation starting at about $200 \mathrm{~ms}$ and reaching the maximum at about $280 \mathrm{~ms}$, similarly in both hemispheres. In the left hemisphere, this enhancement was preceded by an opposite influence of context around $100 \mathrm{~ms}$, i.e., a weaker response to syllables when presented in context than isolation.

The N100m peak activation strength and latency were tested with a 2 (linguistic context) $\times 2$ (syllable type) $\times 2$ (hemisphere) repeated-measures ANOVA. Syllables evoked a weaker $\mathrm{N} 100 \mathrm{~m}$ response in context than isolation in the left hemisphere, but in the right hemisphere the responses were equal (Figure $6 \mathrm{~A})$, as indicated by significant context-by-hemisphere interaction $(F(1,9)=6.2, P$ $<0.05)$ and main effect of context in the left hemisphere $(F(\mathbb{1}, 9)=8.2, P<0.025)$. The peak latency of the N100m (Figure 6A), for sylsent stimuli in the right hemisphere, was about $10 \mathrm{~ms}$ later in context than isolation blocks (context by syllable type $(F(1,9)=6.0, P<0.05)$, post-hoc t-test for sylsent: context vs. isolation $t(9)=2.9, P<0.025$ ) 


\section{LEFT HEMISPHERE RIGHT HEMISPHERE}

\section{A) Grand average: context effect}
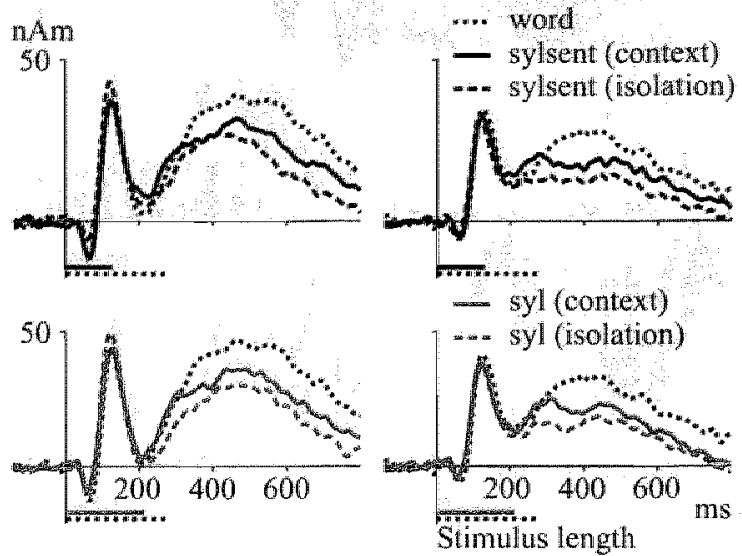

B) Difference waveforms: context - isolation

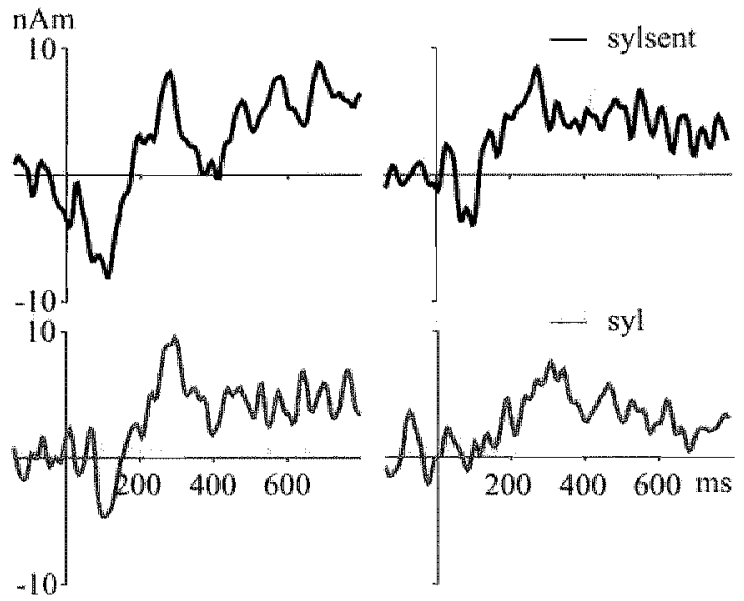

Figure 5. Top-down context effects on the mean time course of activation in the left and right $\mathrm{N} 100 \mathrm{~m} / \mathrm{N} 400 \mathrm{~m}$ source area.

(A) Grand average source waveforms of sentence-initial syllables (sy/sent) and syllables uttered separatelly $(s y)$ when presented in the context of words and sentences (context) and in isolation (isolation). The activation elicited by words is included for reference. The horizontal bars below each graph indicate the mean length of the stimuli. (B) Mean difference of the source waveforms (coment-isolation) for each syllable type. 


\section{LEFT HEMISPHERE RIGHT HEMISPHERE}

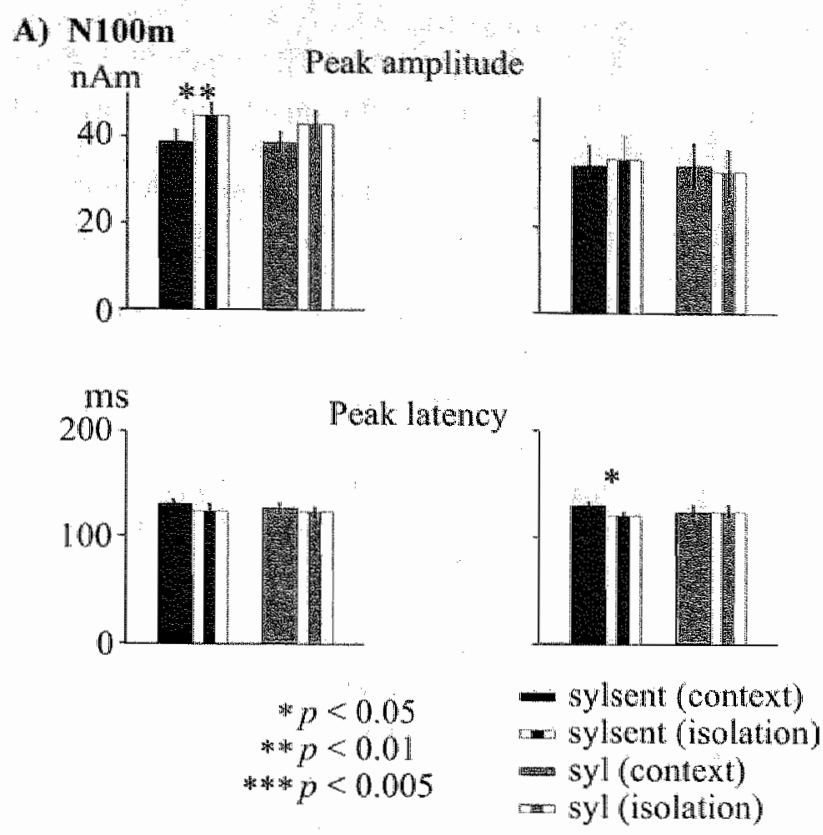

B) $\mathrm{N} 400 \mathrm{~m}$
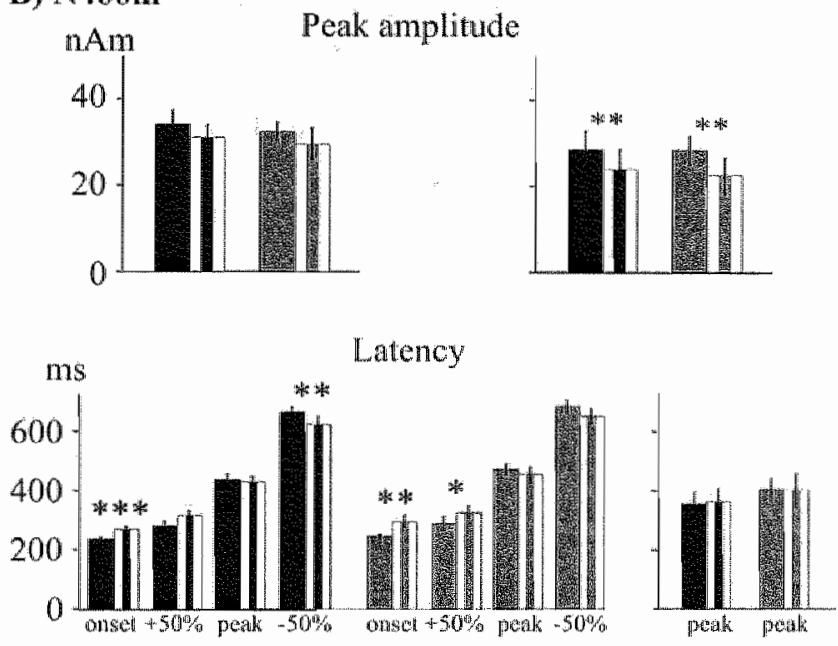

Figure 6. Activation strength and latency characteristics of the N100m and N $400 \mathrm{~m}$.

Mean amplitude and latency values of the (A) NI00m and (B) N400m are given for both syllable types (sylsent and syl) in context and isolation blocks in the left and right hemisphere. Error bars represent standard error of the meam. Asterisks indicate significant differences between conditions (post hoc t comparisons). 
The activation strength and latency at the $N 400 \mathrm{~m}$ response maximum were determined in both hemispheres and tested with a 2 (linguistic context) $\times 2$ (syllable type) $\times 2$ (hemisphere) repeated-measures ANOVA. In the left hemisphere, where the $\mathrm{N} 400 \mathrm{~m}$ response was clearly separate from the preceding $\mathrm{N} 100 \mathrm{~m}$ response, it was also possible to collect the latencies at the onset, and at $50 \%$ of the peak level on the ascending $(+50 \%)$ an descending $(-50 \%)$ slopes; the data were tested with a 2 (linguistic context) $\times 2$ (syllable type) repeated-measures ANOVA. As depicted in Figure $6 \mathrm{~B}$, syllables evoked stronger $\mathrm{N} 400 \mathrm{~m}$ activity in the left than right hemisphere (main effect of hemisphere $(F(1,9)=5.5, P<0.05$ ). Syllables also showed a stronger $\mathrm{N} 400 \mathrm{~m}$ response in context vs isolation blocks (main effect of linguistic context $(F(1,9)=10.3, P<0.025)$. This context effect was significant in the right hemisphere $(F(1,9)=12.6, P<0.01)$, with a similar trend in the left hemisphere $(F(1,9)=3.7, P<0.10)$.

As for the timing (Figure $6 \mathrm{~B}$ ), the $\mathrm{N} 400 \mathrm{~m}$ response in the left hemisphere started earlier and lasted longer for syllables presented in context than isolation blocks (main effect of eontext: onset latency $F(1,9)=20.2, P<0.005$; latency at $50 \%$ of the ascending flank $F(1,9)=4.9, P=0.05$, and at $50 \%$ of the descending flank $F(1,9)=11.0, P<0.01$ ). Context did not influence the $\mathrm{N} 400 \mathrm{~m}$ peak latency in either hemisphere. The $\mathrm{N} 400 \mathrm{~m}$ response tended to reach the peak later in the left than right hemisphere $(F(1,9)=3.3, P=0.10)$.

We also tested the ascending and descending slopes of the $\mathrm{N} 400 \mathrm{~m}$ separately by calculating the area under each flank in the left and right hemisphere (activation. times duration; see Methods). Figure 8 (context and isolation columns) illustrates that syllables evoked a stronger response when presented in context than in isolation, in both time windows and in both hemispheres (main effect of context: ascending window $F(1,9)=11.3, P<0.01$; descending window $F(1,9)=17.9, P<$ 0.005 ).

Interestingly, in the linguistic context, but not in isolation, the MEG signal elicited by both types of syllables seemed to follow the ascending flank of the $\mathrm{N} 400 \mathrm{~m}$ elicited by words until about $300 \mathrm{~ms}$ (Figure 5A). In order to test this observation, we calculated the slope of the MEG signal at 200-300 ms for each individual subject. A one-way ANOVA (3 levels: words, context, isolation) in the left hemisphere revealed a significant difference between conditions $(F(1,9)=3.3$, $P<0.05$ ). Post-hoc t-tests showed that the slope of the activity elicited by words was significantly different from those of syllables in isolation $(P<0.05)$ but not from those of syllables in context $(P=0.703)$. A similar difference in the right hemisphere did not reach significance because of larger variability.

In sum, top-down influence of linguistic context led to a stronger bilateral $\mathrm{N} 400 \mathrm{~m}$ with an additional effect on $\mathrm{N} 400 \mathrm{~m}$ latency in the left hemisphere, i.e., an earlier $\mathrm{N} 400 \mathrm{~m}$ onset and a longer duration. Strikingly, the MEG signal elicited by syllables followed the signal elicited by words along the ascending flank of the $\mathrm{N} 400 \mathrm{~m}$ only when syllables were presented in the linguistic context and not in isolation. 


\section{LEFT HEMISPHERE RTGHT HEMISPHERE}

A) Grand average: acoustic - phonetic effect
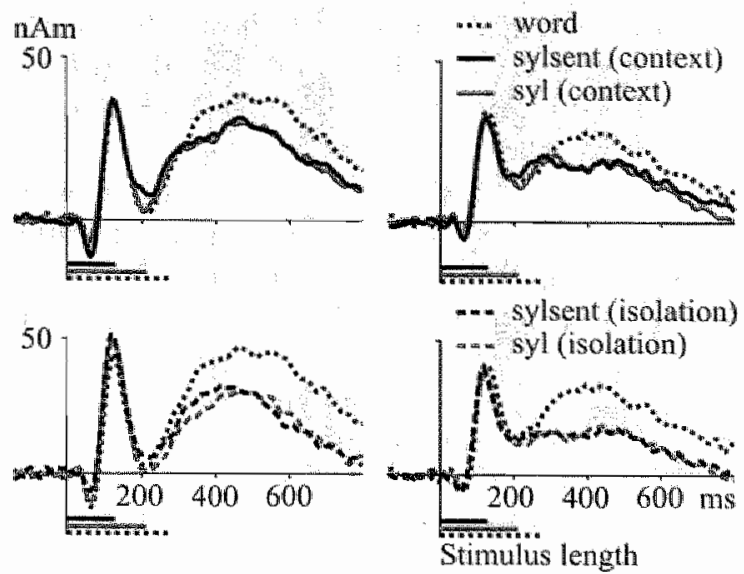

B) Difference waveforms: sylsent - syl

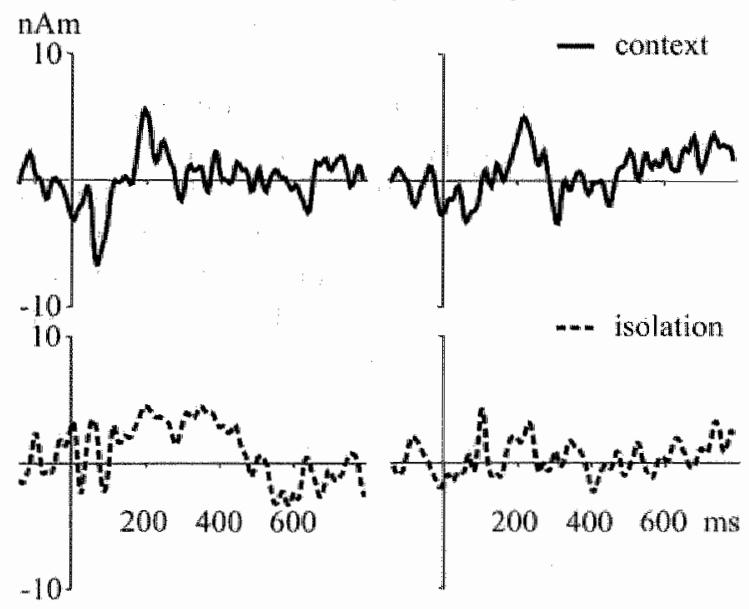

Figure 7. Bottom-up effects of acoustic-phonetic cues on the mean time course of activation in the left and right $\mathrm{N} 100 \mathrm{~m} / \mathrm{N} 400 \mathrm{~m}$ source area.

(A) Grand average source waveforms of sentence-initial syllables (sylsent) and syllables uttered separately (sy) in context and isolarion blocks. The activation elicited by words is included for reference. The horizontal bars below each graph indicate the mean length of the stimuli. (B) Mean difference of the source waveforms (sylsent-syl) for the context and isolation blocks. 


\section{Bottom-up effects on syllable processing: sylsent versus syl}

Figure $7 \mathrm{~A}$ illustrates the influence of bottom-up information by comparing the time course of the $N 100 \mathrm{~m} / \mathrm{N} 400 \mathrm{~m}$ source waveforms elicited by sentence-initial syllables (sylsent) vs. syllables pronounced separately (syl). The activation elicited by words is included for reference. Figure $7 \mathrm{~B}$ shows the mean difference of the source waveforms (sylsent-syl) for the context and isolation blocks, again concentrating around 200-300 ms but clearly weaker than for the top-down influence (cf. Figure 5).

The $N 100 \mathrm{~m}$ activation strength showed no effects of syllable type (Figure $6 \mathrm{~A}$, black vs. grey bars). As for timing, the right-hemisphere N100m was about $6 \mathrm{~ms}$ earlier to sylsent than syl stimuli but only when they were presented in isolation (context-by-syllable type interaction $(F(1,9)=6.0, P<0.05$ ), post-hoc t-test for sylsent vs, $s y l t(9)=3.7, P=0.005$ ). The maximum strength of the $\mathrm{N} 400 \mathrm{~m}$ response (Figure 6B, black vs, grey bars) did not differ between the syllable types. However, the peak latency of the $\mathrm{N} 400 \mathrm{~m}$ was about $29 \mathrm{~ms}$ shorter for sylsent than $\mathrm{syl}$, regardless of the context (main effect of syllable type $F(1,9)=5.3, P<0.05$ ). This effect was significant in the left hemisphere $(F(1,9)=6.0, P<0.05)$ and showed a trend in the same direction in the right hemisphere $(F(1,9)=3.3, P=0.10)$.

The separate test of area under the ascending and descending slopes of the $\mathrm{N} 400 \mathrm{~m}$ response (Figure 8, black vs. grey bars) showed that, in the left hemisphere, sy/sent elicited a significantly stronger response than $s y l$ in the ascending window of the N400m, whereas no significant effect of syllable type was found in the right hemisphere (main effect of syllable type $F(1,9)=5.1, P<0.05$; hemisphere-bycontext-by-syllable type interaction $F(1,9)=4.1, P=0.07$; main effects of syllable type in the left hemisphere $F(1,9)=5.2, P<0.05$ and in the right hemisphere $F(1,9)=1.1$, n.s.). The presence of both bottom-up and top-down factors, i.e., sylsent in context, led to the largest, most word-like response, whereas the absence of both factors, i.e., $s y l$ in isolation, led to the smallest, least word-like response. When syllables were presented in the linguistic context the bottom-up effect appeared to be partly occluded by the stronger top-down effect. Responses to sylsent were indeed significantly larger than responses to $s y l$ when they were presented in isolation $(r(9)=3.4, P<0.01)$ but not when presented in the linguistic context $(r(9)=0.6$, n.s. $)$.

In sum, bottom-up information of acoustic-phonetic cues in sylsent specifically increased neural activity during the build-up of the $N 400 \mathrm{~m}$ response in the left hemisphere. Furthermore, this bottom-up modulation was strongest when syllables were presented in isolation, that is, without the additional presence of the top-down influence of linguistic context. 

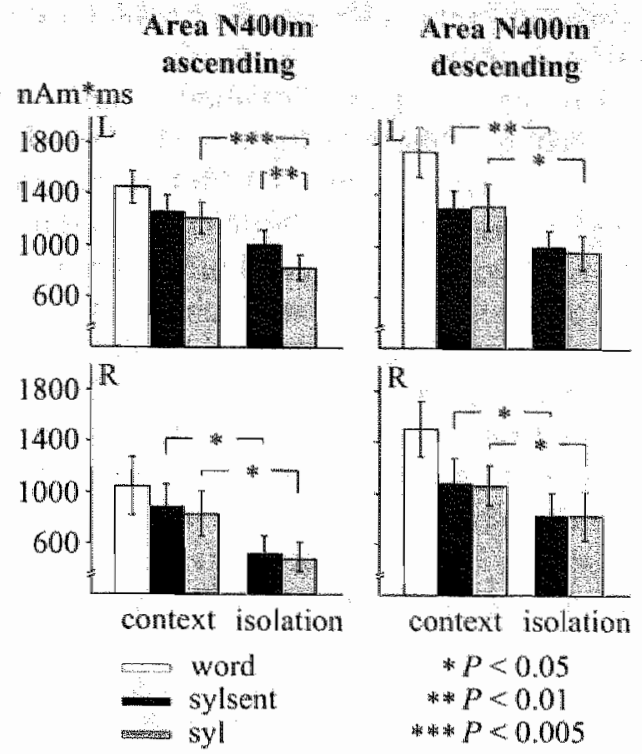

Figure 8. Mean area under the ascending and descending parts of the $N 400 \mathrm{~m}$ source waveform.

Mean area (activation strength multiplied by time) was determined separately in the left (L) and right (R) hemisphere. Error bars represent standard error of the mean. Asterisks indicate significant differences between conditions (post hoc t comparisons).

\section{Discussion}

We investigated neural correlates of speech comprehension by tracking the time course of MEG activation during attentive processing of potentially meaningful syllables as compared with that of words and sentences. Words evoked the expected sequence of cortical activity, characterized by two prominent MEG responses in bilateral superior temporal areas: a transient activity around $100 \mathrm{~ms}(\mathrm{~N} 100 \mathrm{~m})$ and a sustained activity at $200-600 \mathrm{~ms}(\mathrm{~N} 400 \mathrm{~m})$, reflecting the progression from perceptual to lexical-semantic analysis (Helenius et al., 2002; Marinkovic et al, 2003). Syllables did not only elicit a clear N100m response (Kuriki and Murase, 1989; Poeppel et al., 1996; Obleser et al., 2003; Parviainen et al., 2005), but also a sustained $\mathrm{N} 400 \mathrm{~m}$ activity, albeit with a relatively reduced amplitude. The striking finding that all syllables evoked an $\mathrm{N} 400 \mathrm{~m}$ response suggests that syllable processing may proceed at a relatively abstract linguistic level when using a large number of different natural speech syllables and an active target repetition task. Crucially, in the experimental conditions in which we increased the expectation for meaningful speech (i.e., by manipulating lexical-semantic context [context vs. isolation] and acoustic-phonetic cues [sy/sent vs. syl]) the $\mathrm{N} 400 \mathrm{~m}$ response evoked by syllables became more similar to the $\mathrm{N} 400 \mathrm{~m}$ evoked by words. This word-like neural processing of meaningless syllables was most prominent in the ascending window of the $\mathrm{N} 400 \mathrm{~m}$ at $200-300 \mathrm{~ms}$, thus supporting the view that this interval is 
crucial for cognitive processes at the interface of phonological and lexical-semantic analysis (Hagoort and Brown, 2000).

The abstract linguistic nature of the sustained neural activity evoked by our syllables is further illustrated by the similarity in the timing of the $N 400 \mathrm{~m}$ response to sentence-initial syllables (sylsent) and syllables pronounced separately (syl). Although stimulus length was -83 ms shorter for sylsent than $s y l$, the only significant latency difference was a $\sim 29 \mathrm{~ms}$ earlier $\mathrm{N} 400 \mathrm{~m}$ peak latency for sylsent than $s y l$ in the left hemisphere. Tone and vowel stimuli with a duration of 150-200 $\mathrm{ms}$ or longer have been reported to elicit stimulus-locked sustained activity lasting for the duration of the stimulus (Hari et al., 1989; Eulitz et al, 1995). The absence of such stimulus-locked differences in the present study supports the interpretation that syllable processing proceeded beyond this type of low-level perceptual analysis of physical stimulus characteristics.

Whereas cortical activity was clearly bilateral throughout the entire time window, the $\mathbb{N} 400 \mathrm{~m}$ response was somewhat stronger in the left hemisphere. Previous MEG studies have shown a strong left lateralization of the visual $\mathrm{N} 400 \mathrm{~m}$ response (Helenius et al., 1998; Halgren et al., 2002; Marinkovic et al., 2003), and a relatively small leftward bias for the auditory $\mathrm{N} 400 \mathrm{~m}$ (Helenius et al, 2002; Marinkovic et al., 2003; Kujala et al, 2004). Our N400m results corroborate this leftward bias, and suggest an important contribution of left temporal areas during access of meaning-based representations (Scott and Johnsrude, 2003).

The present study specifically investigated top-down and bottom-up effects on the neural processing of natural speech syllables. In the following paragraphs we will discuss these effects in turn. As for the top-down effects, so far, only a few studies have investigated the effects of context on the processing of speech sounds. Most of these studies have compared speech processing during passive listening vs. active tasks (Poeppel et al., 1996; Noesselt et al., 2003; Vihla and Salmelin, 2003) or during the performance of different types of experimental tasks (Szymanski et al., 1999; Obleser et al., 2004). As a consequence, these studies examined context effects which were directly related to distinct attentional demands of the experimental tasks employed. In contrast, we examined context effects on syllable processing independent of task demands as subjects performed the same general stimulus repetition task in all experimental blocks. This allowed us to highlight that the mere presence of words and sentences substantially changes the cortical processing of meaningless syllables. Most strikingly, only in this linguistic context, the MEG signal evoked by syllables followed the signal of words along the ascending flank of the $N 400 \mathrm{~m}$ until $\sim 300 \mathrm{~ms}$. This suggests that when the probability for meaningful speech is high, even meaningless syllables can trigger processes similar to those used in the construction of meaning-based representations.

Besides this specific context effect during the build-up of the $\mathrm{N} 400 \mathrm{~m}$ response, our results also indicated a more general effect of linguistic context. Syllables evoked a bilaterally enhanced $\mathrm{N} 400 \mathrm{~m}$ response when presented in the linguistic context vs. isolation. Importantly, this enhancement of the N400m response was not preceded by a similar enhancement in earlier time windows. In fact there was even some evidence for an opposite modulation of the $\mathrm{N} 100 \mathrm{~m}$ in the left hemisphere, i.e., an amplitude reduction in context vs. isolation. A context-dependent shift in the 
balance between neural activation underlying perceptual and higher-level cognitive processes may underlie these findings. For example, in a lexical-semantic context, brain areas engaged in meaning-based analysis of speech may show a generally enhanced level of activation (Noesselt et al, 2003). Moreover, our N100m findings imply that context-based expectations may modulate the processing of speech already at an early perceptual level. Correspondingly, a recent EEG study reported similarly early N100 reductions to auditory speech stimuli in predictive cross-modal (auditory-visual) contexts (Wassenhove et al., 2005).

Interestingly, the bottom-up cues as present in sentence-initial syllables (sylseni) led to specifically enhanced $\mathrm{N} 400 \mathrm{~m}$ activity in the left hemisphere. This suggests that left superior temporal areas may be tuned to acoustic-phonetic cues that are relevant for lexical access. Thereby the present observations extend previous fMRI findings which have associated these areas with the prelexical processing of phonetic cues and features of phonological significance in the perceiver's native language (Jäncke et al., 2002; Jacquemot et al., 2003; Gandour et $a l ., 2004)$. Additionally, our results identify a specific time window in which these bottom-up cues may modulate the neural processing of speech, i.e., about 200-350 after speech onset when phonetic-phonological processes access lexical-semantic representations.

Which acoustic-phonetic cues underlie the present bottom-up effects? The two syllable types differed in several physical characteristics, with two prominent differenees being a significantly shorter duration and a higher pitch for sylsent than syl. Psycholinguistic studies have shown that duration and pitch may represent lexically relevant prosodic cues (Davis et al, 2002; Salverda et al., 2003). During sentence processing, for example, syllables with longer durations have been found to bias lexical interpretations towards monosyllabic words (e.g. ham) rather than bisyllabic words (e.g. hamster) (Salverda et al, 2003). Moreover, recent findings have indicated that the neural processing of these word-level prosodic cues specifically involves the left posterior superior temporal gyrus (Brechmann and Scheich, 2005; Gandour et al., 2004). Thus, subtle cues related to segmental duration and/or pitch may have contributed to the present bottom-up effects.

Furthermore, due to the continuity of articulatory gestures during the production of speech, natural speech sounds are often co-articulated. Our sy/sent stimuli were CV syllables cut from sentence-initial $\mathrm{CVCV}$ words (see Methods). We specifically checked that it was not possible to predict the identity of the subsequent consonant. Nevertheless, the final portion of the vowels probably contained subtle cues that anticipated articulation of the following consonant. A rich literature on speech coarticulation has shown that listeners use such anticipatory cues in a maximally efficient way to obtain the earliest possible recognition of spoken words (e.g. Warren and Marslen-Wilson, 1987; MarslenWilson and Warren, 1994; Dahan and Tanenhaus, 2004).

The observed left $\mathrm{N} 400 \mathrm{~m}$ enhancement to sylsent stimuli in the present study indicates that implicit knowledge about cues of anticipatory coarticulation and/or lexically relevant prosodic cues may automatically trigger neural processes involved in the access of meaning-based representations. Such an efficient use of bottom-up cues in natural speech may rely on predictive coding (see also Van Wassenhove et al., 2005). That is, based on prior knowledge about, e.g., 
phonological or semantic regularities, the speech-processing system may build online predictions of auditory signals which constrain their subsequent perceptual and/or cognitive processing.

\section{Conclusion}

The processing of meaningless syllables typically does not proceed beyond prelexical perceptual analysis. In contrast, our study reveals that acoustic-phonetic cues and the presence of a lexical-semantic context trigger word-like activation in the posterior superior temporal cortex. Most importantly, our findings indicate that the cortical system subserving meaning-based analysis of speech exploits predictive bottom-up cues in natural speech and context-induced expectation, thereby suggesting a neural basis for the efficiency and the adaptive nature of speech comprehension.

\section{Acknowledgements}

This study was supported by the Ter Meulen Fund of the Royal Netherlands Academy of Arts and Sciences, the Foundation "De Drie Lichten" in the Netherlands, the Sigrid Juselius Foundation, Finnish Cultural Foundation, and the Centre of Excellence Programme 2000-2005 of the Academy of Finland. We thank Sakari Arvela and Antti Kemppinen for reading the stimuli on tape, Poju Antsalo for valuable help with stimulus recordings and Mika Seppä for help in brain coordinate transformations. 


\section{References}

Boersma, P., and Weenink, D. (2002). Praat 40, a system for doing phonetics with the computer [Computer software] (Amsterdam, The Netherlands, Universiteit van Ainsterdam).

Bonte, M. L., and Blomert, L. (2004). Developmental dyslexia: ERP correlates of anomalous phonological processing during spoken word recognition. Cognitive Brain Research $21,360-376$.

Brechmann, A., and Scheich, $\mathbb{H}$. (2005). Hemispheric shifts of sound representation in auditory cortex with conceptual listening. Cerebral Cortex $15,578-587$.

Cheour, M., Ceponiene, R, Lehtokoski, A, Luuk, A., Allik, J., Alho, K., and Nabtanen, R. (1998). Development of language-specific phoneme representations in the infant brain. Nature Neuroscience $1,351-353$.

Connolly, J. F., and Phillips, N. A. (1994). Event-related potential components reflect phonological and semantic processing of the terminal word of spoken sentences. Joumal of Cognitive Neurascience 6, 256-266.

Dahan, D., and Tanenhaus, M. K. (2004). Continuous mapping from sound to meaning in spokenlanguage comprehension: Immediate effects of verbubased thematic constraints. Journal of Experimental Psychology: Learning, Memory and Cognition 30, 498-513.

Davis, M. H., Marslen-Wilson, W. D., and Gaskell, M. (2002). Leading up the lexical garden path: Segmentation and ambiguity in spoken word recognition. Journal of Experimental Psychology: Human Perception and Performance 28, 218-244.

Dumay, N., Benraiss, A., Barriol, B., Colin, C., Radeau, M., and Besson, M. (2001). Behavioral and electrophysiological study of phonological priming between bisyllabic spoken words. Journal of Cognitive Neurosicience $13,121-143$.

Eggermont, J. J., and Ponton, C. W. (2002). The neurophysiology of auditory perception: firom single units to evoked potentials. Audiology and Neurootology 7, 71-99.

Eulitz, C., Diesch, E., Pantev, C., Hampson, S., and Elbert, T. (1995). Magnetic and electric brain activity evoked by the processing of tone and wowel stimuli. Jounal of Neuroscience 15,2748 2755

Gandour, J., Tong, Y., Wong, D., Talavage, T., Dzemidzic, M., Xu, Y., Li, X., and Lowe, M. (2004). Hemispheric roles in the perception of speech prosody. Neuroimage 23, 344-357.

Hagoort, P., and Brown, C. M. (2000). ERP effects of listening to speech: Semantic ERP effects. Neuropsychologia $38,1518-1530$.

Halgren, E., Dhond, R. P., Christensen, N., Van Petten, C., Marinkovic, K., Lewine, J. D., and Dale, A. M. (2002). N400-like magnetoencephalography responses modulated by semantic context, word frequency, and lexical class in sentences. Neuroimage 17, 1101-1116.

Hämäläinen, M., Hari, R., IImoniemi, R. J., Knuutila, $J$, and Lounasmaa, O. V. (1993). Magnetoencephalography - theory, instrumentation, and applications to noninvasive studies of the working human brain. Reviews of Modern Physics 65,4 $₫ 3-497$.

Hari, R., Hämäläinen, M., Kaukoranta, E., Mäkelä, J., Joutsiniemi, S. L., and Tiihonen, J. (1989). Selective listening modifies activity of the human auditory cortex. Experimental Brain Research $74,463-470$.

Helenius, P., Salmelin, R., Service, E., and Connolly, J. F. (1998). Distinct time courses of word and context comprehension in the left temporal cortex. Brain $\$ 21,1133-1142$. 
Helenius, P., Salmelin, R, service, E, Connolly, J. F, Lemonen, S., and Lyytinen, H (2002). Cortical ativation during spoken-word segmentation in nonreading-impaired and dyslexic adults. Joinal of Neuroscience $22,2936-2944$.

Hickok, $G_{.,}$and Poeppel, D. (2000). Towards a functional neuroanatomy of speech perception. Trends in Cognitive Seiences $4,131-138$.

Jacquemot, $\mathrm{C}$, Pallier, C., LeBihan, D, Dehaene, S, and Dupoux, E. (2003). Phonological grammar shapes the auditory contex. a functional magnetic resonamce imaging study. Joumal of Neuroscience 23,9541-9546.

Jancke, L, Wustenberg, T, Scheich, H, and Heinze, H. J. (2002). Phonetic perception and the temporal cortex. Neuroimage $15,733 \cdots 746$.

Kujala, A, Aho, Ko, Service, E, Ilmoniemi, R. J, and Connolly, J. F. (2004). Activation in the anterior left auditory cortex associated with phonological analysis of speech input: localization of the phonological mismatch negativity response with MEG. Cognitive Brain Research 21,106 113.

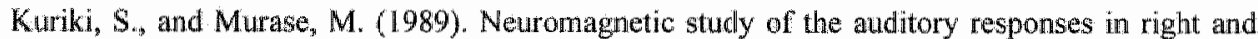
left hemispheres of the human brain evoked by pure tones and speech sounds. Experimental Brain Restearch 77, 127-134.

Kutas, M, and Federmeier, K. D. (2000). Electrophysiology reveals semantic metnory use in language comprehension. Trends in Cognitive Sciences 4, 463-470.

Kutas, M, and Hillyard, S. A. (1980). Reading senseless sentences: brain potentials reflect semantic incongruity. Science 207, 203-205.

Kutas, M., and Schmitt, B. M. (2003). Language in Microvolts. In Mind, Brain, and Language: Multidisciplinary Perspectives, M. T. Banich, and M. A. Mack, eds. (Mahwah, NJ, US, Erlbaum Assoc. Inc., Lawrence), pp. 171-209.

Marinkovic, K., Dhond, R. P., Dale, A. M., Glessner, M., Carr, V., and Halgren, E. (2003). Spatiotemporal dynamics of modality-specific and supramodal word processing. Neuron 38,487 497.

Marslen-Wilson, W., and Warren, P. (1994). Levels of perceptual representation and process in lexical access: words, phonemes, and feanres. Psychological Review 101,653-675.

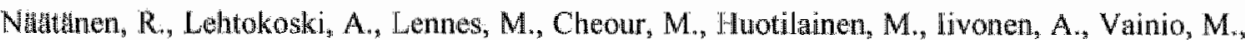
Alku, P., Ilmoniemi, R. J., Luuk, A. et al. (1997). Language-specific phoneme representations revealed by electric and magnetic brain responses. Nature $385,432-434$.

Noesselt, T., Shah, N. J., and Jancke, L. (2003). Top-down and bottom-up modulation of language related areas - an fMRI study. BMC Neuroscience 4, 13.

Obleser, J., Elbert, T., and Eulitz, C. (2004). Attentional influences on functional mapping of speech sounds in human auditory cortex. BMC Neuroscience 5, 24.

Obleser, J, Lahiri, A, and Eulitz, C. (2003). Auditory-evoked magnetic field codes place of articulation in timing and topography around 100 milliseconds post syllab]e onset. Neuroumage $20,1839-1847$.

ORourke, T. B., and Holcomb, P. J. (2002). Electrophysiological evidence for the efficiency of spoken word processing. Biological Psychology 60, 121-150.

Parviainen, T., Helenius, P., and Salmelin, R. (2005). Cortical differentiation of speech and nonspeech sounds at $100 \mathrm{~ms}$ : implications for dyslexia. Cerebral Cortex 15,1054-1063. 
Perrin, FE, and Garcia-Larrea, L. (2003). Modulation of the N400 potential during anditory phonological/semantic interaction. Cognitive Brain Research 17, 36-47.

Philjips, C., Pellathy, T., Marantz, A., Yellin, E., Wexler, K., Poeppel, D., Mcoinis, M., and Roberts, T. (2000). Auditory cortex accesses phonological categories: an MEG mismatch sudy. Journal of Cognitive Neuroscience 12, $1038-1055$.

Poeppel, D., Yellin, E., Phillips, C., Roberts, T. P., Rowley, H. A., Wexler, K., and Marantz, A. (1996). Task-induced asymmetry of the auditory evoked Mlo0 neuromagnetic lield elicited by speech sounds. Cognilive Brain Research 4, $231-242$.

Salverda, A. P., Dahan, D., and McQueen, J. M. (2003). The role of prosodic boundaries in the resolution of lexical embedding in speech comprehension. Cognition $90,51-89$.

Schormann, T., Henn, S., and Zilles, K. (1996). A new approach to fast elastic alignment with applications to human brains. Lecture Notes in Computer Science 1131, 337-342.

Scott, S. K., and Johnsrude, I. S. (2003). The neuroanatomical and functional organization of speech perception. Trends in Neurosciences 26, 100-107.

Szymanski, M. D., Yund, E. W., and Woods, D. L. (1999). Human brain specialization for phonetic attention. Neuroreport 10, 1605-1608.

Van den Brink, D., Brown, C. M., and Hagoort, P. (2001). Electrophysiological evidence for early contextual influences during spoken-word recognition: $N 200$ versus $\mathrm{N} 400$ effects. Journal of Cognitive Neuroscience $13,967-985$.

Van Petten, C. K., Coulson, S., Rubin, S., Plante, E, and Parks, M. (1999). Time course of word identification and semantic integration in spoken language. Journal of Experimental Psychology: Learning, Memory and Cognition 25,394-417.

van Wassenhove, V., Grant, K. W., and Poeppel, D. (2005). Visual speech speeds up the neural processing of auditory speech. Proceedings of the National Academy of Sciences USA 102, 11811186.

Vihla, M., Lounasmaa, O. V., and Salmelin, R. (2000). Cortical processing of change detection: dissociation between natural vowels and two-frequency complex tones. Proceedings of the National Academy of Sciences USA 97, 10590-10594.

Vihla, M., and Salmelin, R. (2003). Hemispheric balance in processing attended and non-attended vowels and complex tones. Cognitive Brain Research 16, 167-173.

Warren, P., and Marslen-Wilson, W. D. (1987). Continuous uptake of acoustic cues in spoken word recognition. Perception and Psychophysics 41, 262-275.

Winkler, I., Lehtokoski, A., Alku, P., Vainio, M., Crigler, I., Csépe, V., Aaltonen, O., Raimo, I., Alho, K., Lang, H., et al. (1999). Pre-attentive detection of vowel contrasts utilizes both phonetic and auditory memory representations. Cognitive Brain Research 7, 357-369.

Woods, R. P., Grafton, S. T., Watson, J. D., Sicotte, N. L., and Mazziotta, J. C. (1998). Automated image registration: II. Intersubject validation of linear and nonlinear models. Joumall of Computer Assisted Tomography 22, 153-165. 


\section{Summary}

This thesis investigates neurophysiological correlates of speech processing in adults, normally reading children, and children with developmental dyslexia. It focuses on the neural time course of prelexical analysis. Brain activity was measured with electro-encephalography (EEG) or magneto-encephalography (MEG). Both are non-invasive techniques that allow the investigation of on-line information processing in the brain with millisecond precision. In the EEG studies (chapters 2-5), strength and timing of neurophysiological activity was calculated from event-related potentials (ERPs) as measured at specific locations on the scalp. In the MEG study (chapter 6) activated brain areas were modelled using equivalent current dipoles (ECDs).

The studies in this thesis provide empirical evidence for the existence of several levels of prelexical processing and/or representation in the brain. In particular, they suggest that the neural processing of speech exploits subtle acoustic-phonetic cues (chapter 6), phonetic-phonological information of word onsets (chapters 2 and 3) and phonological regularities in the sequential arrangement of phonemes (chapters 4 and 5). Furthermore, this thesis contributes to a better understanding of normal developmental changes in prelexical processing (chapters 2, 3 and 5) and prelexical processing anomalies in children with developmental dyslexia (chapters 3 and 5).

Chapter 1 provides a concise introduction to the main theoretical and methodological issues addressed in the thesis. The following experimental studies are presented in the context of ongoing developments in psycholinguistic and cognitive neuroscientific research on speech processing, language development and developmental dyslexia.

During early school years, the prelexical processing of speech may change considerably due to vocabulary growth and the acquisition of reading. Chapter 2 describes an ERP study in which such developmental changes were investigated. In two experiments, we examined ERP correlates of implicit phonological processing (alliteration priming) during spoken word recognition (auditory lexical decision task). Subjects were pre-schoolers who were not able to read yet (5-6 yr), beginning readers (7-8 yr) and adults. Developmental changes in ERP morphology and latency indicated an increase in speed and efficiency of neural processes necessary for word recognition. In addition, group differences in ERP priming effects supported the idea that the neural system subserving the recognition of spoken words undergoes substantial restructuring at the level of phonological analysis.

In a subsequent study, described in Chapter 3, we used the same experimental paradigm to investigate ERP correlates of implicit phonological processing in children with developmental dyslexia. Developmental dyslexia is a persistent difficulty in learning to read in children with otherwise normal intellectual functioning and educational opportunities. The last 25 years of research have firmly established the idea that difficulties in phonological processing play a central role in this disorder. Yet, on-line phonological processing (in)capacities in dyslexics remain virtually unexplored, as studies have typically used tasks that focus on either 
phonological awareness or, at the other extreme, basic perception. To study neurophysiological correlates of implicit phonological processing, we compared ERP morphology and ERP alliteration priming effects in dyslexic and normally reading children ( $7-10 \mathrm{yr})$. Our results indicated that, in the absence of phonological task requirements, dyslexics exhibit selective processing anomalies at an earlier phonetic-phonological level, while processing at a later phonological-lexical level proceeds normally. Based on these findings we formulated the hypothesis that dyslexia involves a specific dysfunction in the prelexical processing of speech.

Chapters 4 and 5 investigated neurophysiological correlates of a prelexical regularity that starts to influence speech processing during early language development, i.e. the distributional frequency of speech sound (phoneme) combinations. This distributional frequency is typically called phonotactic probability, where phonotactic refers to the sequential arrangement of phonemes in the syllables and words of a given language. We employed an ERP measure sensitive to experience-dependent changes in auditory cortical responses to speech, i.e. the mismatch negativity (MMN). In a modified passive oddball paradigm that minimizes the contribution of acoustic processes, we presented pairs of non-words that differed by the degree of phonotactic probability. The results of this study revealed that auditory cortical responses to meaningless speech are modulated by phonotactic regularities of phoneme clusters, with comparable effects in normally reading adults (chapter 4) and children (chapter 5). More generally, these findings highlight the relevance of the language environment in shaping the neural system underlying the processing of speech.

In chapter 5 we further investigated the hypothesis that dyslexia involves an anomaly in the prelexical processing of speech (chapter 3). Using our phonological MMN paradigm we tested whether dyslexic children would show a neurophysiological sensitivity to phonotactic probability comparable to that of normally reading children and adults. We used non-word stimuli that involved a clear phonetic contrast $(/ \mathrm{s} /$ fricative $\mathrm{vs}$. $/ \mathrm{k} / \mathrm{stop}$ consonant) for which no auditory discrimination problems have been reported in dyslexics. Accordingly, our results showed comparable acoustic-phonetic processing of these non-words in normally reading and dyslexic children. However, dyslexic children did not show a normal sensitivity to variation in phonotactic probability. These results support and extend our previous findings (chapter 3 ) and indicate that the prelexical processing deficiency in dyslexic children also includes the implicit processing of phonological regularities. More specifically, this study corroborates the idea that developmental dyslexia involves a deficit in the phonetic-phonological processing of speech that may not be reducible to a low-level auditory/sensory deficit.

How is the perception of speech sounds influenced by acoustic-phonetic cues and the linguistic context in which they are presented? In chapter 6 we used MEG to investigate the influence of lexical-semantic context (top-down information) and acoustic-phonetic cues (bottom-up information) on the neural processing of meaningless, natural, speech syllables in the auditory cortex. Subjects were normally reading adults. The processing of synthetic meaningless speech sounds typically does not proceed beyond prelexical perceptual analysis. However, our MEG findings revealed that realistic acoustic-phonetic cues and the presence of a lexical-semantic context trigger word-like activation in the superior temporal 
cortex. The efficiency of meaning-based analysis of speech may thus be subserved by a cortical system finely tuned to lexically relevant acoustic-phonetic and contextual cues. 


\section{Samenvatting}

Dit proefschrift onderzoekt neurofysiologische maten voor spraakverwerking in volwassenen, normaall lezende kinderen, en kinderen met dyslexie. Het richt zich op het tijdsverloop van prelexicale verwerking in de hersenen. Hersenactiviteit werd gemeten met behulp van elektro-encefalografie (EEG) of magneto-encefalografie (MEG). Beiden zijn non-invasieve technieken die het mogelijk maken om informatie verwerking in de hersenen op milliseconden niveau te onderzoeken. In de EEG studies (hoofdstuk $2 \mathrm{t} / \mathrm{m}$ 5), werd het tijdsverloop en de mate van neurofysiologische activiteit geschat aan de hand van event-related potentials (ERPs) gemeten op specifieke locaties op de schedel. In de MEG studie (hoofdstuk 6) werden actieve hersengebieden in kaart gebracht met behulp van equivalent current dipoles (ECDs).

De studies in dit proefschrift leveren empirisch bewijs voor het bestaan van verschillende niveau's van prelexicale verwerking en/of representaties in de hersenen. Ze wijzen er specifiek op dat de hersenen tijdens de verwerking van spraak gebruik maken van subtiele akoestisch-fonetische cues (hoofdstuk 6), fonetisch-fonologische informatie aan het begin van woorden (hoofdstukken 2 en 3) en fonologische regelmatigheden in de opeenvolging van fonemen (hoofdstukken 4 en 5). Bovendien draagt dit proefschrift bij aan een verbeterd inzicht in normale ontwikkelingsgerelateerde veranderingen in prelexicale verwerking (hoofdstukken 2 , 3 en 5) en anomalieën in prelexicale verwerking bij kinderen met ontwikkelingsdyslexie (hoofdstukken 3 en 5).

Hoofdstuk 1 geeft een beknopte inleiding in de belangrijkste theoretische en methodologische onderwerpen die in dit proefschrift aan de orde komen. De daaropvolgende experimentele studies worden besproken in de context van lopende ontwikkelingen in psycholinguïstisch en cognitief neurowetenschappelijk onderzoek naar spraakverwerking, taalontwikkeling en ontwikkelingsdyslexie.

Tijdens de eerste schooljaren zouden aanzienlijke veranderingen in de prelexicale verwerking van spraak plaats kunnen vinden ten gevolge van een groeiende woordenschat en het leren lezen. Hoofdstuk 2 beschrijft een ERP studie waarin zulke ontwikkelingsgerelateerde veranderingen onderzocht werden. We onderzochten ERP maten voor impliciete fonologische verwerking (alliteratie priming) tijdens de herkenning van gesproken woorden (auditieve lexicale beslissingstaak). Proefpersonen waren kleuters die nog niet konden lezen (5-6 jaar), beginnende lezers ( $7-8$ jaar) en volwassenen. Ontwikkelingsgerelateerde veranderingen in de morfologie en latentie van ERPs wezen op een toename in snelheid en efficiëntie van de neurale processen die nodig zijn voor woordherkenning. Bovendien ondersteunden groepsverschillen in ERP priming effecten het idee dat het neurale systeem voor gesproken woordherkenning een aanzienlijke herstructurering ondergaat op het niveau van fonologische analyse.

In een volgende studie, beschreven in hoofdstuk 3, gebruikten we hetzelfde experimentele paradigma om ERP maten voor impliciete fonologische verwerking bij kinderen met ontwikkelingsdyslexie te onderzoeken. Ontwikkelingsdyslexie wordt gekenmerkt door aanhoudende moeilijkheden met het leren lezen bij 
kinderen die verder over normale intellectuele vaardigheden en onderwijsmogelijkheden beschikken. Onderzoek in de afgelopen 25 jaar heeft het idee gevestigd dat moeilijkheden in de fonologische verwerking een centrale rol spelen bij dyslexie. Toch is er weinig bekend over het on-line verloop van fonologische verwerking in dyslectici, omdat studies doorgaans taken gebruikt hebben die zich richten op óf fonologisch bewustzijn, of, aan de andere kant, basale waarneming. Om neurofysiologische maten voor impliciete fonologische verwerking the bestuderen, hebben we ERP morfologie en ERP alliteratie-priming effecten in dyslectische en normaal lezende kinderen ( $7-10$ jaar) onderzocht. Onze resultaten gaven aan dat dyslectici, zonder de vereisten van een fonologische taak, selectieve anomalieèn vertonen in de vroege verwerking van fonetisch-fonologische informatie, terwijl de latere fonologisch-lexicale verwerking normaal verloopt. Op basis van deze bevindingen formuleerden we de hypothese dat dyslexie gepaard gaat met een specifieke afwijking in de prelexicale verwerking van spraak.

Hoofdstukken 4 en 5 onderzochten neurofysiologische maten voor een prelexicale regelmatigheid die de verwerking van spraak al tijdens de vroege taalontwikkeling beinvloedt, dwz. de frequentie van voorkomen van spraakklank (foneem) combinaties. Deze frequentie van voorkomen wordt doorgaans fonotactische waarschijnlijkheid genoemd, waarbij fonotactisch staat voor de rangschikking van opeenvolgende fonemen in de lettergrepen en woorden van een gegeven taal. We gebruilkten een ERP maat die gevoelig is voor ervaringsgerelateerde veranderingen in auditieve corticale reacties op spraak, dwz. de mismatch negativity (MMN). Non-woord paren die verschilden in de mate van fonotactische waarschijnlijkheid werden aangeboden in een aangepast passief oddball paradigma dat de bijdrage van akoestische processen minimaliseert. De resultaten van deze studie onthulden dat auditieve corticale reacties op betekenisloze spraak beïnvloedt worden door fonotactische regelmatigheden van foneemclusters, met vergelijkbare effecten voor normaal lezende volwassenen (hoofdstuk 4) en kinderen (hoofdstuk 5). Meer algemeen benadrukken deze bevindingen de relevantie van de talomgeving bij de vorming van het neurale systeem voor spraakverwerking.

In hoofdstuk 5 werd de hypothese dat dyslexie gepaard gaat met een anomalie in de prelexicale verwerking van spraak (hoofdstuk 3) nader onderzocht. Door gebruik te maken van ons fonologische MMN paradigma werd getest of dyslectische kinderen een neurofysiologische gevoeligheid voor fonotactische waarschijnlijkheid zouden vertonen die vergelijkbaar is met die van normaal lezende volwassenen en kinderen. We gebruikten non-woord stimuli met een duidelijk fonetisch contrast (/s/ fricatief vs. $/ \mathrm{k} /$ plosief), waarvoor geen auditieve discriminatie problemen bij dyslectici gerapporteerd zijn. In overeenkomst hiermee lieten onze resultaten vergelijkbare akoestisch-fonetische verwerking van deze nonwoorden zien in normaal lezende en dyslectische kinderen. Daarentegen toonden dyslectische kinderen geen normale gevoeligheid voor variatie in fonotactische waarschijnlijkheid. Deze resultaten ondersteunen en verbreden onze voorgaande bevindingen (hoofdstuk 3) en geven aan dat het prelexicale verwerkingstekort in dyslectische kinderen ook betrekking heeft op de impliciete verwerking van fonologische regelmatigheden. In het bijzonder benadrukt deze studie het idee dat ontwikkelingsdyslexie gepaard gaat met een tekort in de fonetisch-fonologische 
verwerking van spraak dat mogelijk niet reduceerbaar is tot een basaal auditief/sensorisch tekort.

Hoe wordt de waarneming van spraakklanken beinvloed door akoestischfonetische cues en de lingü̈stische context waarin ze worden atangeboden? In hoofdstuk 6 gebruikten we MEG om de invloed van de lexical-semantische context (top-down informatie) en akoestische-fonetische cues (bottom-up informatie) op de neurale verwerking van betekenisloze gesproken lettergrepen te onderzoeken. Proefpersonen waren normaal lezende volwassenen. De verwerking van kunstmatige, betekenisloze spraakklanken gaat doorgaans niet verder dan prelexicale perceptuele analyse. Onze MEG bevindingen onthulden echter dat natuurlijke akoestisch-fonetische cues en de aanwezigheid van een lexicaalsemantische context leiden tot woordachtige verwerking van lettergrepen in de auditieve cortex. De efficiëntie van betekenisgerelateerde analyse van spraak is dus mogelijk gebaseerd op een corticaal systeem dat precies afgestemd is op akoestischfonetische en contextuele cues die relevant zijn voor lexicale verwerking. 


\section{Acknowledgements}

"What are you actually doing day by day at University as a PhD student? Thinking? Sitting behind a computer? Studying? Ah, you also teach! And what kind of research do you do? Neuroscience of language development and dyslexia? Hm... interesting, a bit complicated though... Good luck!"

Sometimes it is difficult to explain to people outside the academic world, what motivates the effort, the stress, and the long days of work which are behind a PhD thesis... Besides scientific curiosity, one of the reasons is certainly that these long days are shared with many nice and interesting people.

First, I would like to thank my supervisor Leo Blomert for his support and for creating the possibility to perform ERP research with normally reading and dyslexic children. Your supervision has shaped me as a researcher. Many thanks go to Rainer Goebel as my promotor but also as a dear friend. Knowing that I could always knock on your door for some reassuring words or enthousiastic stories about science and scientists has been a strong source of support for me. Special thanks go to Bernadette Jansma for her motherly support and the many advices.

During the last year of my $\mathrm{PhD}$ I had the great opportunity to perform a study in the group of Riitta Salmelin at the Brain Research Unit of the Low Temperature Laboratory in Espoo, Finland. Riitta, it was a great pleasure to learn the secrets of MEG from you!

Many people have contributed during the different stages of the work described in this thesis. For help during the acquisition of behavioural and EEG data I would like to thank Marlou Kwaks, Lisa van der Plas, Hanne Poelmans, Anniek Vaessen and Nadia Zellagui. Many thanks go to Johan Gielissen, Ron Hellenbrand and Jacco Ronner for their technical support in the EEG and speech labs. Many thanks also go to Lisa Jonkman for her advices on the analysis of developmental ERP data, and to Holger Mitterer for his advices on the analysis of speech signals with Praat. A special thanks goes to Annemie Jeukens for her great help and efficiency. Moreover, this work would not have been possible without the support of the Regionaal Instituut voor Dyslexie (RID), de Maastrichtse basisscholen de Kring, St. Aloysius en de Perroen, and above all, the willingness of all the children and parents to come to our EEG lab and participate in the experiments, for which I am very grateful.

In these years I especially shared a lot of fun and frustrations with "the girls": Nienke van Atteveldt, Amanda Kaas and Sandra Smeets. Nienke, thanks for the thousands of conversations and a lot of loud laughter. Amanda, your incredible sweetness keeps on surprising me, it is great to have you as an office-mate. Many thanks also go to sporty Sandra, it is a pity that you do not live in Maastricht anymore, but happily enough we have our girl-weekends.

Furthermore, I would like to thank many colleagues/friends in Maastricht for all the lunches, conversations in the corridors, dinners and parties, including Miguel Castello-Branco, Niko Kriegeskorte, Henk and Bernadette Jansma, Claudia and Rainer Goebe], Alard Roebroeck, Judith Peters, Joel Reithler, Holger Mitterer, Michael Capalbo, Alex Sack, Hester Breman, Federico De Martino, Francesco Gentille, Vincent van de Ven, Mart Bles and Bettina Sorger. 
Many thanks also go to my Finnish colleagues/friends and lunch-mates for making me feel at home in Helsinki and for teaching important Finnish expressions like "jenkkakahvat" Tina Parviainen, Topi Tanskanen, Jan Kujala, Marieke Longchamp, Gina Caetano, Hanna Renvall, Kaisa Hytönen, Miiu Saarela, Mika Seppa, and many others.

Ik ben mijn ouders, Gerard en Eveline, en broers en zussen, Jorne, Jacomij, Salomé en Andreas, heel dankbaar omdat ze er altijd voor mij zijn. Grazie mille anche alla mia cara mamma Napolitana Guiseppina Nigro. Endless thanks go to Elia Formisano. Especially for your continuous support and for coping so well with my "capatosta". 


\section{Curriculum Vitae}

Milene Bonte was born in Warnsveld, the Netherlands on March 9th 1976. She attended the Vrije School de Berkel in Zutphen and obtained lier VWO diploma in 1995. From 1995 until 1999 she studied Psychology at the Universiteit Maastricht. During this time she also worked as a teaching and research assistant at the Universiteit Maastricht. In 1999 she graduated with a specialization in cognitive neuroscience (cum laude). Her masters thesis described an MEG study of developmental changes in auditory speech processing which she performed at the Universität Konstanz, Germany. From 1999 until 2005 she was employed as a PhDstudent (AiO) and junior lecturer at the Universiteit Maastricht. The studies described in this thesis were performed at the Universiteit Maastricht and at the Helsinki University of Technology, Finland. Currently, she is employed as assistant professor (universitair docent) at the Department of Cognitive Neuroscience, Faculty of Psychology, Universiteit Maastricht. 